\title{
ENHANCING CAPACITY AND MANAGING DEMAND TO INCREASE SHORT-TERM THROUGHPUT ON THE SAN FRANCISCO-OAKLAND BAY BRIDGE
}

\author{
A Thesis \\ presented to \\ the Faculty of California Polytechnic State University, \\ San Luis Obispo \\ In Partial Fulfillment \\ of the Requirements for the Degree \\ Master of Science in Civil and Environmental Engineering
} by Kevin Carstens December 2016 
(C) 2016

Kevin Carstens

ALL RIGHTS RESERVED 
COMMITTEE MEMBERSHIP

TITLE:

Enhancing Capacity and Managing Demand to Increase Short-

Term Throughput on the San Francisco-Oakland Bay Bridge

AUTHOR:

Kevin Carstens

DATE SUBMITTED: December 2016

COMMITTEE CHAIR: Anurag Pande, Ph.D.

Associate Professor, Civil Engineering

COMMITTEE MEMBER: $\quad$ Robert Bertini, Ph.D., P.E.

Director, Center for Urban Transportation Research

Professor, Civil and Environmental Engineering

University of South Florida

COMMITTEE MEMBER: Cornelius Nuworsoo, Ph.D.

Professor, City \& Regional Planning 


\begin{abstract}
Enhancing Capacity and Managing Demand to Increase Short-Term Throughput on the San Francisco-Oakland Bay Bridge

Kevin Carstens
\end{abstract}

While there are many proposals for fixing congestion between San Francisco and Oakland in California by adding a new bridge or tube, these solutions will take decades to implement even though a solution is needed now. This thesis assesses sixteen different strategies for reducing congestion in the short-term in the four categories of improving transit, promoting carpooling, implementing intelligent transportation systems practices, and incentivizing alternatives to using the Bay Bridge. Top priorities include HOV improvements on the West Grand Avenue and Powell Street onramps, altering WestCAT Lynx and BART transit services, partnering with rideshare apps to increase transit station accessibility (last mile problem), partnering with vanpool/minibus apps, promoting carpooling and implementing a citizen report system for carpool violators, shifting corporate cultures away from requiring employees to drive and drive alone, and lastly, altering land-use planning practices. To reach this conclusion, an inventory of current proposals and relevant research was compiled. Ridership and capacity data for the various modes of transportation across the bay were assessed for shortfalls and opportunities. Through this research and its resultant conclusions, focus can be placed on the best strategies to pursue in the near-term, while the Bay Area waits on a second bridge or tube in the long-term.

Keywords: Demand, Capacity, Bay Area, Congestion, BART, HOV, San Francisco, Public Transit, Carpool 


\section{ACKNOWLEDGMENTS}

I would like to thank the Metropolitan Transportation Commission (MTC) for their generous support of this research. I also want to thank MTC's Ashley Nguyen and Andrew Fremier for their guidance throughout the development of this thesis. Additionally, I thank my committee, Dr. Pande, Dr. Bertini, and Dr. Nuworsoo, for their invaluable assistance with the planning, presentation, and execution of this research. Thank you as well to my family and friends for helping me through this stressful process. Lastly, I would especially like to thank my wife Alisha for all of her patience and support. 


\section{TABLE OF CONTENTS}

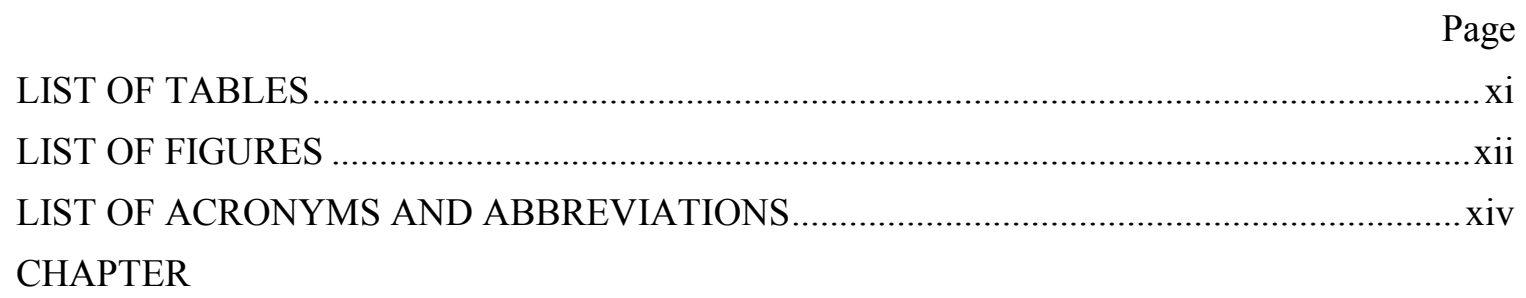

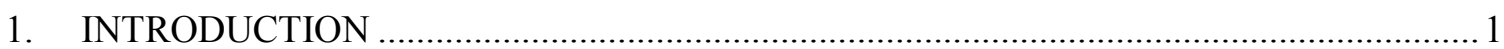

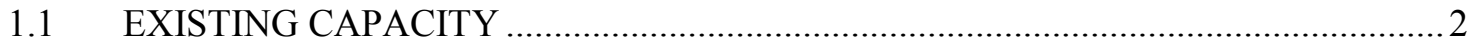

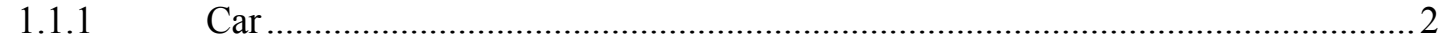

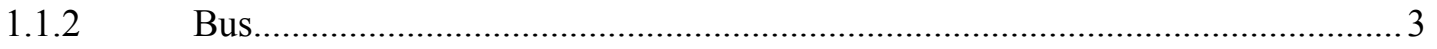

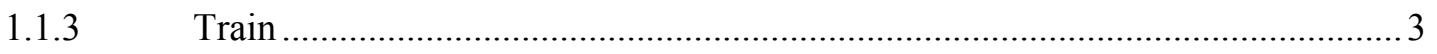

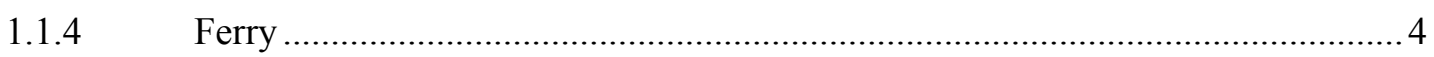

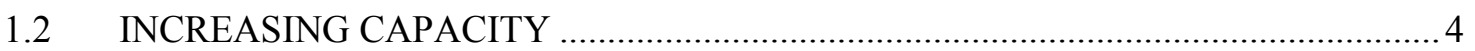

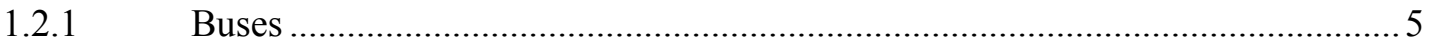

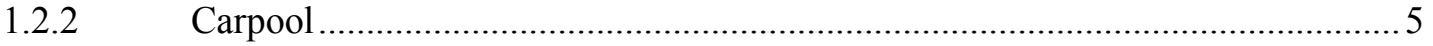

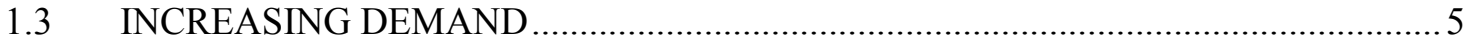

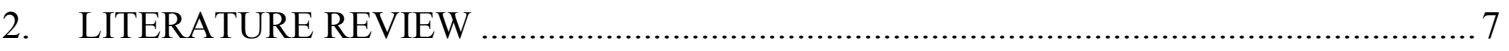

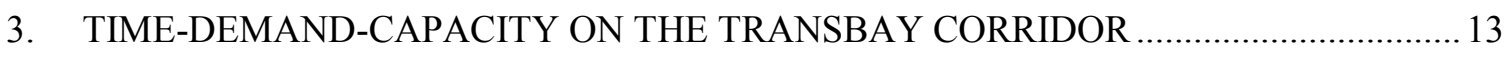

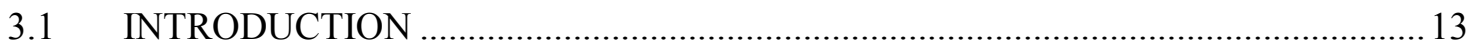

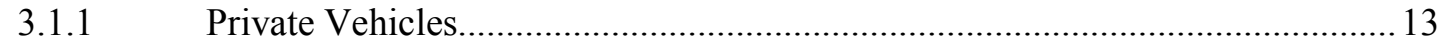

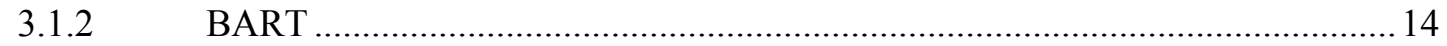

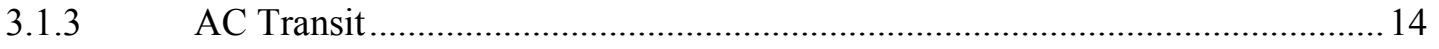

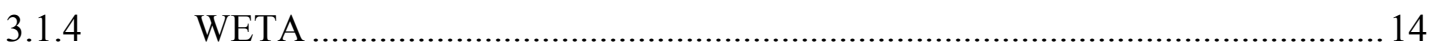

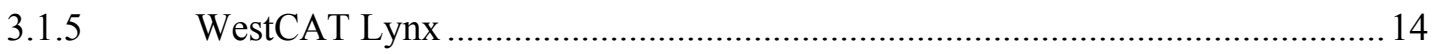

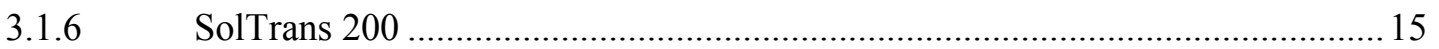

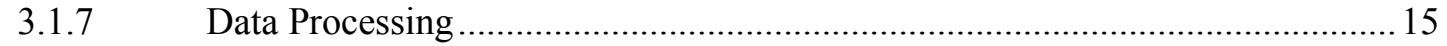

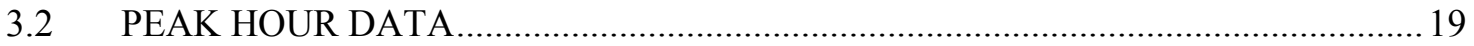

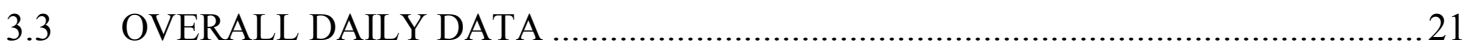

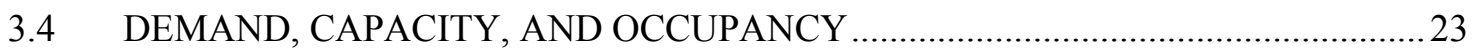

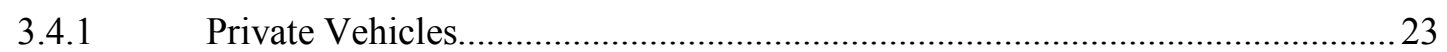

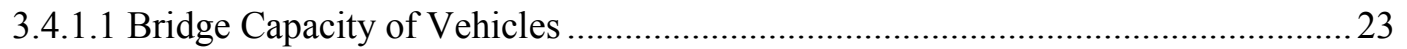

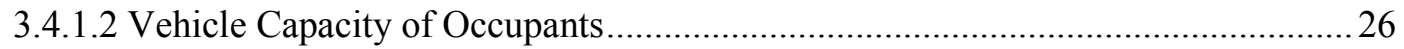




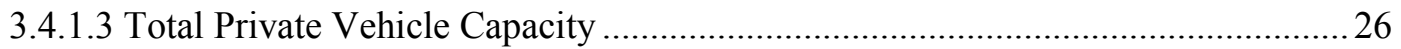

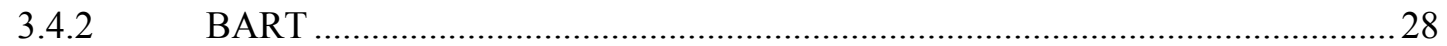

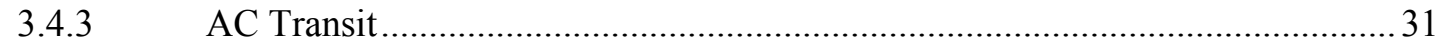

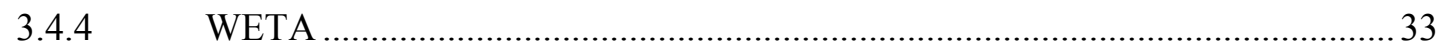

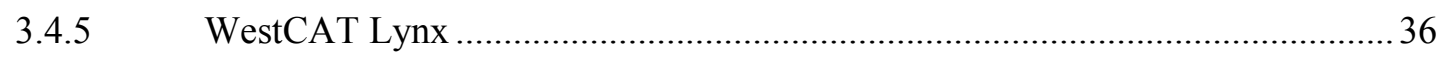

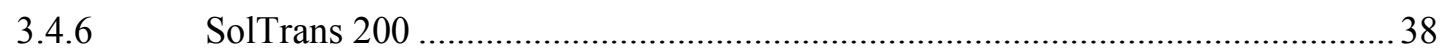

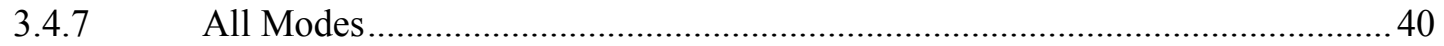

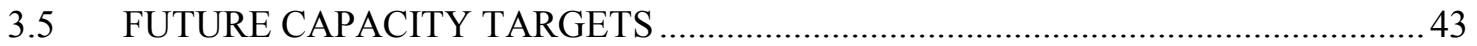

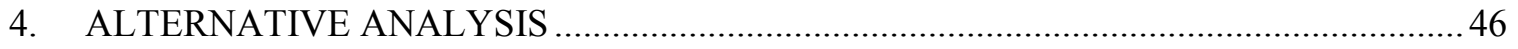

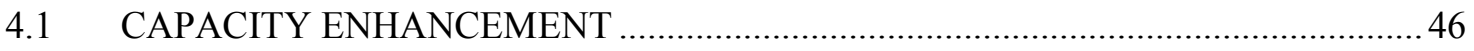

4.1.1 Strategy 1: Upgrade West Grand Avenue Onramp to Bus Lane Standards ........ 46

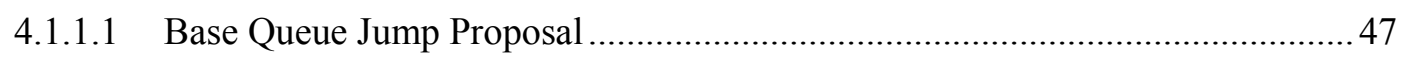

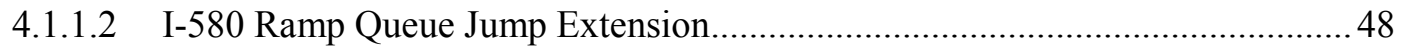

4.1.1.3 Maritime Intersection Queue Jump Extension ............................................... 50

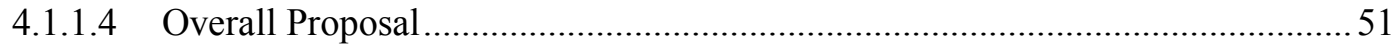

4.1.2 Strategy 2: HOV Improvements at Powell Street and I-80 in Emeryville ......... 53

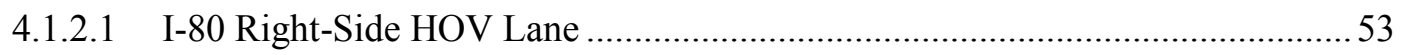

4.1.2.2 Improve HOV Access at Powell Street and I-80 .................................................56

4.1.2.3 New Park-and-Ride at Powell Street under I-80 ............................................. 57

4.1.3 Strategy 3: MacArthur Onramp Bus Lane ......................................................... 59

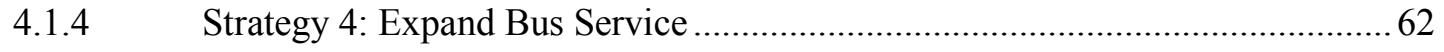

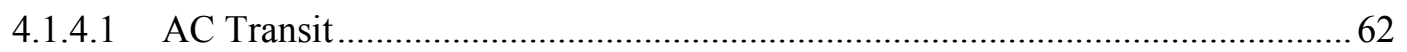

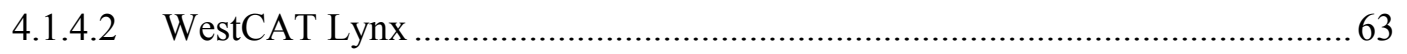

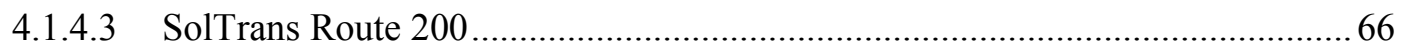

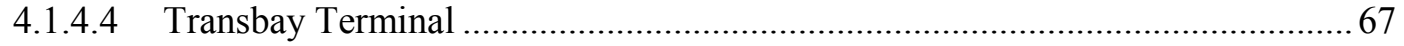

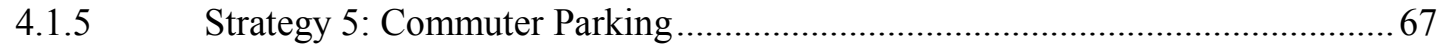

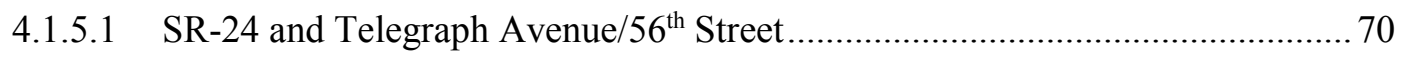

4.1.5.2 I-580 and Broadway/Piedmont Avenue .......................................................... 71

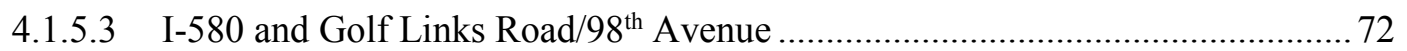

4.1.5.4 I-580 and Fairmont Drive/Foothill Boulevard .............................................. 73

4.1.5.5 Benefits and Costs of Proposed Park-and-Ride Lots ....................................... 75

4.1.5.6 BART Parking Capacity Increases.................................................................... 75 
4.1.5.7 Partnering with Rideshare Mobile Applications, an Alternative to More

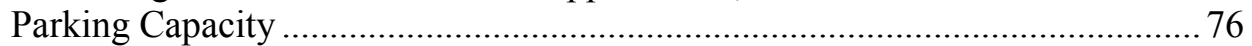

4.1.6 Strategy 6: Partner with Developers of Ridesharing Mobile Applications ........ 77

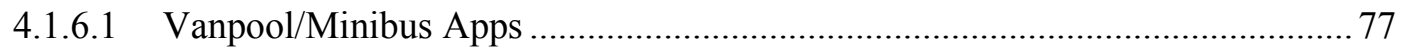

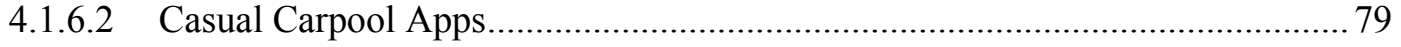

4.1.7 Strategy 7: Enhanced Casual Carpooling ........................................................ 80

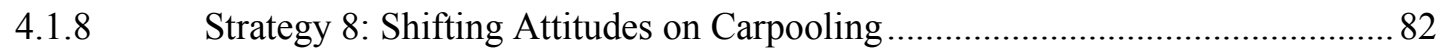

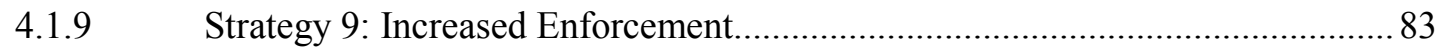

4.1.10 Strategy 10: Electronic Tolling at the Bay Bridge Toll Plaza ............................. 85

4.1.10.1 Golden Gate Bridge Toll Plaza Conversion Case Study .................................. 85

4.1.10.2 Relevance to Bay Bridge Toll Plaza Conversion ............................................... 86

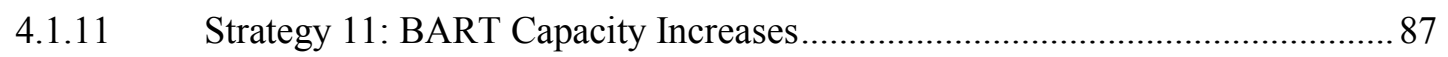

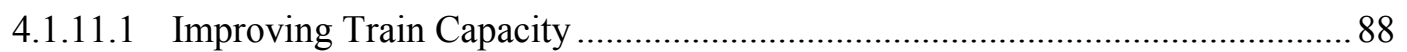

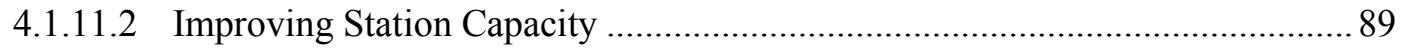

4.1.12 Strategy 12: Altered BART Service .............................................................. 90

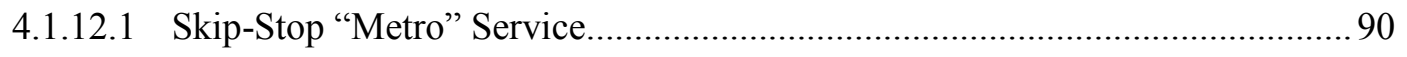

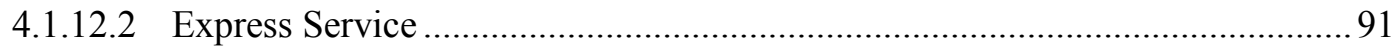

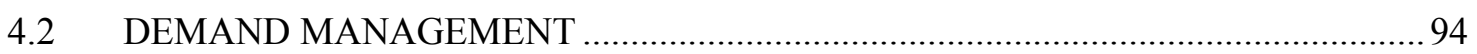

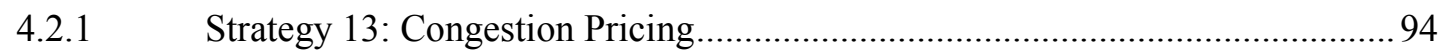

4.2.1.1 Congestion Pricing to Offset Demand.............................................................. 95

4.2.1.2 Congestion Pricing to Increase HOV Occupancy ..............................................96

4.2.1.3 Relation of Toll Effectiveness to Parking Fare Rates ....................................... 98

4.2.2 Strategy 14: Eastbound Tolling ...................................................................... 98

4.2.2.1 Central Business District Congestion Tolling ................................................. 98

4.2.2.2 Convert the Bay Bridge Toll Plaza into a Bidirectional Facility....................... 100

4.2.3 Strategy 15: Changing Corporate Cultures ..................................................... 102

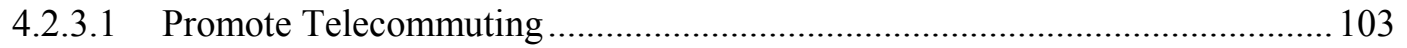

4.2.3.2 Changing Workplace Car Demands ............................................................. 105

4.2.4 Strategy 16: Land-Use Planning Changes..................................................... 106

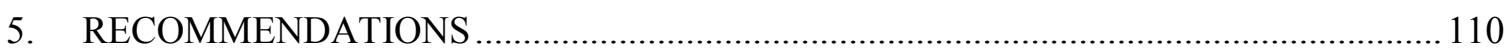

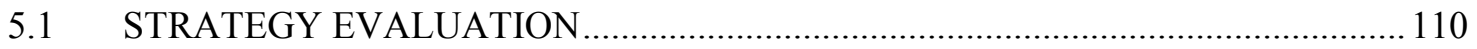

5.1.1 Strategy 1: Upgrade West Grand Avenue Onramp to Bus Lane Standards ..... 110

5.1.2 Strategy 2: HOV Improvements at Powell Street and I-80 in Emeryville ........ 111 
5.1.2.1 Convert the Right Lane of I-80 to HOV.

5.1.2.2 Powell Street Onramp Conversion to HOV and Adding More Movements to Access the Onramp .................................................................................... 112

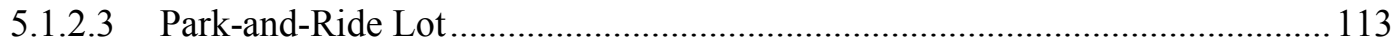

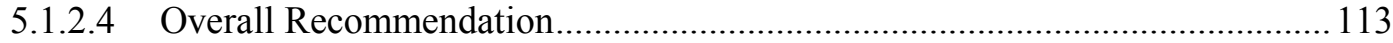

5.1.3 Strategy 3: MacArthur Onramp Bus Lane ....................................................... 114

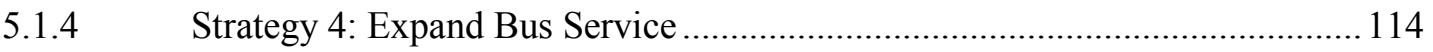

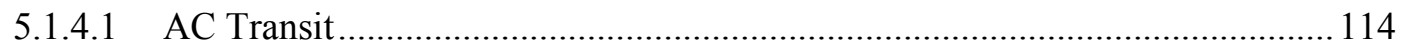

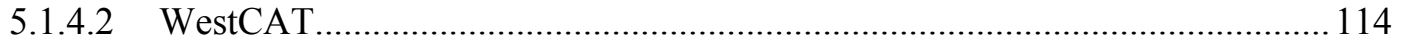

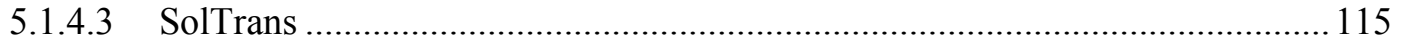

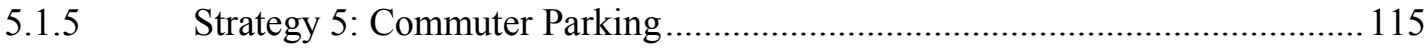

5.1.5.1 I-80 and Buchanan Street ........................................................................... 115

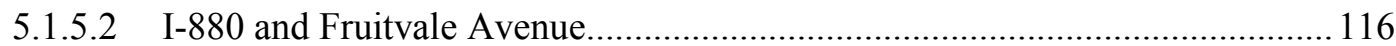

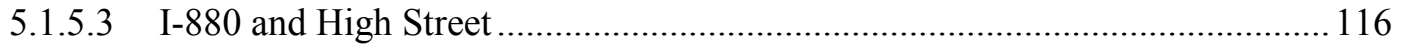

5.1.5.4 I-580 and Fairmont Drive/Foothill Boulevard ................................................. 116

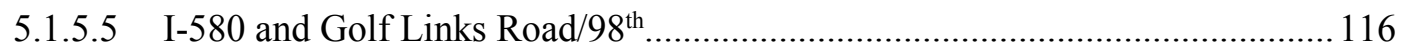

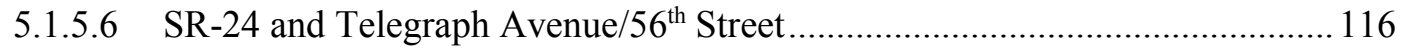

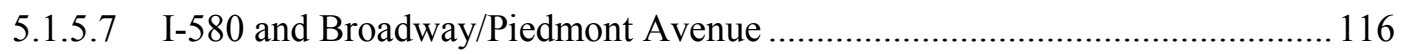

5.1.5.8 BART Parking Capacity Increases................................................................ 117

5.1.5.9 Partner with Ridesharing Apps for Station Access ........................................ 117

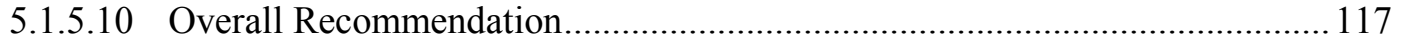

5.1.6 Strategy 6: Partner with Developers of Ridesharing Mobile Applications ...... 118

5.1.7 Strategy 7: Enhanced Casual Carpooling ….................................................... 118

5.1.8 Strategy 8: Shifting Attitudes on Carpooling .................................................... 119

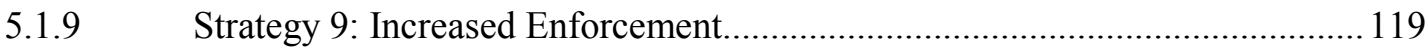

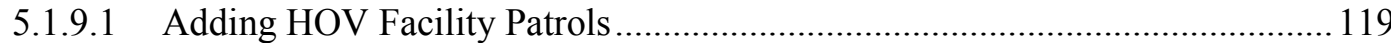

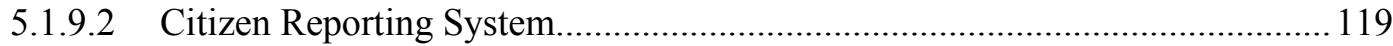

5.1.10 Strategy 10: Electronic Tolling at the Bay Bridge Toll Plaza ............................ 120

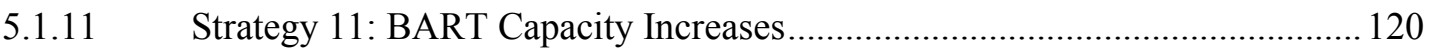

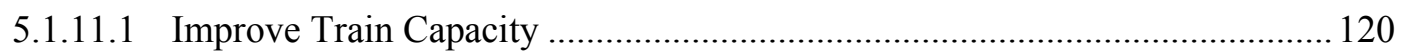

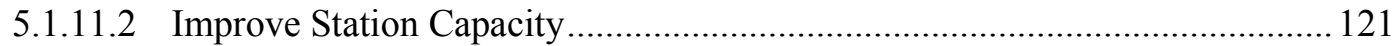

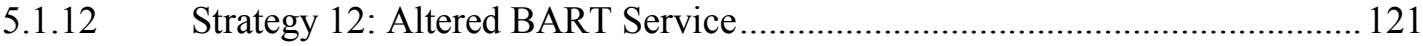

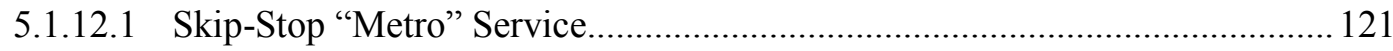




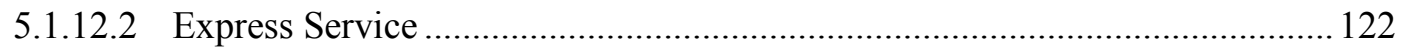

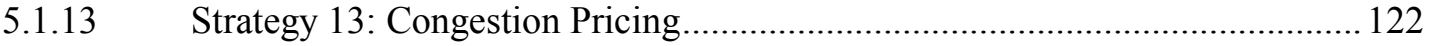

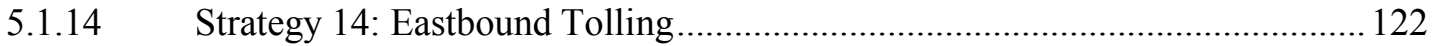

5.1.14.1 Downtown San Francisco Cordon................................................................ 122

5.1.14.2 Convert the Bay Bridge Toll Plaza into a Bidirectional Facility...................... 123

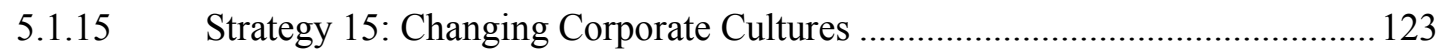

5.1.16 Strategy 16: Land-Use Planning Changes..................................................... 124

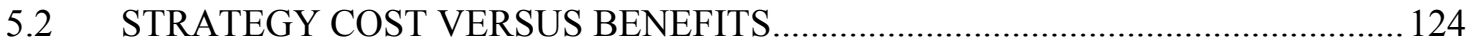

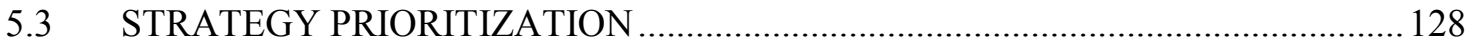

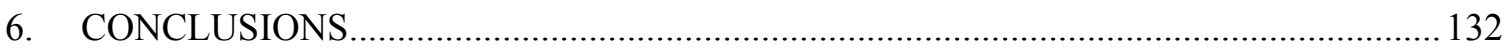

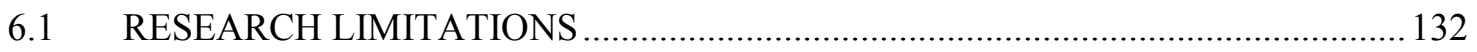

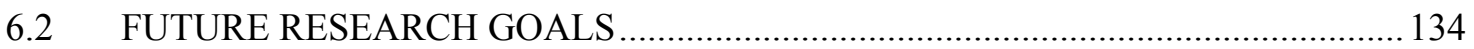

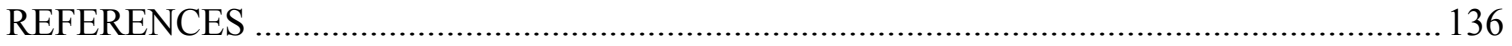

APPENDICES

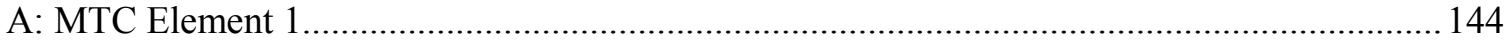

B: BATA Alternative 5: Powell St. / I-80 Ramp HOV Improvement ....................................... 151

C: BATA Alternative 2: MacArthur Boulevard Bus Ramp....................................................... 153

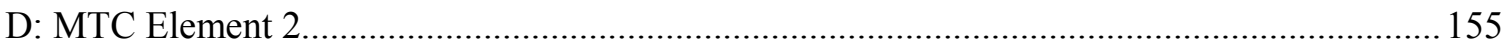

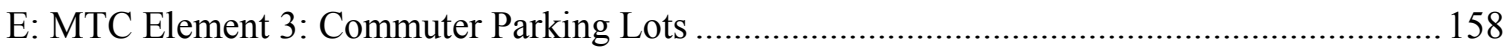

F: All Electronic Toll Collection Strategic Development Plan Financial Breakdown ................ 160

G: BATA BART Alternative: Capacity Expansion Description ................................................. 163

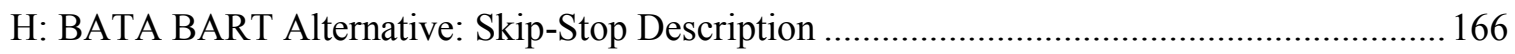




\section{LIST OF TABLES}

Table $\quad$ Page

3.1 Instances When WETA Ferry Service Hit Capacity ........................................................... 34

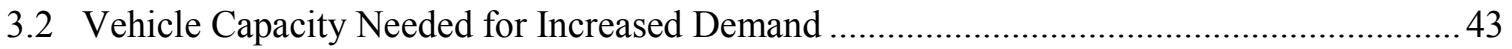

3.3 Vehicle Capacity Needed for Increased Demand, with Adjusted Mode Shares..................... 44

4.1 Cost Estimate for I-80 Right-Side HOV Lane Improvements, Alternative 1 ........................54

4.2 Cost Estimate for I-80 Right-Side HOV Lane Improvements, Alternative 2 ....................... 54

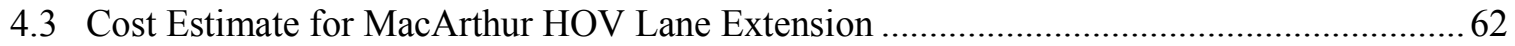

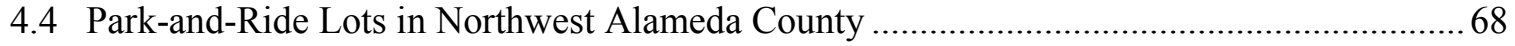

4.5 Breakdown of Bay Area Commuters by Mode................................................................... 82

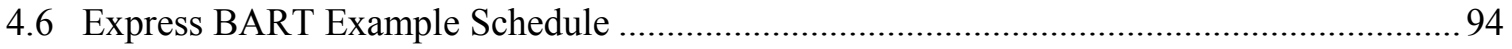

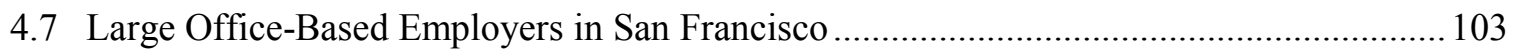

5.1 Roster of Strategies with Cost and Benefit Bins.............................................................. 125

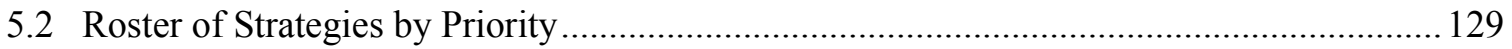




\section{LIST OF FIGURES}

Figure Page

1.1 Bay Bridge Congestion (American Highway Users Alliance, 2015).................................... 1

1.2 AC Transit Transbay Bus Service (Alameda County Transit, 2015)..................................... 4

2.1 Bus on Right Using Shoulder to Jump Queue (MTC, 2011) .............................................. 8

3.1 Westbound Person Throughput across the Transbay Corridor by Mode ............................... 17

3.2 Eastbound Person Throughput across the Transbay Corridor by Mode ................................ 18

3.3 Location of Relevant Transit Nodes in Downtown San Francisco ....................................... 19

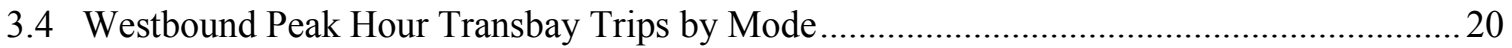

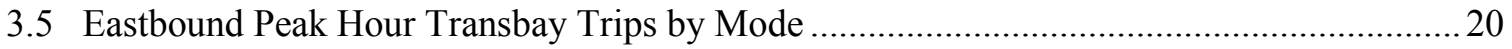

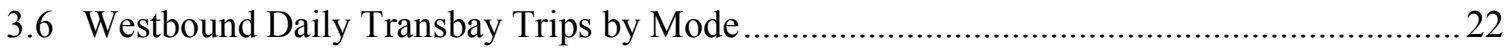

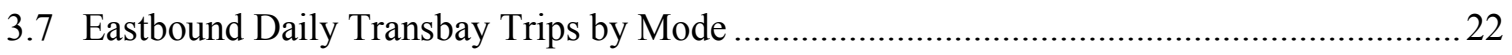

3.8 Average Bay Bridge Crossings by Hour in Terms of Passenger Car Equivalents................. 25

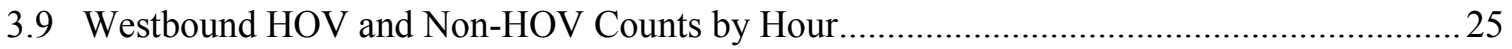

3.10 Westbound Actual Throughput and Theoretical Capacity of the Bay Bridge ......................22

3.11 Eastbound Actual Throughput and Theoretical Capacity of the Bay Bridge........................22

3.12 Percent of Theoretical Capacity Used on the Bay Bridge...................................................28

3.13 Westbound BART Transbay Tube Ridership and Seat Surplus or Deficit ............................ 30

3.14 Eastbound BART Transbay Tube Ridership and Seat Surplus or Deficit .............................. 30

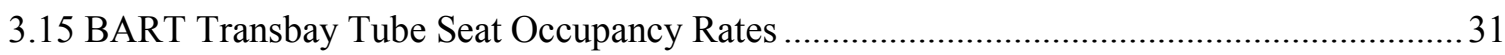

3.16 Westbound AC Transit Transbay Ridership and Seat Surpluses .......................................... 32

3.17 Eastbound AC Transit Transbay Ridership and Seat Surpluses .......................................... 32

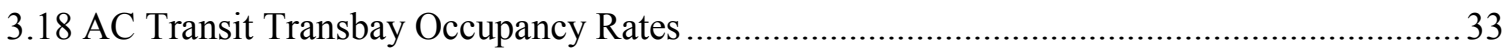

3.19 Westbound WETA Transbay Ridership and Capacity Surpluses ........................................ 35

3.20 Eastbound WETA Transbay Ridership and Capacity Surpluses .......................................... 35

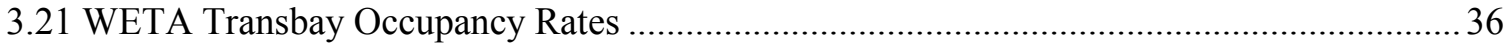

3.22 Westbound WestCAT Lynx Ridership and Capacity Surpluses........................................... 37

3.23 Eastbound WestCAT Lynx Ridership and Capacity Surpluses ............................................ 37

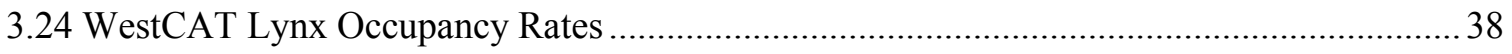

3.25 Westbound SolTrans Route 200 Ridership and Capacity Surpluses.................................... 39

3.26 Eastbound SolTrans Route 200 Ridership and Capacity Surpluses..................................... 39

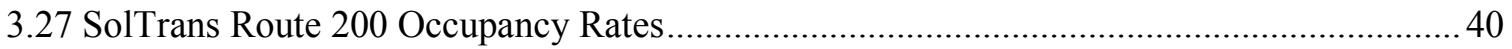


3.28 Westbound Actual Throughput versus Excess Capacity and Occupancy Rate 41

3.29 Eastbound Actual Throughput versus Excess Capacity and Occupancy Rate....................... 42

4.1 West Grand Avenue Queue Jump Overview ................................................................... 47

4.2 West Grand Avenue Before (a) and After (b) HOV Lane Extension .................................. 48

4.3 West Grand Avenue Before (a) and After (b) HOV Lane Extension Past I-580 Onramp ..... 49

4.4 West Grand Avenue Before (a) and After (b) HOV Lane Extension Past Maritime

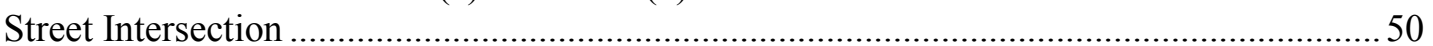

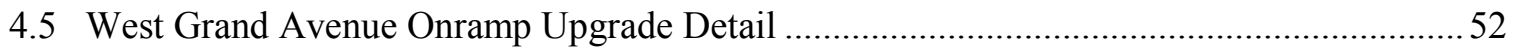

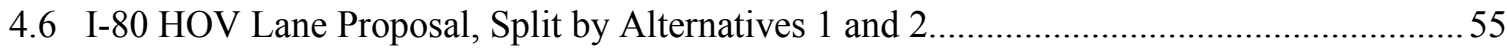

4.7 Powell Street Park-and-Ride Lot and HOV Onramp Improvements .....................................5 58

4.8 Proposed Bus Reroutes to Serve Park-and-Ride Lot …........................................................59

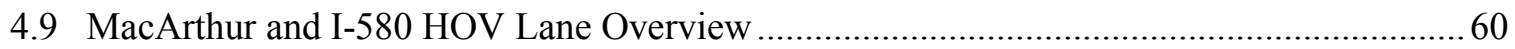

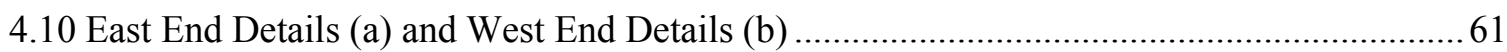

4.11 Current (a) and Proposed (b) WestCAT Lynx and Route 30Z Operations ............................65

4.12 Park and Ride Lots in Northwestern Alameda County ........................................................ 69

4.13 Proposed SR-24 and Telegraph Avenue $/ 56^{\text {th }}$ Street Park-and-Ride Lot ............................... 71

4.14 Proposed I-580 and Golf Links Road/98 ${ }^{\text {th }}$ Avenue Park-and-Ride Lot ................................ 73

4.15 Proposed I-580 and Fairmont Drive/Foothill Boulevard Park-and-Ride Lot ........................ 74

4.16 Chariot's Richmond Racer Route (Chariot, 2016a) .............................................................. 78

4.17 Bay Bridge Toll Plaza Congestion (Federal Highway Administration, 2011) ...................... 87

4.18 Platform Overcrowding Plagues BART During Peak Hours (Jones, 2016) ......................... 89

4.19 Time Savings from Eliminating Slow Segments (top) versus Increasing Top Speed (bottom) (Tang, Dick, \& Caughron, 2016) .......................................................................... 92

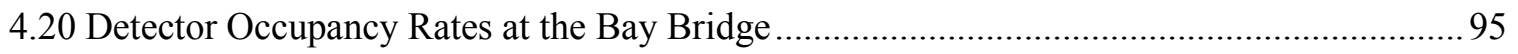

4.21 SFCTA Proposal for Downtown Outflow Cordon Tolling (SFCTA, 2010a) ..................... 100

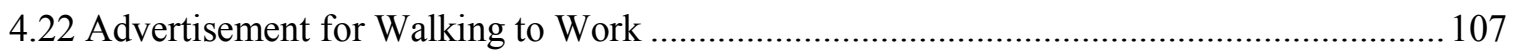

4.23 Peak vs. Off-Peak Demand by Mode in the Westbound (a) and Eastbound (b) Directions.

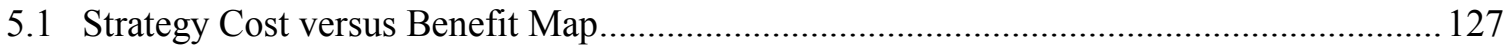




\section{LIST OF ACRONYMS AND ABBREVIATIONS}

AADT Annual Average Daily Traffic

ABAG Association of Bay Area Governments

AC Transit Alameda-Contra Costa Transit District

App Mobile Phone Application

BART Bay Area Rapid Transit

BATA Bay Area Toll Authority

Caltrans California Department of Transportation

CBD Central Business District

CCCTA Central Contra Costa Transit Authority

CHP California Highway Patrol

FAST Fairfield and Suisun Transit

FTA Federal Transit Administration

HOV High-occupancy vehicle

ITS Intelligent Transportation Systems

MTC Metropolitan Transportation Commission

MW Megawatt

PeMS Performance Measurement System

PPP Public-Private Partnership

RFID Radio-Frequency Identification

SFCTA San Francisco County Transportation Authority

SolTrans Solano County Transit

TOD Transit-Oriented Development

VMT Vehicle Miles Traveled

WestCAT Western Contra Costa Transit Authority

WETA Water Emergency Transportation Authority

WSDOT Washington State Department of Transportation 


\section{INTRODUCTION}

As anyone from the San Francisco Bay Area can attest, trying to get to San Francisco from the East Bay can be a nightmare during the morning peak period. Currently, there are four main ways to cross the Bay between Oakland and San Francisco: by car or by bus on the San FranciscoOakland Bay Bridge, by train through BART's Transbay Tube, or by ship on the San Francisco Bay Ferry. However, all of these modes are at capacity and straining to cope with the increasing travel demands of the region. The American Highway Users Alliance ranked the approaches of the Bay Bridge as the $12^{\text {th }}$ and $16^{\text {th }}$ most congested freeways in the US by miles of queue (American Highway Users Alliance, 2015). See Figure 1.1. Of note, only the congestion on the I-80 approaches are depicted, as evening eastbound congestion can extend to the I- 280 interchange in San Francisco, and morning westbound congestion can extend well onto I-580 and I-880 in Oakland.

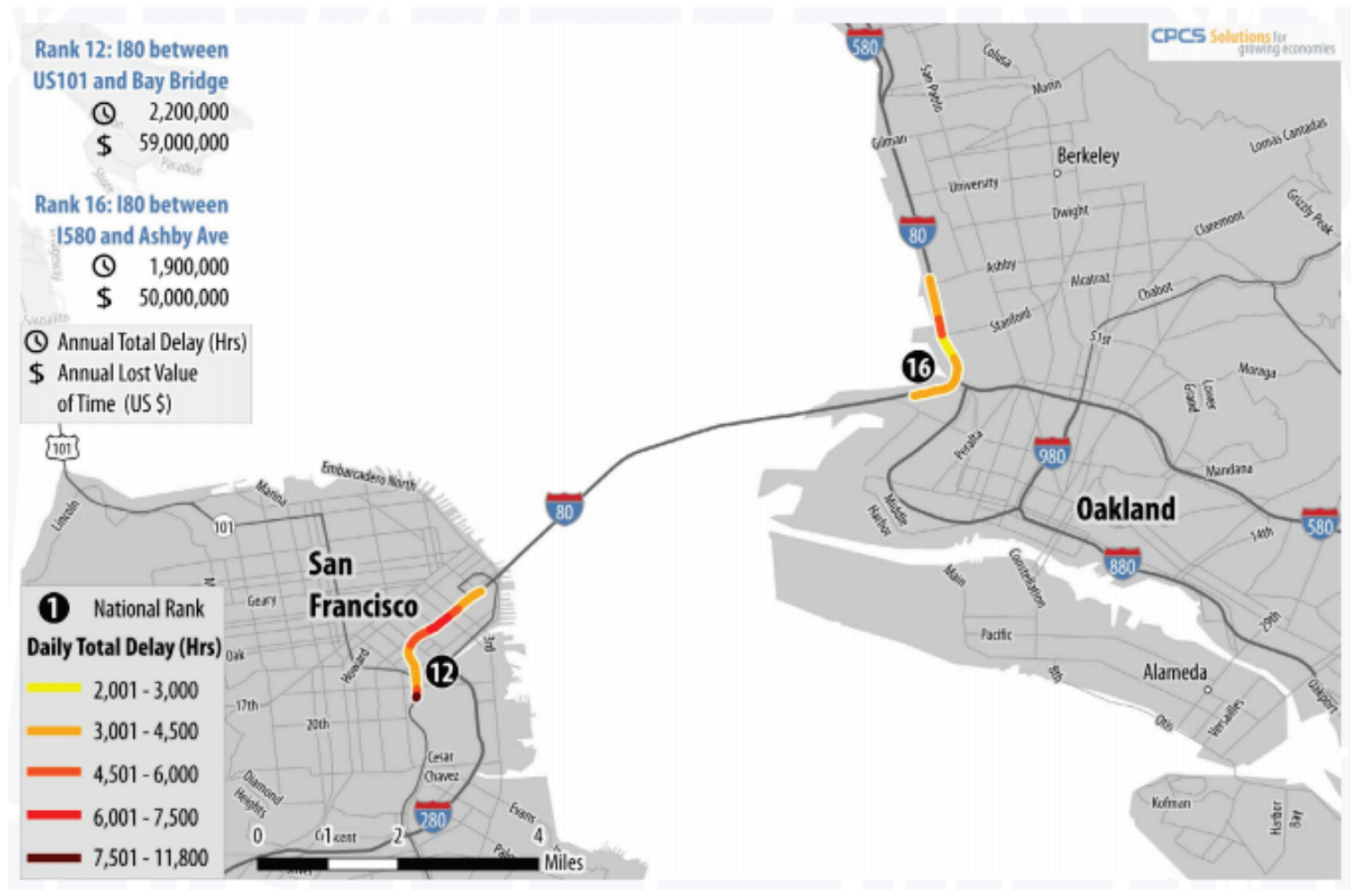

Figure 1.1: Bay Bridge Congestion (American Highway Users Alliance, 2015) 
To deal with this demand, there are proposals to expand or build new infrastructure. For example, public officials have begun discussions on building a second Transbay Tube to relieve crowding in the existing tube, and provide additional capacity (Cabanatuan, 2015). However, this tube is at least 30 years off due to major financial and political challenges. Additionally, while a second Bay Bridge has never progressed beyond discussions, some proponents are advocating for its construction (Middlebrook \& Mladjov, 2014). In light of recent experiences with challenges/delays these long-term infrastructure projects in California and elsewhere (e.g. highspeed rail) have faced, short-term solutions need to be explored to increase capacity across the bay while the long-term solutions (e.g. second Transbay Tube) are implemented.

\subsection{EXISTING CAPACITY}

This section outlines the four main ways to cross the bay: car, bus, train, or ferry.

\subsubsection{Car}

In order to cross the bay by car, one must either use the San Francisco-Oakland Bay Bridge or take extensive detours through the Richmond-San Rafael and Golden Gate Bridges to the north (around 27 miles), or San Mateo-Hayward Bridge to the south (around 45 miles). The bridge consists of five lanes in each direction, with a toll facility on the westbound direction on the east side of the bay. The annual average daily traffic (AADT) is 253,000 vehicles per day, or 25,300 per lane (Caltrans, 2015a). Of these, around 124,750 vehicles per day pay tolls (Bay Area Toll Authority, 2016). This makes sense, as tolls are only collected in one direction, and buses do not pay tolls. As will be discussed in Section 3.4.1, the peak hour demand per direction is around 8,000 to 9,500 vehicles.

The Bay Area Toll Authority (BATA), the agency that oversees the bridge's operations, promotes carpooling and diversification of travel times through congestion pricing. During peak periods, $\$ 6$ per two axle vehicle (such as a car) is charged, compared to only $\$ 4$ during non-peak periods. Carpool vehicles (three or more occupants) are only charged $\$ 2.50$ at all times. Buses are 
not tolled, nor are pedestrians and bicyclists (Bay Area Toll Authority, 2016). However, at present pedestrian and cyclist access only extends from Oakland to Yerba Buena Island, and not all the way to San Francisco.

\subsubsection{Bus}

Each weekday, Alameda County (AC) Transit provides over 500 bus trips across the bay on 28 lines (Transbay Service, 2016). See Figure 1.2. AC Transit carries 13,500 riders per day, which puts the system over capacity during peak periods and results in many complaints about overcrowding (Hursh, 2015). WestCAT Lynx, operated by the Western Contra Costa Transit Authority, provides 53 daily weekday bus trips between Hercules and downtown San Francisco (WestCAT Lynx, 2015). Fourteen daily bus trips are provided from Vallejo directly to the Transbay Terminal by SolTrans Route 200, operated by SolTrans and administered by the Water Emergency Transportation Authority (WETA) (Water Emergency Transportation Authority, 2013).

Greyhound and Amtrak also provide buses over the Bay Bridge for longer distance travel. For instance, Amtrak California provides 30 weekday buses per day between San Francisco and Emeryville, where each bus connects with a Capital Corridor train with service to either San Jose or Sacramento (Capital Corridor Joint Powers Authority, 2015). However, these are typically excluded from commuter considerations as their service is more oriented to long-distance travel. Private companies such as Google provide private buses, but it is hard to assess their actual significance in terms of addressing capacity constraints during peak hours without fixed routes or schedules.

\subsubsection{Train}

Transbay rail service is provided by Bay Area Rapid Transit (BART) through the Transbay Tube that connects the San Francisco peninsula to Oakland and points beyond. Currently, BART carries 423,120 weekday passengers (Bay Area Rapid Transit [BART], 2015). Of these, 21,000 passengers per hour cross the Bay during rush hour, nearing the line capacity of 25,000 passengers per hour (BART, 2014a). 


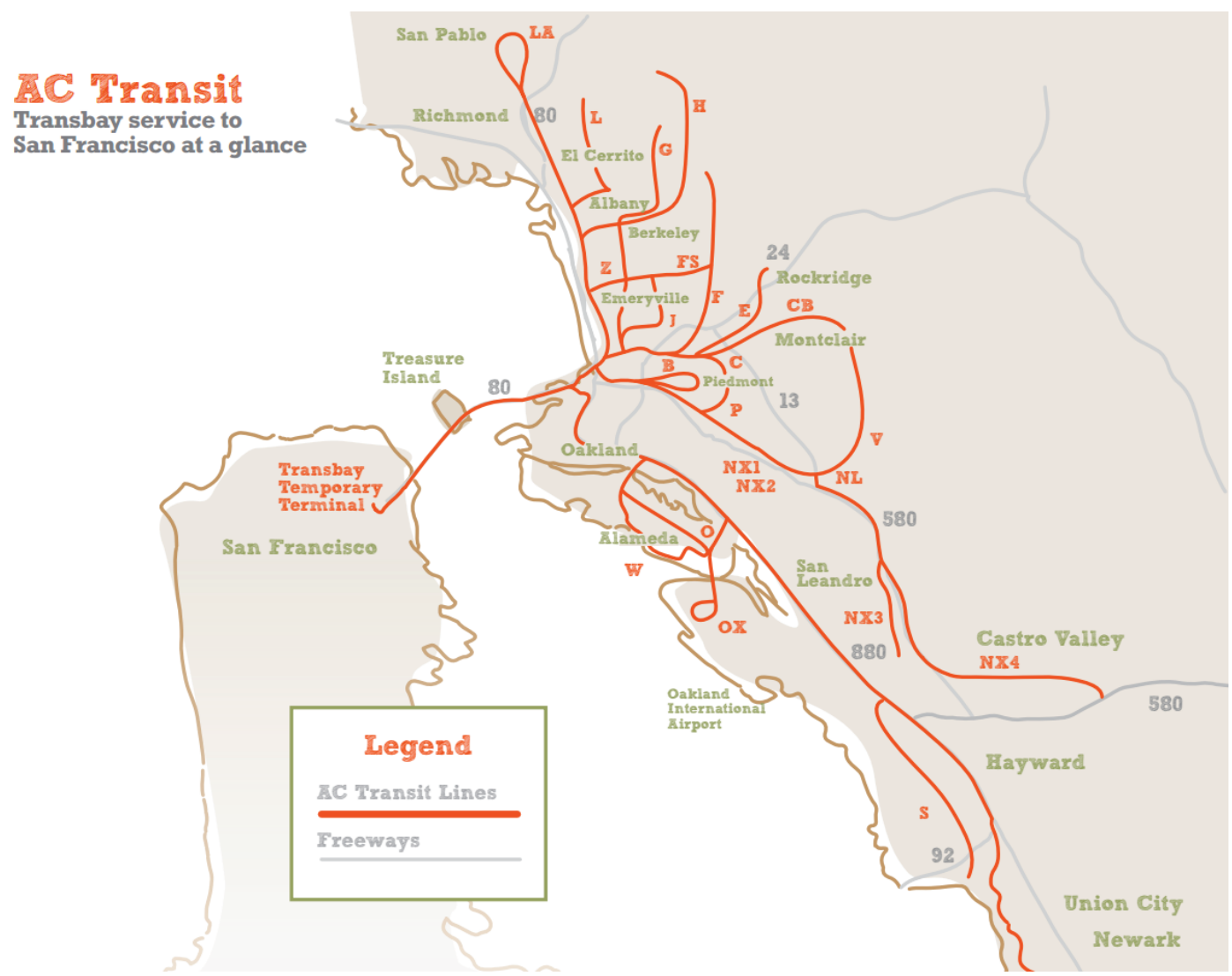

Figure 1.2: AC Transit Transbay Bus Service (Alameda County Transit, 2015)

\subsubsection{Ferry}

The San Francisco Bay Ferry provides service from Oakland, Alameda, and Vallejo, to South San Francisco and several locations in San Francisco (San Francisco Bay Ferry, 2016). These routes carry 11,200 weekday passengers across the Bay (Water Emergency Transportation Authority, 2013). However, due to inadequate docking facilities, service is currently at or near capacity.

\subsection{INCREASING CAPACITY}

As evidenced above and assessed more in-depth in Chapter 3, the Transbay corridor is at capacity or nearing capacity across all forms of transportation. BART and the San Francisco Bay Ferry are looking into their own solutions, both long-term (e.g. a second Transbay Tube) and short- 
term (e.g. more ferries and docks) (Cabanatuan, 2015; Metropolitan Transportation Commission [MTC], 2009; Water Emergency Transportation Authority, 2014). Regarding the San FranciscoOakland Bay Bridge, since vehicular capacity has been reached, increasing person throughput is going to necessitate increasing vehicular occupancy. MTC has been considering two options: increasing the effectiveness of buses and of carpooling.

\subsubsection{Buses}

In order to increase both bus ridership and bus throughput, several tactics are needed. These include tactics already underway, such as upgrading bus capacity at the new Transbay Terminal in San Francisco (Alameda County Transit, 2015). This will help reverse terminal capacity restrictions compared to the current temporary terminal by tripling the number of buses that can simultaneously be served. As well, AC Transit plans to purchase 10 double-decker buses to add capacity to the transbay corridor. In the long-term, AC Transit is planning to offer bus rapid transit (BRT) service on the Grand-MacArthur corridor to the Bay Bridge and downtown San Francisco (Alameda County Transportation Commission, 2011). This includes implementing transit signal priority, shoulder running, and $\mathrm{HOV} /$ bus only lanes in strategic locations.

\subsubsection{Carpool}

Another way to increase person throughput without relying on increasing vehicle throughput is to increase the number of persons per car. This is best done through incentivizing carpooling. MTC has already implemented some tactics, such as high-occupancy vehicle (HOV) priority lanes at the Bay Bridge toll facility, and reducing carpool tolls to $\$ 2.50$ (compared to $\$ 6.00$ for non-HOVs) (Bay Area Toll Authority, 2016). MTC is considering other incentives, such as extending managed lanes (HOV or other express lanes) or more park-and-ride lots.

\subsection{INCREASING DEMAND}

These increases in capacity will be necessitated as the Bay Area grows well into the future. The Association of Bay Area Governments (ABAG) predicts that the population of the Bay Area 
will grow by $30 \%$ from 2010 to 2040 (MTC, 2013, p. 32). Assuming this correlates to an equal rise in transportation use, the existing systems will be further strained trying to keep up. As well, MTC and $\mathrm{ABAG}$ desire to shift $10 \%$ of travelers away from private vehicles and into public transit or active modes of transportation, in addition to reducing overall vehicle-miles traveled (VMT) of the region by $10 \%$ by 2040 (MTC, 2013, p. 106). In order to realize these goals, additional non-private vehicle capacity and managing demand among existing capacity will be necessary. 


\section{LITERATURE REVIEW}

In order to arrive at solutions to the problem of demand exceeding capacity on the Bay Bridge, research on the feasibility and efficacy of various incentives for increasing person throughput is needed. In order to best perform this research, a review of existing literature is conducted. Solutions, best practices, and prior pitfalls can be gleaned from completed papers and integrated into this research. To this end, a variety of papers have been surveyed and their results compiled below.

In their "West Grand Avenue On-Ramp and Immediate Transbay Mobility Improvement Projects" presentation, MTC outlines four elements towards improving Transbay mobility: West Grand Avenue on-ramp shoulder running lane, adding new Transbay buses and encouraging existing AC Transbay buses on I-580 westbound to use West Grand Avenue, providing commuter parking, and improving on-demand shared mobility (MTC, 2011).

Element 1, adding a shoulder running lane to the West Grand Avenue on-ramp onto the approach to the Bay Bridge, will allow buses to skip queues that arise from the presence of the metering lights at the toll plaza. See Figure 2.1. This will require several modifications, such as improving drainage grate durability.

Element 2, adding new Transbay buses and encouraging existing AC Transbay buses on I580 westbound to use West Grand Avenue, will improve run times and service reliability. New routes will add to transit rider versatility, and using West Grand Avenue in conjunction with Element 1 will allow buses to skip toll plaza traffic.

Element 3, providing commuter parking, calls for adding three new park-and-ride facilities along the I-80 and I-880 corridors around Oakland. These three lots will add 700 spaces of capacity for users to either join in carpooling or board a bus. The first three elements are estimated to cost $\$ 35.6 \mathrm{~m}$.

Element 4, improving on-demand shared mobility, is not really covered by the presentation, but seems to suggest partnering with ride sharing mobile applications, such as Uber and Lyft. 


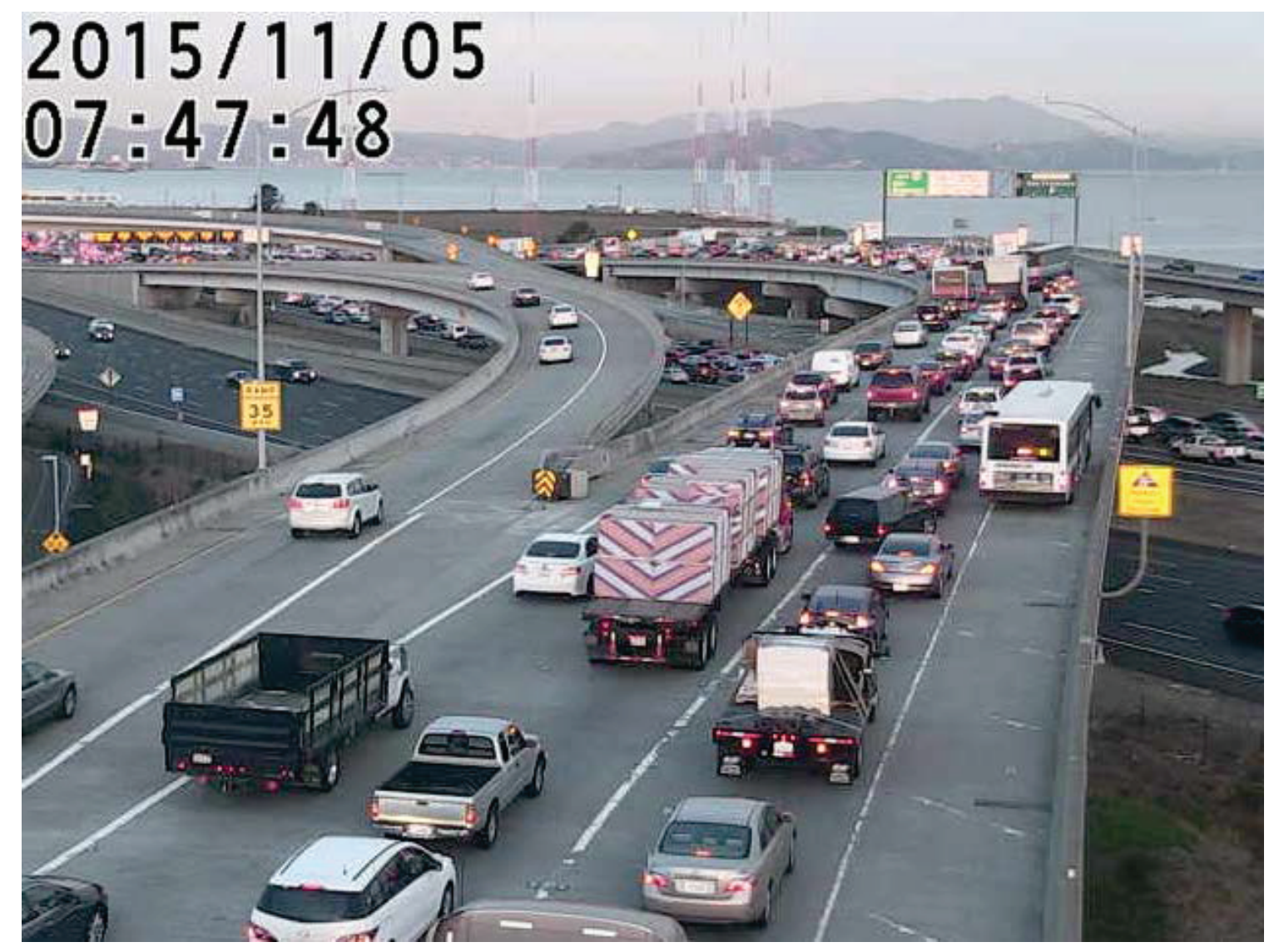

Figure 2.1: Bus on Right Using Shoulder to Jump Queue (MTC, 2011)

Further insight on proposed transbay improvements can be gleaned from BATA's San Francisco Bay Crossings Study Update. This report updates the 2000 San Francisco Bay Crossings Study, taking the previous study's conclusions and updating them with findings from the twelve years between reports (AECOM, 2012). This includes predictions for reduced travel demand and tolling revenue, and increased environmental and construction costs. Despite the reduced travel demand, demand is still predicted to exceed capacity on the existing bridges and the Transbay Tube by 2035 .

Three alternatives from 2000 were not recommended for further study due to the changing conditions listed above. These are: building a new multimodal bridge/tunnel from SR 238 in the 
East Bay to I-380 on the Peninsula, widening the San Mateo Bridge, and improving the approaches to the Dumbarton Bridge.

The report introduces three new BART crossing alternatives, four new transit improvement alternatives, and 19 highway improvement alternatives. Of these, it recommends all four new transit improvement alternatives: BART station capacity improvements, BART skip-stop “metro" service, a bus terminal in the East Bay, and expanding bus service. It also recommends four of the highway improvement alternatives: adding a bus ramp to MacArthur Boulevard, improving HOV access at Powell Street and I-80, and implementing open road tolling on the San Mateo and Dumbarton bridges. None of the new BART crossing alternatives were recommended for further study.

Another study on public transit was performed by Jochum et al. in their 2015 capstone project entitled "Comprehensive Public Transportation." This paper is a university capstone project that analyzes a Columbus, Ohio, initiative to reduce single-occupancy commutes to $70 \%$ of the mode share (Jochum, Clendenin, Good, Mescher, \& Blevins, 2015). The team analyzed the best practices of five different modes of transportation (car, bus, bike, walk, and rail) in five different cities (Indianapolis, Austin, Minneapolis, Charlotte, and Paris), and conducted an interview with a director of the Charlotte Area Transportation System. They concluded that Columbus should unify transportation administrations, work with employers to develop incentive programs for using transit, and implement HOV lanes and light rail.

Speaking of public transit, Paul Belmonte's 2014 thesis “All Aboard: Investigating Public Transit Use across Income Levels and Implications for Transportation Policy in the United States" analyses the correlation between transit use and a variety of factors at different income levels (Belmonte, 2014). It beings with an overview of how little attention transit receives in terms of funding when compared to roadways, and the (perhaps related) share of commutes made by transit versus by private automobile. Belmonte found that income relates to transit usage non-linearly, in that the poorest and wealthiest commuters are more likely to use transit than middle-income commuters. 
One theory is that middle-income earners tend to live in auto-dependent suburbs, whereas both the wealthy and poor typically live in central cities, which are better supported by transit. A solution Belmonte mentions to increasing transit usage is to switch gas tax over to a VMT tax, which would incentivize shorter commutes. In addition, he proposes government-supported ridesharing arrangements and telecommuting. Belmonte concludes with a proposed inequalitydensity matrix that charts various incentives for transit usage against axes of income inequality and urban density. After determining local conditions and what specific solution is desired, various proposals can be analyzed based on where they fall on the matrix.

Another way to reduce VMT is detailed in Mark Goh's 2002 paper "Congestion Management and Electronic Road Pricing in Singapore.” This paper details Singapore's experience in preparing the island nation for congestion management and capping the roadway vehicle population (Goh, 2002). Since Singapore is such a small and dense nation, the standard strategy of matching congestion with roadway widening is not an option. As well, many users only consider the personal cost of automotive usage (gas, maintenance, time, etc.) and not the greater societal costs (adding to congestion, greenhouse gas emissions, etc.). The Singaporean government has realized this, and since the 1970's has aggressively implemented a variety of tactics to curtail automotive usage, ranging from making purchases more expensive, to levying fees to enter the central business district (CBD), to expanding public transit. These approaches have had varying levels of success.

One more modern solution is to implement road pricing, which tracks congestion and assesses a respective electronic fee. This system is similar to systems implemented in Hong Kong and the Netherlands in the 1980's. Unlike these systems, Singapore's road pricing network works through overhead gantries that "tag" cash cards in each vehicle, rather than a tracking system due to privacy concerns. Lastly, Goh concludes that viable transit alternatives are necessary to avoid strangling CBD vitality. 
Another idea involving toll tags is Kalon Kelley’s 2007 “Casual Carpooling - Enhanced” proposal. This paper assesses a technology that could incentivize carpooling by means other than access to an HOV lane (Kelley, 2007). Traditionally, carpool is incentivized through access to special, often faster HOV lanes, or reduced tolls. This does not promote increasing vehicle occupancy beyond the minimum to receive this benefit, nor in areas without HOV or toll incentives. Kelley proposes a system where each commuter carries a radio frequency identification device (RFID) that connects to the driver's device and chimes in whenever passing a special gantry. This could help promote maximizing car occupancy and carpooling in places where HOV lanes or tolls are impractical (such as surface streets).

This system could also increase personal safety by ensuring that all drivers and passengers are held accountable by association with their RFID card and by extension, file on record. This could create a review system similar to Uber or other ridesharing programs, where passengers can see a driver's ratings and vice versa. Lastly, supply and demand can be managed by increasing occupancy requirements during the most congested times of day, or increasing rewards for drivers who go to underserved casual carpool nodes.

Lastly, relating to incentivizing carpool is Wang and Chen's 2012 study on "Attitudes, Mode Switching Behavior, and the Built Environment: A Longitudinal Study in the Puget Sound Region." This paper proposes that commuters who switch from carpooling to driving alone do so mostly for structural factors, such as travel time or travel cost (Wang \& Chen, 2012). On the other hand, commuters who switch from driving alone to carpooling do so mostly for psychosocial factors, i.e. personal attitudes and beliefs. This was done through an analysis of commuters in 1989 by those who drive alone versus those who carpool, and a follow-up in 1996 assessing if they had switched and if so, why. Wang and Chen also found that many change their beliefs to fit whichever choice they pursue, e.g. after switching from carpooling to driving alone, that driver will begin to feel like carpooling is burdensome. 
One telling piece of evidence is that structural incentive programs, such as fee reduction or exemption for carpools, and ride-matching services, affect carpool rates by only one percent. Wang and Chen conclude that instead, psychosocial factors should be promoted as they are why most carpoolers made the switch. One proposed solution is to raise the commuting population's awareness about the costs, personal and societal, of driving alone.

Summed together, this research gleans a variety of solutions for improving operations on the transbay corridor that will form the basis for this research. Some strategies, such as those from MTC, focus directly on the Bay Area, and will be fleshed out further and compared against other strategies in Chapter 4. Other strategies implemented elsewhere, or simply proposed, will be assessed for relevance to the Bay Area. Lastly, some strategies are original to this thesis and are either inspired by the literature reviewed above, or are wholly new ideas. 


\section{TIME-DEMAND-CAPACITY ON THE TRANSBAY CORRIDOR}

\subsection{INTRODUCTION}

One powerful tool for analyzing the transbay situation is to compile a time-demand diagram. This diagram, presented as Figure 3.1 for westbound and Figure 3.2 for eastbound, lays out the fluctuations in throughput across the bay, broken down by mode. It is important to note that the data represented is throughput, not demand, as the data provided covers how many people or vehicles actually crossed the bay, not the number who attempted or otherwise desired to but did not. As outlined in the introduction, there are four primary modes connecting San Francisco to the East Bay: private vehicles, buses, BART, and WETA (the ferry). For this diagram, bus service has been broken down by agency: AC Transit, WestCAT Lynx, and SolTrans 200. Details on each of these modes is provided below.

\subsubsection{Private Vehicles}

Information on the number of private vehicles was provided by Kevin Chen at MTC, in the form of PeMS and toll plaza data (Caltrans, 2016a; Caltrans, 2016b; Caltrans, 2015b). He also provided a report that details occupancy rates (persons per vehicle) through the toll plaza (Caltrans, 2012). This report states that on the bridge, HOVs have an average occupancy of 3.5 persons per vehicle, and general purpose vehicles (typically non-HOVs) have an average occupancy of 1.2 persons per vehicle. These values were used to convert westbound vehicle counts, which were split by HOV and non-HOV, into persons. The weighted average occupancy heading westbound was used to estimate the eastbound occupancy, assuming a conservation of travelers and vehicles. This weighted average occupancy is 1.54 persons per vehicle. Since the toll plaza only measures westbound traffic, eastbound traffic was measured using PeMS data. Vehicle count data is from September $1^{\text {st }}, 2015$ to October $31^{\text {st }}, 2015$, for both PeMS and the toll plaza. Vehicle occupancy data is from typical 2012 peak hour toll plaza traffic. 


\subsubsection{BART}

Data for BART ridership was provided by Brendan Monaghan (personal communication, October 4, 2016), and BART capacity was provided by Duncan Watry (personal communication, September 22, 2016), both with BART. The BART ridership data included station origindestination pairs, sorted by destination and recorded upon exit in 15 minute bins. This data covered August $1^{\text {st }}, 2016$ to September $30^{\text {th }}, 2016$. The provided capacity data was a train timetable, with the length of each train in terms of cars specified. Using data from BART's website, seating capacity and crush capacity was found to be around 70 and 200 persons, respectively (BART, 2016a).

\subsubsection{AC Transit}

Data for AC Transit was provided by Michael Eshleman at AC Transit (personal communication, October 11, 2016). This data included ridership counts for every transbay trip made by an AC Transit bus, and their respective load factors. A load factor is the percentage of capacity used when the bus was at its maximum passenger load, which was used to compute bus capacities. For instance, a load factor of 0.5 in a bus with 25 riders would correspond to a capacity of 50 riders. The data provided covers June $27^{\text {th }}, 2016$ to August $19^{\text {th }}, 2016$.

\subsubsection{WETA}

Data for the ferry service was provided by WETA's Scott Houston (personal communication, July 17, 2016). The data included passenger counts and ferry name for every trip operated by WETA in June of 2016. The ferry names were then matched to a separate table of capacities by ferry.

\subsubsection{WestCAT Lynx}

Data for the Lynx was provided by WestCAT's Julia Schnell (personal communication, July 20, 2016). This data logs each fare, its timestamp, and its coordinates for the month of October, 2015. Bus capacity was provided as 57 seats per bus. 


\subsubsection{SolTrans 200}

Data for Route 200 was provided by WETA's Scott Houston (personal communication, October 4, 2016). This is because even though SolTrans operates Route 200, WETA administers it as a supplement to its ferry service, which is why the route only connects the Vallejo Ferry Building to the San Francisco Transbay Terminal. The data provided covers ridership for the month of June, 2016, and capacity is assumed to be 57 riders per bus, similar to WestCAT Lynx.

\subsubsection{Data Processing}

For all transit data, ridership per trip per day was provided. By averaging the ridership across the same trip on different days, average ridership per trip could be attained. For the private vehicle data, the number of vehicles through the toll plaza by hour and day were provided, which were then averaged to find the typical number of vehicles through the toll plaza by hour. This was then multiplied by the average occupancy rates mentioned before to convert vehicles into persons.

All bus and ferry data was provided by trip, and so it was possible to ascertain the average ridership and capacity per trip. BART data was provided by 15 minute increments, and private vehicle data was provided hourly. For the sake of legibility, it was decided that 15 minute bins would be the best unit of time to work with. The bus and ferry runs were binned into 15 minute intervals, and the private vehicle data was simply quartered, so that the counts for four 15 minute intervals would equal the counts for one hour.

For the transit data, the most pertinent point of the trip for this thesis is crossing the bay. To this end, bus data is binned based on when the bus arrives at the Temporary Transbay Terminal for westbound trips, and when it departs for eastbound trips. Likewise, WETA's data is binned based on westbound arrivals and eastbound departures to/from the San Francisco Ferry Building. Lastly, the BART data is binned based on when the existing passenger would have passed through the Embarcadero Station. For example, it takes 33 minutes to ride BART from the Embarcadero Station to the Walnut Creek station in the East Bay, so the 1:45pm Walnut Creek exits from 
peninsula station origins were placed in the $1: 15 \mathrm{pm}$ bin. A location map of the San Francisco transit nodes relevant to this analysis is provided in Figure 3.3. 


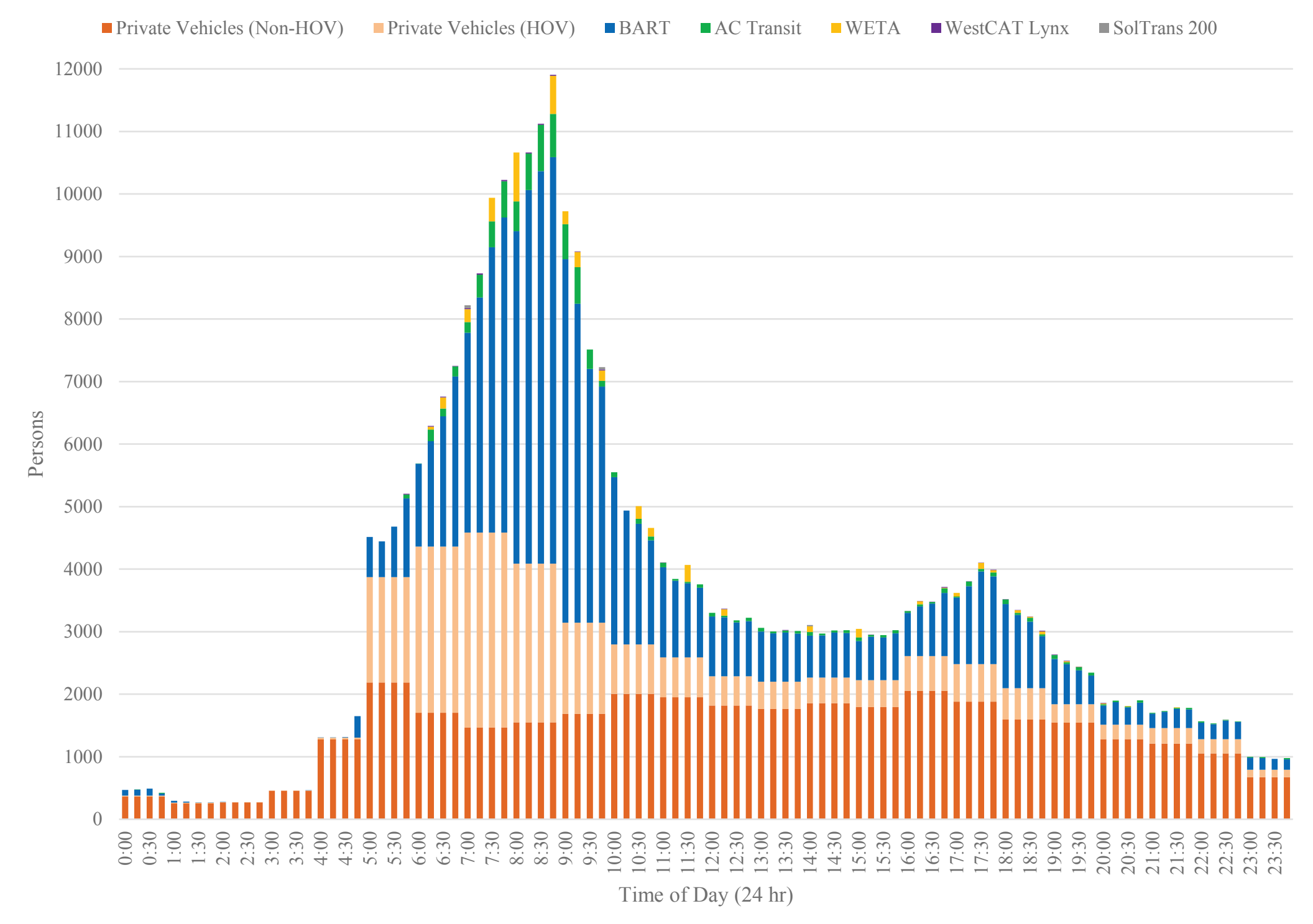

Figure 3.1: Westbound Person Throughput across the Transbay Corridor by Mode 


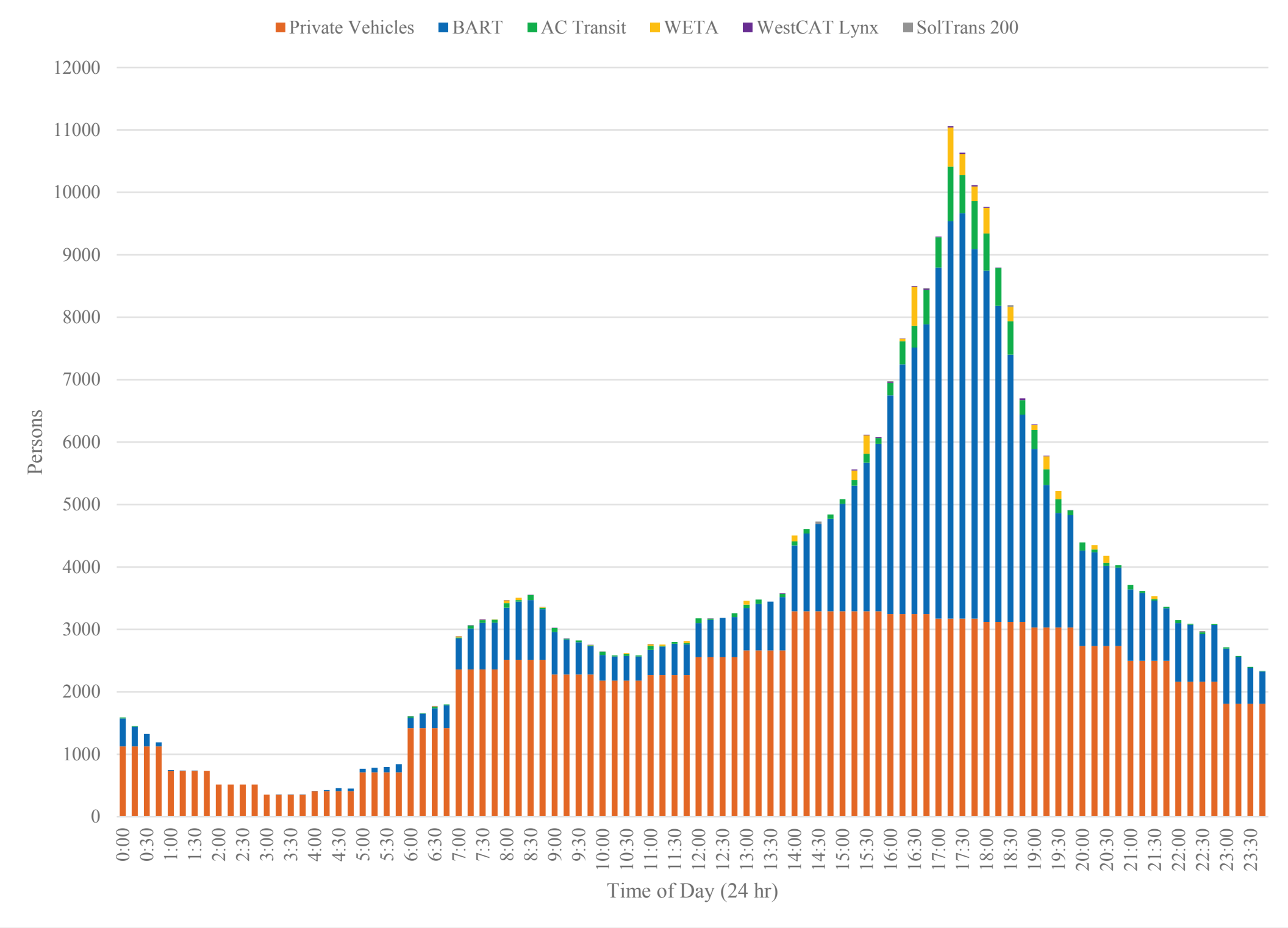

Figure 3.2: Eastbound Person Throughput across the Transbay Corridor by Mode 


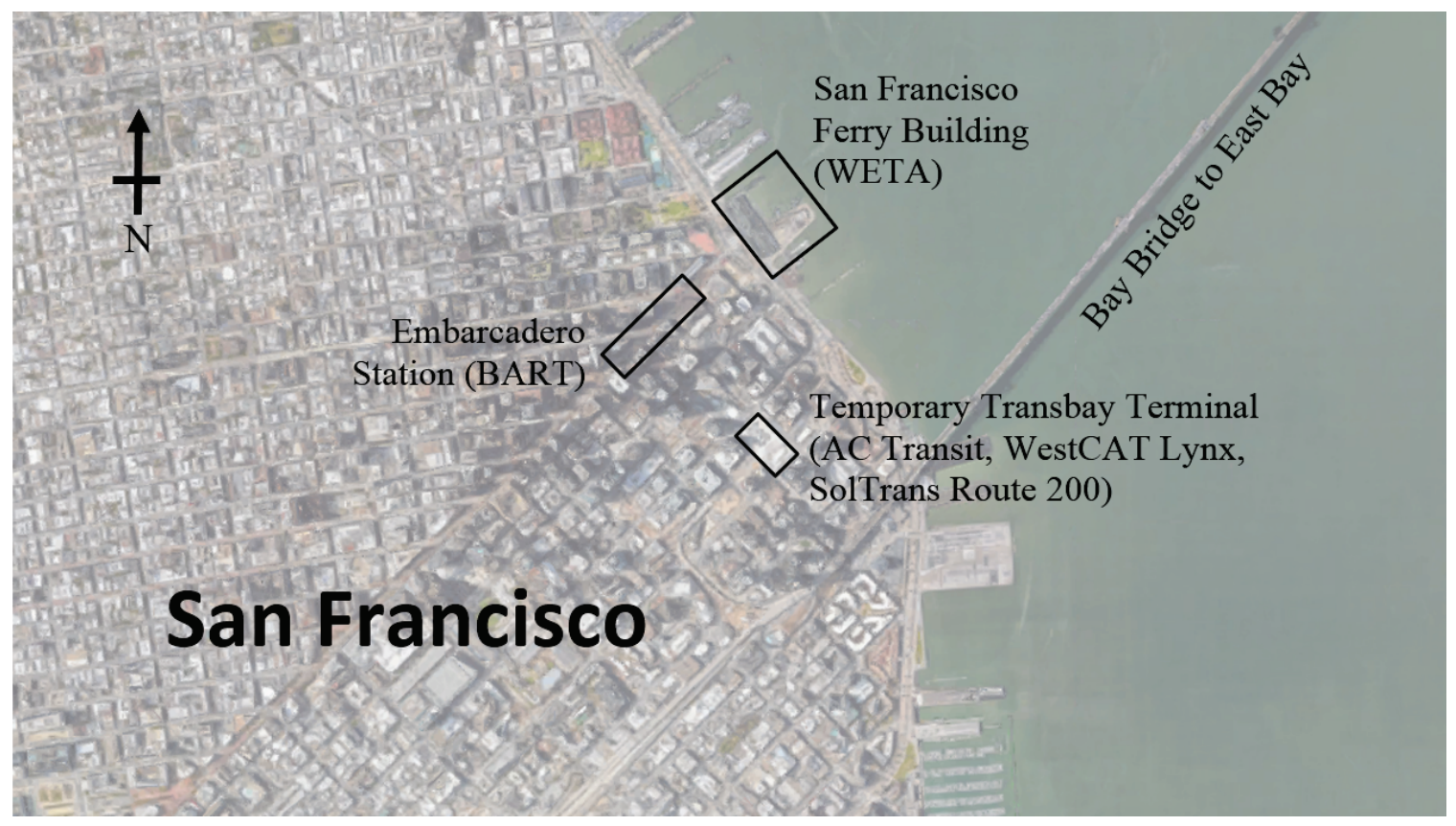

Figure 3.3: Location of Relevant Transit Nodes in Downtown San Francisco

\subsection{PEAK HOUR DATA}

By isolating the peak hour in each direction, a better mode breakdown can be created. In the westbound direction, the peak hour is 8:00am to 9:00am, when 44,351 commuters enter San Francisco from across the bay. In the eastbound direction, this hour is $5: 15 \mathrm{pm}$ to $6: 15 \mathrm{pm}$, when 41,582 commuters head the other way. The outright majority of these trips are made via BART, with a sizable minority made in private vehicles, as Figures 3.4 and 3.5 depict. AC Transit, WETA, and WestCAT Lynx make up the remainder of the trips, $10.9 \%$ eastbound and $8.9 \%$ westbound. SolTrans Route 200 does not run during either of these peak hours. 


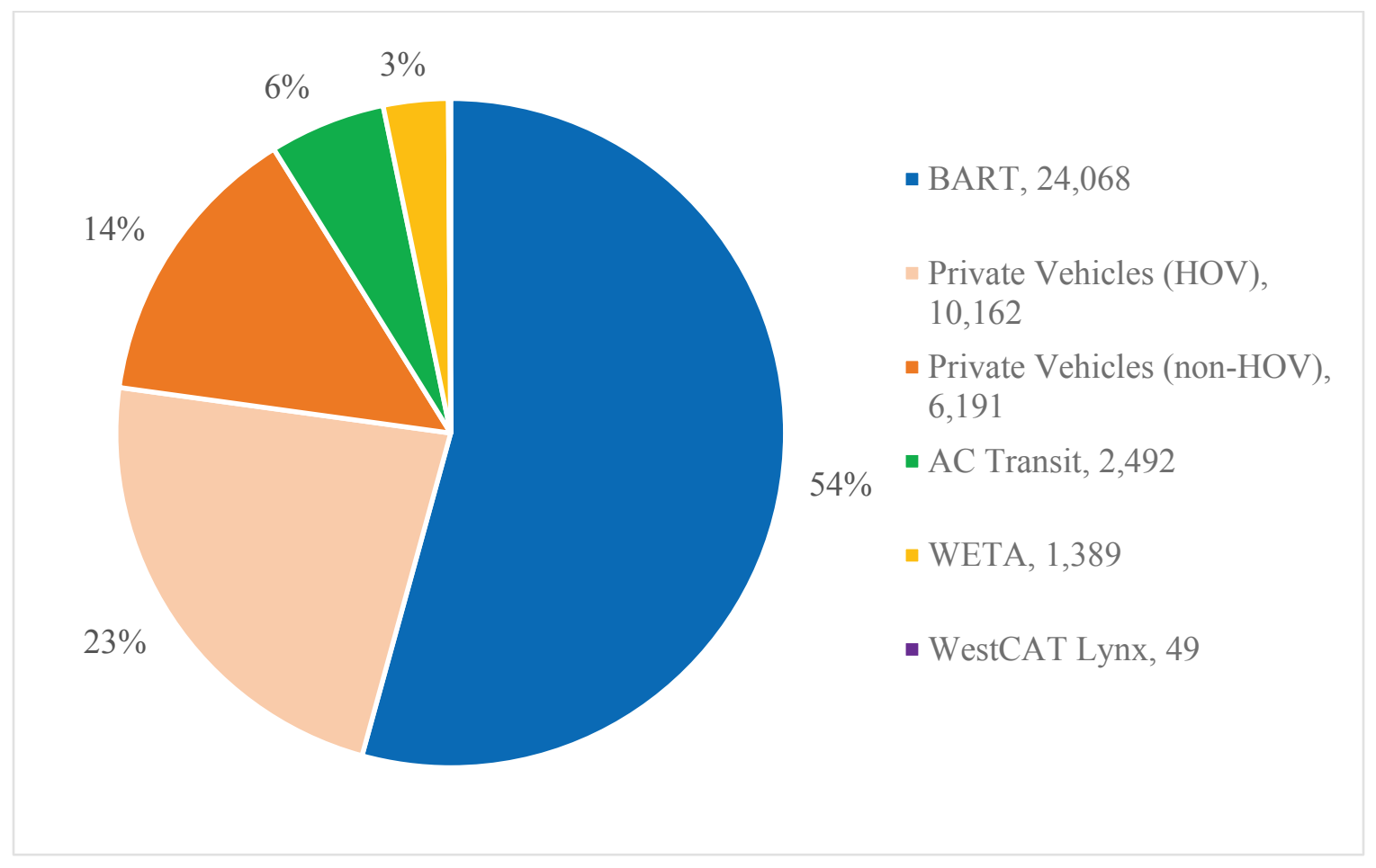

Figure 3.4: Westbound Peak Hour Transbay Trips by Mode

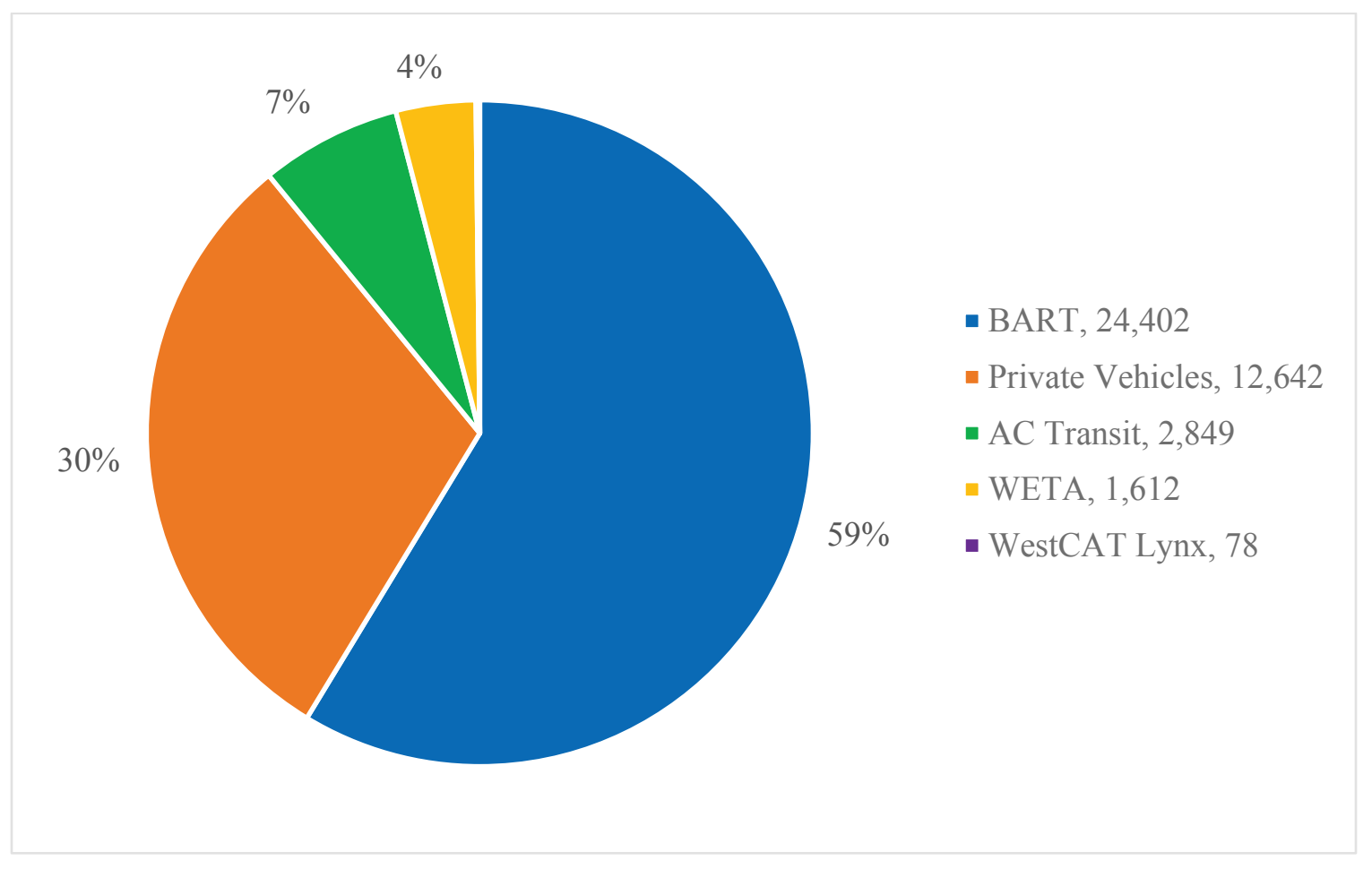

Figure 3.5: Eastbound Peak Hour Transbay Trips by Mode 


\subsection{OVERALL DAILY DATA}

In addition to assessing transbay crossings through the day and during the peak hours, it is also pertinent to evaluate the day as a whole. In total, around 333,825 people cross the bay into San Francisco and 333,010 cross the bay leaving San Francisco every day. The majority of these trips are made via private vehicle, in sharp contrast to BART's dominance during the peak hours. This is because while BART reigns supreme during peak hours in the peak directions, all other hours are dominated by private vehicle traffic. Transit modes other than BART carry barely any riders in the "reverse commute" direction (out of San Francisco in the morning and into San Francisco in the evening), while private vehicles see only a mild drop in throughput. Another interesting note is that BART carries around 234,000 commuters across the bay daily, out of around 440,600 total daily BART riders (BART, 2016b). This means that 53\% of BART's ridership, just over half, utilize the Transbay Tube, highlighting the infrastructure's critical importance to BART's operations. The breakdown of mode choice across the bay through the day is provided in Figure 3.6 for the westbound direction, and Figure 3.7 for the eastbound direction. 


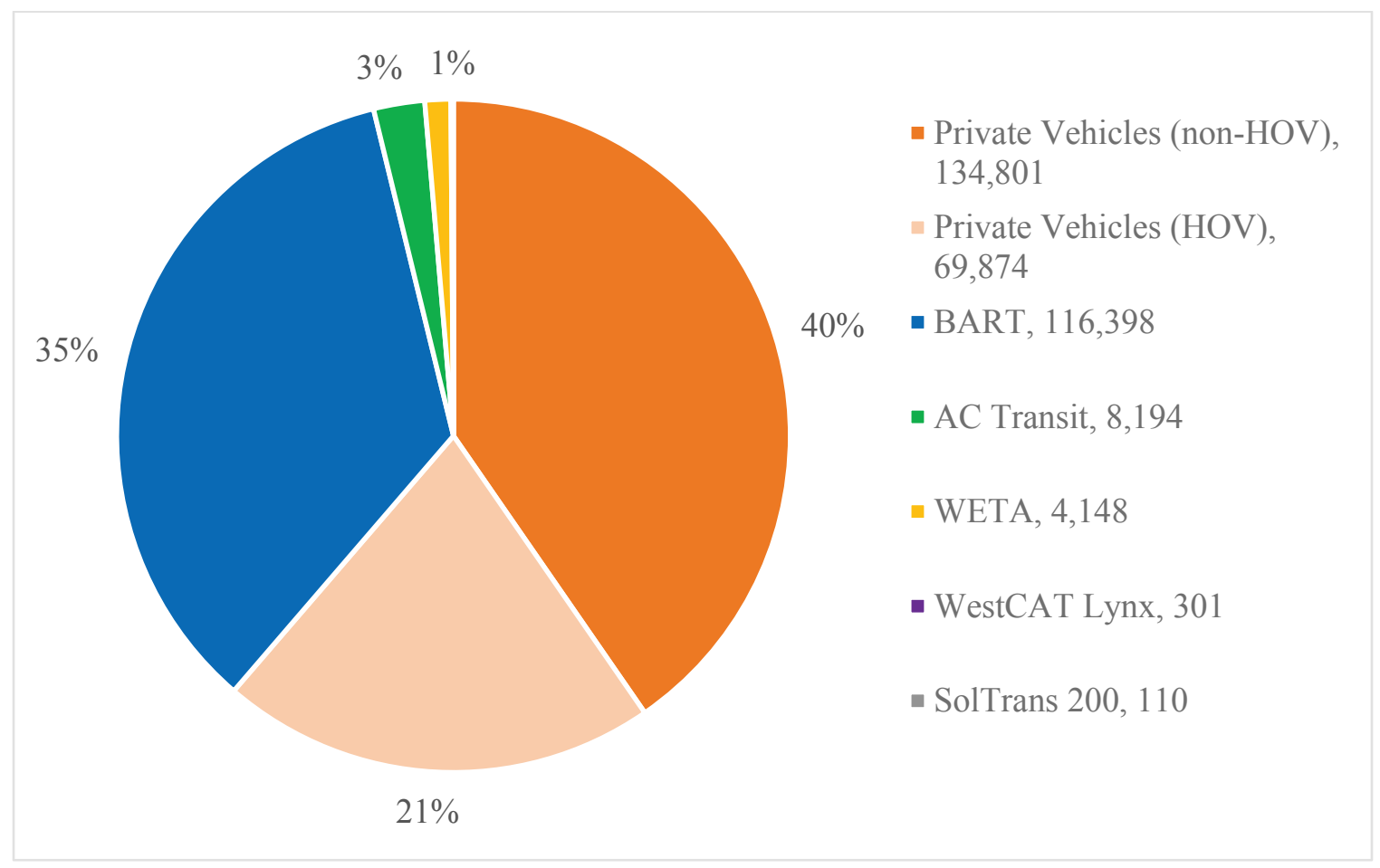

Figure 3.6: Westbound Daily Transbay Trips by Mode

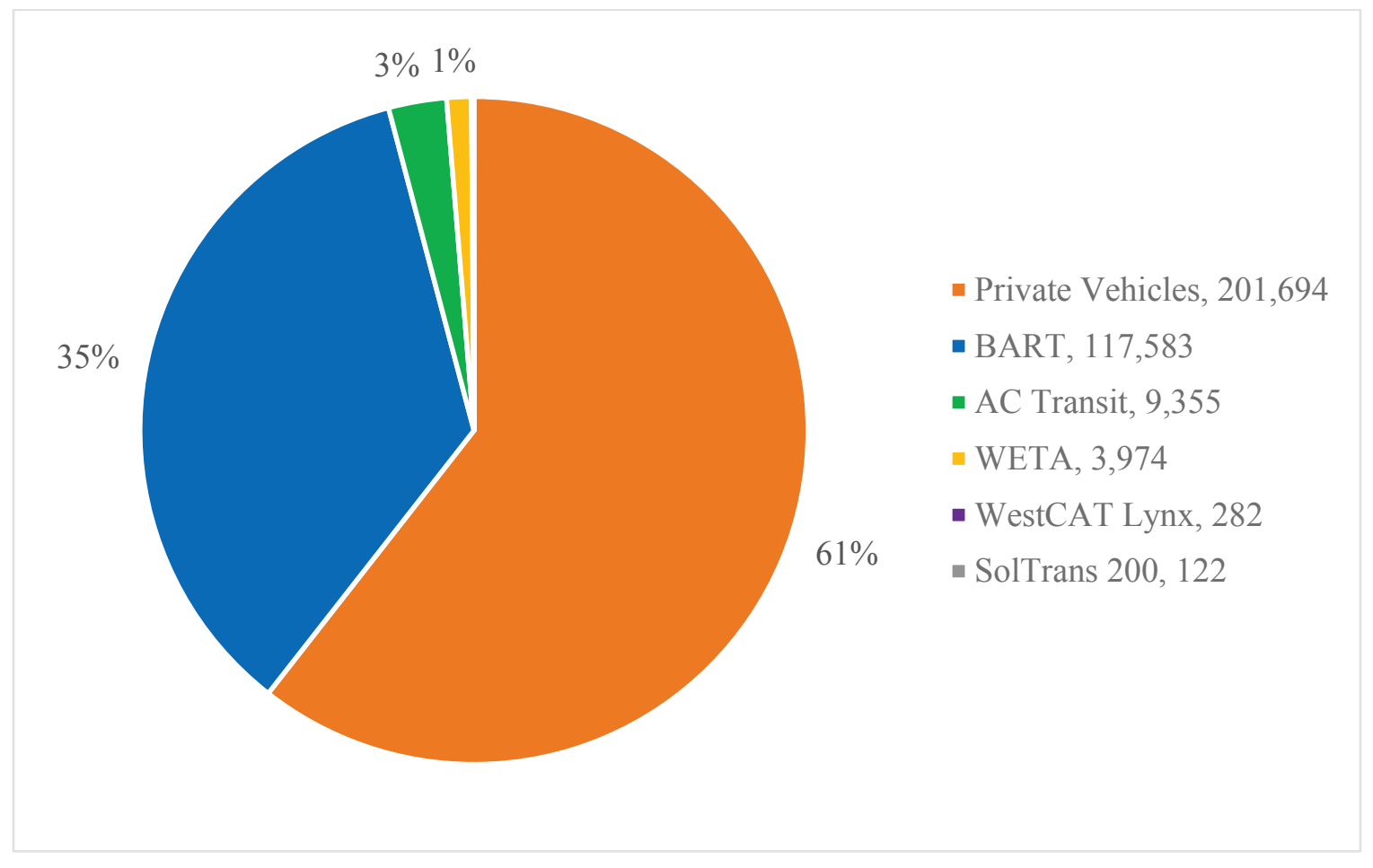

Figure 3.7: Eastbound Daily Transbay Trips by Mode 


\subsection{DEMAND, CAPACITY, AND OCCUPANCY}

Demand (or more exactly, throughput) is only part of the equation. The problem with congestion is that inherently there is more demand than capacity. Therefore, it is important to consider limitations imposed by capacity as well. The easiest way to do this is to take a look at each mode individually.

\subsubsection{Private Vehicles}

With private vehicles, there are two forms of capacity: the number of vehicles able to cross the bridge, and the number of people able to sit in each vehicle.

\subsubsection{Bridge Capacity of Vehicles}

Since the Bay Bridge is at capacity during the peak hours, as evidenced by the massive queues that build up to cross the bridge, it is safe to assume that the greatest hourly vehicle count is a reasonable estimate of capacity. This corresponds to 9,222 vehicles that cross at 5:00am to 6:00am in the westbound direction, and 8,512 vehicles that cross at $3: 00 \mathrm{pm}$ to $4: 00 \mathrm{pm}$ in the eastbound direction. These numbers make sense, as freeway capacity is estimated to be 1,700 to 2,300 passenger cars per hour per lane (Caltrans, p. 133). At five lanes, this translates to 8,500 to 11,500 passenger cars per hour on the bridge. While I- 80 on the Bay Bridge is a freeway and as such should have capacity towards the higher end of the range, conditions are not ideal due to a reduced speed limit (50 MPH), narrow lanes, and narrow to non-existent shoulders. It is also important to note that this range is in terms of passenger cars, while the actual counts are in terms of vehicles, which include passenger cars as well as trucks, buses, and RVs. According to Caltrans, $2.58 \%$ of Bay Bridge traffic in 2014 were trucks (Caltrans, 2014, p. 97). Out of around 263,000 vehicles crossing the Bay Bridge daily, only 655 (0.25\%) are scheduled commuter buses. Noncommuter buses and RVs are assumed to be negligible. Using an equivalency value of 1.5 passenger cars per truck/bus and a truck/bus percentage of $2.83 \%(2.58 \%+0.25 \%)$, this adds 130 
westbound and 120 eastbound vehicles (Caltrans, p. 133). This comes out to an equivalent of 9,352 westbound and 8,632 eastbound passenger cars.

Another interesting point to note is that the observed peak hour for private vehicle counts preceded the peak hour for all modes. In the westbound direction, the all-mode peak hour is 8:00am to 9:00am, whereas the private vehicle peak hour is 5:00am to 6:00am. In the eastbound direction, the all-mode peak hour is $5: 15 \mathrm{pm}$ to $6: 15 \mathrm{pm}$, whereas the private vehicle peak hour is $3: 00 \mathrm{pm}$ to 4:00pm. This separation of peak hours is most likely due to congestion slowing down traffic during the all-mode peak hour. The private vehicle peak hour volume indicates the most amount of cars that are able to cross the bridge right before demand increases too high and conditions break down. Demand to cross may be higher at 8:00am and 5:15pm, but due to queuing delay less cars are able to get through. While actual demand is nearly impossible to measure, actual throughput is easy to obtain, as demonstrated before in Figures 3.1 and 3.2. This throughput is presented again below in Figure 3.8, this time in terms of passenger car equivalents rather than occupants or vehicles.

The westbound direction seems to fluctuate more than eastbound, most likely due to complications from the toll plaza and its metering lights. While many drivers opt to use FasTrak for a toll-in-motion experience, many stick to paying cash, which requires stopping for a cash transaction. Additionally, HOVs (which must use FasTrak) are physically separated from other FasTrak users, and so the rate of HOV usage fluctuating can also cause the toll plaza throughput to fluctuate. It is also important to consider that the metering lights only permit a certain throughput, so HOVs (which are not stopped by the meter) count against FasTrak and cash vehicles, reducing their throughput. The HOV toll is only discounted from 5:00am to 10:00am and 3:00pm to 7:00pm, and HOVs pay the same toll as non-HOVs otherwise. Therefore, it makes sense that HOVs see a huge uptick during particularly the morning carpool hours, as shown in Figure 3.9. 


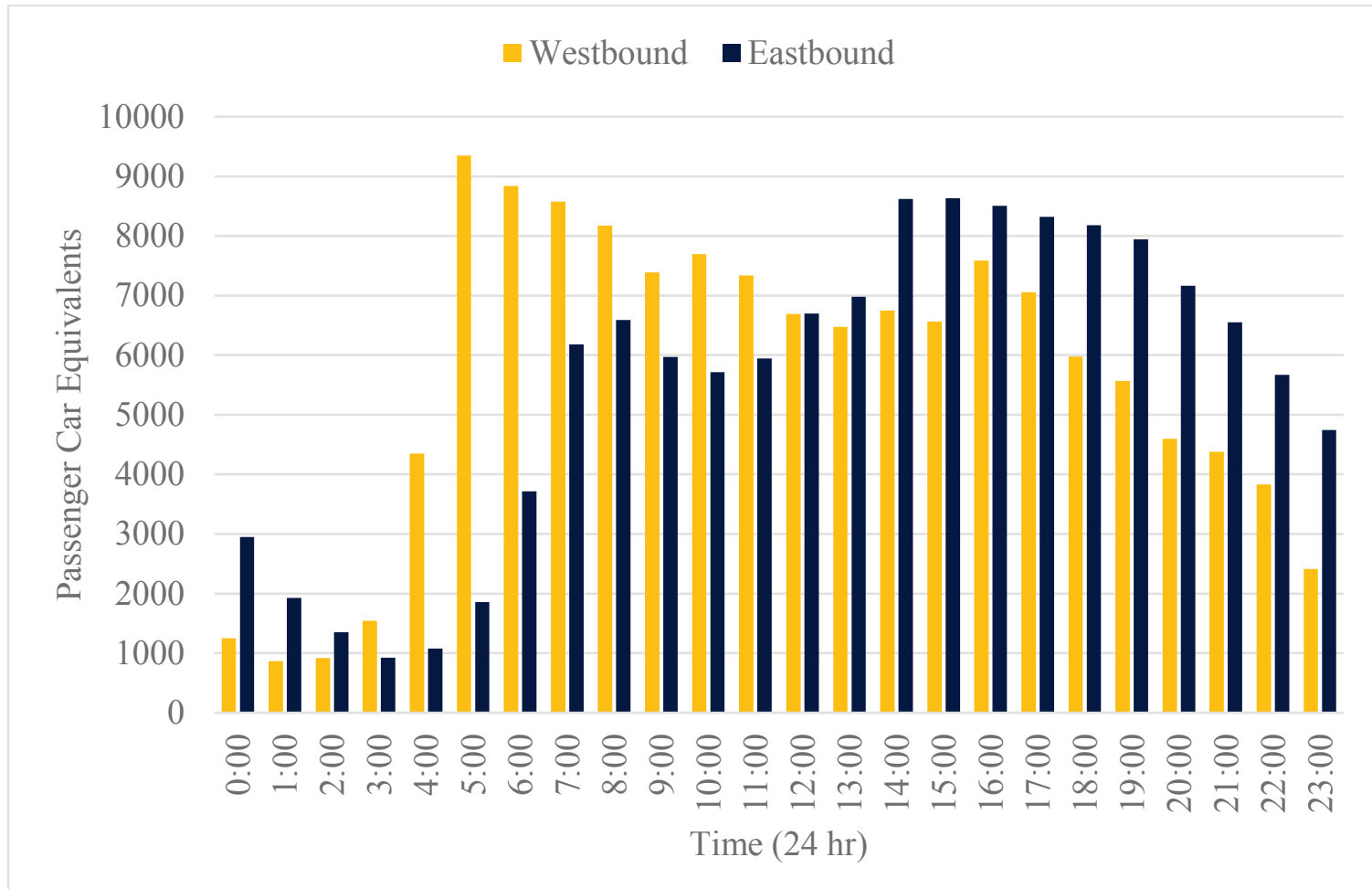

Figure 3.8: Average Bay Bridge Crossings by Hour in Terms of Passenger Car Equivalents

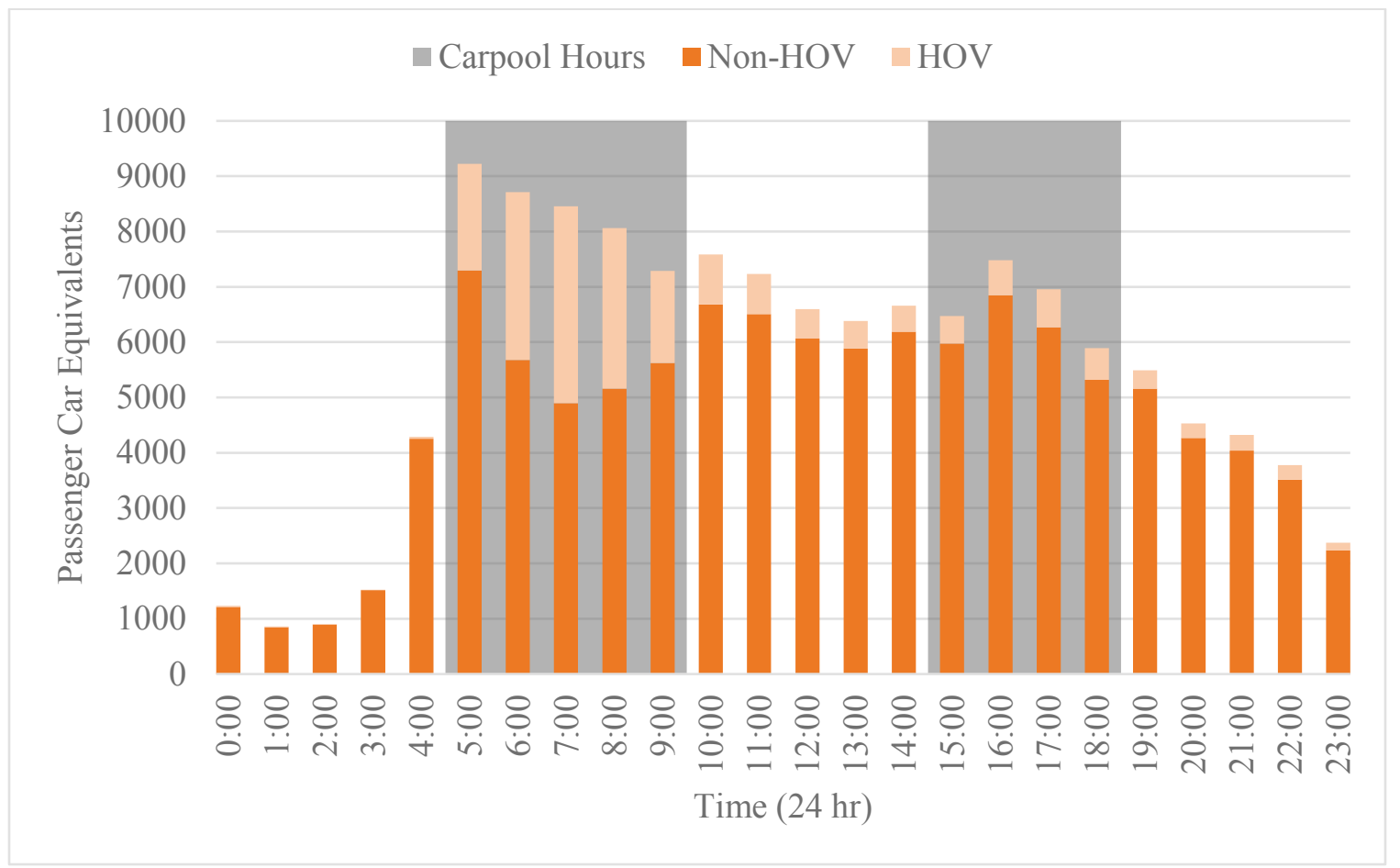

Figure 3.9: Westbound HOV and Non-HOV Counts by Hour 
On the other hand, eastbound traffic seems to be much more stable during the afternoons, approximately $2: 00 \mathrm{pm}$ to $8: 00 \mathrm{pm}$. This is most likely because without a toll plaza or metering lights, traffic is free to flow (and queue) without consideration for FasTrak versus cash or HOV versus non-HOV. Instead, demand hits capacity at around 8,632 passenger cars per hour as previously discussed, and any demand greater than that gets stuck in queues on I-80 and US-101 west of the bridge, and in downtown San Francisco.

\subsubsection{Vehicle Capacity of Occupants}

While the data for average passenger car size in terms of seats does not seem to be available, a value of five seats per car can be approximated as the median value. This value comes from an inventory of market share by vehicle that shows that SUVs, sedans, and other car types consist of around a third of sales each (IHS Markit, 2014). Typical capacity is seven or eight persons for SUVs, five persons for sedans, and two to five persons for the remainder, which includes coupes, pickups, hatchbacks, etc. Therefore, it is most prudent to use the median value of five seats per car. The major drawback to this methodology is that it relies on sales data rather than active private fleet data, which is not available. However, an inspection of actual traffic on the Bay Bridge confirms that five seats per vehicle is at minimum a reasonable estimate.

\subsubsection{Total Private Vehicle Capacity}

Combining the vehicle seat capacity from Section 3.4.1.2 with the bridge capacity from Section 3.4.1.3 yields the total theoretical capacity of seats crossing the bridge throughout the day. This can be paired with occupancy data from Section 3.1.1 to find the percent of theoretical capacity used. Throughput versus theoretical capacity across the day is shown in Figure 3.10 for westbound and Figure 3.11 for eastbound, and percent of theoretical capacity used across the day is shown in Figure 3.12. 


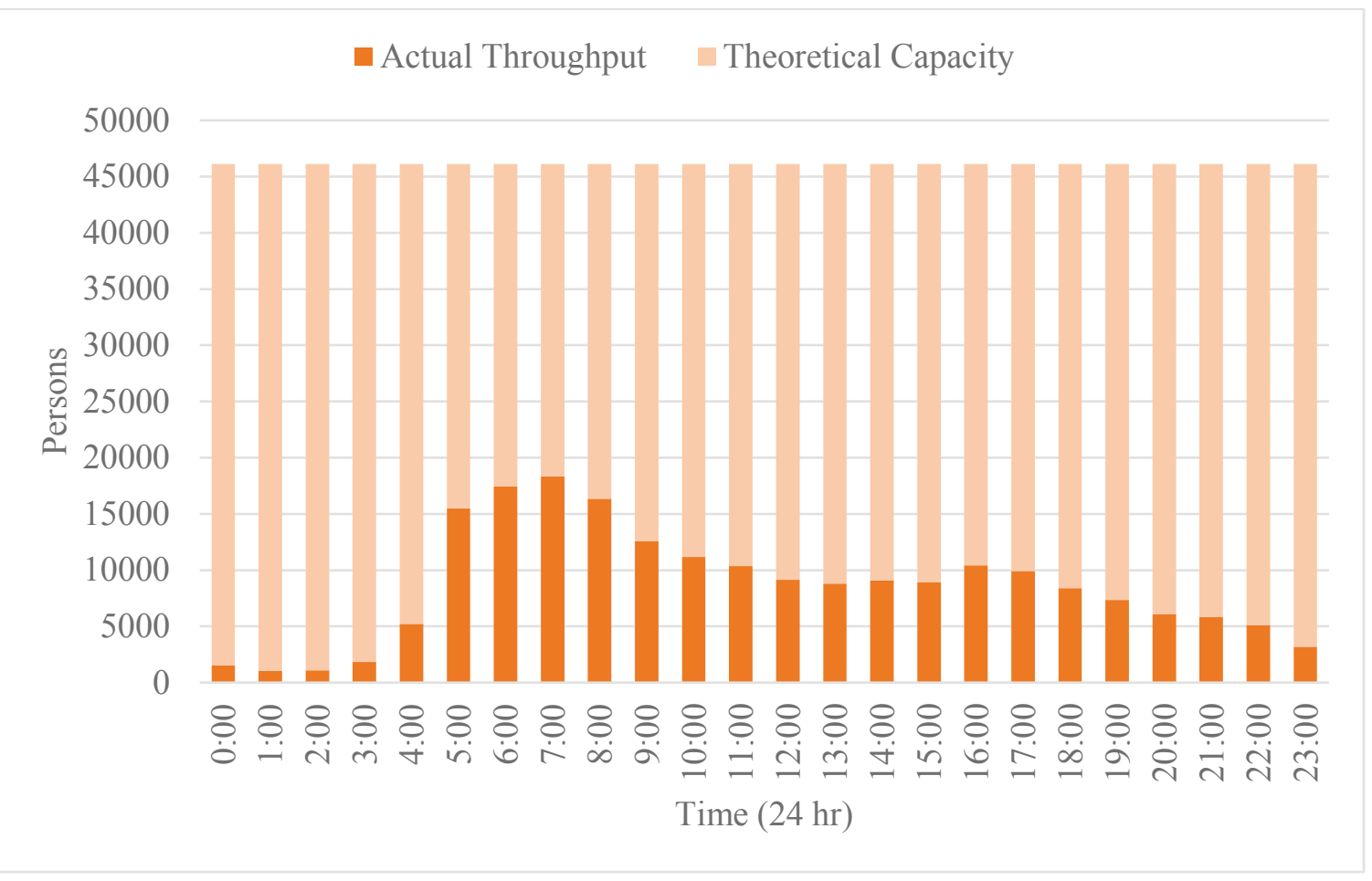

Figure 3.10: Westbound Actual Throughput and Theoretical Capacity of the Bay Bridge

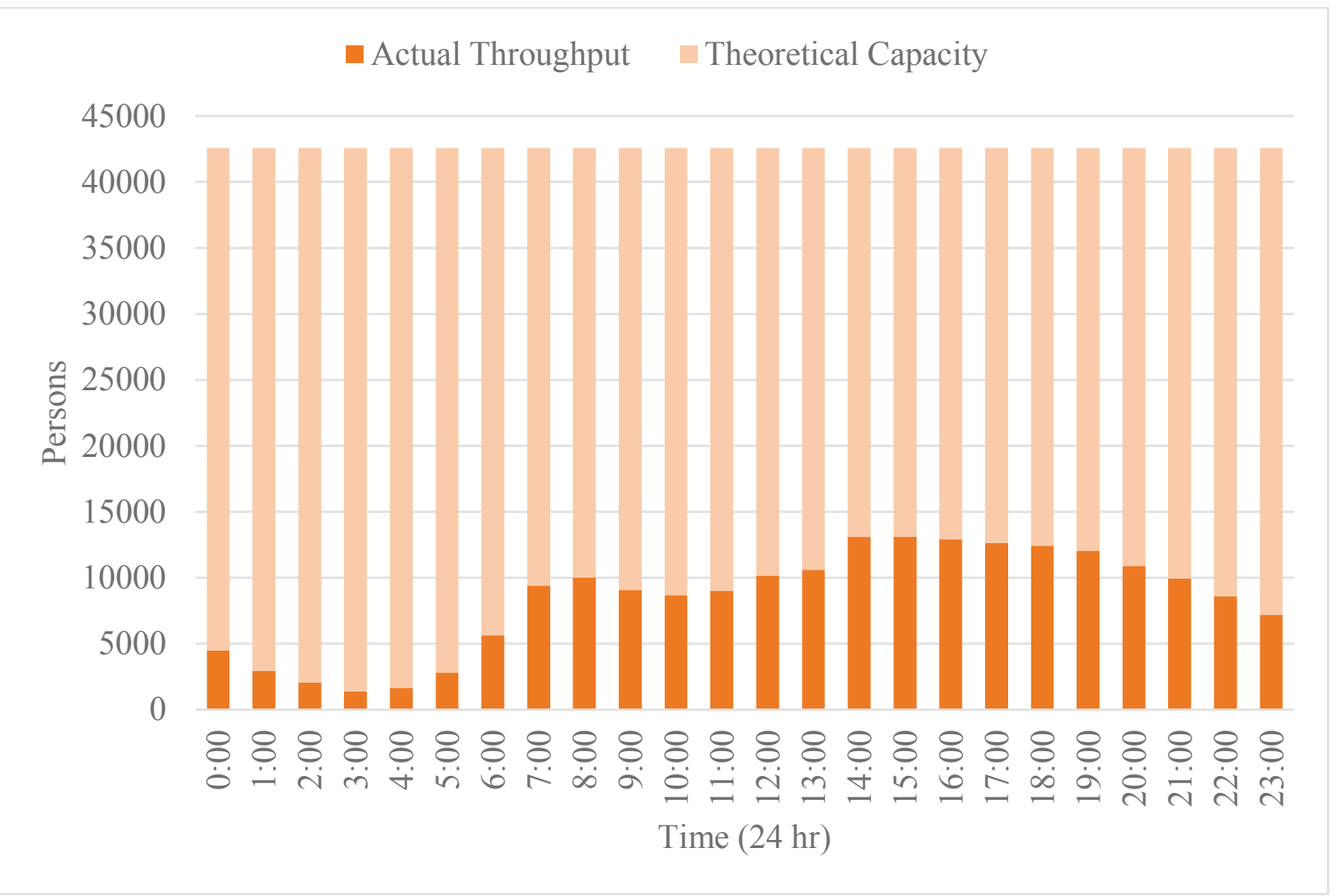

Figure 3.11: Eastbound Actual Throughput and Theoretical Capacity of the Bay Bridge 


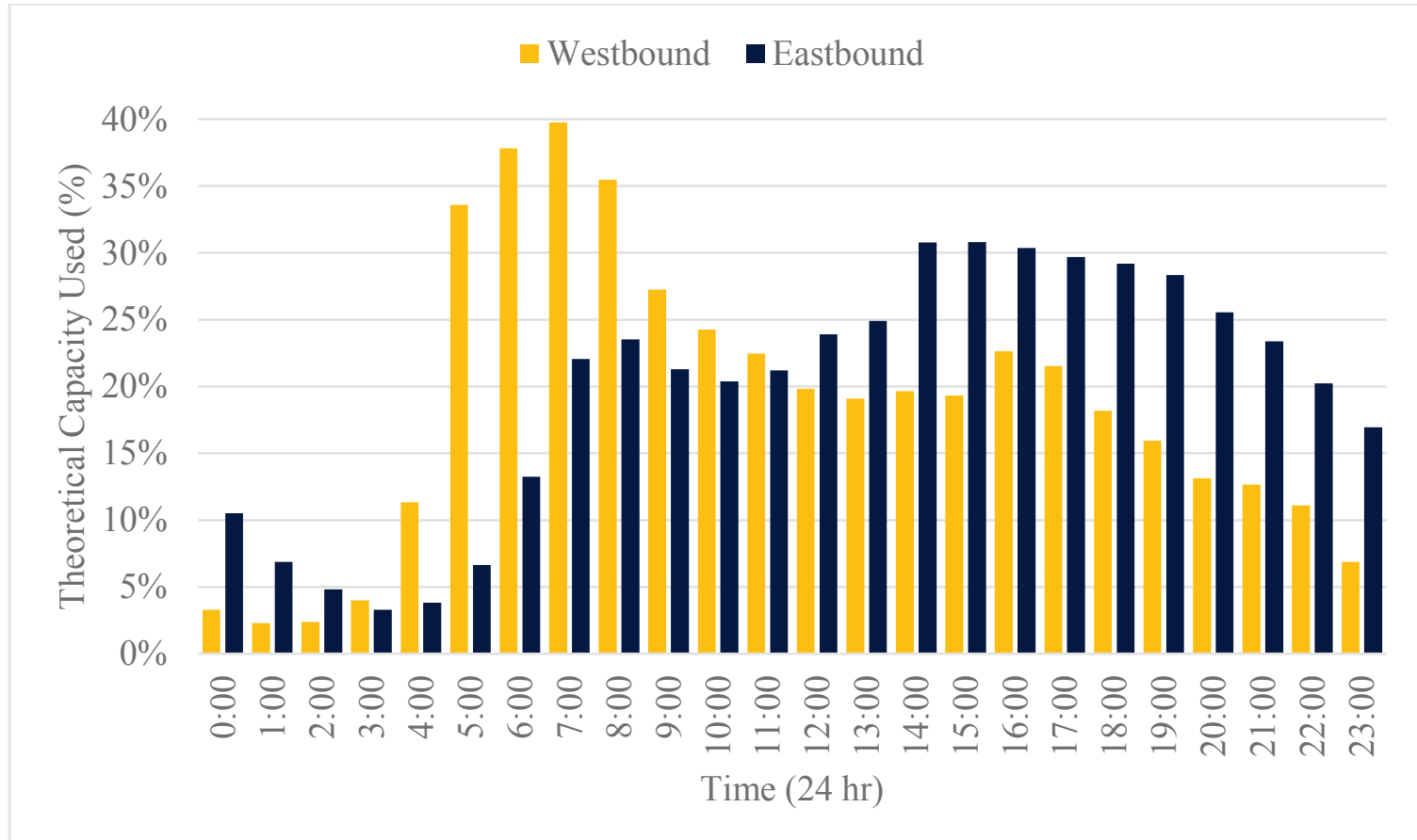

Figure 3.12: Percent of Theoretical Capacity Used on the Bay Bridge

The westbound capacity was found to be 46,108 persons per hour, from multiplying the greatest hourly throughput, 9,222 vehicles as discussed in Section 3.4.1.1, by five seats per vehicle. The eastbound capacity of 42,559 persons per hour was found the same way, using 8,512 vehicles per hour. Interestingly, due to varying rates of carpool usage, the greatest use of capacity in the westbound direction was during the 7:00am hour, at 40\%, not at 5:00am when the greatest number of vehicles crossed. This means that from 7:00am to 8:00am, $40 \%$ of the private vehicle seats that crossed the Bay Bridge were occupied. In the eastbound direction, the greatest use of capacity was during both the 2:00pm and 3:00pm hours, with 31\% each. Across the day, the westbound direction had an average of $18.5 \%$ use of capacity, and the eastbound had an average $19.7 \%$ use of capacity.

\subsubsection{BART}

For BART, complete origin-destination ridership numbers are available due to the nature of BART's fare system, where users must tag in and tag out in order to charge the relevant fare. 
The more complex task is assessing capacity. While a timetable of train lengths was provided, train length needed to be converted to passenger capacity. As mentioned before, two capacity numbers are provided on BART's website: around 70 seated and 200 in crush conditions. It is important to note that perceived comfort is not tied to these numbers, however, due to the natural tendency for passengers to gravitate toward the center of the train. For instance, it is not uncommon for the middle cars to be standing-room only while the end cars have available seats. Likewise, some seats are disregarded outright by riders due to sanitary concerns or preference to stand rather than sit next to a stranger. Lastly, some riders consume multiple seats with bags or by spreading out.

Regarding crush capacity, while 200 is the outright maximum capacity of a car, this is often not fully realized due to passengers failing to compress into the middle or taking up extra space, again with bags or by spreading out. At no point did ridership surpass the crush capacity, and the closest it came was in the eastbound direction at $5: 30 \mathrm{pm}$ to $5: 45 \mathrm{pm}$, when there were 6,492 riders and a crush capacity of 9,000 for a crush capacity percentage of $72.1 \%$. Comparatively, the seat capacity during this period was 3,150 seats, for a seat capacity percentage of $206.1 \%$. The full data for ridership versus seat capacity is provided in Figure 3.13 for westbound and Figure 3.14 for eastbound. Figure 3.15 charts the seat capacity percentage for both directions across the day. 


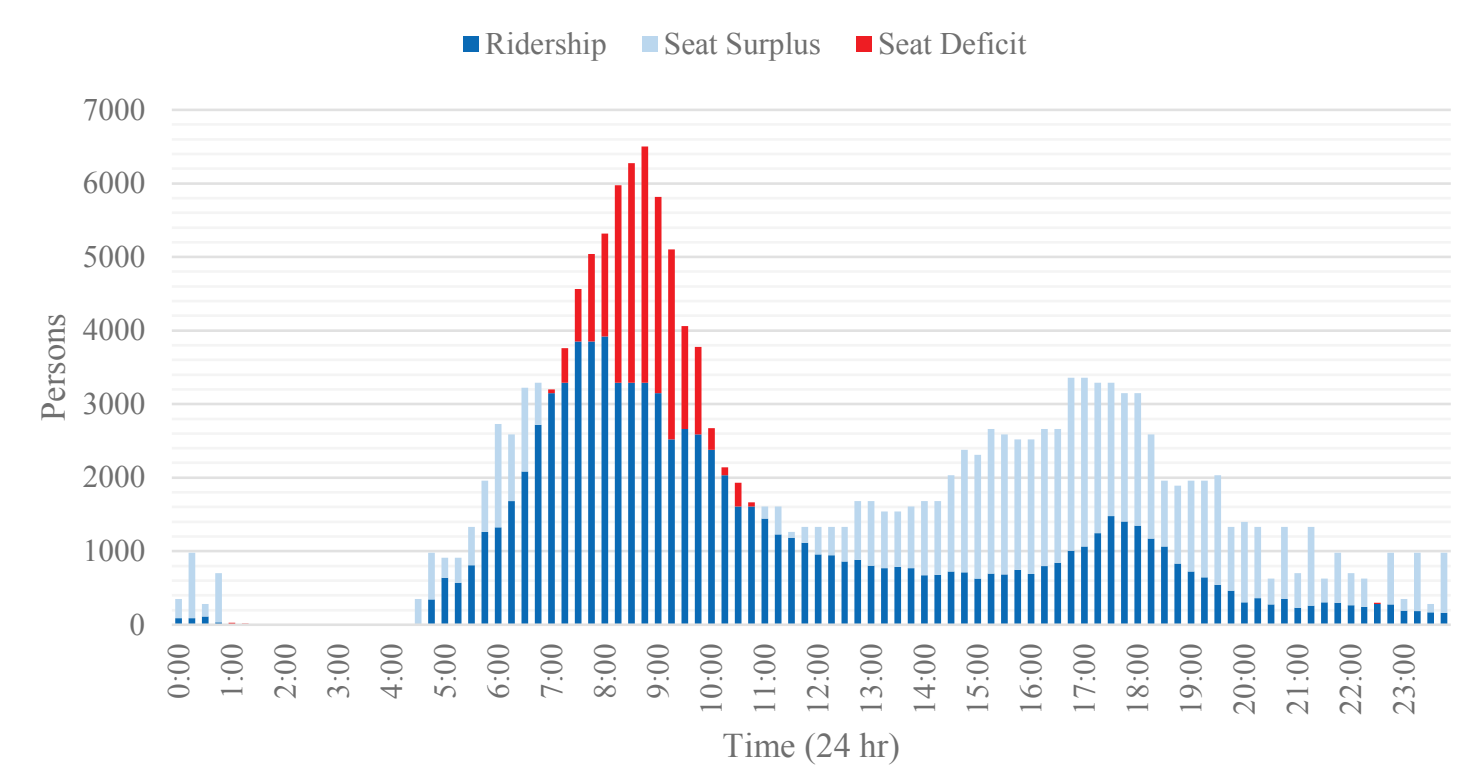

Figure 3.13: Westbound BART Transbay Tube Ridership and Seat Surplus or Deficit

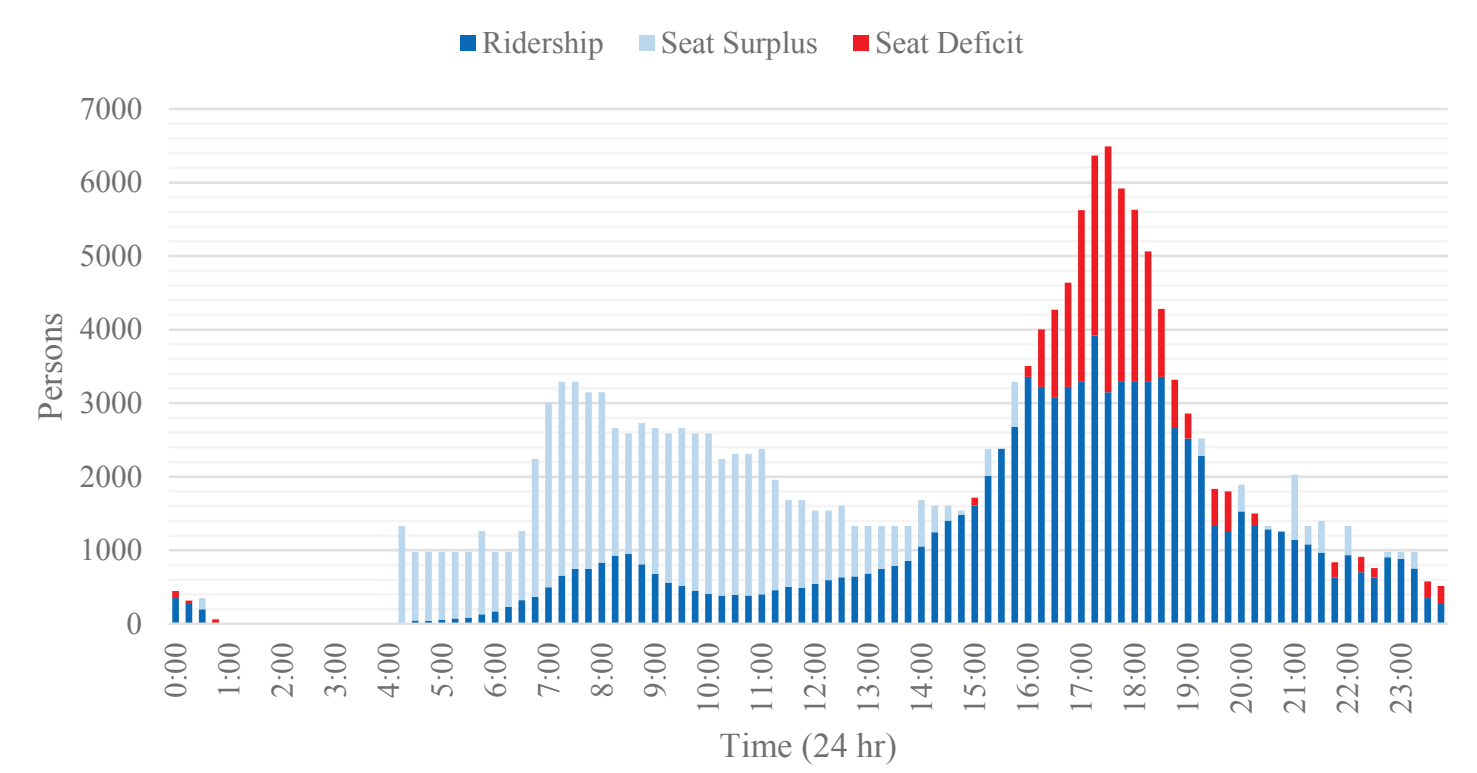

Figure 3.14: Eastbound BART Transbay Tube Ridership and Seat Surplus or Deficit 


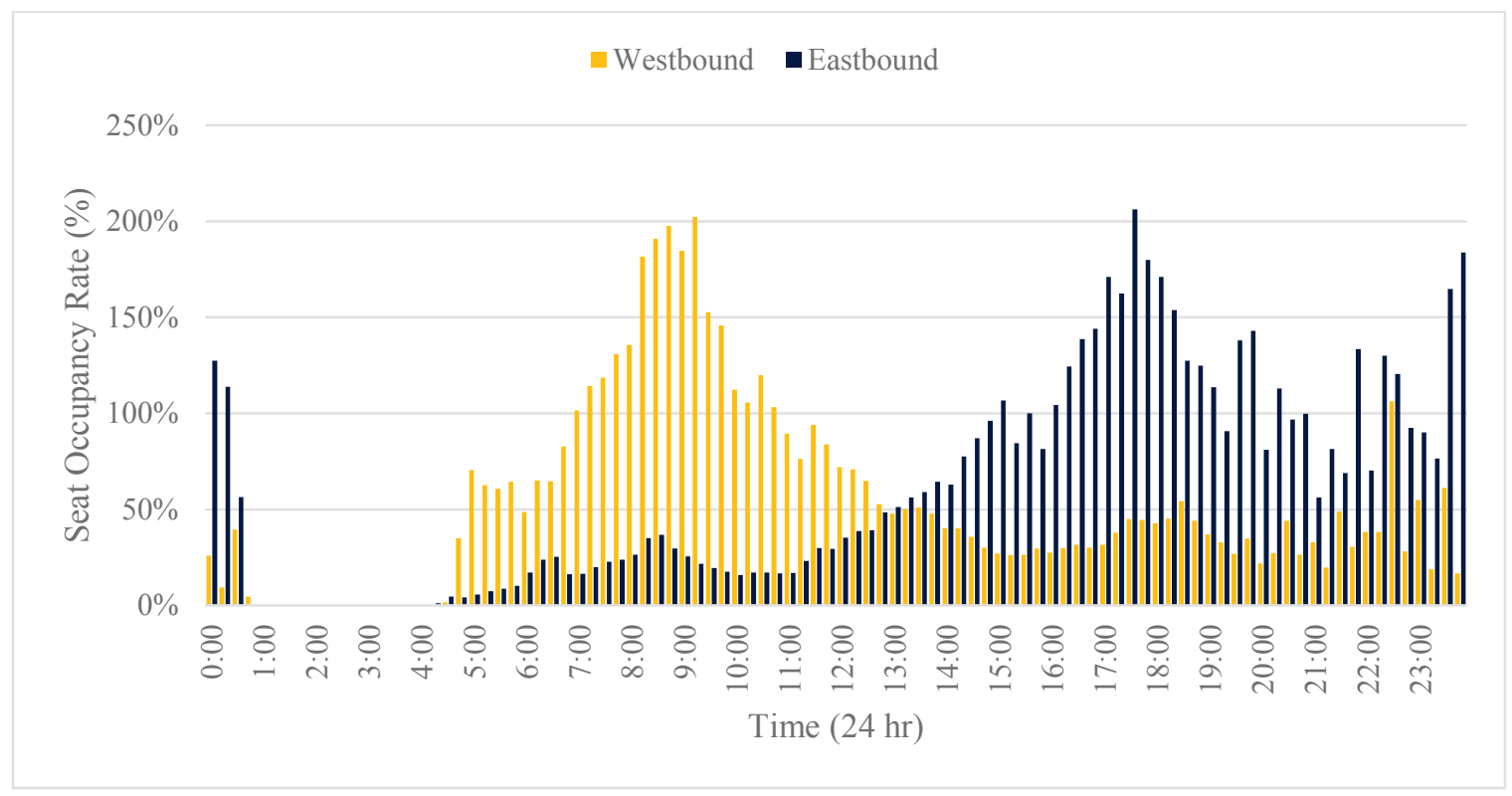

Figure 3.15: BART Transbay Tube Seat Occupancy Rates

\subsubsection{AC Transit}

AC Transit provided data for ridership and load factors for each run made over a two month time period. As previously discussed, the load factor is the percentage of capacity used. This relationship was used to determine capacities of AC Transit's transbay services. It is important to note that these are crush capacities rather than seating capacities. While seating capacity data is not available, it can be assumed to be less than the average calculated capacity of 85 , which is a reasonable capacity for a transbay bus between seated and standing riders. Figures 3.16 and 3.17 provide ridership versus capacity for the westbound and eastbound directions, respectively. 


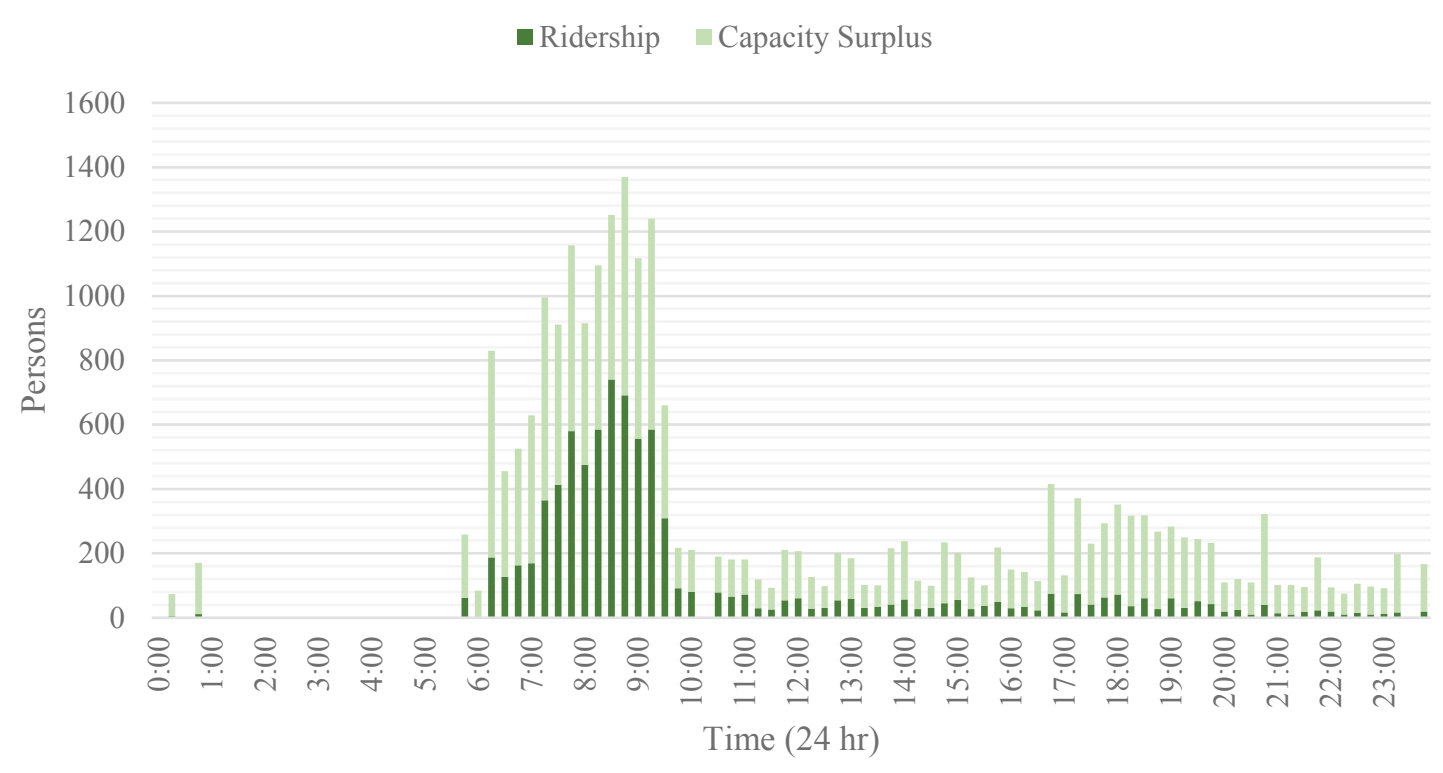

Figure 3.16: Westbound AC Transit Transbay Ridership and Seat Surpluses

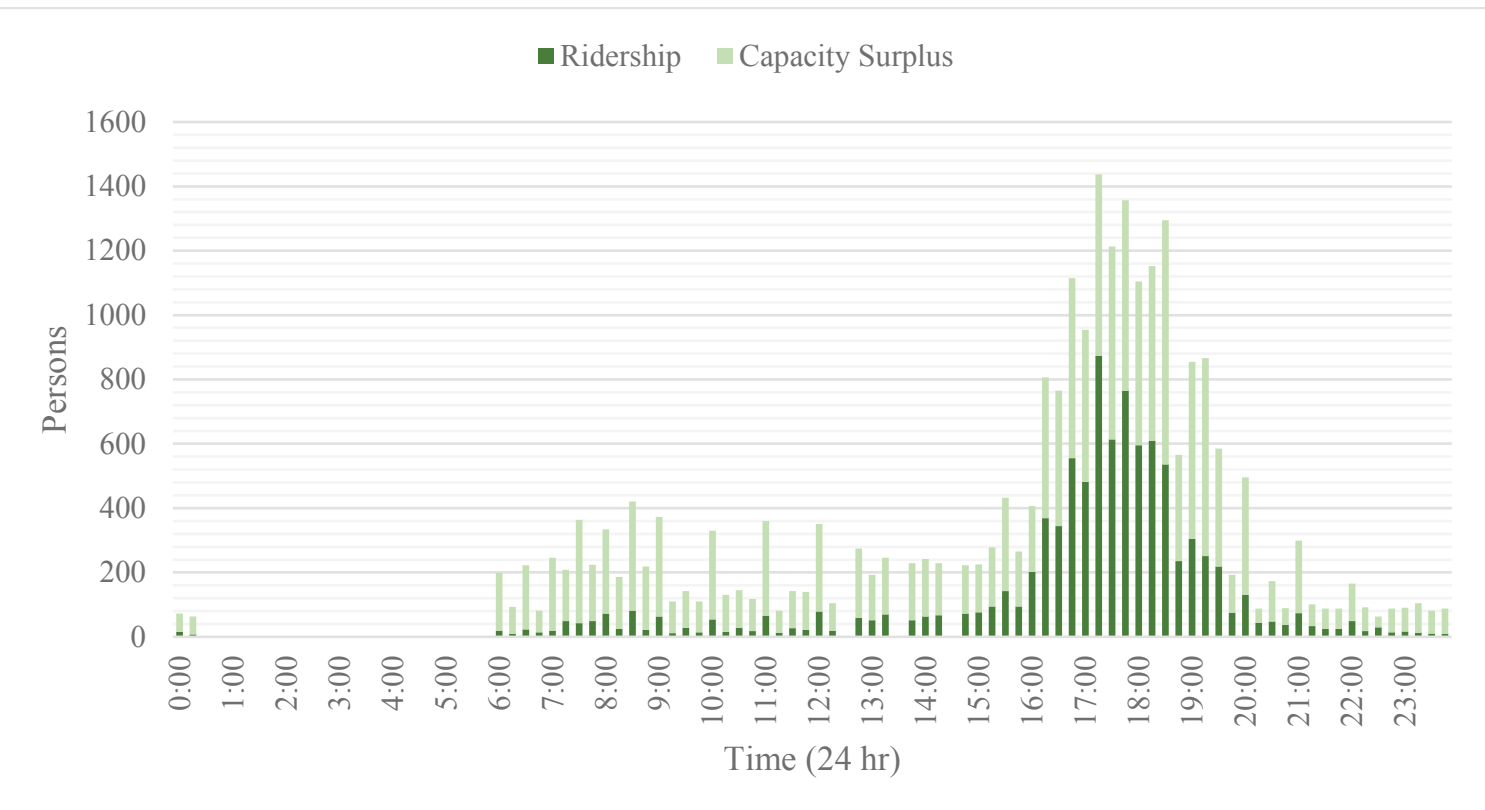

Figure 3.17: Eastbound AC Transit Transbay Ridership and Seat Surpluses

The highest quarter-hourly occupancy for AC Transit is $61 \%$ at $5: 15 \mathrm{pm}$ to $5: 30 \mathrm{pm}$ in the eastbound direction. While this implies excess capacity, it is simply an average across all buses 
leaving the Transbay Terminal during those 15 minutes, while actual occupancies of each bus may differ. For instance, the 5:10pm eastbound Route $\mathrm{C}$ has an average occupancy of $32 \%$, versus the 5:15pm eastbound Route $\mathrm{J}$ at $88 \%$. Only one run of one route recorded operating above capacity: the 5:30pm eastbound Route FS at 105\% occupancy. Figure 3.18 charts the average occupancy rate for both directions across the day.

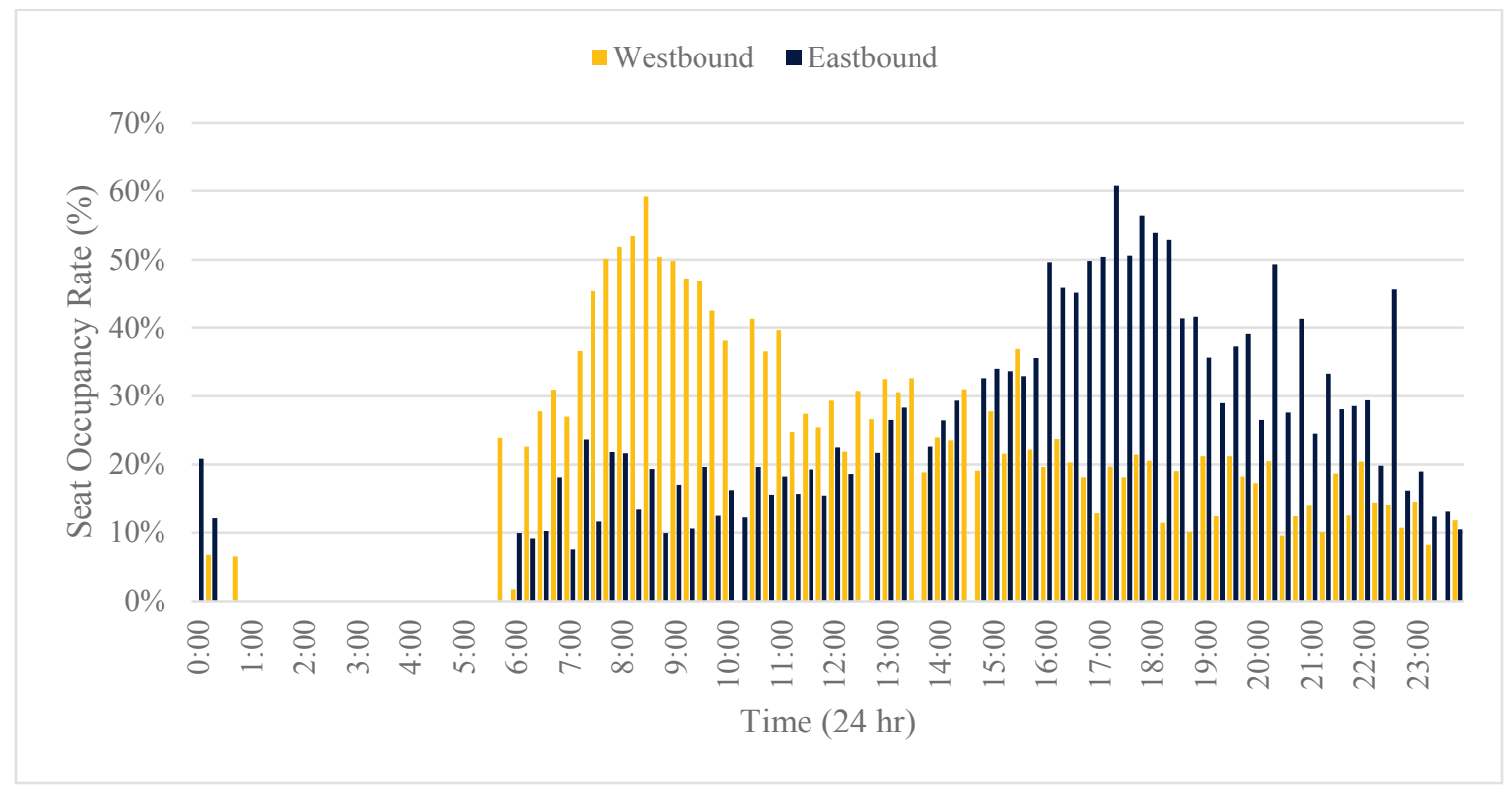

Figure 3.18: AC Transit Transbay Occupancy Rates

\subsubsection{WETA}

Data for WETA included passenger counts and vessel names for each run made during the study month. Vessel capacities by name were also provided, so it was a trivial matter to match capacity to ridership. WETA operates 12 revenue ferries that range in capacity from Gemini at 149 , to Zelinsky at 399. Additionally, the tourist company Blue \& Gold Fleet provided four of its ferries to aid with vessel shortages over the course of the month, three with a capacity of 396 and one (the Bay Monarch) with a capacity of 693. Despite these seemingly large capacities, over the course of 
the month the ferry hit capacity a total of 48 times. Table 3.1 lists these full ferries. For some runs, the capacity is shown as a range because multiple ferries with different capacities were used.

Table 3.1: Instances When WETA Ferry Service Hit Capacity

\begin{tabular}{|c|c|c|c|c|c|}
\hline \multirow{2}{*}{ Instances } & \multicolumn{2}{|c|}{ Departure } & \multicolumn{2}{c|}{ Arrival } & \multirow{2}{*}{ Capacity } \\
\cline { 2 - 5 } & Location & Time & Location & Time & \\
\hline 1 & Alameda/Oakland & $7: 45 \mathrm{am}$ & Ferry Building & $8: 00 \mathrm{am}$ & 250 \\
\hline 10 & Ferry Building & $5: 20 \mathrm{pm}$ & Alameda/Oakland & $5: 40 \mathrm{pm}$ & 331 \\
\hline 12 & Vallejo & $7: 00 \mathrm{am}$ & Ferry Building & $7: 55 \mathrm{am}$ & $320-330$ \\
\hline 1 & Vallejo & $7: 45 \mathrm{am}$ & Ferry Building & $8: 45 \mathrm{am}$ & 267 \\
\hline 1 & Vallejo & $10: 30 \mathrm{am}$ & Ferry Building & $11: 30 \mathrm{am}$ & 267 \\
\hline 6 & Ferry Building & $3: 30 \mathrm{pm}$ & Vallejo & $4: 25 \mathrm{pm}$ & 267 \\
\hline 7 & Ferry Building & $4: 30 \mathrm{pm}$ & Vallejo & $5: 30 \mathrm{pm}$ & $267-330$ \\
\hline 8 & Ferry Building & $5: 15 \mathrm{pm}$ & Vallejo & $6: 15 \mathrm{pm}$ & $320-330$ \\
\hline 2 & Ferry Building & $6: 00 \mathrm{pm}$ & Vallejo & $6: 55 \mathrm{pm}$ & 267 \\
\hline
\end{tabular}

In addition to these 48 instances of hitting capacity, there were many more where the ferry was only a few riders short of capacity. Since ridership was determined via hand count, it is entirely possible that there were more at capacity than listed above. Additionally, a total of 1,764 runs were analyzed, meaning at-capacity runs represent around $2.7 \%$ of all runs. In terms of the monthly average, no block of time was at or over capacity, the nearest being the eastbound 5:15pm-5:30pm block at $96 \%$ occupancy. However, it is important to note that due to safety concerns, ferries are not allowed to operate above their official capacity. Therefore, if demand is higher than capacity, the extra riders can't “crush" in like with a bus or BART. Instead, they are left behind and must either wait for the next ferry or find an alternative mode of transportation. Data for ridership versus capacity is provided in Figure 3.19 for westbound and Figure 3.20 for eastbound. Figure 3.21 charts the occupancy rate for both directions across the day. 


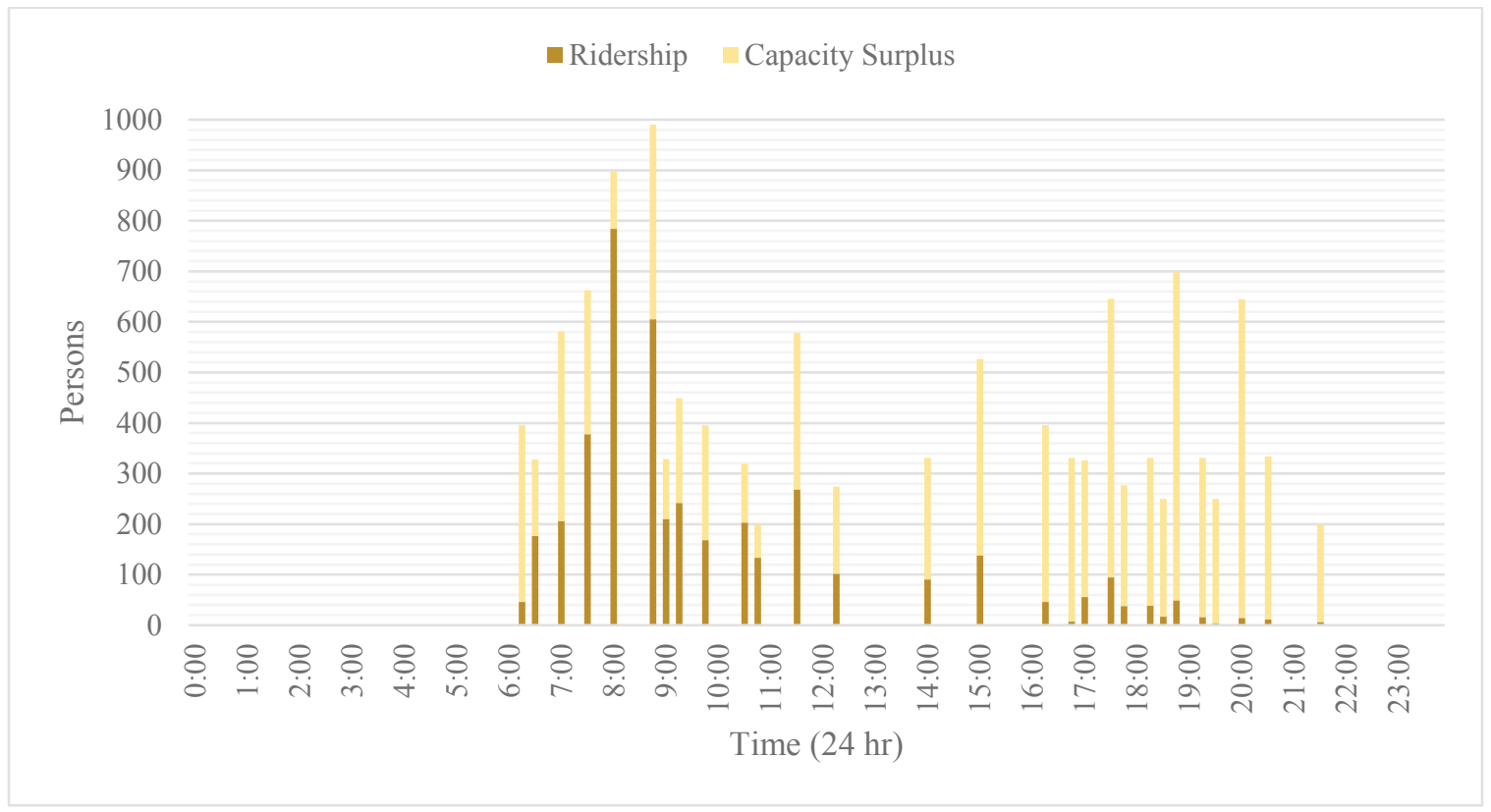

Figure 3.19: Westbound WETA Transbay Ridership and Capacity Surpluses

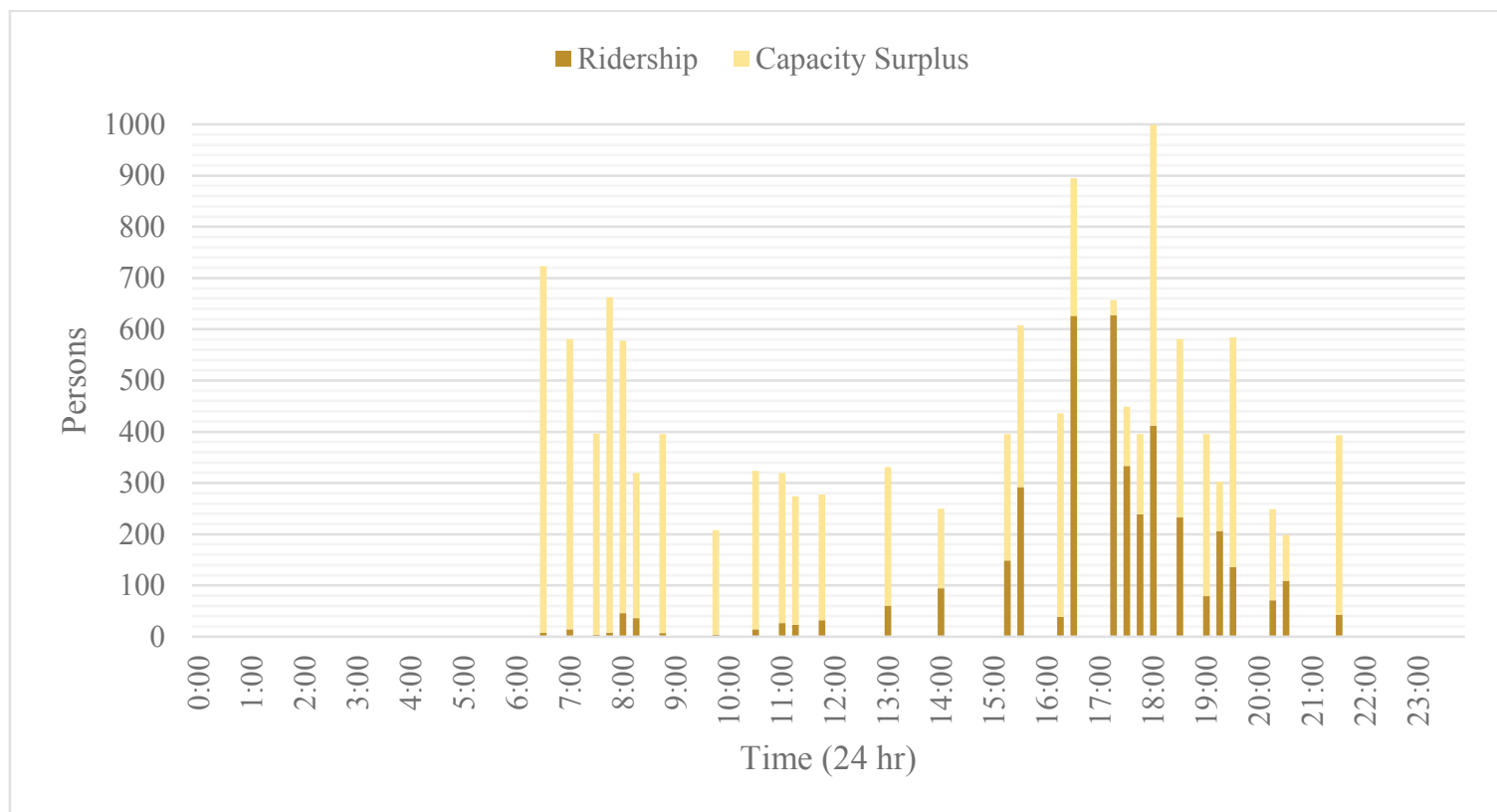

Figure 3.20: Eastbound WETA Transbay Ridership and Capacity Surpluses 


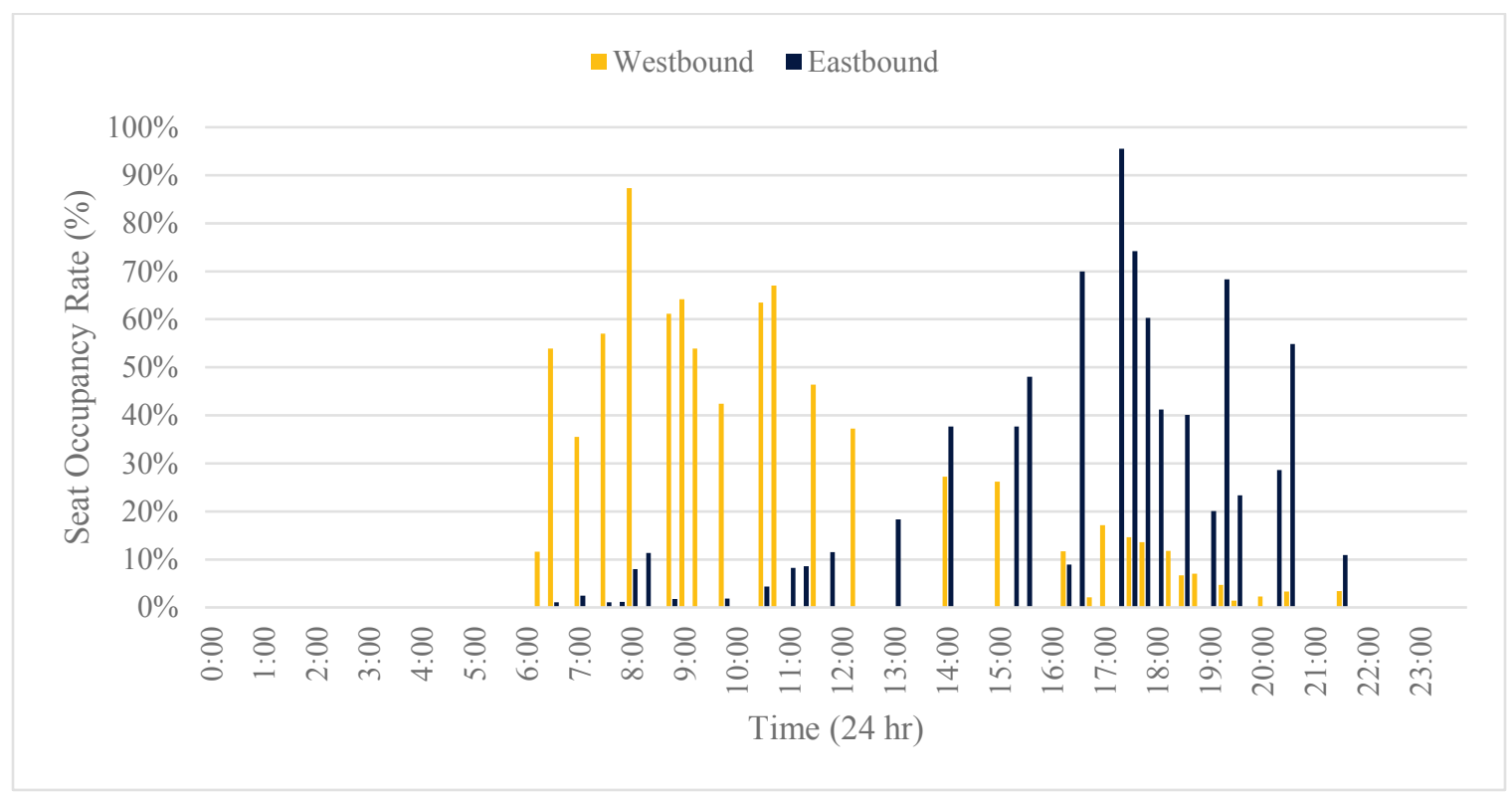

Figure 3.21: WETA Transbay Occupancy Rates

\subsubsection{WestCAT Lynx}

Data for the Lynx service from Hercules to San Francisco included fare tags for every rider during the study month. These were split by trip and direction based on timestamp and coordinates. Capacity was easy to quantify since WestCAT utilizes a standard commuter bus with a seated capacity of 57 riders on all runs. While potentially additional riders could stand, in practice that might prove uncomfortable for the 30-45 minute bus ride. Just as well that this is a rare concern given that the highest ridership instance during the study month was 41 riders. Ridership versus surplus capacity data is provided in Figures 3.22 and 3.23 for westbound and eastbound, respectively. The 57 rider capacity becomes apparent by the height of each bar, and the two bars in each direction that are twice that height are simply time bins with two runs. Occupancy rate data is provided in Figure 3.24. 


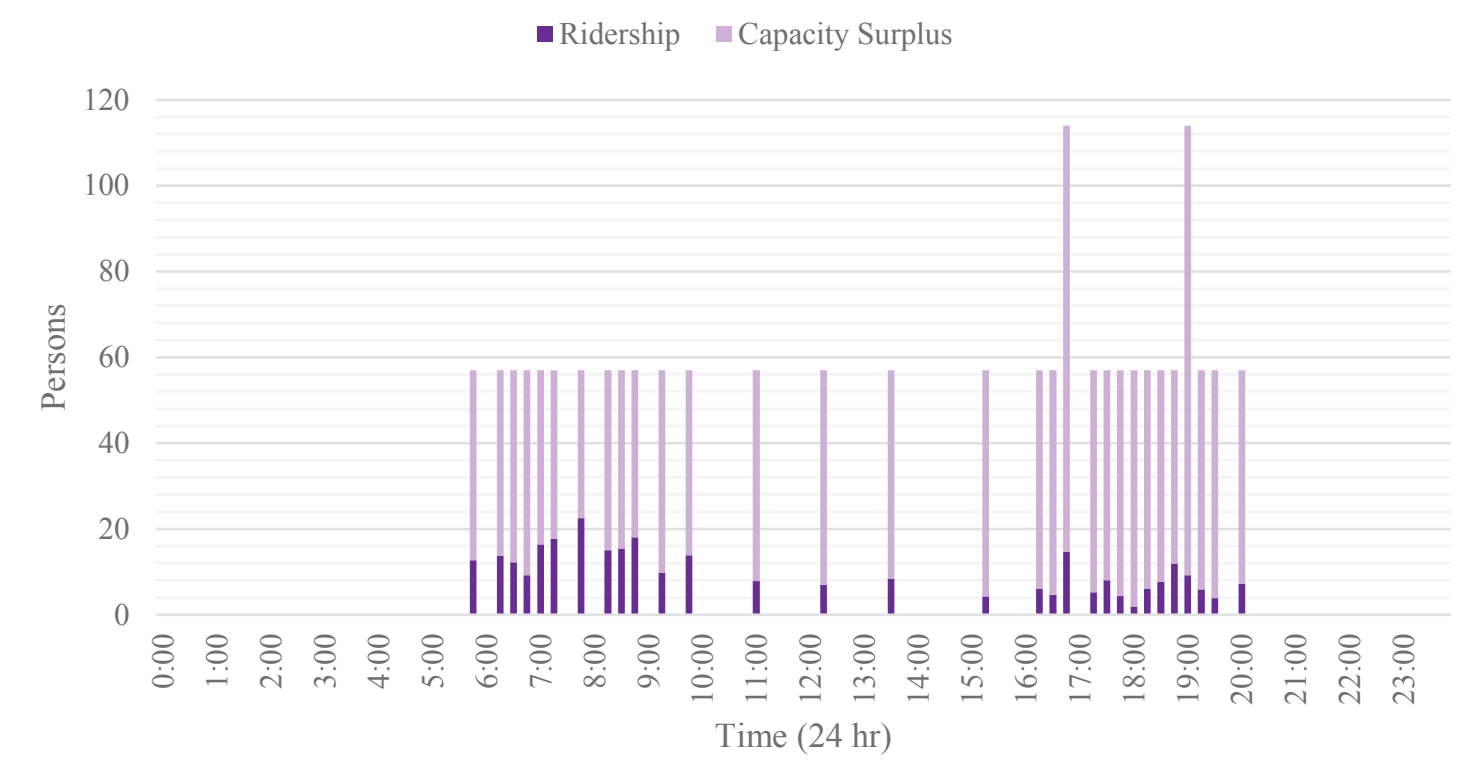

Figure 3.22: Westbound WestCAT Lynx Ridership and Capacity Surpluses

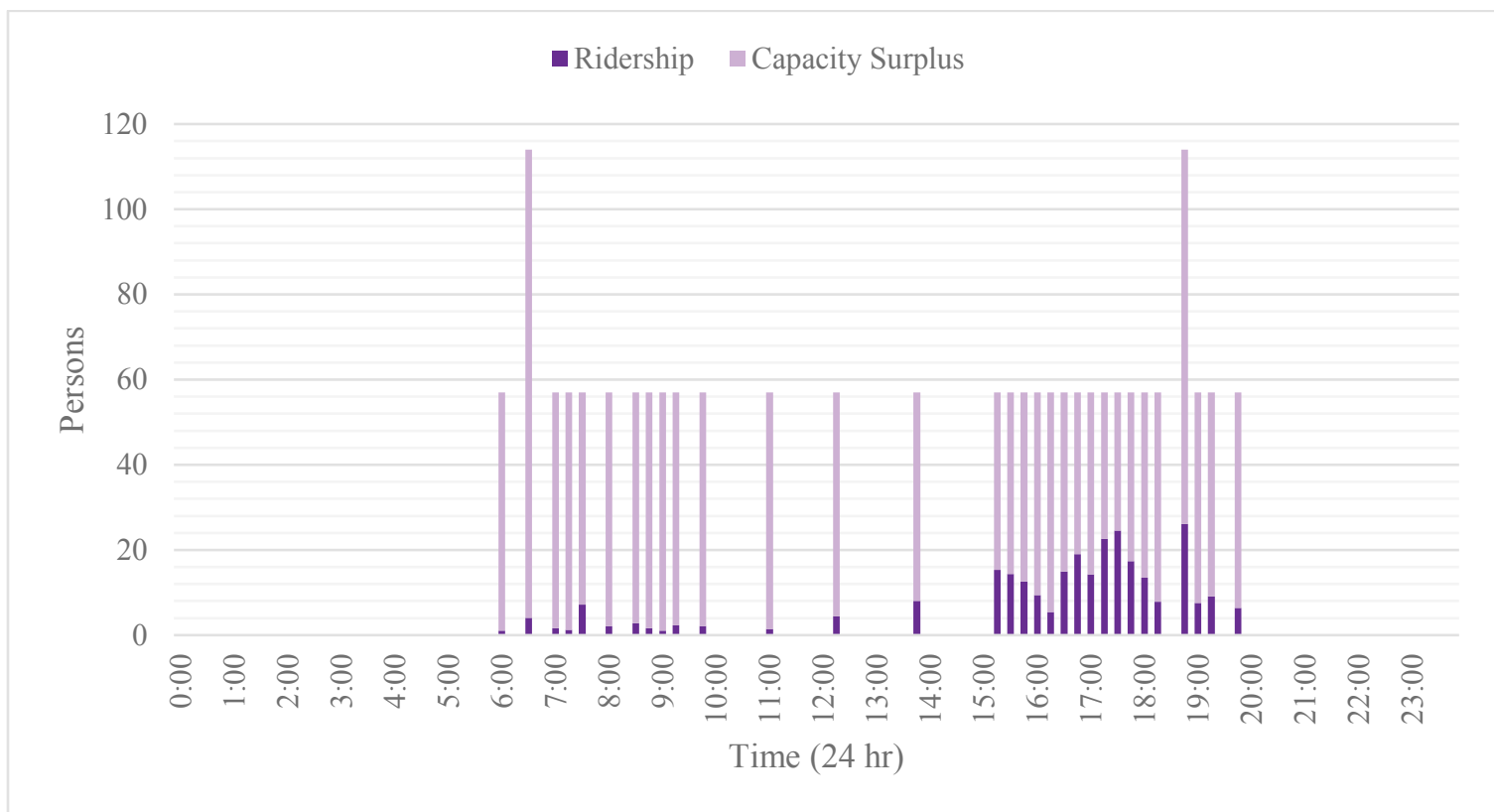

Figure 3.23: Eastbound WestCAT Lynx Ridership and Capacity Surpluses 


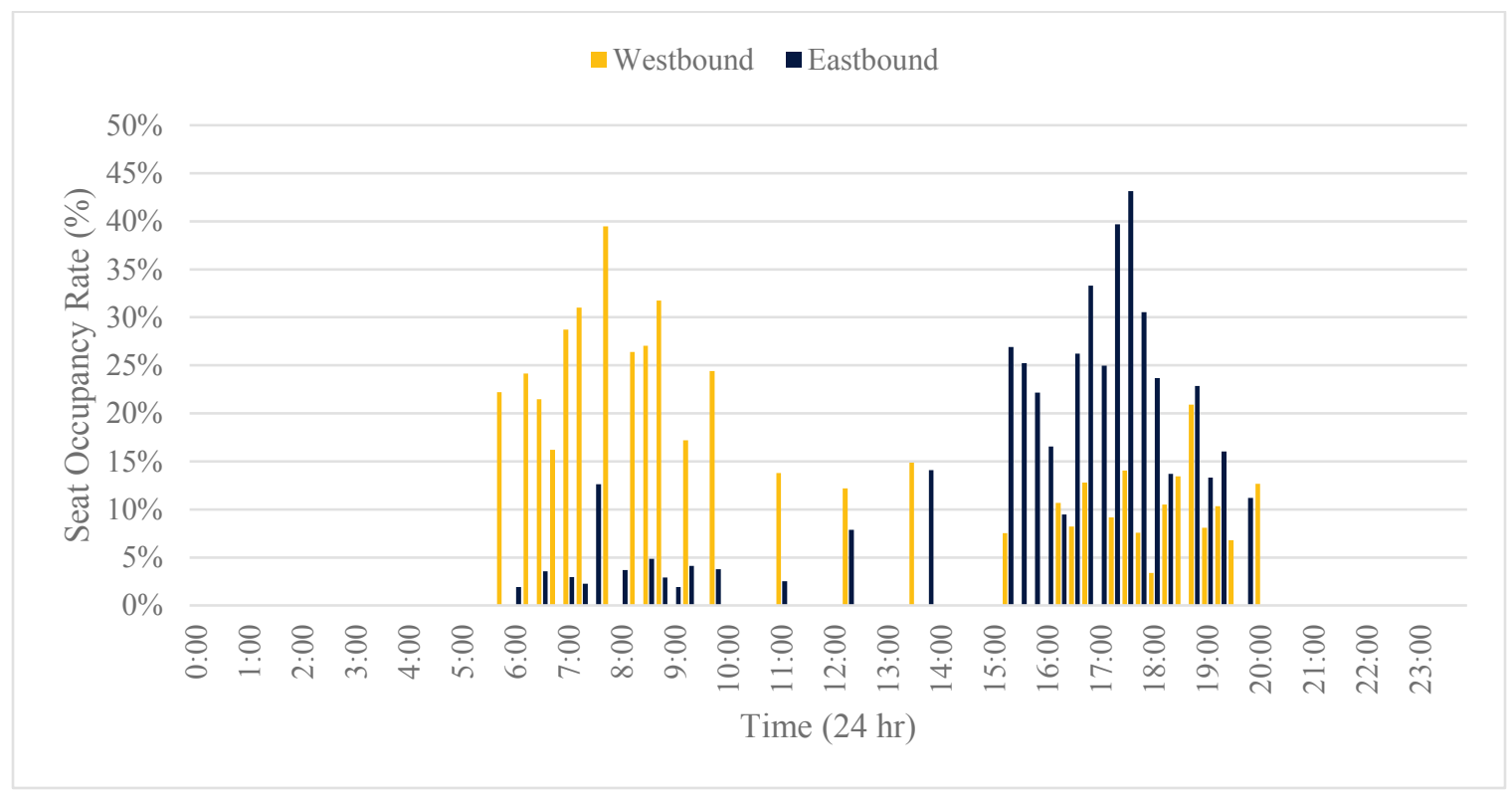

Figure 3.24: WestCAT Lynx Occupancy Rates

\subsubsection{SolTrans 200}

As previously mentioned, data for SolTrans Route 200 was provided by WETA as the ferry agency administers the route as a supplement for its Vallejo-San Francisco ferry service, even though SolTrans operates the bus route. Passenger counts for the month were provided and averaged, and capacity was given as 57 seated riders per bus, similar to WestCAT Lynx. Despite the infrequent service of the route, many of the runs were near capacity due to the route's function as a relief service to the much more frequent ferry. Because of the difference in scale, it is easy to see how an overcrowded ferry with a capacity of 300+ riders would fill up a 57 seat commuter bus. During the study month, three runs hit capacity and another 16 had more than 50 riders, representing $7 \%$ of the 264 sample runs. Ridership versus surplus capacity data is provided in Figures 3.25 and 3.26 for westbound and eastbound, respectively. Occupancy rate data is provided in Figure 3.27. 


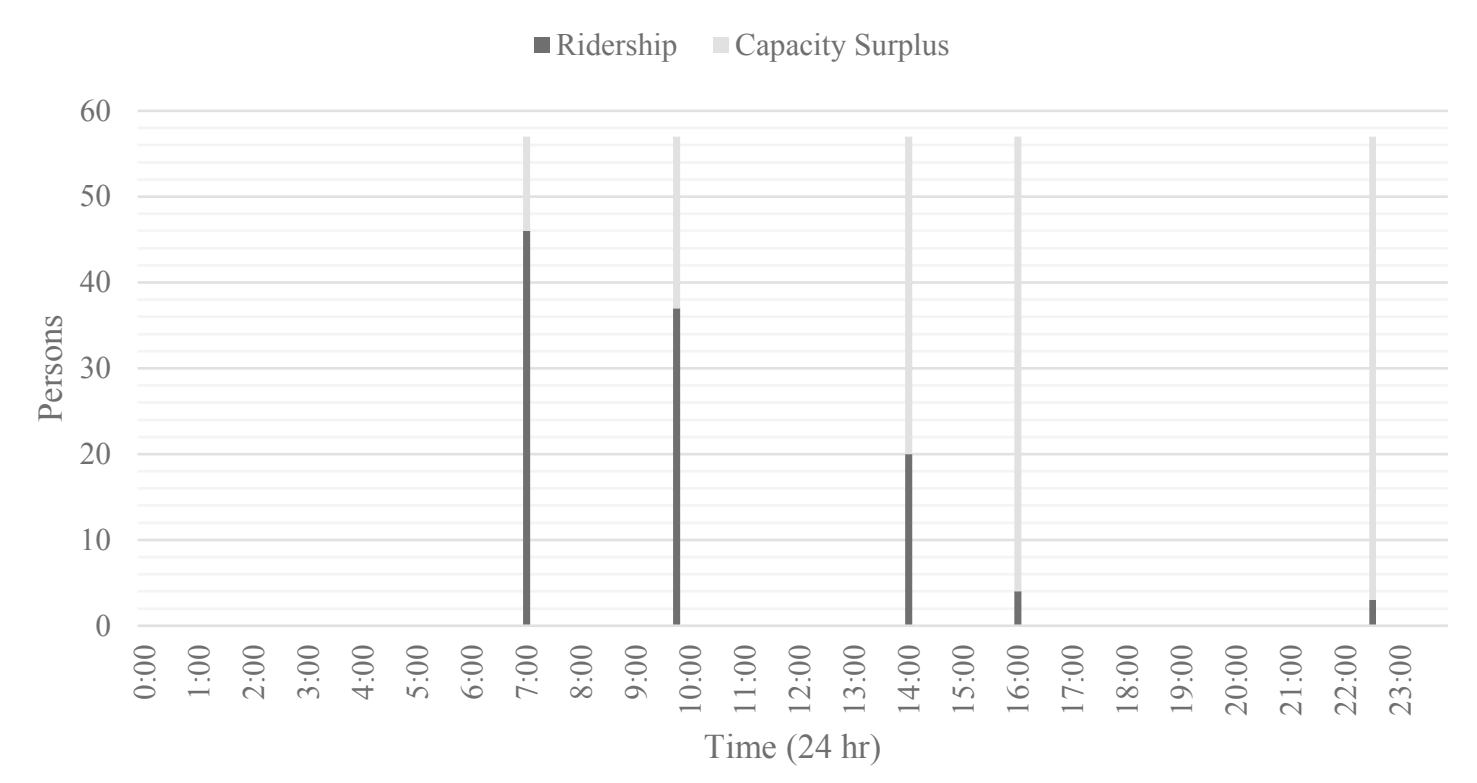

Figure 3.25: Westbound SolTrans Route 200 Ridership and Capacity Surpluses

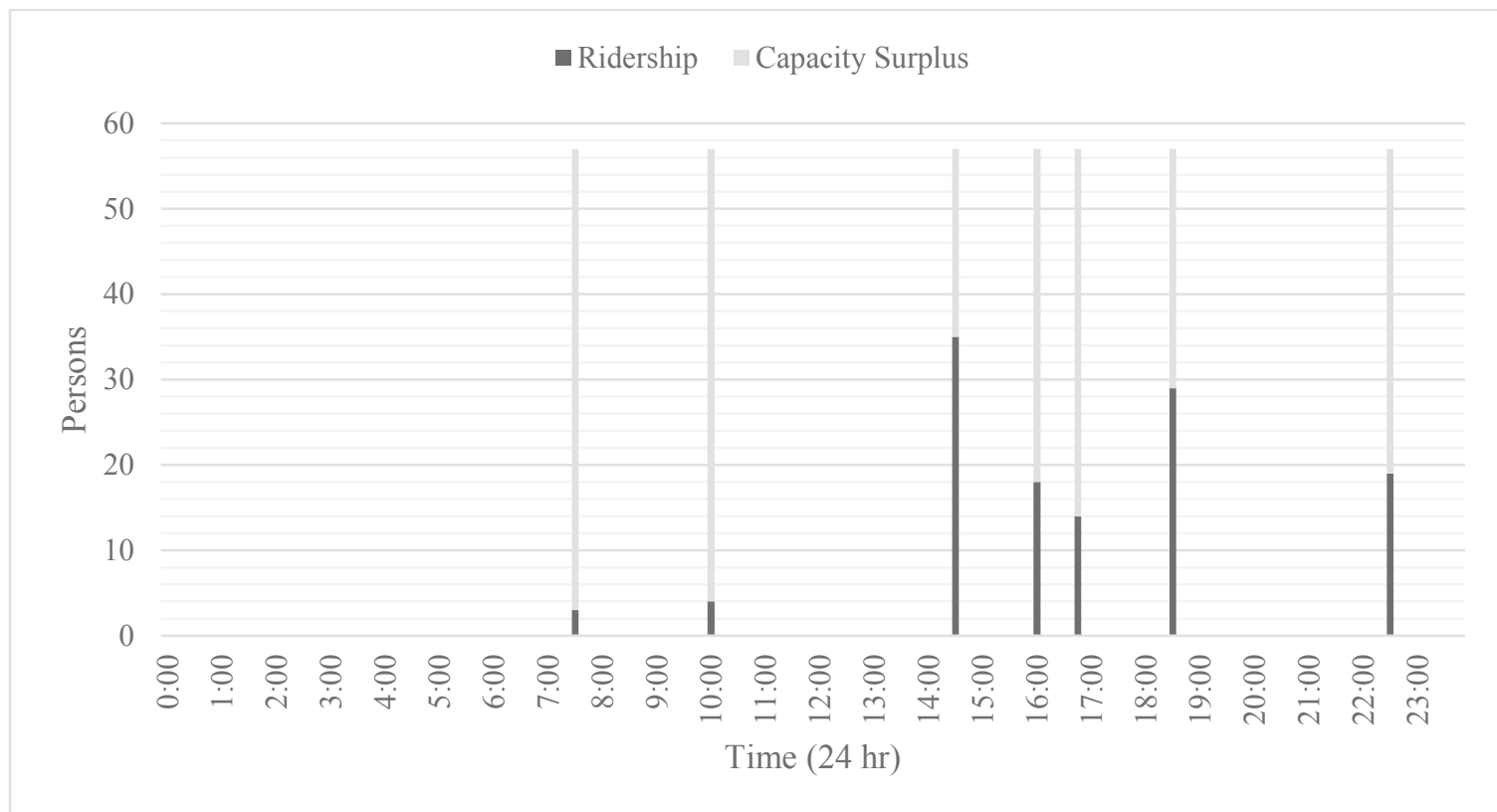

Figure 3.26: Eastbound SolTrans Route 200 Ridership and Capacity Surpluses 


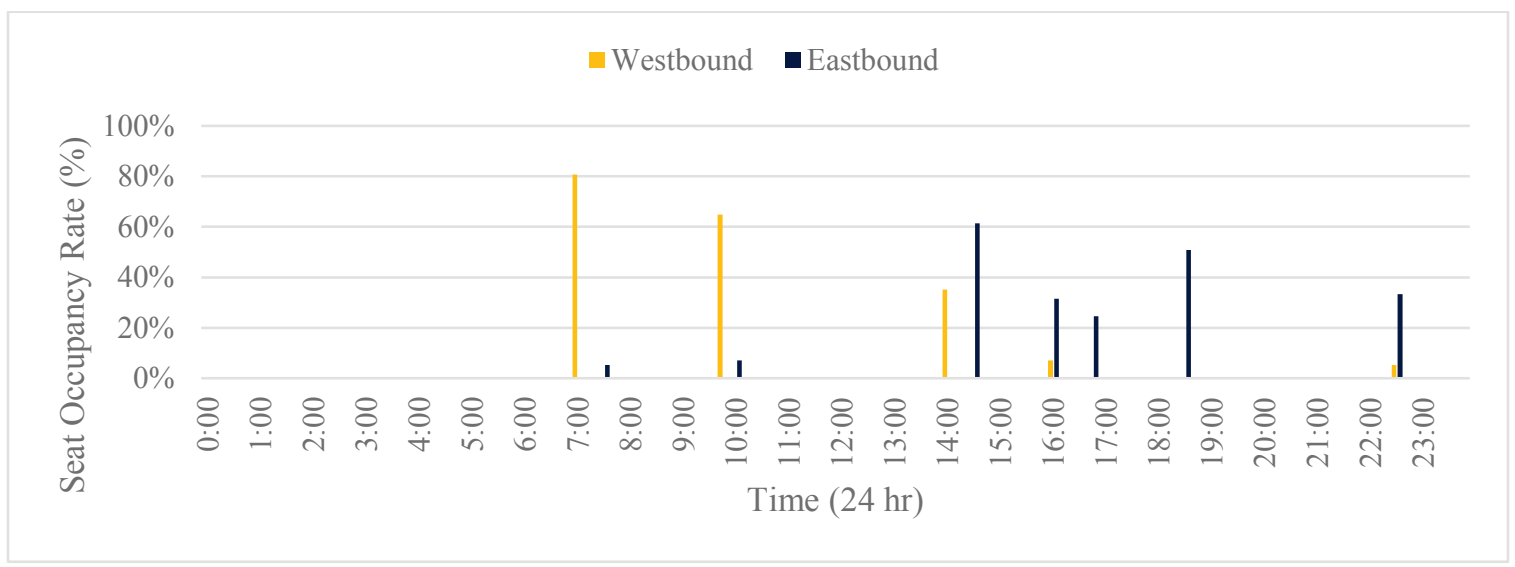

Figure 3.27: SolTrans Route 200 Occupancy Rates

\subsubsection{All Modes}

Now that the occupancy rate has been assessed by mode, the total throughput and capacity for the transbay corridor can be compiled. Of note, converting the private vehicle data from hourly to every 15 minutes was done by simply quartering the hourly data, similar to Section 3.1.7. In Figure 3.28 for westbound and Figure 3.29 for eastbound, the total number of persons crossing the bay is charted against the total number of seats crossing the bay. A line denoting the percentage of seats occupied accompanies these charts.

During the early morning hours of 1:00am to 4:00am, the total capacity is simply the theoretical 15 minute private vehicle capacity with five seats each. This amounts to 11,527 seats every 15 minutes westbound and 10,640 seats every 15 minutes eastbound. All greater capacity values are from transit services. Interestingly, during one 15 minute interval in each direction, the number of riders exceeded the theoretical 15 minute private vehicle capacity. This was 11,905 riders at 8:45am in the westbound direction, and 11,047 riders at 5:15pm in the eastbound direction. The greatest westbound capacity was 17,261 seats at 8:00am, and the greatest eastbound capacity was 16,712 seats at $5: 15 \mathrm{pm}$. The greatest westbound occupancy was $69 \%$ at both $8: 30 \mathrm{am}$ and $8: 45 \mathrm{am}$, and the greatest eastbound occupancy was also $69 \%$, at 5:30pm. The total occupancy across the day was $25.6 \%$ in the westbound direction and $27.2 \%$ in the eastbound direction. 


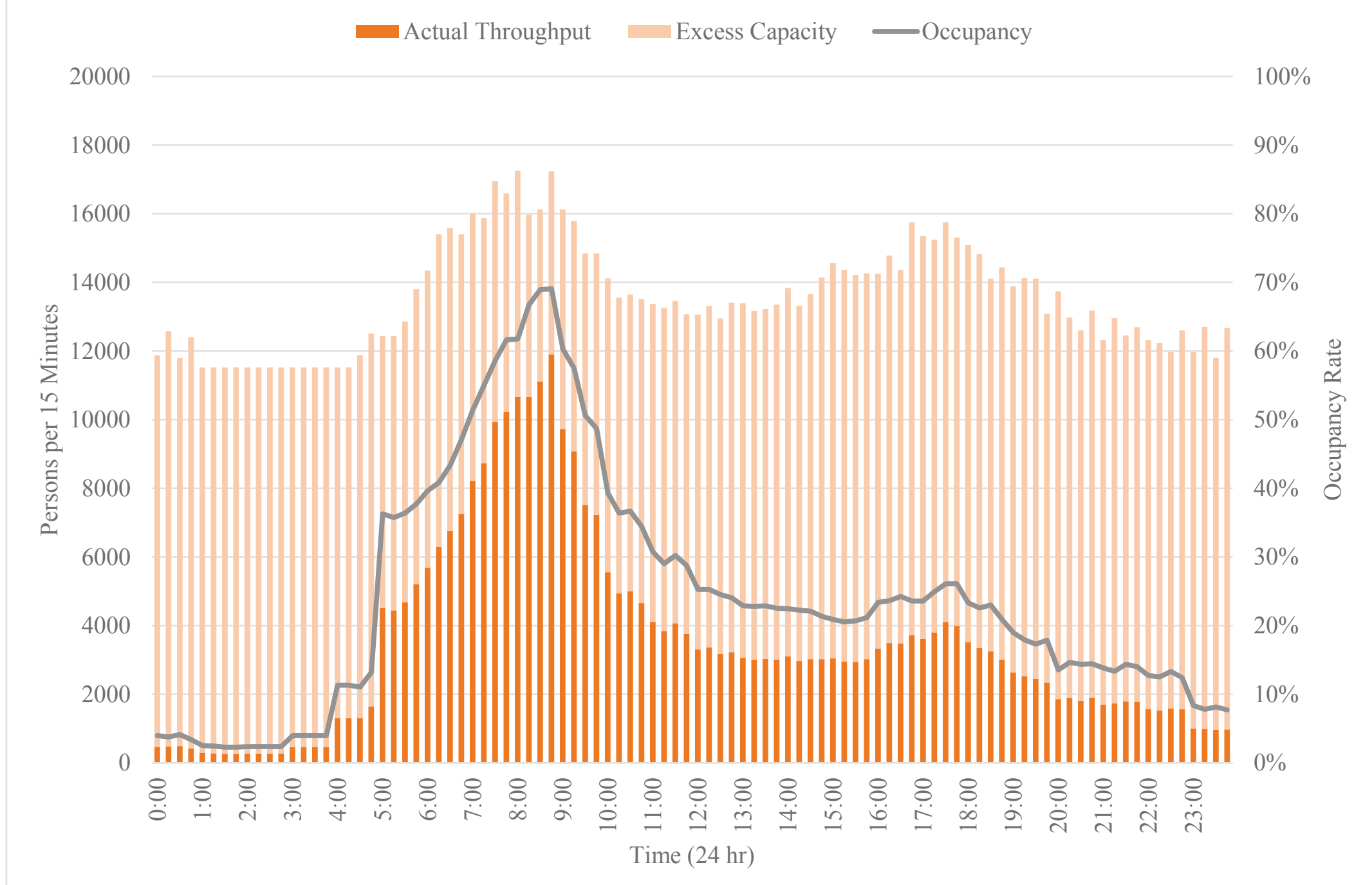

Figure 3.28: Westbound Actual Throughput versus Excess Capacity and Occupancy Rate 


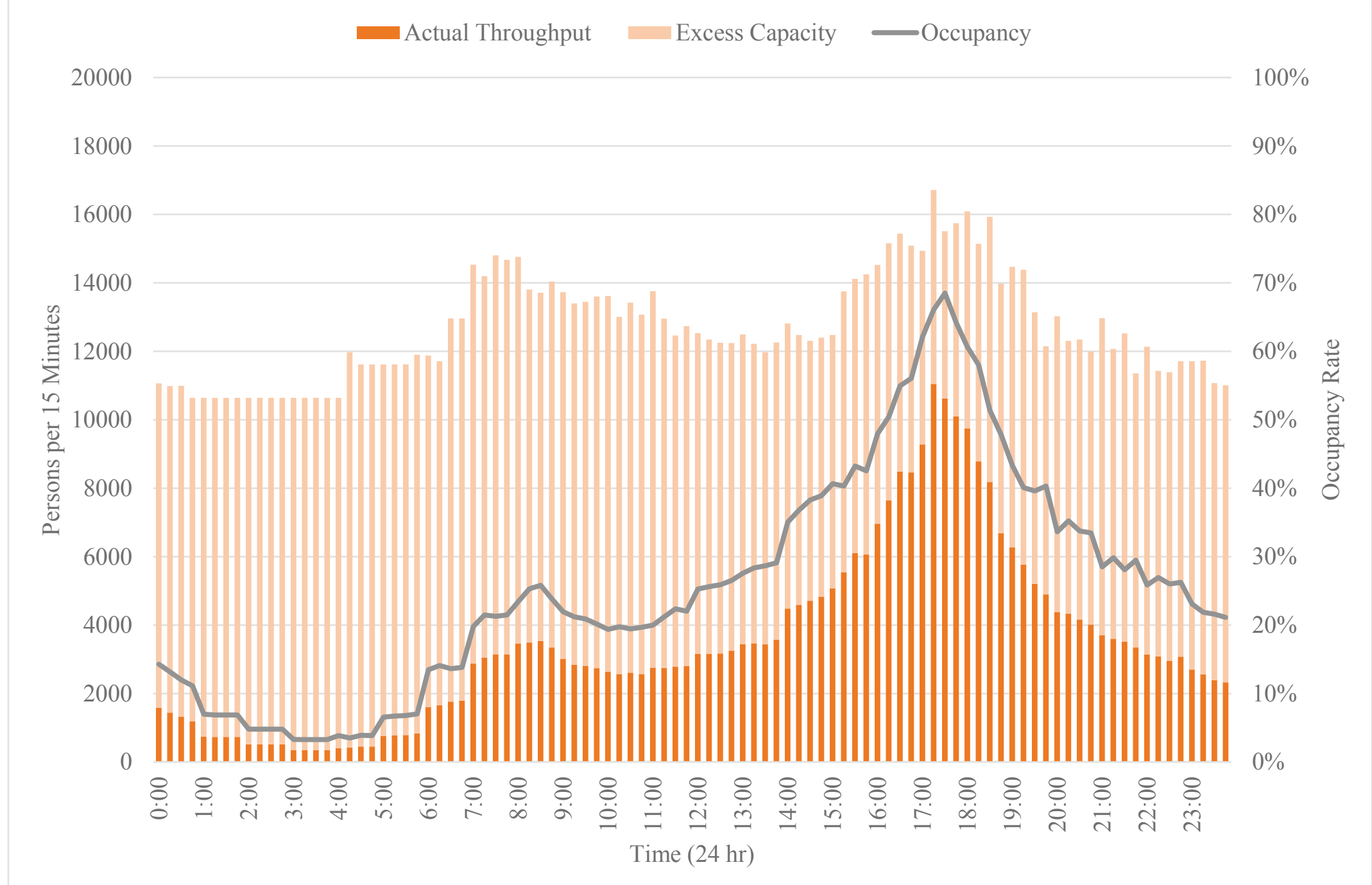

Figure 3.29: Eastbound Actual Throughput versus Excess Capacity and Occupancy Rate 


\subsection{FUTURE CAPACITY TARGETS}

The above discussion covers demand and capacity as it stands today, but what about in the future? As mentioned in Section 1.3, the Bay Area population is predicted to grow by $30 \%$ from 2010 to 2040 (MTC, 2013, p. 32). If there is an equal increase in demand, then a matching increase in capacity will be necessary to simply maintain existing occupancy levels and prevent additional overcrowding. Table 3.2 lists the total present daily trips by mode, and total daily trips with a $30 \%$ increase in demand per mode. Additionally, it includes a tally of how many vehicles per mode would be needed to handle this added demand, assuming each vehicle is at capacity using the shown vehicle capacities. Lastly, it demonstrates how many additional vehicles would be needed if the fleet size per mode was also increased $30 \%$ to keep each vehicle at its current occupancy.

Table 3.2: Vehicle Capacity Needed for Increased Demand

\begin{tabular}{|l|c|c|c|c|c|c|c|}
\hline Mode & $\begin{array}{c}\text { Private } \\
\text { Vehicle }\end{array}$ & BART & $\begin{array}{c}\text { AC } \\
\text { Transit }\end{array}$ & WETA & $\begin{array}{c}\text { WestCAT } \\
\text { Lynx }\end{array}$ & $\begin{array}{c}\text { SolTrans } \\
\text { Route } \\
200\end{array}$ & Total \\
\hline Present Daily Trips & 406,369 & 233,981 & 17,549 & 8,122 & 583 & 232 & 666,836 \\
\hline $30 \%$ of Present Daily Trips & 121,911 & 70,194 & 5,265 & 2,437 & 175 & 70 & 200,051 \\
\hline $\begin{array}{l}\text { Maximum Vehicle } \\
\text { Occupancy }\end{array}$ & 5 & 200 & 85 & 310 & 57 & 57 & - \\
\hline $\begin{array}{l}\text { Additional Vehicle-Trips } \\
\text { Needed to Handle Future } \\
\begin{array}{l}\text { Demand, at Maximum } \\
\text { Vehicle Capacity }\end{array}\end{array}$ & 24,383 & 351 & 62 & 8 & 4 & 2 & 24,810 \\
\hline Current Vehicle Occupancy & 1.54 & 52 & 30 & 99 & 9 & 20 & - \\
\hline $\begin{array}{l}\text { Additional Vehicle-Trips } \\
\text { Needed to Handle Future } \\
\text { Demand, at Current Vehicle } \\
\text { Capacity }\end{array}$ & 79,163 & 1,350 & 176 & 25 & 20 & 4 & 80,738 \\
\hline
\end{tabular}


However, MTC and ABAG also desire to increase the non-private vehicle mode share by $10 \%$, from the current region-wide average of $16 \%$ to $26 \%$ (MTC, 2013, p. 106). As can be deduced from Figures 3.6 and 3.7, the current non-private vehicle mode share on the transbay corridor exceeds this goal already, at 39\%. This corridor does not get a pass though, as the goal is to increase the region as a whole, and the best way to do so would be to increase the non-private vehicle mode share on all corridors, transbay included. Table 3.3 copies Table 3.2, but redistributes the 200,051 new trips in order to reduce the future private vehicle mode share by $10 \%$, from $61 \%$ to $51 \%$, with the trips being proportionally distributed to the remaining modes.

Table 3.3: Vehicle Capacity Needed for Increased Demand, with Adjusted Mode Shares

\begin{tabular}{|l|c|c|c|c|c|c|c|}
\hline Mode & $\begin{array}{c}\text { Private } \\
\text { Vehicle }\end{array}$ & BART & $\begin{array}{c}\text { AC } \\
\text { Transit }\end{array}$ & WETA & $\begin{array}{c}\text { WestCAT } \\
\text { Lynx }\end{array}$ & $\begin{array}{c}\text { SolTrans } \\
\text { Route } \\
200\end{array}$ & Total \\
\hline Present Daily Trips & 406,369 & 233,981 & 17,549 & 8,122 & 583 & 232 & 666,836 \\
\hline $\begin{array}{l}\text { Future Additional Daily } \\
\text { Trips }\end{array}$ & 35,743 & 147,600 & 11,070 & 5,124 & 368 & 146 & 200,051 \\
\hline Future Mode Share & $51.0 \%$ & $44.0 \%$ & $3.3 \%$ & $1.5 \%$ & $0.1 \%$ & $0.0 \%$ & $100 \%$ \\
\hline $\begin{array}{l}\text { Maximum Vehicle } \\
\text { Occupancy }\end{array}$ & 5 & 200 & 85 & 310 & 57 & 57 & - \\
\hline $\begin{array}{l}\text { Additional Vehicle-Trips } \\
\text { Needed to Handle Future } \\
\text { Demand, at Maximum } \\
\text { Vehicle Capacity }\end{array}$ & 7,149 & 738 & 131 & 17 & 7 & 3 & 8,045 \\
\hline $\begin{array}{l}\text { Current Vehicle } \\
\text { Occupancy }\end{array}$ & 1.54 & 52 & 30 & 99 & 9 & 20 & - \\
\hline $\begin{array}{l}\text { Additional Vehicle-Trips } \\
\text { Needed to Handle Future } \\
\text { Demand, at Current } \\
\text { Vehicle Capacity }\end{array}$ & 23,210 & 2,839 & 370 & 52 & 41 & 8 & 26,520 \\
\hline
\end{tabular}


Comparing these two tables shows the power of the goal to increase non-private vehicle modes of transportation. Whereas 24,810 vehicle-trips are needed with each vehicle at capacity using the current modal split, only 8,045 are needed by moving $10 \%$ of private vehicle users to transit. It is important to note that this would not be done only by convincing all but 35,743 of the future daily trips to take public transportation, but by convincing some future users in conjunction with some of the existing 406,369 users to switch as well.

Taking an overall look at these targets for capacity increases to match future demand argues the need to evaluate ways to increase capacity or better manage demand to make use of underutilized capacity. For example, at present BART has 80,529 daily extra seats than riders. As Figures 3.13 and 3.14 in Section 3.4.2 demonstrate, most of these seats are available only in the off-peak directions and times. Even if the $30 \%$ growth, or 70,194 new riders, is evenly distributed, BART will begin to hit seat capacity on off-peak trips, and the crush loads will become even worse during peak trips. Especially if the goal of shifting private vehicle trips to public transit is achieved, and BART finds itself with 147,600 new daily transbay riders by 2040 . 


\section{ALTERNATIVE ANALYSIS}

Now that it has been shown that the transbay services are straining to keep up with demand during peak commute hours, solutions can be explored. As mentioned in the introduction, a second bridge or tube will take many decades to come to fruition. Therefore, the focus here is on solutions that are more short-term. Sixteen strategies have been proposed in two broad categories: capacity enhancement and demand management.

\subsection{CAPACITY ENHANCEMENT}

The first category, capacity enhancement, contains twelve strategies that focus on improving the capacity of the transbay corridor. These include tactics focusing on adding onramp HOV queue jumps, incentivizing carpooling, and increasing transit capacity.

\subsubsection{Strategy 1: Upgrade West Grand Avenue Onramp to Bus Lane Standards}

Currently, there is a wide shoulder on the West Grand Avenue onramp onto I- 80 that is unused except by occasional buses or HOVs jumping the queue of cars waiting for the toll plaza. This tactic would legitimize this queue jump by improving the hardscape to bus lane standards, including restriping, signage, upgrading drainage inlets, and enforcement. This incentive was first proposed by MTC as Element 1 in their presentation, "West Grand Avenue On-Ramp and Immediate Transbay Mobility Improvement Projects," outlined in the literature review and included in Appendix A.

This proposal includes a base queue jump on West Grand Avenue from the I-580 eastbound off-ramp to the existing HOV ramp from the West Grand Avenue viaduct. Two possible extensions include extending the queue jump back from the I-580 eastbound off-ramp to the Maritime Street intersection, and extending the queue jump through that intersection down West Grand Avenue. See Figure 4.1. 


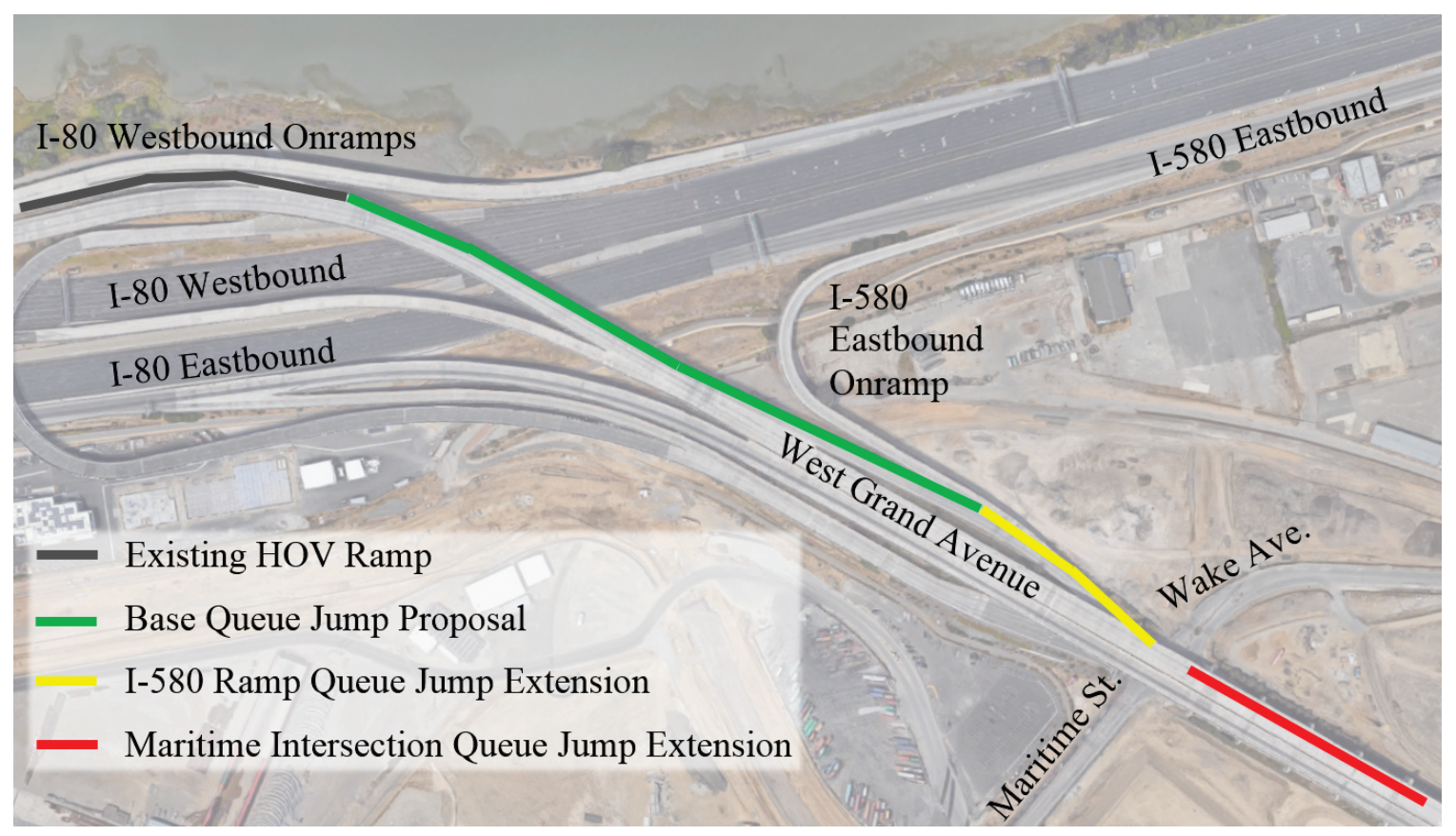

Figure 4.1: West Grand Avenue Queue Jump Overview

\subsubsection{Base Queue Jump Proposal}

The most instrumental part of this strategy is extending the existing HOV lane upstream from its current start, where the West Grand Avenue to I-80 westbound onramp splits into two structures, one for general purpose traffic and one for HOV. By extending it to the I-580 eastbound onramp, HOVs and especially buses coming from West Grand Avenue will be able to jump the toll plaza queue that backs up onto West Grand Avenue during peak hours.

By taking $1 \mathrm{ft}$. from the left shoulder, $8 \mathrm{ft}$. from the right shoulder, $0.5 \mathrm{ft}$. from the two left lanes and $1.5 \mathrm{ft}$. from the right lane, four even lanes of $11.5 \mathrm{ft}$. can be generated with a remainder of $4 \mathrm{ft}$. for the left shoulder and $2 \mathrm{ft}$. for the right shoulder. This will allow the three general purpose lanes to remain, while making room for a new HOV lane. A cross section of the proposed change is provided in Figure 4.2. 


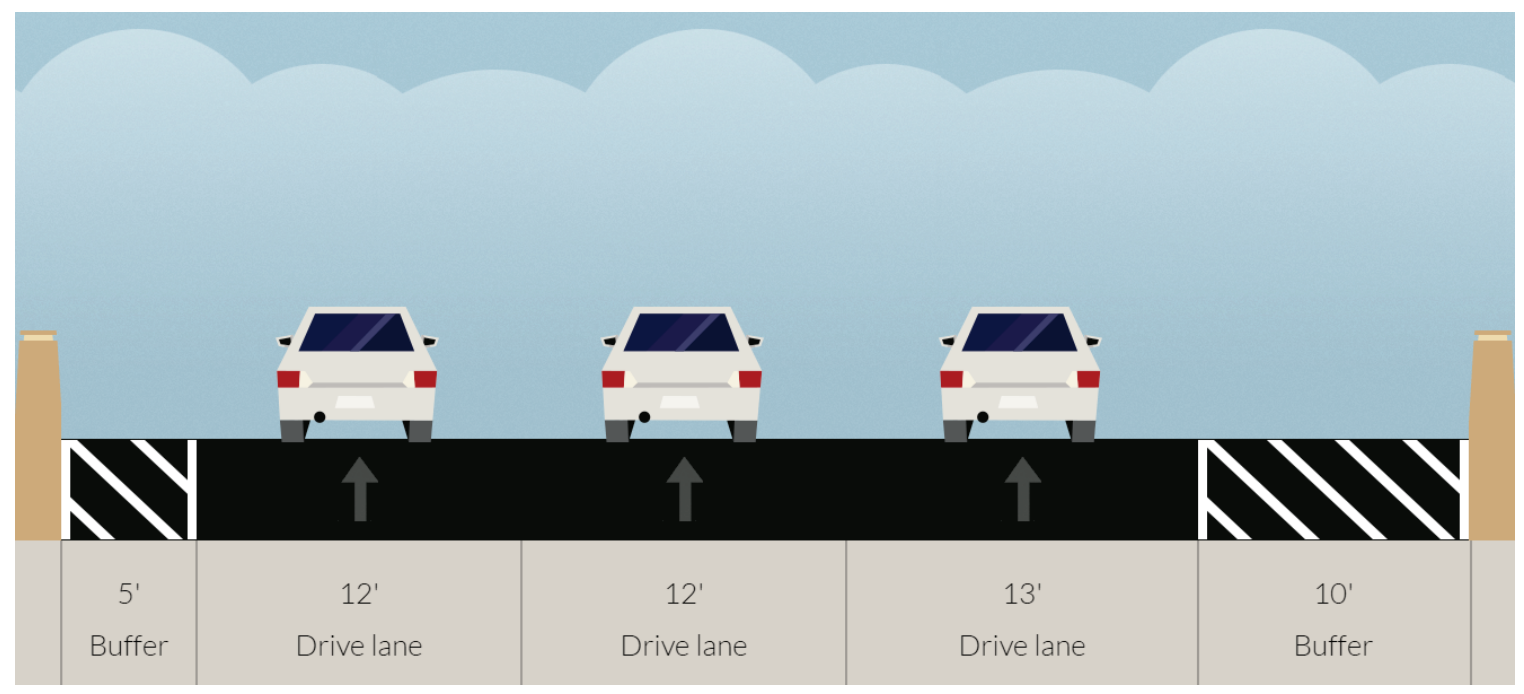

(a)

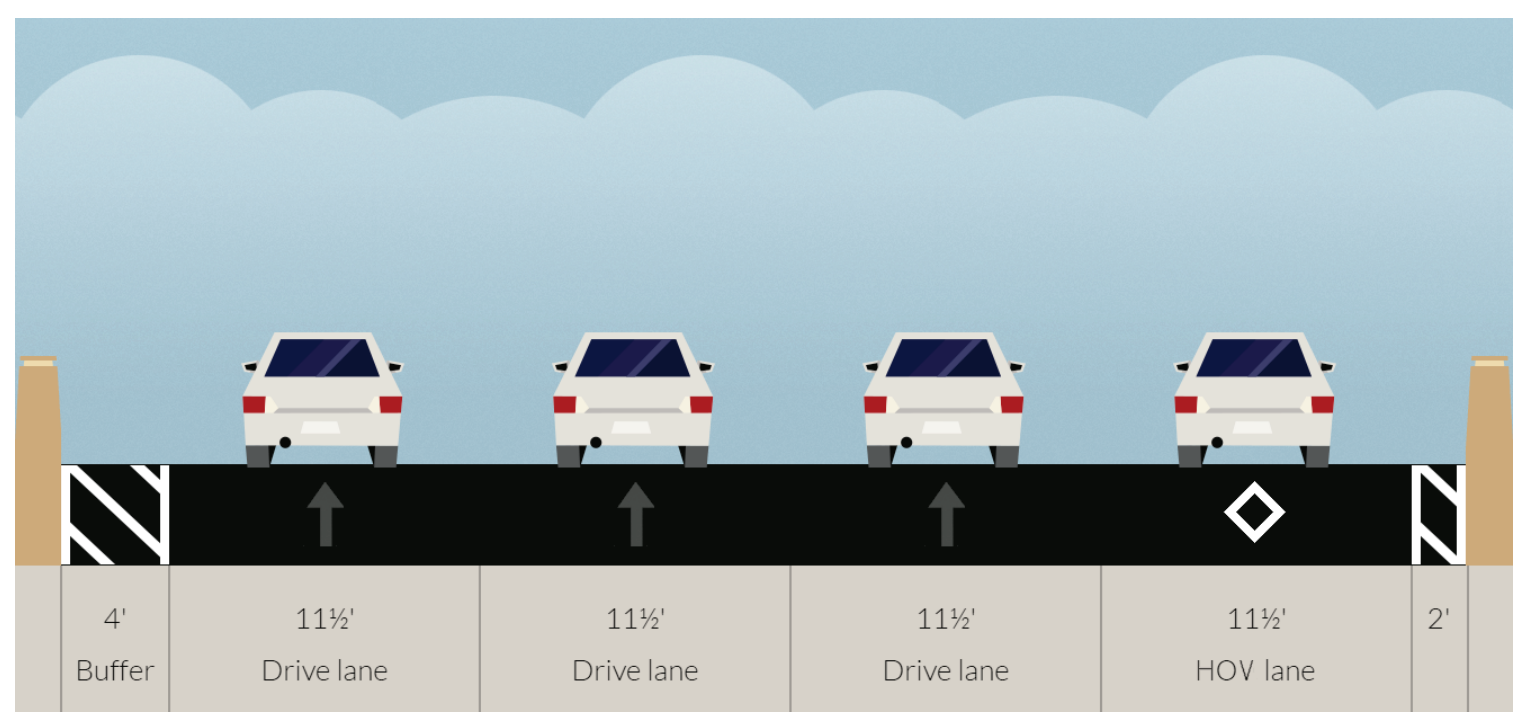

(b)

Figure 4.2: West Grand Avenue Before (a) and After (b) HOV Lane Extension

\subsubsection{I-580 Ramp Queue Jump Extension}

As helpful as the above HOV extension would be, it would be more effective to extend the queue jump past the I-580 eastbound onramp to the intersection with Maritime Street. This is because the extension will allow buses and HOVs to skip the worse of the congestion straight from the Maritime intersection to the toll plaza and beyond. From the Maritime Street intersection to the 
I-580 eastbound onramp, the lane can be signed and striped for general purpose traffic heading to I-580 east and HOV traffic heading to I-80. Since traffic on this ramp is only 1500 vehicles daily (Caltrans, 2015c, p. 133), this should not greatly impact the HOV functionality of the proposed lane.

By taking $3 \mathrm{ft}$. from the left shoulder, $4.5 \mathrm{ft}$. from the right shoulder, and $1.5 \mathrm{ft}$. from each lane, three even lanes of $10.5 \mathrm{ft}$ each can be generated with a remainder of $2 \mathrm{ft}$. for the left shoulder and $2.5 \mathrm{ft}$. for the right shoulder. The narrow lanes are acceptable as this is right before a merge on a curve, so site geometry warrants slower speeds. A cross section of this segment is provided in Figure 4.3.

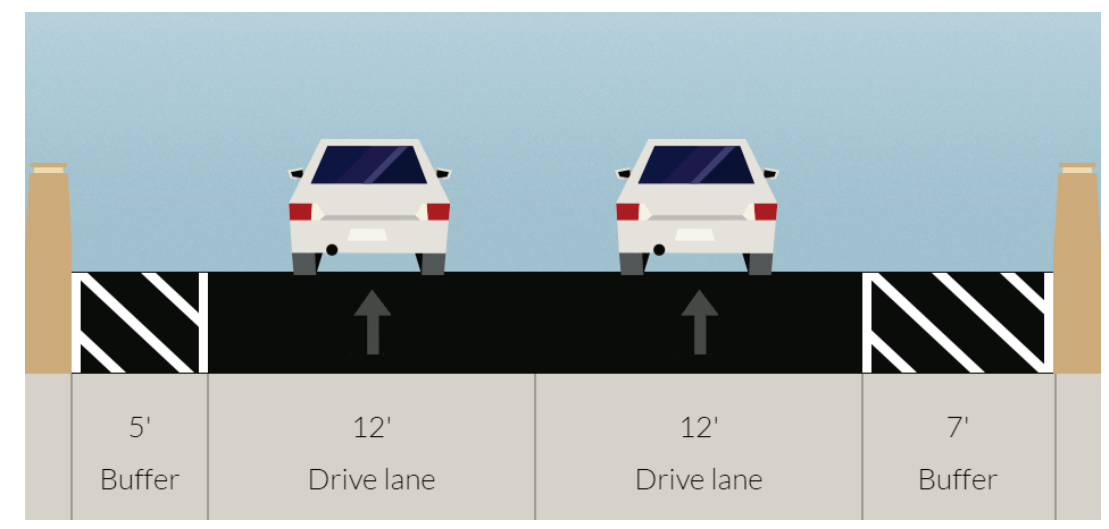

(a)

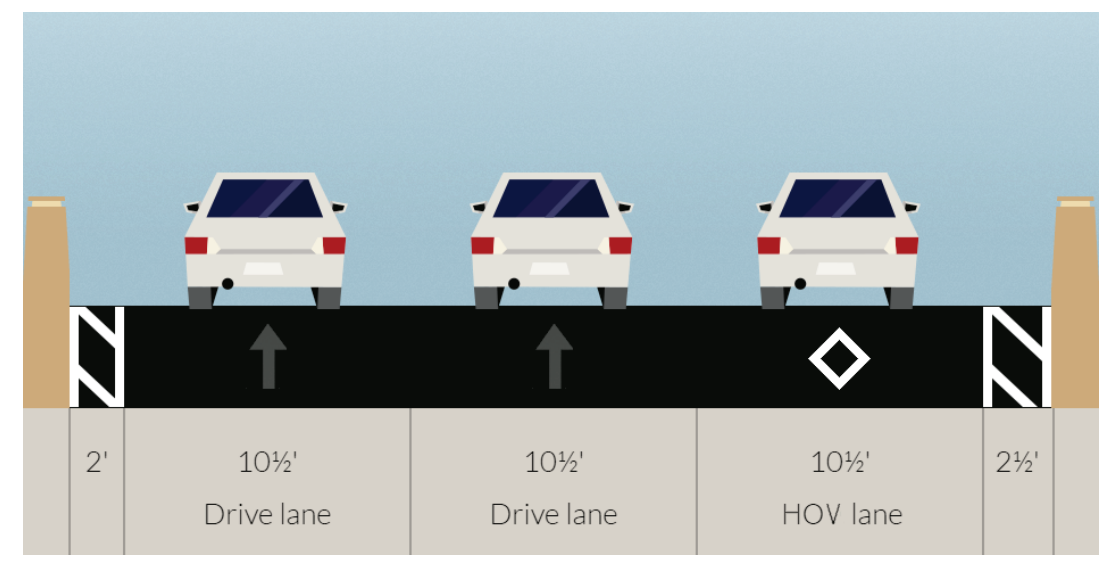

(b)

Figure 4.3: West Grand Avenue Before (a) and After (b) HOV Lane Extension Past I-580 Onramp 


\subsubsection{Maritime Intersection Queue Jump Extension}

Lastly, HOV operations can be further improved by extending this queue jump past West Grand Avenue's intersection with Maritime Street. This will allow buses and other HOVs to make use of a dedicated lane to help jump past the queue to pass through the intersection and rush hour gridlock all the way from the toll plaza. Traffic turning right onto Wake Avenue could also use this lane. Impact to HOV traffic is estimated to be minimal, as there are only a few tenants on Wake Avenue. By taking a foot from each lane and adding it to the current $8 \mathrm{ft}$. shoulder, four $11 \mathrm{ft}$. lanes can be generated. A cross section of this segment is provided in Figure 4.4.

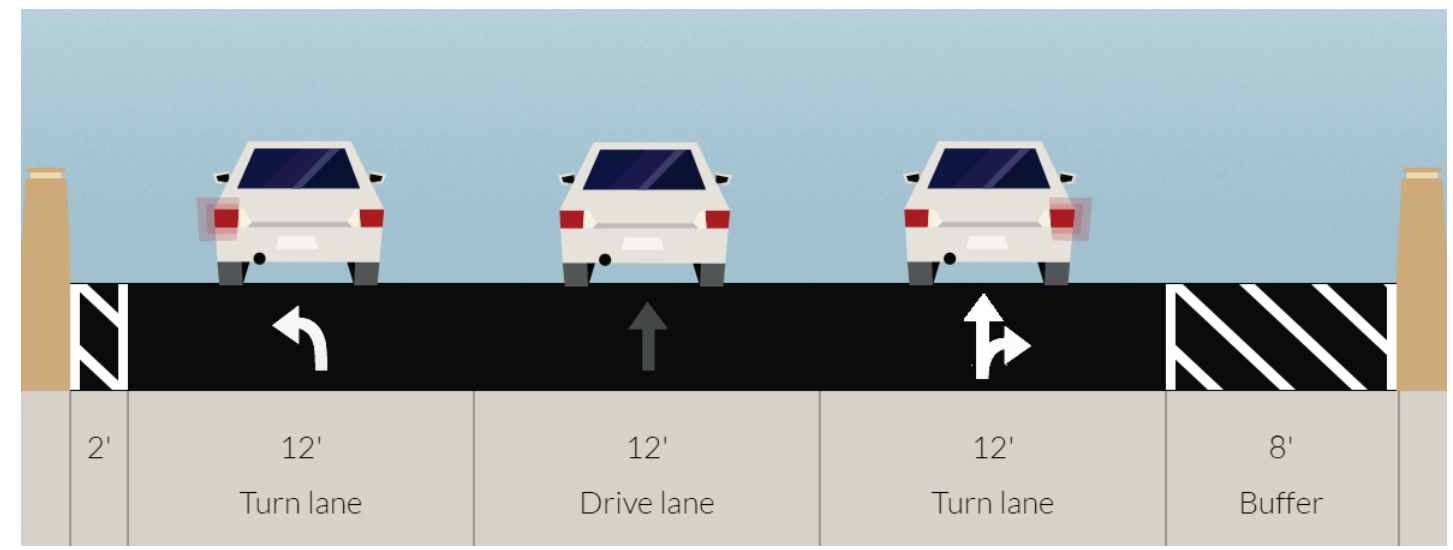

(a)

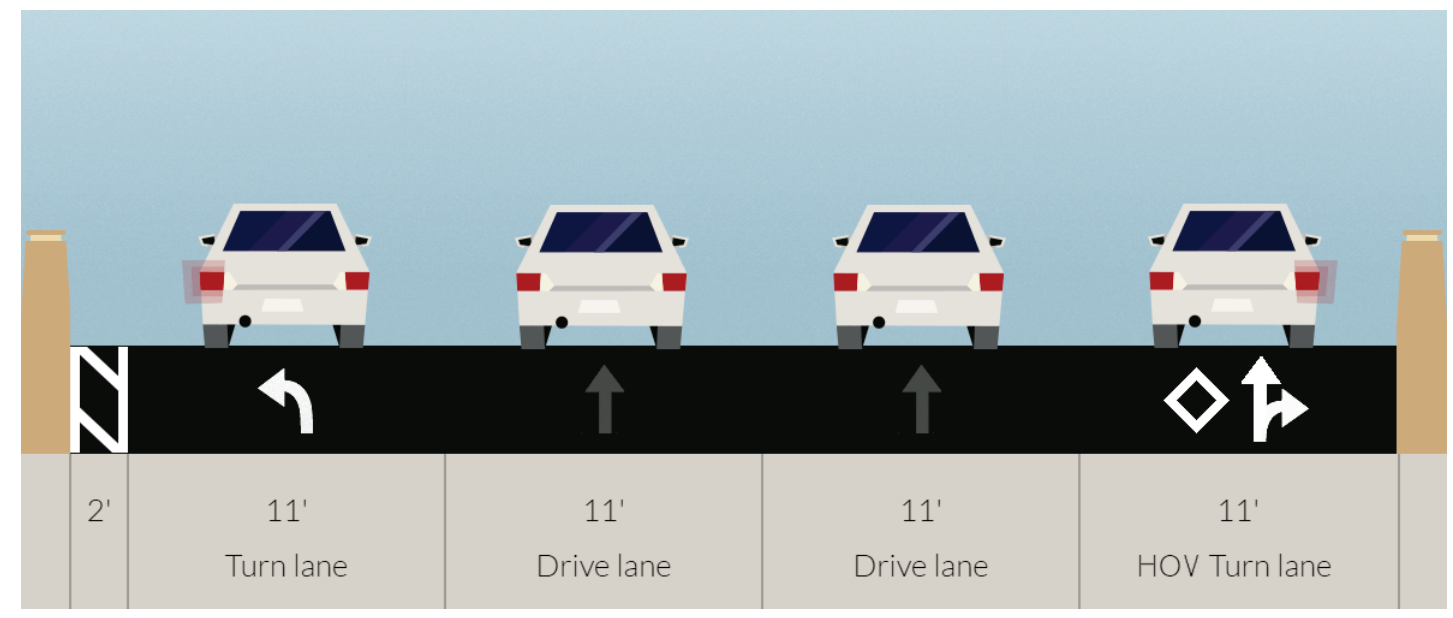

(b)

Figure 4.4: West Grand Avenue Before (a) and After (b) HOV Lane Extension Past Maritime Street Intersection 


\subsubsection{Overall Proposal}

With all elements combined, a bus or HOV can skip past the queue for the Maritime Street intersection and all the way to the toll plaza, without having to merge into general purpose traffic and potentially getting stuck there. This can result in major time savings for HOVs and buses; AC Transit transbay services could save eleven minutes during peak demand times by their estimate. AC Transit can make extensive use of this shortcut by rerouting Transbay service from south of the Bay Bridge through West Grand Avenue, in conjunction with transit signal priority on the West Grand Avenue corridor. MTC anticipates the cost of this project to be around $\$ 3,000,000$ for around 9,700 linear feet of restriping to accommodate the HOV lane, seventeen drain grate replacements, and signal and signage changes at the Maritime intersection (MTC, 2011, p. 11).

As shown in Appendix A, a number of design exceptions will be required for this proposal:

1. Nonstandard lane widths: $11.5 \mathrm{ft}$. from the existing HOV ramp to the I-580 eastbound ramp, 10.5ft. from the I-580 eastbound ramp to the Maritime Street intersection, and $11 \mathrm{ft}$. from the Maritime Street intersection to the end of the queue jump.

2. Nonstandard shoulders: $4 \mathrm{ft}$. left and $2 \mathrm{ft}$. right from the existing HOV ramp to the I-580 eastbound ramp, $2 \mathrm{ft}$. left and $2.5 \mathrm{ft}$. right from the I-580 eastbound ramp to the Maritime Street intersection, and 2ft. left from the Maritime Street intersection to the end of the queue jump, with no right shoulder.

3. Nonstandard gore on the ramp from West Grand Avenue to I-580 eastbound.

4. Nonstandard merge on West Grand Avenue past the I-580 eastbound ramp 


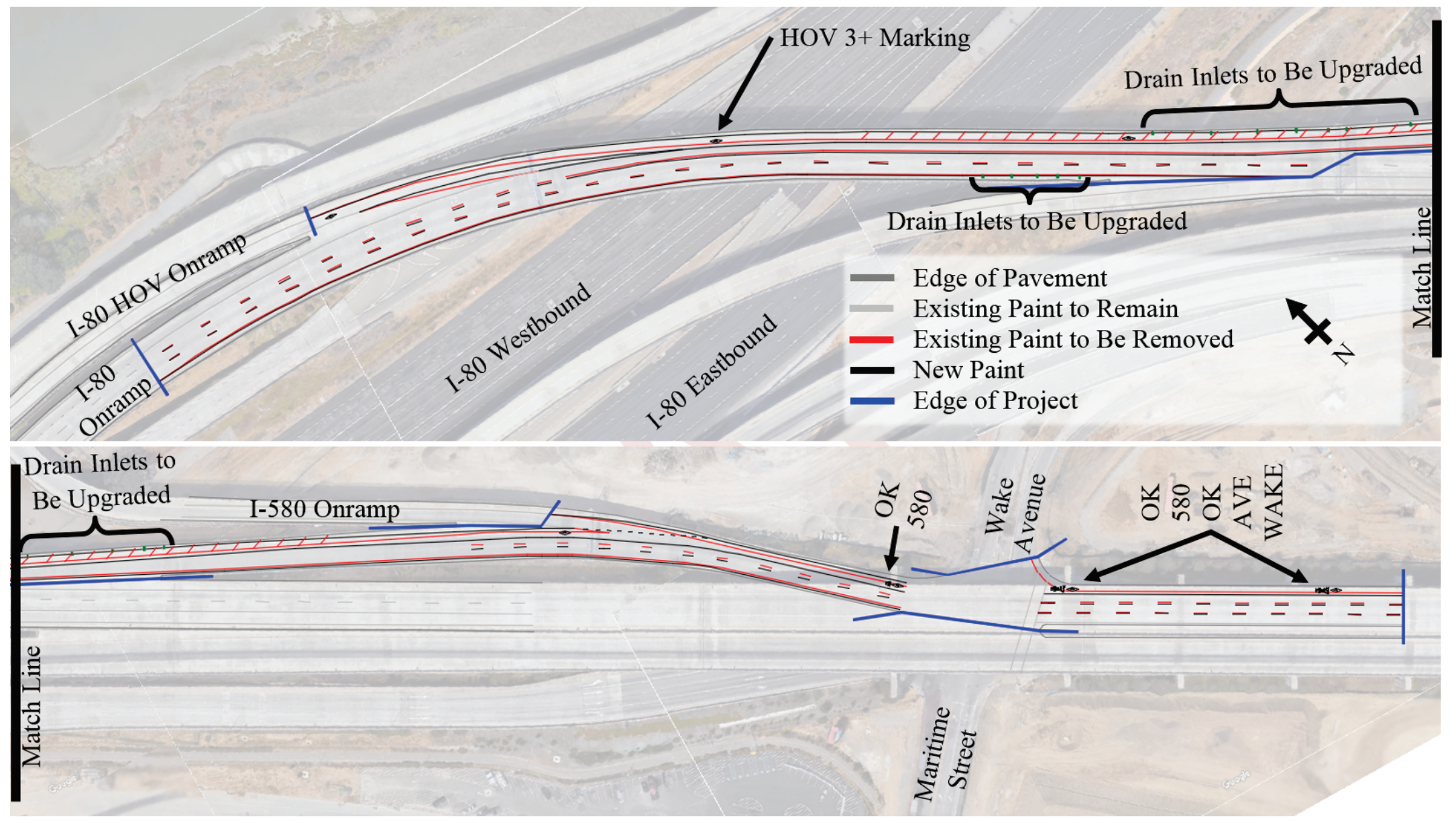

Figure 4.5: West Grand Avenue Onramp Upgrade Detail 


\subsubsection{Strategy 2: HOV Improvements at Powell Street and I-80 in Emeryville}

Several changes to the Powell Street and I-80 interchange in Emeryville, as well as to I-80 through Emeryville, can improve the attractiveness of HOV and transit. These changes include adding a right-side HOV lane on I-80 from the southbound Powell off-ramp to the existing rightside HOV lane before the toll plaza, converting the existing southbound Powell onramp to HOV and adding movements from the Powell Street intersection to allow more approaches to access the ramp, and building a new park-and-ride lot under the I-80 overpass.

\subsubsection{I-80 Right-Side HOV Lane}

Currently, there is a wide right shoulder along most of I-80 through Berkeley and the toll plaza. This could be upgraded to an HOV lane to help buses and carpoolers bypass queues from the toll plaza. The lane would start just past the southbound Powell Street off-ramp, where the rightmost lane ends in a merge. It will extend this merge through the interchange with a few feet of pavement widening to connect to the southbound West Frontage Road onramp. There, restriping would allow the HOV lane to continue through the merge. This merge of HOV and general purpose traffic could be managed with an "all access okay next $1 / 2$ mile" policy similar to the left-side onramp from the Watt/I-80 light rail station in Sacramento.

Continuing on, Alternative 1 would be to convert the rightmost lane to HOV until it can connect with the existing HOV lane right before the toll plaza. This would leave two general purpose lanes where there were three. This alternative is estimated to cost around $\$ 165,500$, as outlined in Table 4.1. Alternative 2 would be more expensive, but have better operations, as it removes the barrier from the southbound Powell Street onramp and reroutes traffic in the proposed I-80 right-side HOV lane onto the onramp. Of note, the barrier is there to prevent onramp traffic from accessing I-580 eastbound across three lanes of traffic in a short merge, and so it would be important to maintain this limitation in any future alteration. Currently, the onramp merges with the existing general purpose lanes before curving to the west to cross the bay. Instead, this more expensive alternative would add a new isolated lane that bypasses the existing I- 80 HOV structure 
and connects with the existing HOV lane from the right. This alternative is estimated to cost around $\$ 868,500$, as outlined in Table 4.2. These alternatives are shown in Figure 4.6.

Table 4.1: Cost Estimate for I-80 Right-Side HOV Lane Improvements, Alternative 1

\begin{tabular}{|c|c|c|c|c|c|}
\hline Cost Type & Amount & Unit & Unit Cost & Total Cost & Source \\
\hline New Pavement & 530 & Square Yards & $\$ 151.11$ & $\$ 80,088.30$ & (Plotner, 2015) \\
\hline New Paint & 4900 & Linear Feet & $\$ 1.52$ & $\$ 7,448.00$ & (Caltrans, 2016e) \\
\hline Remove Paint & 2500 & Linear Feet & $\$ 1.00$ & $\$ 2,500.00$ & (Caltrans, 2016d) \\
\hline
\end{tabular}

$53 \%$ Soft Costs (20\% contingency, $15 \%$ overhead and profit, $10 \%$ general requirements, $5 \%$ permit and $\$ 47,719.24$ inspection, $3 \%$ bonds and insurance):

Total: $\$ 137,755.54$

$20 \%$ Soft Costs (10\% time-related overhead and 10\% mobilization):

$\$ 27,551.11$

Total: $\$ 165,306.65$

Rounded: $\quad \$ 165,500.00$

Table 4.2: Cost Estimate for I-80 Right-Side HOV Lane Improvements, Alternative 2

\begin{tabular}{|c|c|c|c|c|c|}
\hline Cost Type & Amount & Unit & Unit Cost & Total Cost & Source \\
\hline New Pavement & 3000 & Square Yards & $\$ 151.11$ & $\$ 453,330.00$ & (Plotner, 2015) \\
\hline Remove Barrier & 165 & Linear Feet & $\$ 33.90$ & $\$ 5,593.50$ & (Caltrans, 2016f) \\
\hline New Paint & 7300 & Linear Feet & $\$ 1.52$ & $\$ 11,096.00$ & (Caltrans, 2016e) \\
\hline Remove Paint & 2900 & Linear Feet & $\$ 1.00$ & $\$ 2,900.00$ & (Caltrans, 2016d) \\
\hline
\end{tabular}

$53 \%$ Soft Costs (20\% contingency, $15 \%$ overhead and profit, $10 \%$ general requirements, $5 \%$ permit and $\$ 250,647.34$

inspection, $3 \%$ bonds and insurance):

Total: $\$ \$ 723,566.84$

$20 \%$ Soft Costs (10\% time-related overhead and 10\% mobilization):

$\$ 144,713.37$

Total: $\$ 868,280.21$

Rounded: $\$ 868,500.00$ 


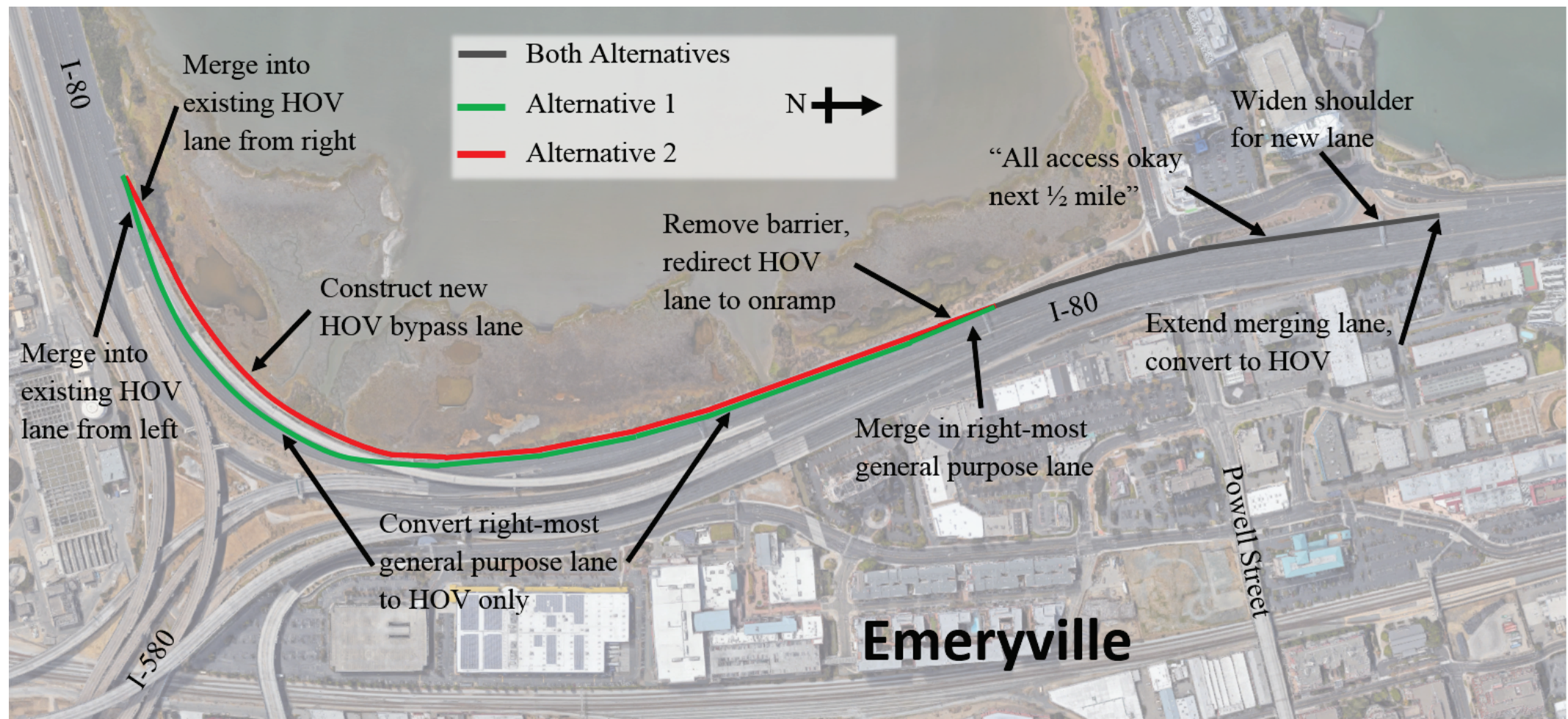

Figure 4.6: I- 80 HOV Lane Proposal, Split by Alternatives 1 and 2 
Currently, AC Transit routes FS, G, H, L, LA, and LC, WestCAT Lynx, and SolTrans Route 200 all use I-80 southbound through the area this improvement would serve, representing 1,824 daily riders and 713 AM peak hour riders who would receive a time-savings benefit. Additionally AC Transit routes C, F, J, and Z enter on Powell, representing an additional 1,879 daily and 413 AM peak hour riders, for a total ridership of 3,703 per day and 1,126 during the AM peak hour.

\subsubsection{Improve HOV Access at Powell Street and I-80}

BATA's “San Francisco Bay Crossings Study Update,” outlined in the literature review, recommends improving HOV access to the freeway from this important arterial. Currently, the only direction that can access the Powell Street diagonal onramp onto I- 80 west is from the west. While there is demand for this movement, the majority of traffic seeking to get onto I- 80 west is coming from the east, and must turn right from Powell onto West Frontage Road to get to the freeway. Operationally, this makes sense as it eliminates left-turn traffic from westbound Powell Street to the I-80 west onramp. However, only 2,400 daily vehicles make use of the restricted Powell Street onramp, versus 20,300 daily vehicles for the West Frontage Road onramp (Caltrans, 2015c, p. 28). This leaves much unused capacity that could be utilized by HOV movements from westbound Powell Street.

The intersection used to have this configuration, but it was altered to improve operations. However, adding back in the movements for HOV only should greatly improve the attractiveness of HOV and transit by improving travel times and travel time reliability. As well, it will enable HOVs to access the HOV facilities at the toll plaza, as the current configuration essentially forces HOVs to sit in general purpose traffic, unless they are able to dart across five lanes of traffic in the short span between the West Frontage Road onramp and the I-80 left-side HOV ramp exit to the toll facility. Even without the other elements, adding these HOV movements alone will allow transit to jump around 0.8 miles of queue on I-80 using the lengthy Powell Street onramp. 
BATA's diagram of this proposed change is included in Appendix B. According to their cost estimates, this conversion will cost $\$ 1,248,000$ and have a time-savings benefit of $\$ 6,468,000$, for a cost-benefit ratio of 5.18 (AECOM, 2012).

\subsubsection{New Park-and-Ride at Powell Street under I-80}

The last element of this strategy is to construct a park-and-ride lot underneath I-80 on the south side of Powell Street. This lot could potentially contain 60 regular stalls, 3 handicap stalls, 3 compact stalls, and 6 motorcycle stalls, for 72 spots total, as well as amenities for transit pickup/drop-off. Currently, AC Transit routes C, F, J, and Z pass by this proposed lot and so could easily serve the lot. Figure 4.7 shows a possible configuration for this lot in conjunction with the improved HOV access at Powell Street and westbound I- 80 onramp. Figure 4.8 shows how buses could navigate the lot. This element is estimated to cost $\$ 494,000$, from $\$ 6,857.14$ per stall times 72 stalls and rounded up to the nearest thousand dollars. The per-stall value comes from MTC's estimate for new park-and-ride lots, as will be outlined in Section 4.1.5. It is important to note that this cost does not overlap BATA's estimate for the intersection modifications at Powell and West Frontage Road/I-80 Westbound Onramp.

Many more spaces could be developed on the west side of the I- 80 westbound onramp, but these would less environmentally sound, as they would encroach on the nearby wetland reserves. Additionally, at present the site hosts several sculptures. These could be relocated to the other sculpture garden on the north side of Powell Street under the bridge, which is otherwise unaffected by this project. 


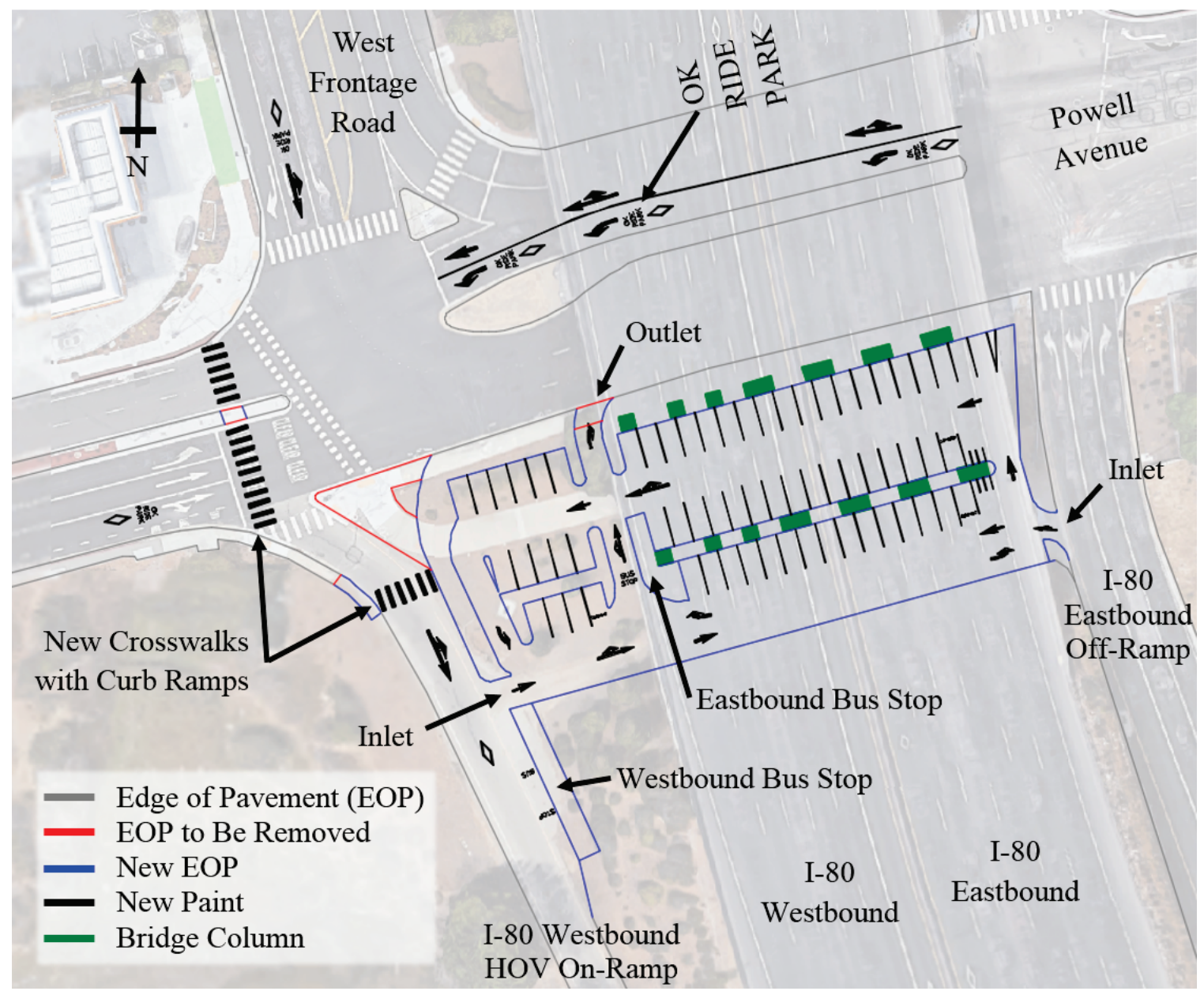

Figure 4.7: Powell Street Park-and-Ride Lot and HOV Onramp Improvements 


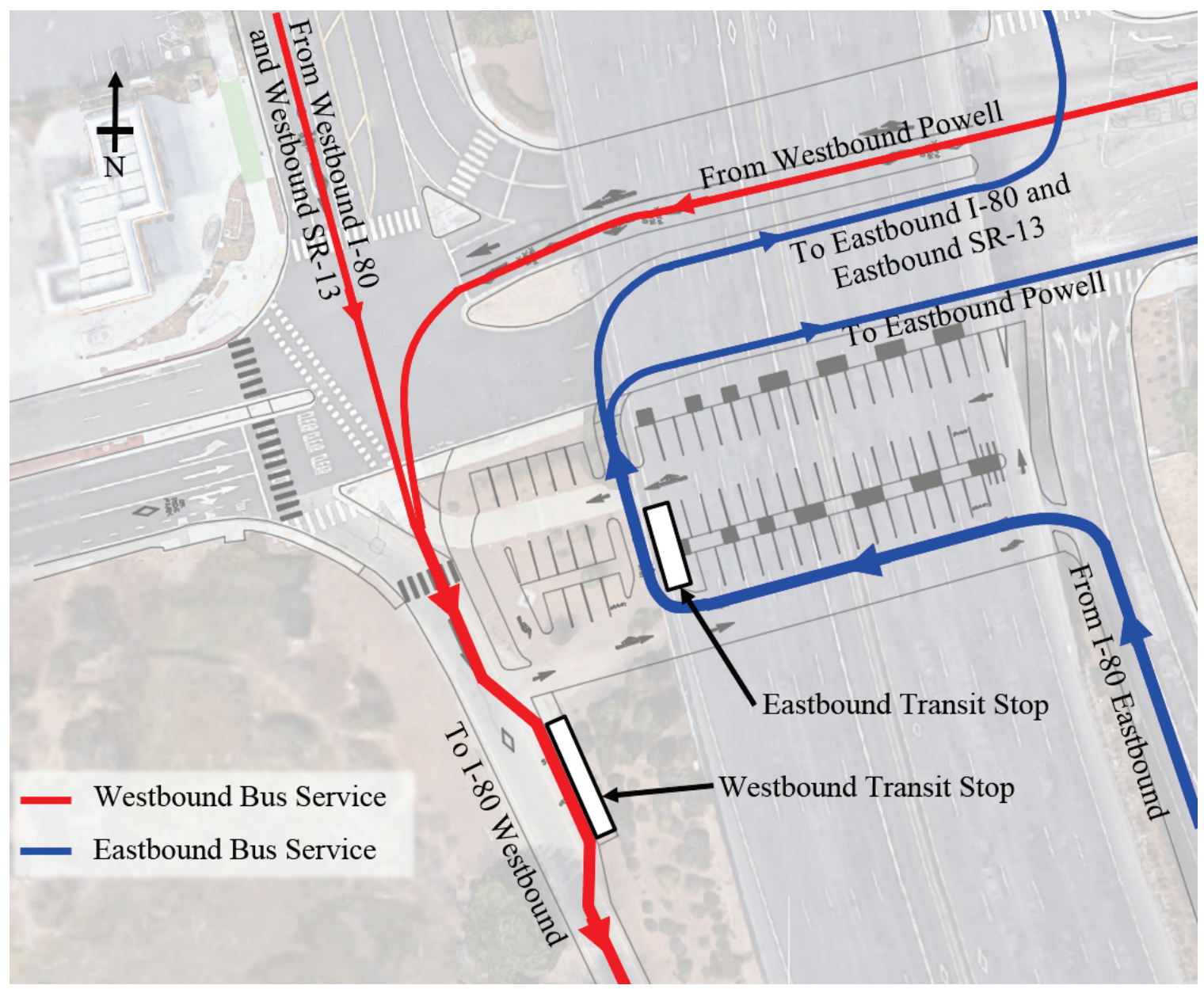

Figure 4.8: Proposed Bus Reroutes to Serve Park-and-Ride Lot

\subsubsection{Strategy 3: MacArthur Onramp Bus Lane}

This proposal, part of BATA's report, would add a bus lane to the MacArthur onramp similar to the West Grand Avenue proposal above. Currently, there is no movement from MacArthur Boulevard that goes to San Francisco. The existing onramp only goes to I-80 eastbound (to Berkeley and beyond). The MacArthur to I-80 westbound movement used to exist, but was removed for operational reasons. When the movement was still there, the ramp from I-580 westbound to I-80 eastbound (that the movement tied to) was only one lane. However, the I-580 westbound to I-80 eastbound ramp has since been expanded to two lanes, requiring the MacArthur 
onramp to be barricaded until past the merge to avoid entering vehicles from jumping across two lanes to access I-80 westbound to San Francisco.

BATA's proposal only calls for reversing one of the two lanes of the I-580 eastbound to MacArthur eastbound off-ramp and adding structural work to accommodate carrying the new onramp from the eastbound viaduct to connect with the westbound viaduct. As much time savings as this proposal offers, it could be further improved by converting the leftmost lane on I-580 westbound into HOV from the new ramp to the existing end of the HOV lane before the toll plaza. This will allow buses and carpools to travel from MacArthur through I-580 and straight to the toll plaza without having to mix with general traffic and incur related delays. To best reduce operational complications from taking away a general purpose lane, the rightmost lane through this corridor should be converted from FasTrak only to general purpose. The lanes can resume their existing configuration where the viaduct touches down and the HOV lane moves aside.

BATA's original work is presented in Appendix C. Figure 4.9 maps the proposed changes, and Figure 4.10 calls out details at either end of the proposal. The new onramp alone is estimated to cost $\$ 11,100,000$ and provide $\$ 13,340,000$ in time savings benefits, for a cost-benefit ratio of 1.20 (AECOM, 2012). The HOV lane extension is anticipated to cost an additional $\$ 17,500$ while providing several minutes' worth of saved time across the 0.7 mile extension. The HOV lane extension costs are outlined in Table 4.3 below.

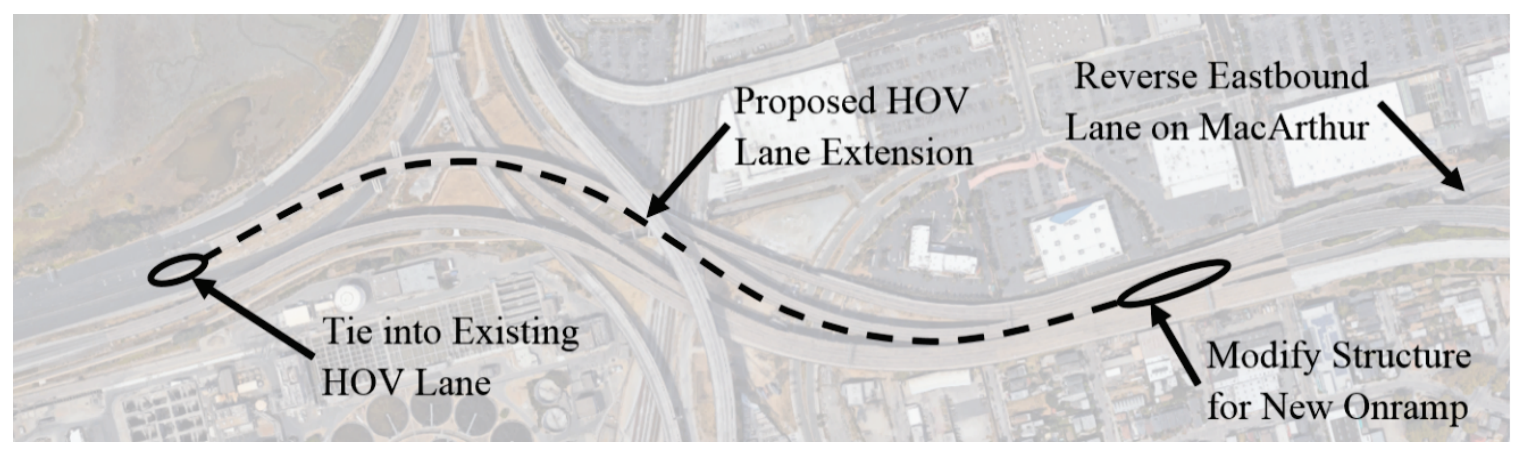

Figure 4.9: MacArthur and I-580 HOV Lane Overview 


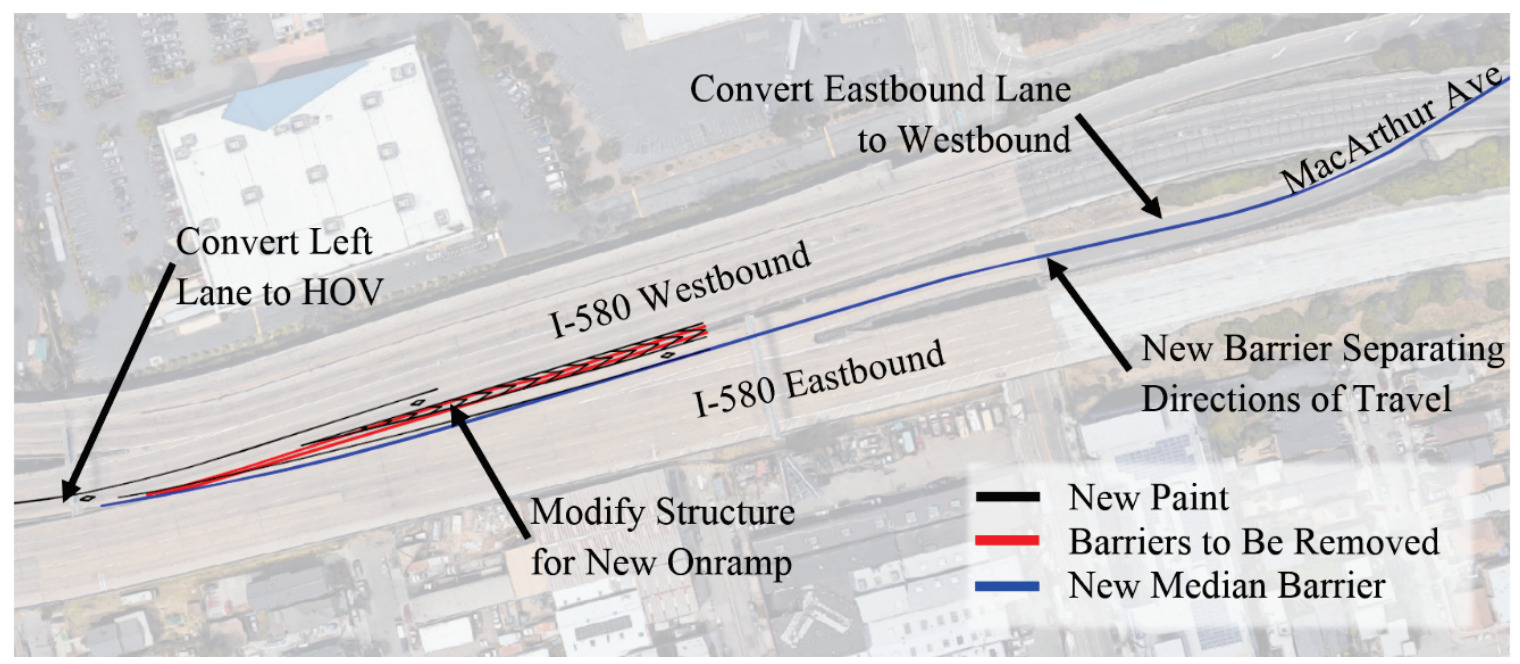

(a)

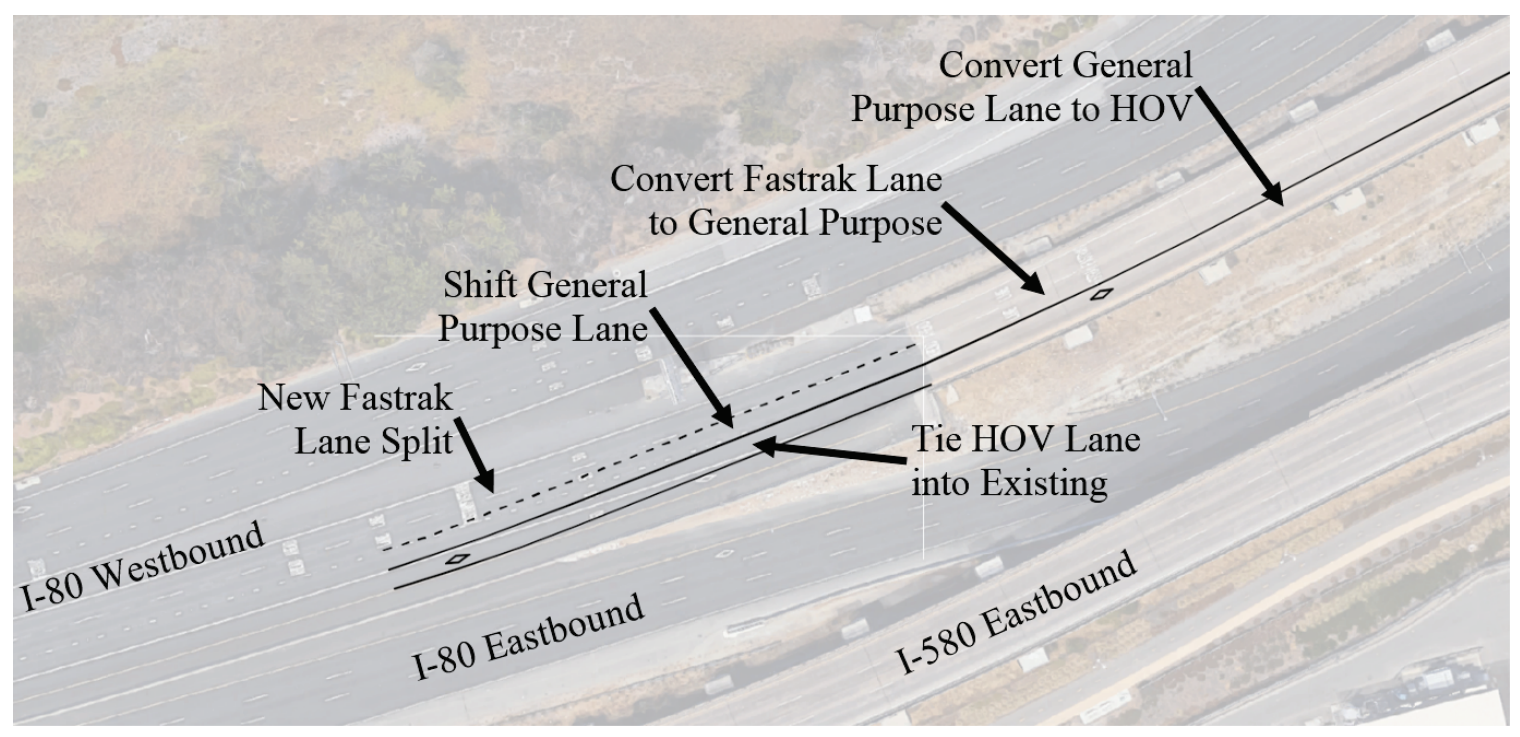

(b)

Figure 4.10: East End Details (a), and West End Details (b) 
Table 4.3: Cost Estimate for MacArthur HOV Lane Extension

\begin{tabular}{|c|c|c|c|c|c|}
\hline Cost Type & Amount & Unit & Unit Cost & Total Cost & Source \\
\hline New Paint & 5200 & Linear Feet & $\$ 1.52$ & $\$ 7,904.00$ & (Caltrans, 2016e) \\
\hline Remove Paint & 1500 & Linear Feet & $\$ 1.00$ & $\$ 1,500.00$ & (Caltrans, 2016d) \\
\hline
\end{tabular}

$53 \%$ Soft Costs $(20 \%$ contingency, $15 \%$ overhead and profit, $10 \%$ general requirements, $5 \%$ permit and inspection, $3 \%$ bonds and insurance):

$\$ 4,984.12$

Total: $\quad \$ 14,388.12$

$20 \%$ Soft Costs (10\% time-related overhead and $10 \%$ mobilization):

$\$ 2,877.62$

Total: $\$ 17,265.74$

Rounded: $\quad \$ 17,500.00$

\subsubsection{Strategy 4: Expand Bus Service}

This strategy is to add additional Transbay buses to both expand service and increase capacity. This tactic is also recommended by BATA's "San Francisco Bay Crossings Study Update," outlined in the literature review. To expand on these recommendations, perhaps WestCAT Lynx could expand service to Contra Costa County cities that are unserved by BART other than Hercules, such as San Pablo, Pinole, and Martinez. As well, perhaps SolTrans could expand their Vallejo-San Francisco (Route 200) service to Fairfield and possibly Vacaville. This incentive was first proposed by MTC as Element 2 in their presentation, "West Grand Avenue On-Ramp and Immediate Transbay Mobility Improvement Projects," outlined in the literature review and included in Appendix D.

\subsubsection{AC Transit}

AC Transit currently carries 17,549 riders per day across the Bay Bridge, including 2,492 into San Francisco during the AM peak hour and 2,849 out of San Francisco during the PM peak hour. This alone replaces a lane of private vehicle usage on the Bay Bridge using average rush hour private vehicle throughput and occupancy, which comes out to around 2,880 persons per hour per 
lane. While this is great, additional capacity could take things further. MTC proposes replacing 20 buses and adding 8 buses on two pilot services, at a cost of $\$ 27,800,000$ (MTC, 2011). The replacement buses will increase attractiveness and ridership, and the new services will attract new markets of riders

\subsubsection{WestCAT Lynx}

Currently, Contra Costa County's only transbay service, the WestCAT Lynx, connects a variety of stops in Hercules directly to San Francisco. It carries around 580 passengers per weekday, including 190 during the morning rush and 250 during the evening rush. One stop is the Hercules Transit Center, where the Lynx connects with local WestCAT services, creating an easy transfer for San Francisco-bound riders. However, several local routes do not connect to the Hercules Transit Center, but rather the Richmond Parkway Transit Center. The Lynx misses out on these potential transfers to instead provide local service to Hercules.

Rather than spending time circulating around Hercules, the Lynx service should instead focus on intercity connectivity, leaving the local circulation to local routes. This will allow the Lynx to improve travel time reliability by avoiding surface traffic in Hercules and instead stick to freeways. Additionally, it will allow the Lynx to connect to more transit centers and bring on additional riders.

One such transit center is the Martinez Amtrak Station, which is currently connected to the Lynx via WestCAT Route 30Z between the station and the Hercules Transit Center. By having the Lynx take over this service, it will free Route $30 \mathrm{Z}$ rolling stock and overhead to provide the local Hercules service that the Lynx would be dropping. Adding on the Richmond Parkway Transit Center would connect the Lynx to the remaining WestCAT routes that do not serve the Hercules Transit Center.

In summary, the Lynx should convert to a route serving only the Martinez Amtrak Station, Hercules Transit Center, Richmond Parkway Center, and San Francisco Transbay Terminal, and Route $30 \mathrm{Z}$ should be repurposed to serve the lost local Hercules service. This will boost service to 
areas of Contra Costa County not served by BART and pull additional riders out of their cars and onto the Lynx. A diagram of these proposed changes is provided in Figure 4.11.

As part of these changes, local service provided by the $30 \mathrm{Z}$ in Martinez would be eliminated, including a spur to Muir Road and the VA Medical Center in Martinez. This is acceptable, however, as the local Martinez service would still be provided by Central Contra Costa Transit Authority's (CCCTA's) Routes 16 and 98X. Additionally, lost Muir Road and VA Medical Center service would still be provided by CCCTA's Route 28, and to an extent, Route 3.

At present, the Lynx directly connects to WestCAT Routes 10, 11, 12, 15, 19, 30Z, C3, JR, JL, JX, and JPX. Through this realignment, the Lynx will also directly connect to WestCAT Routes $16,17,18,19$, as well as gaining a second connection to JR and JPX. Additionally, this realignment will directly connect the WestCAT Lynx at the Martinez Amtrak Station to CCCTA's Routes 3, 16, 18, 19, 28, and 98X, as well as Tri Delta Transit's Route 200. At the Richmond Parkway Transit Center, the WestCAT Lynx will gain connections to AC Transit's Routes 70, 71, 376, LA, and LC. In total, this will bring the number of East Bay routes connecting to the WestCAT Lynx from 11 to 27 . 


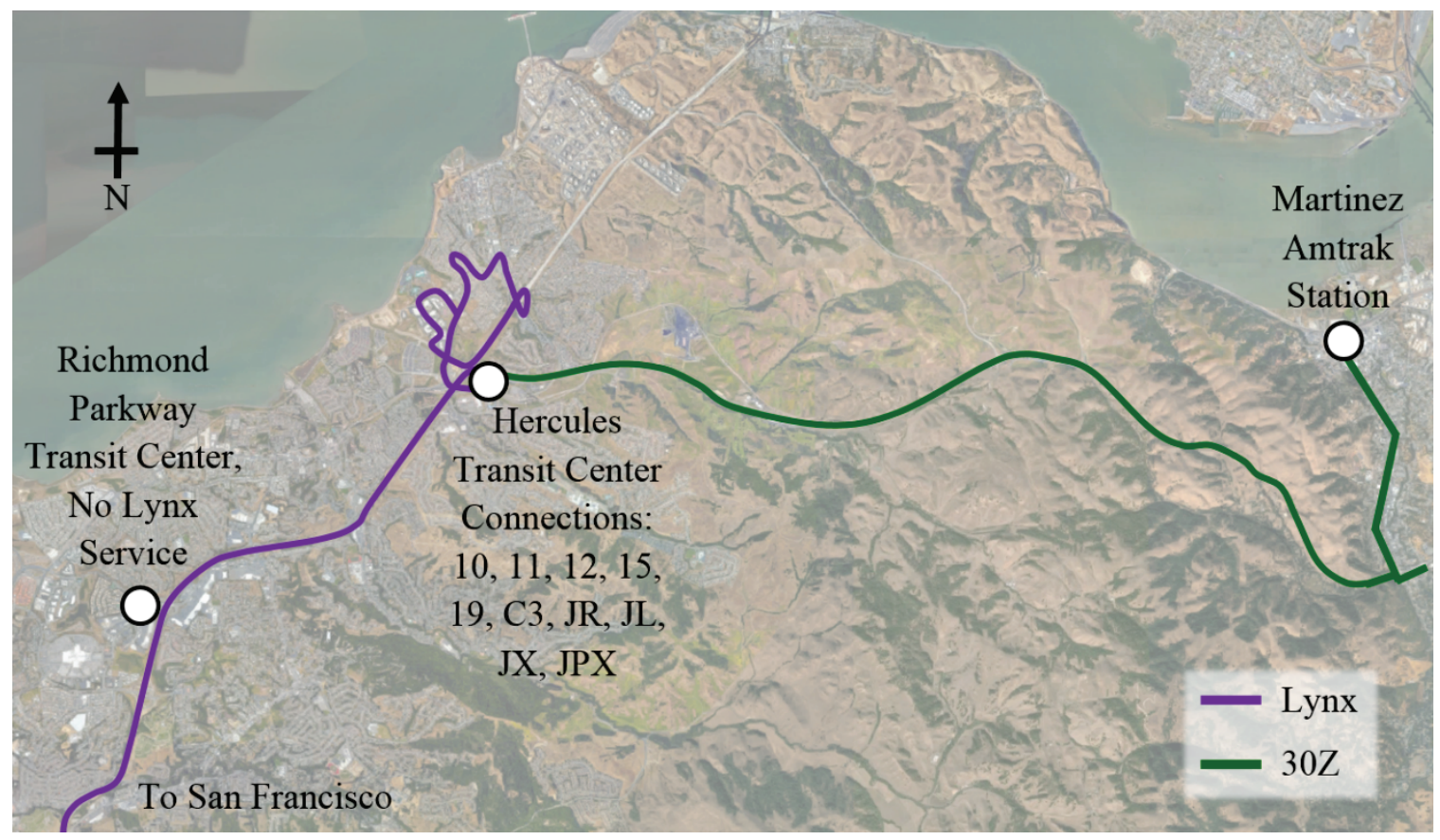

(a)

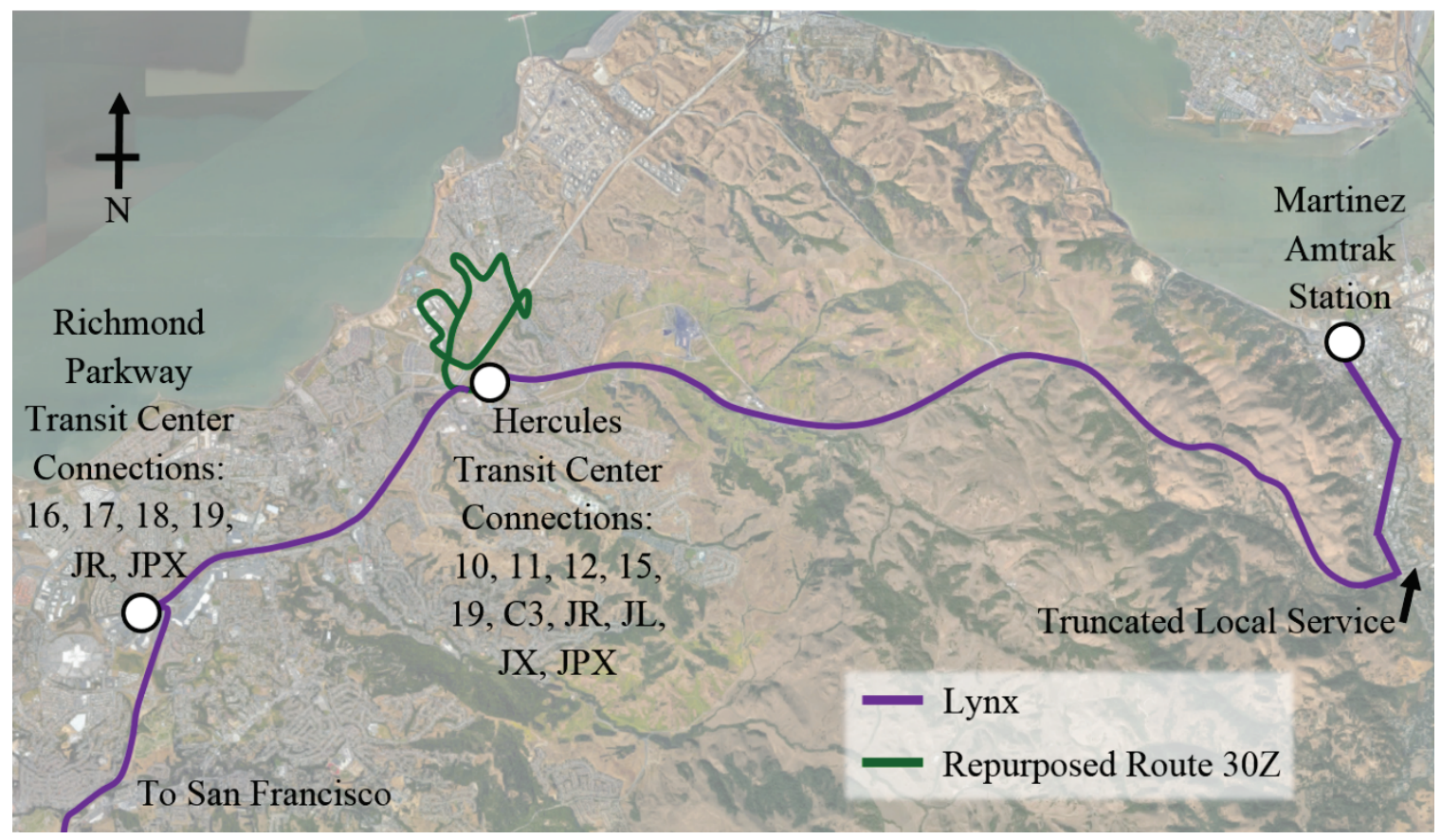

(b)

Figure 4.11: Current (a) and Proposed (b) WestCAT Lynx and Route 30Z Operations 


\subsubsection{SolTrans Route 200}

Currently, the only direct bus service from Solano County to San Francisco is SolTrans Route 200. While operated by SolTrans, this service is actually administered by WETA as a supplement to the ferry. One possible improvement to this service would be to extend it from the Vallejo Ferry Building to transit centers in Fairfield and Vacaville.

However, a study of Solano County bus riders found that just over $11 \%$ of current riders ultimately reach San Francisco (Solano Transportation Authority, 2014). These riders overwhelmingly take Fairfield and Suisun Transit's (FAST's) Routes 40 and 90, and SolTrans's Routes 78 and 80, which provide service between Solano County cities and the El Cerrito del Norte and Walnut Creek BART stations. Still, most of the riders of these services are only traveling within Solano County between Vallejo and Fairfield.

A study commissioned by STA recommends reconfiguring intercity service to a "BARTlike service design" (Arup, 2014, p. 2). This will provide many of the same service improvements as expanding Route 200. Additionally, there are plans to eliminate Route 200 service in favor of increased ferry service, as the buses dedicated to Route 200 are aging and will need to be retired soon (P. Kamhi, personal communication, September 29, 2016). Only 6.5\% of Vallejo-San Francisco passengers use the bus versus the ferry (Transportation Analytics, 2016, p. 4.3). Lastly, the US Census's American Community Survey estimates that around 9,854 daily commuters travel from Solano County to San Francisco (Employment Devlopment Department, 2013). Of these, around 1,700 take WETA's Vallejo and Route 200 services, and 490 ride other SolTrans routes to the East Bay before transferring to another service (mostly BART) that connects to San Francisco (Solano Transportation Authority, 2014, p. 11). This means that around 22\% of Solano County commuters to San Francisco already use public transit, which is relatively fairly high considering the lack of frequent metro-like service provided by BART or other such operators. 


\subsubsection{Transbay Terminal}

While not a part of this thesis, it is important to note that the new Transbay Terminal, slated for revenue operations in late 2017, will drastically improve operations over the current Temporary Transbay Terminal. At present, transbay buses need to negotiate several congested blocks of downtown San Francisco between the freeway and the terminal. While SFMTA has done great work with dedicated bus lanes and movements to and from the terminal, buses still get caught up by the intersections, their queues, and confused (or just ignorant) private vehicle drivers. With the new grade-separated ramps between the Bay Bridge and Transbay Terminal, transbay services will be able to shave precious minutes off of travel times, increasing attractiveness and ridership.

\subsubsection{Strategy 5: Commuter Parking}

One reason potential carpoolers drive alone is a lack of suitable meeting places. Perhaps coworkers live too far out of the way to be worth sharing rides, or perhaps it is hard to find a parking lot that does not mind carpoolers that leave behind their cars during the workday. By constructing additional park-and-ride lots, more commuters can join together on their way to work, reducing traffic on the roads and boosting the efficacy of other carpooling tactics.

Currently, there are four such lots in northwestern Alameda County (Caltrans, 2015d), defined as west of the San Leandro and Berkeley Hills and north of the City of Hayward. These spots provide a total of 503 stalls. Element 3 of MTC's aforementioned presentation recommends three new park-and-ride facilities along the I-80 and I- 880 corridors around Oakland for both carpooling and transit. These proposed spots will provide a total of 700 stalls, as outlined in Appendix E. Facilities along SR-24 and I-580 could provide additional benefit, to the tune of 569 stalls. This would increase the park-and-ride capacity of northwestern Alameda County from 503 stalls to 1,772 stalls. Table 4.4 outlines these lots, and Figure 4.12 provides a location map. For each lot, Table 4.4 denotes the nearby HOV facilities, for which there are few. However, all carpoolers from these lots heading into San Francisco are able to use the toll plaza HOV facilities. 
Table 4.4: Park-and-Ride Lots in Northwest Alameda County

\begin{tabular}{|c|c|c|c|c|c|c|}
\hline Freeway & Surface Street(s) & City & Status & Stalls & $\begin{array}{c}2015 \\
\text { Occupancy } \\
\end{array}$ & $\begin{array}{c}\text { Nearby HOV } \\
\text { Facilities } \\
\end{array}$ \\
\hline $\mathrm{I}-580$ & Center St & $\begin{array}{l}\text { Castro } \\
\text { Valley }\end{array}$ & Existing & 138 & $80.4 \%$ & None \\
\hline $\mathrm{I}-580$ & $\begin{array}{c}\text { Foothill Blvd and } \\
\text { John Dr }\end{array}$ & $\begin{array}{l}\text { Castro } \\
\text { Valley }\end{array}$ & Existing & 8 & $100.0 \%$ & None \\
\hline $\mathrm{I}-580$ & Fruitvale Ave & Oakland & Existing & 178 & $66.9 \%$ & None \\
\hline $\mathrm{I}-880$ & $\begin{array}{c}7^{\text {th }} \text { St and Linden } \\
\text { St }\end{array}$ & Oakland & Existing & 179 & $102.2 \%$ & $\begin{array}{c}\text { I- } 880 \text { eastbound } \\
\text { onramp queue } \\
\text { jump }\end{array}$ \\
\hline $\mathrm{I}-80$ & Buchanan St & Albany & $\begin{array}{l}\text { Proposed } \\
\text { (MTC) }\end{array}$ & 268 & - & I-80 HOV lanes \\
\hline $\mathrm{I}-880$ & Fruitvale Ave & Oakland & $\begin{array}{l}\text { Proposed } \\
\text { (MTC) }\end{array}$ & 272 & - & None \\
\hline $\mathrm{I}-880$ & High St & Oakland & $\begin{array}{l}\text { Proposed } \\
\text { (MTC) }\end{array}$ & 160 & - & None \\
\hline SR-24 & $\begin{array}{c}\text { Telegraph Ave } \\
\text { and } 56^{\text {th }} \mathrm{St}\end{array}$ & Oakland & $\begin{array}{l}\text { Proposed } \\
\text { (Carstens) }\end{array}$ & 85 & - & None \\
\hline $\mathrm{I}-580$ & $\begin{array}{l}\text { Broadway and } \\
\text { Piedmont Ave }\end{array}$ & Oakland & $\begin{array}{c}\text { Proposed } \\
\text { (Carstens) }\end{array}$ & 200 & - & None \\
\hline $\mathrm{I}-580$ & $\begin{array}{l}\text { Golf Links Rd } \\
\text { and } 98^{\text {th }} \text { Ave }\end{array}$ & Oakland & $\begin{array}{l}\text { Proposed } \\
\text { (Carstens) }\end{array}$ & 174 & - & None \\
\hline $\mathrm{I}-580$ & $\begin{array}{l}\text { Fairmont Dr and } \\
\text { Foothill Blvd }\end{array}$ & $\begin{array}{l}\text { Castro } \\
\text { Valley }\end{array}$ & $\begin{array}{l}\text { Proposed } \\
\text { (Carstens) }\end{array}$ & 110 & - & None \\
\hline
\end{tabular}




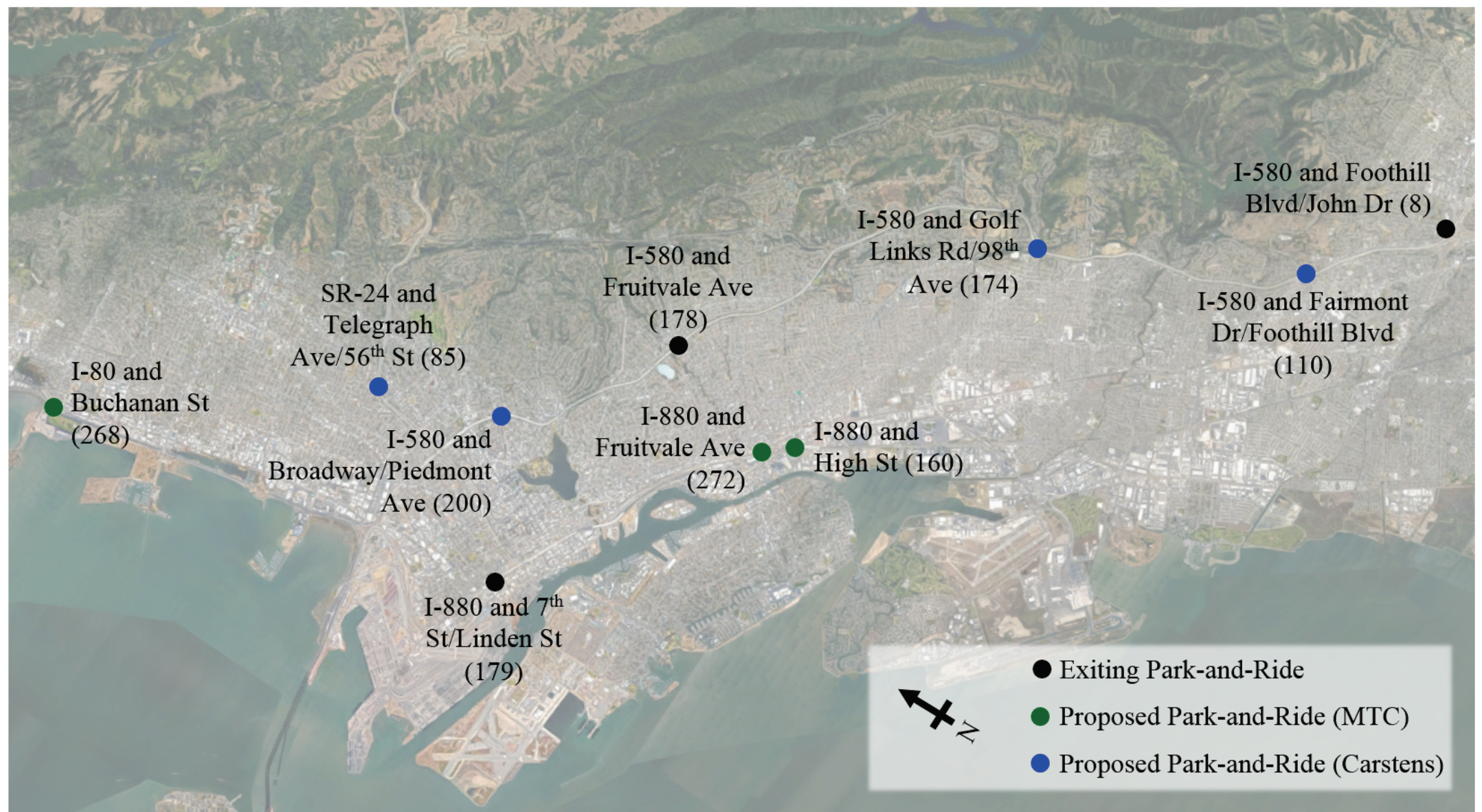

Figure 4.12: Park and Ride Lots in Northwestern Alameda County 


\subsubsection{SR-24 and Telegraph Avenue/56 ${ }^{\text {th }}$ Street}

This proposed lot covers the two vacant lots on either side of $56^{\text {th }}$ Street, below SR-24 and BART, and immediately west of Telegraph Avenue in the Bushrod and Shafter neighborhoods of northern Oakland. The southern vacant lot is bounded by $55^{\text {th }}$ Street, Telegraph Avenue, $56^{\text {th }}$ Street, and the embankment for SR-24 and BART. This space currently contains a driveway, a small, unmarked lot, and a utility shed. By expanding the pavement, the space can be made to accommodate approximately 35 stalls. The northern vacant lot is bounded by Carberry Avenue, $56^{\text {th }}$ Street, Telegraph Avenue, and lots built-out with business and residential. Currently, this space is completely vacant, with no pavement or other obvious land use. It could be altered to accommodate approximately 50 stalls, in addition to copious street parking on the streets around the lot. Figure 4.13 outlines the proposed lot and its vicinity.

The advantage of this lot is that it would add capacity in an area that is poorly served by other park-and-ride lots. It would put to work vacant land that could not be converted to better uses due to the constraints of the SR-24 and BART overpasses.

However, while it has great connectivity to SR-24 to the east, it lacks easy connections to the west (towards San Francisco). This could decrease appeal of the site to casual carpoolers, who would need to go further out of their way to access the lot than a simple touch-and-go from the freeway.

In terms of transit, AC Transit local routes 6 and 12 pass by the proposed lot location on Telegraph Avenue. Route 6 has fairly direct service to the $12^{\text {th }}$ Street and $19^{\text {th }}$ Street BART stations, while Route 12 makes a more roundabout trip. More pertinently, transbay Route E passes close to the site and provides direct service to downtown San Francisco. It could deviate from its current path by a few blocks to accommodate the new lot. However, this would add a few minutes to the travel time, potentially offsetting ridership increases from serving the lot. 


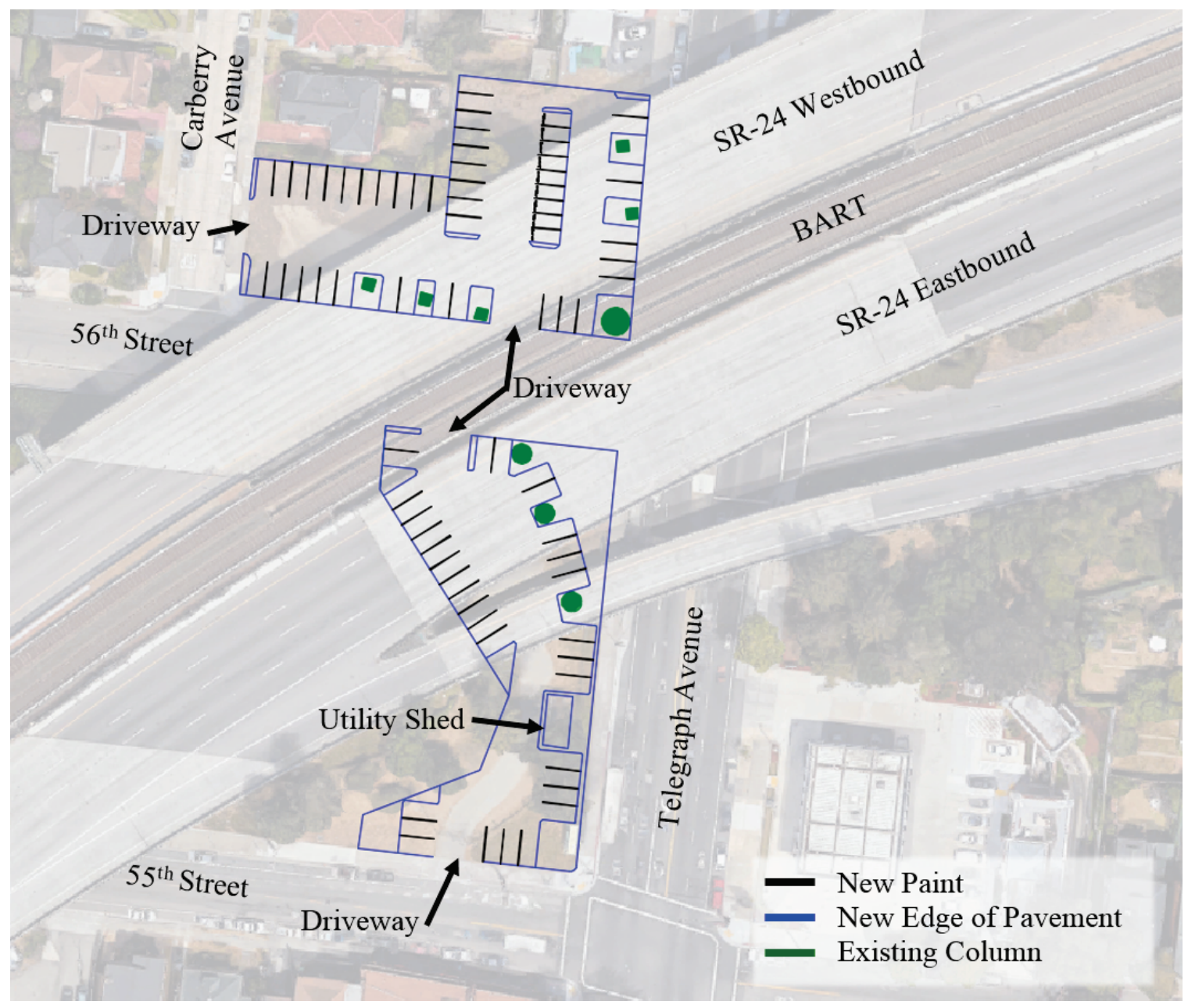

Figure 4.13: Proposed SR-24 and Telegraph Avenue $/ 56^{\text {th }}$ Street Park-and-Ride Lot

\subsubsection{I-580 and Broadway/Piedmont Avenue}

This proposed lot would upgrade the existing lots underneath I-580 and between Broadway and Piedmont Avenue, and Piedmont Avenue and Richmond Boulevard, to park-and-ride standards. Currently, the parking lots under this section of I-580 are underutilized and could be better repurposed. Additionally, there is room to expand parking further underneath I-580 between the northbound and southbound directions of Richmond Boulevard, which are split by an approximately $100 \mathrm{ft}$. median. While the median technically is the Oak Glen Park, the features of the park are suspended underneath I-580. While a diagram of this lot was impossible to 
conceptualize due to the I-580 viaduct covering the study location, an assessment of the current lot promotes around 200 spaces for this proposed park-and-ride location.

The advantage of this lot is its central location along with large size. It has the potential to capture single occupancy vehicles at one of the last possible moments before they join the queue to cross the toll plaza and onto the bridge. However, except for an eastbound off-ramp, there is not easy access to the freeway from this lot, which greatly decreases appeal.

Regarding transit, AC Transit local route $51 \mathrm{~A}$ provides frequent service to the $12^{\text {th }}$ Street and $19^{\text {th }}$ Street BART stations and passes by the location via Broadway. Additionally, transbay routes $\mathrm{B}, \mathrm{NX}, \mathrm{NX} 1, \mathrm{NX} 2$. NX3, NX4, NXC, P, and V pass overhead on I-580. While one of these could divert and provide direct service to the lot, because of the poor freeway connections it could add seven or more minutes to the average travel time.

\subsubsection{I-580 and Golf Links Road/98 ${ }^{\text {th }}$ Avenue}

This proposed lot would convert a currently empty field into approximately 174 park-andride stalls. The lot is in the Grass Valley neighborhood of Oakland and is bounded by I-580, Golf Links Road, $98^{\text {th }}$ Avenue, and the eastbound I-580 onramp. The proposed lot is diagramed in Figure 4.14 .

The main advantage of the location is that it has no current use and is simply vacant. It is a large, flat, and clear space in an area that is otherwise built-out, hilly, or wooded. However, the main criticism of this location is that the land could potentially be better utilized than as a surface lot. Due to its proximity to the freeway, it would do well as a shopping center or high density residential.

Regarding transit, AC Transit transbay route NX4 passes the location on I-580. With a slight detour, it could serve the location with minimal delay. 


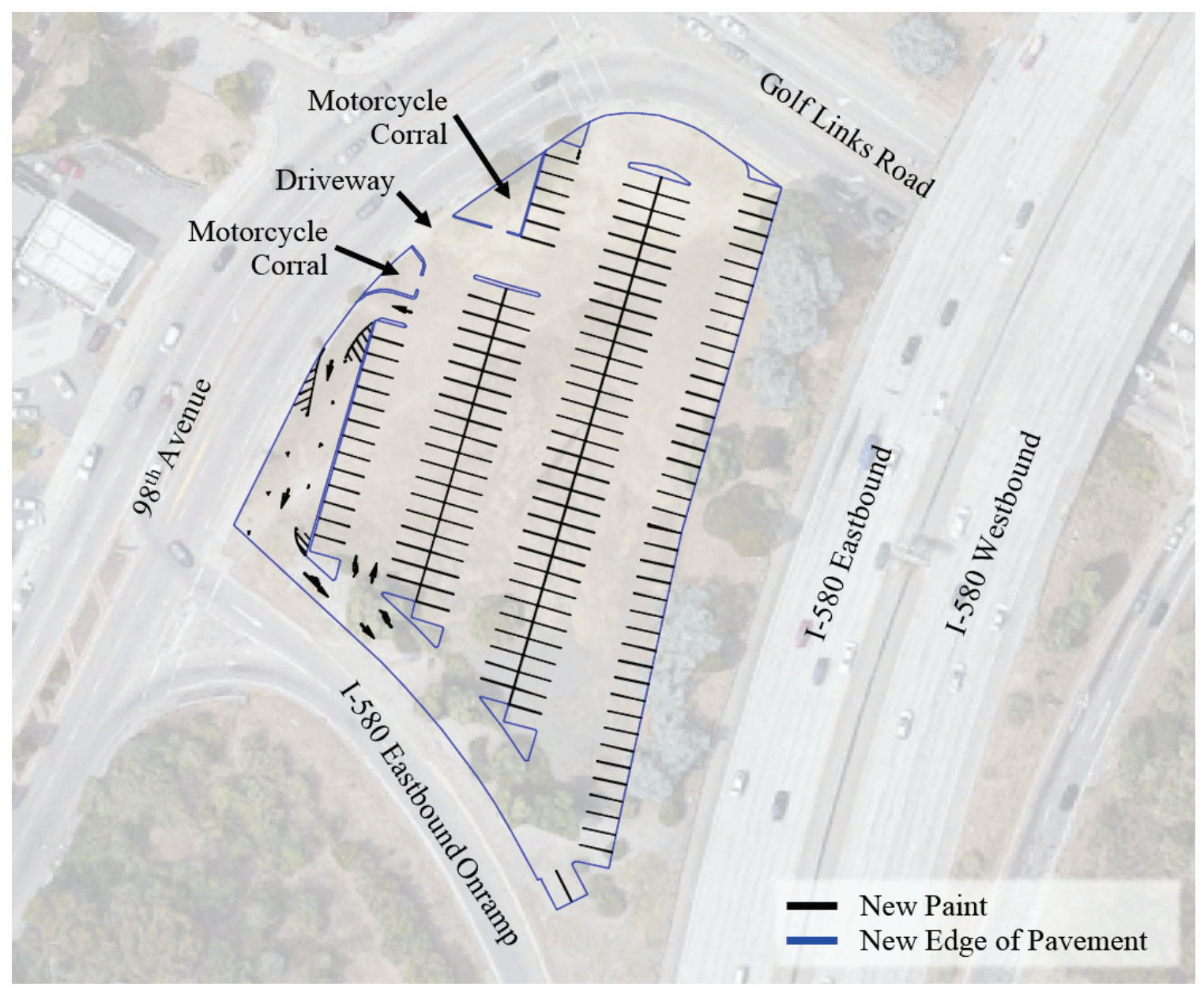

Figure 4.14: Proposed I-580 and Golf Links Road $/ 98^{\text {th }}$ Avenue Park-and-Ride Lot

\subsubsection{I-580 and Fairmont Drive/Foothill Boulevard}

This proposed lot would convert an unutilized freeway interchange quadrant into a parkand-ride facility with 110 stalls. The lot is surrounded by I-580, the I-580 westbound off-ramp, Foothill Boulevard, and Fairmont Drive. In order to satisfactorily design a driveway to this lot, modification of the existing hardscape will be necessary. The off-ramp will need to be "tee'd" with Foothill Boulevard, and the raised median of Foothill Boulevard will need to be modified to accommodate the new intersection. Additionally, Foothill Boulevard recently has undergone a "complete street" makeover to better accommodate cyclists with buffered bike lanes and high 
visibility markings. These improvements, mostly done via paint, will need to be maintained. Figure 4.15 diagrams this proposed lot.

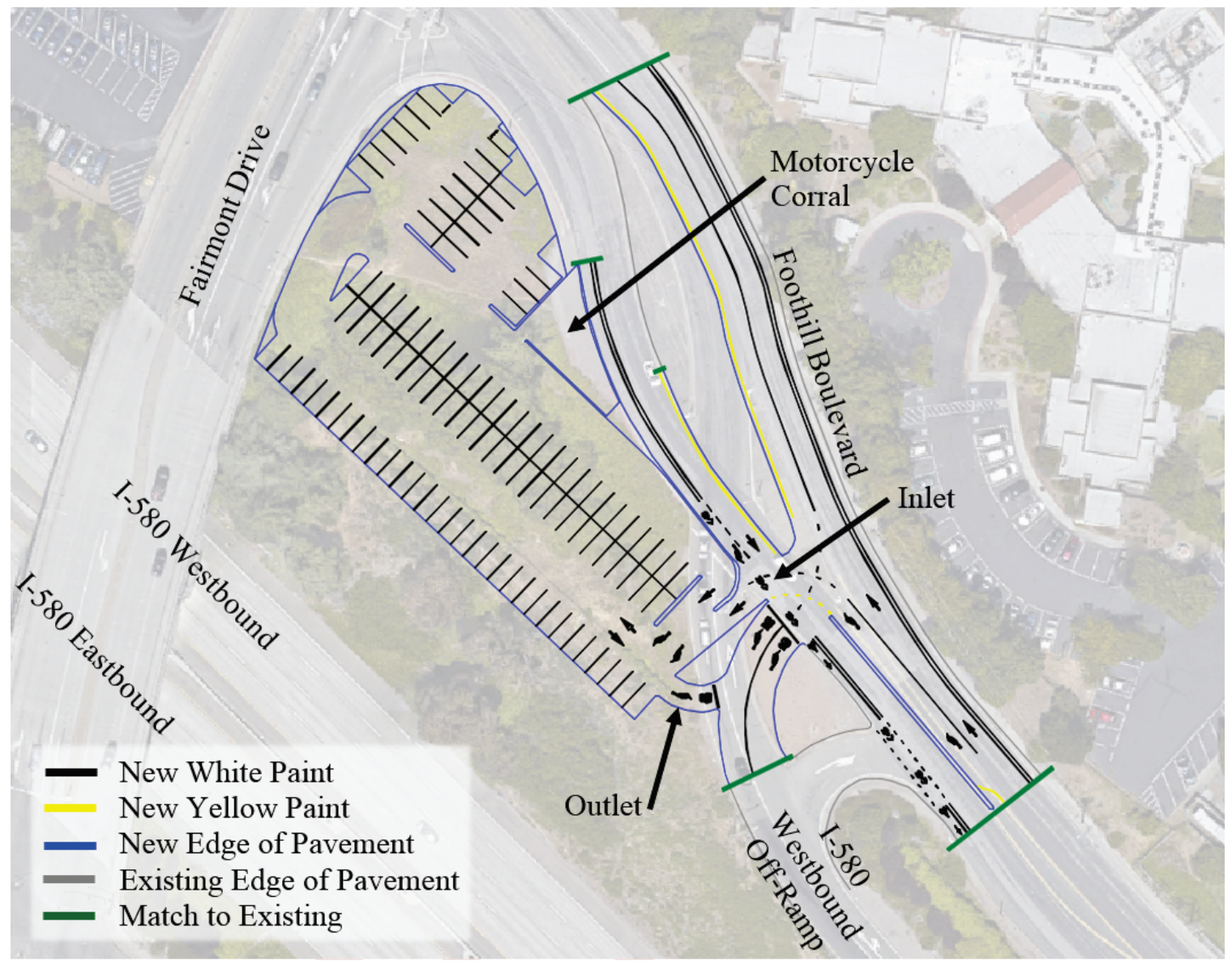

Figure 4.15: Proposed I-580 and Fairmont Drive/Foothill Boulevard Park-and-Ride Lot

Similar to the proposed Golf Links Road/ $98^{\text {th }}$ Avenue lot, the primary advantage of this location is that it is an otherwise unused vacant piece of flat and clear land in an otherwise built-up neighborhood. However, due to its small size and location within a freeway interchange, the location is not as suitable for other uses and so perhaps is best converted into a park-and-ride facility. Not much other than perhaps a fast food restaurant or gas station could fit in this location.

AC Transit local route 75 already connects the Bay Fair and San Leandro BART stations to Foothill Boulevard next to the proposed lot. AC Transit local route 89 also already connects the 
Bay Fair and San Leandro BART stations to Fairmont Avenue next to the proposed lot. More directly, the AC Transit transbay routes NX4 and NXC already stop at Fairmont Avenue and Foothill Boulevard on their way to and from San Francisco. Therefore, no schedule changes will be necessary to accommodate this lot.

\subsubsection{Benefits and Costs of Proposed Park-and-Ride Lots}

The overarching benefit of adding park-and-ride capacity is pulling cars off of the bridge, reducing queues and delays. With a total of 1,772 Caltrans-maintained stalls between existing and proposed lots, as well as additional AC Transit and BART lots, significant demand is shifted from private vehicles on the Bay Bridge to alternative modes.

MTC estimated that their three proposed lots will cost a total of $\$ 4,800,000$ for 700 stalls, or $\$ 6,857.14$ per stall, as shown in Appendix E. At that rate, the additional 569 stalls in this thesis would total around $\$ 3,900,000$, for $\$ 8,700,000$ total.

\subsubsection{BART Parking Capacity Increases}

It is important to note that the lots listed in Table 4.6 and mapped in Figure 4.12 are not the only parking lots in northwestern Alameda County, but rather only those park-and-ride lots maintained by Caltrans or proposals that would be maintained by Caltrans. Most notably, BART also operates parking lots at 27 of the 31 East Bay stations (those without are Downtown Berkeley, Oakland International Airport, and $19^{\text {th }}$ Street and $12^{\text {th }}$ Street in Downtown Oakland). Despite this, or perhaps because of it, BART parking fills to capacity as early as 6am. By 8:45am, many stations are at parking capacity, and the system as a whole is at $73 \%$ capacity (Phillips, 2016). There is a waiting list for parking permits that can reach 3,800 drivers (Richards, 2016).

BART has several plans for capacity increases with bond measures and the Warm Springs/Berryessa extensions. However, BART spokesperson Linton Johnson states that adding additional parking will increase vehicle miles traveled (VMT) and greenhouse gases (Phillips, 2016). Therefore, BART is seeking alternatives, such as building transit-oriented development (TOD). TODs will enable transit users to use BART without needing to drive, freeing up spaces 
for residents commuting from afar. However, two commuters present case studies of how limited parking perhaps ironically increases VMT. Jonathon Peacock lives near a BART station that fills by 7:40am. He must then drive further to the next station to find parking, or perhaps even drive all the way into San Francisco. Likewise, Jessica Morgan lives near another BART station, but often has to drive past several other BART stations to find a spot (Phillips, 2016).

These drivers, and many others, will simply keep driving until either they find a spot or they give up on BART and drive all the way to work. Providing TOD will help solve the issue, but providing additional parking will help solve the increased VMT resulting from commuters having to bypass close stations for farther stations with open spots. Ultimately, a radical change in urban planning practices will be necessary to create widespread reductions in VMT, but short of that, additional park and ride capacity will help.

4.1.5.7 Partnering with Rideshare Mobile Applications, an Alternative to More Parking Capacity

Summit, New Jersey, a suburb of New York City, is trying a $21^{\text {st }}$ Century solution to the ages-old last mile challenge. By partnering with Uber to offer reduced or even free trips to the town's NJ Transit train station, the city is saving millions of dollars on expanding parking capacity (Hawkins, 2016). BART could make similar use of ridesharing applications to increase utilization of its stations without the need for expensive parking garages. Like the residents of Summit, BART riders might be spurred by cheap fares to and from the station, especially when considered as a replacement for paying for a parking permit or split as a carpool.

AC Transit and WestCAT Lynx could also make use of the program to funnel riders to transbay bus nodes, especially given that the bus services largely operate without the aid of parkand-ride lots. A key bus stop without an attached lot could suddenly become an important part of the network as rideshare app users begin to flock to it using the incentive program.

The program could be coupled with the Clipper fare-card system to further integrate into the existing network. This could also prohibit users from cheating the system by taking a subsidized 
fare to a centrally located transit node, then walking to a local destination rather than getting on transit as intended.

One hazard to keep in mind is the volatile nature of mobile application companies. Uber's financial reports indicate recent losses upwards of \$2 billion per year (Smith, 2016). This is most likely related to a tactic to squeeze out competition with low prices and driver incentives, but could pose long-term problems for an agency relying on Uber if the tactic fails to pan out and the company shuts down.

\subsubsection{Strategy 6: Partner with Developers of Ridesharing Mobile Applications}

MTC's presentation lastly recommends improving on-demand shared mobility through partnering with rideshare mobile application ("app") companies. This ranges from a “jitney/minibus" service where private operators pick up groups of commuters from predetermined locations using vans or minibuses, to simply coordinating casual carpools among private drivers and riders. A series of apps for these services already exist, and are prime for coupling into a publicprivate partnership (PPP).

\subsubsection{Vanpool/Minibus Apps}

The first category involves apps where the commute vehicle is owned by the app developers, including RidePal, Bridj, MagicBus, and Chariot. These companies operate vans and minibuses along fixed routes in select cities for prices competitive with public transit on schedules oriented towards demand. An example is shown in Figure 4.16.

As private operators, these companies realize many operating advantages over transit. One advantage is less administrative oversight, as the operators only answer to their own corporate office and not a pyramid of public agencies and other stakeholders. They also have more flexibility in schedule modifications to suit fluctuating demand, as they can add and cull routes without public input. Perhaps most of all, they enjoy an absence of rules that can constrict public operators, such as the environmental review process that slows down service expansion, public review process that slows down service modifications, and many federal regulations. For example, FTA's Charter Bus 
Service regulation prohibits transit agencies from providing charter bus service in most instances (Federal Transit Administration, 2016). However, private companies are free to provide contracted services in addition to public services, and they do. For example, Chariot provides private commute services for companies such as Virgin America, Glassdoor, and Whole Foods (Chariot, 2016b). By partnering with specific companies, a private operator helps take cars off the road with very specifically targeted routes to and from that company at times integrated with the company's schedule.

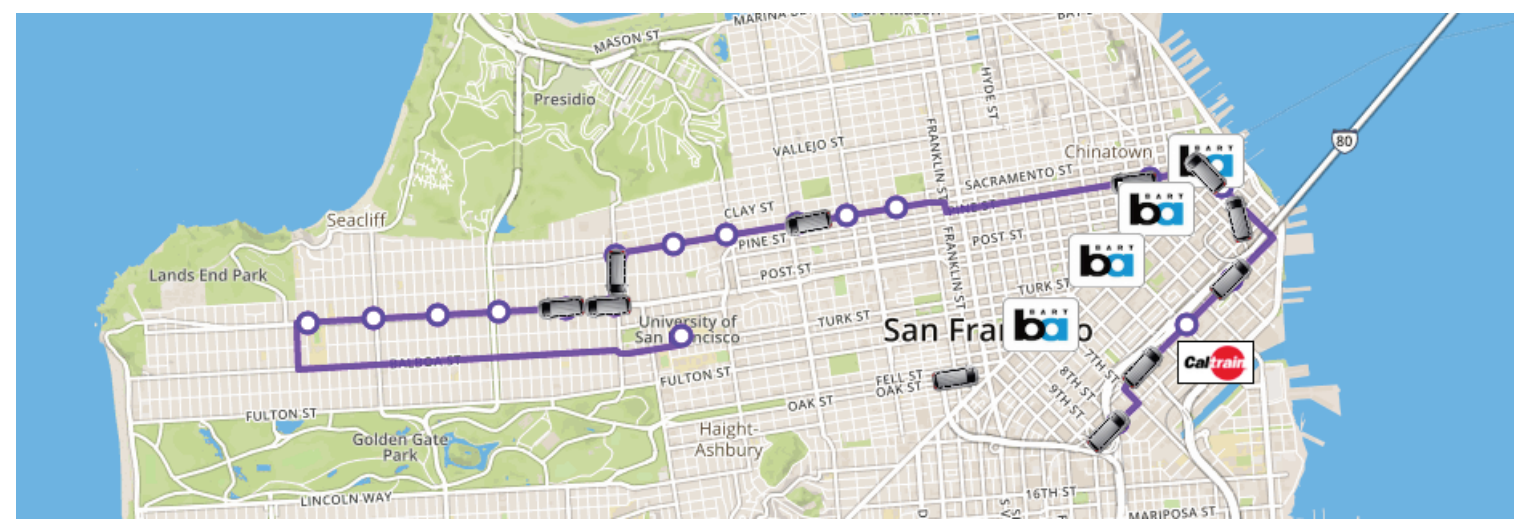

Figure 4.16: Chariot's Richmond Racer Route (Chariot, 2016a)

However, private operators do have some disadvantages. Primarily, they do not receive the recognition that public operators do. For example, a tourist or new resident of San Francisco knows there is a public transport system and quickly learns about Muni and BART services. However, learning about private operators takes much longer since most operate in only one or two select markets. Additionally, public transit providers have marked stops, integrated transit maps, and so on, whereas private operators most often use unmarked stops, and maps and schedules that do not promote connections to other modes. Lastly, the sluggish process to modify routes that hinders public transit agencies assures route consistency over time, whereas private operators could simply disappear overnight, stranding workers who organized their commute patterns around the service. 
Through a PPP, these companies could bolster their services to include commutes from underserved East Bay locations to underserved Peninsula locations. For example, all transbay bus services across the bridge terminate at the Transbay Terminal for economy of scale purposes, but a vanpool route would have more flexibility to terminate at other locations in San Francisco. This could attract riders who forgo public transit due to the lack of direct connections. A PPP also legitimizes a private enterprise and ensures stability, which increases the appeal as riders know the service will still be there tomorrow. It would also allow the private operators to utilize public transit infrastructure, such as bus queue jumps, stations, or ITS technologies. In brief, public partnering with private vanpool/minibus operators can help fill holes left by public transit with flexible and dynamic service.

\subsubsection{Casual Carpool Apps}

The second category of mobile carpool applications involve apps where the driver uses their own car and is a free agent to drive only when he or she desires. These apps include Via, Scoop, uberPOOL, and Waze Carpool. These operate similarly to the vanpool/minibus apps, but are even more dynamic. They enjoy the most flexibility and responsiveness to fluctuating demands, but are also typically more expensive to use. A PPP with these apps would mostly promote the rate of carpooling, and so is prime for coupling with other carpool incentives, such as queue jumps, express lanes, reduced tolls, and other dedicated infrastructure. These apps have a huge potential to secure riders who forgo public transit for any number of reasons, from lack of availability to concerns over cleanliness, other users, and so on.

Any PPP with a casual carpool app will need to be certain that the partnership is promoting high occupancy rates. If a commuter is forgoing driving alone to be chauffeured alone by a rideshare operator, then there will be no improvement in operations. In fact, operations may worsen as the rideshare driver doubles back to pick up another fare. To avoid this, incentives to increase occupancy past the first passenger will be critical. 


\subsubsection{Strategy 7: Enhanced Casual Carpooling}

As outlined in the literature review, Kalon Kelley proposes an interesting way to incentivize casual carpooling. This involves creating a program that distributes RFID beacons to passengers and drivers, with incentives for both carpooling in places without $\mathrm{HOV}$ infrastructure and for filling up with more passengers than the minimum required to access said HOV infrastructure.

Due to the proliferation of phones capable of Bluetooth connections since Kelley's paper, perhaps an enhanced casual carpool system could make use of Bluetooth instead of RFID. Only the driver would need a receiver that could identify Bluetooth-enabled phones in the vehicle, and then use RFID to transmit passenger information to overhead gantries using existing hardware. This could be taken a step further, by being paired with a mobile application that allows rating systems, rideshare requests, payment reimbursement, customer support, and so on.

Since casual carpooling is unregulated, an unofficial set of "guidelines" has been developed based on common courtesy (What Are Casual Carpools?, 2016; SF Casual Carpool, 2015). These include observing safe practices, minding music and food or drink, and splitting tolls. However, one troubling piece of advice offered is "to form as many carpools as possible" (What Are Casual Carpools?, 2016). The idea being that since a vehicle only needs three occupants to use HOV facilities and pay HOV fares, that casual carpoolers should strive to limit themselves to three per vehicle to maximize the number of carpools that can get through. However, this defeats the spirit of carpooling, which is to take as many cars off the road as possible by increasing the occupancy rate of the remaining vehicles. If there are six people waiting and a driver in an SUV pulls up, why shouldn't they all pile into that one vehicle? If it creates a shortage for the next driver that comes along, then that driver should switch to riding.

Using an enhanced casual carpool system will maximize occupancy per vehicle by reducing rates even further the more a vehicle is filled. It would also couple well with a VMT tax, as that tax would be split more ways the more occupants are in a vehicle. A rebate system could 
even be established to refund VMT taxes for miles driven with a full car. Additionally, through associating a smartphone app with occupancy, it will be harder to cheat. This is because potential cheaters would have to have an entire extra smartphone with the app, or go out of their way to purchase an extra fob. Some might, but the majority would be deterred by the extra expense or effort.

The system could also be integrated with existing apps, such as the aforementioned Via, Scoop, uberPOOL, and Waze Carpool. If one of these systems is tracking a carpool heading towards a toll gantry, the system could automatically apply the same toll rate alterations as towards enhanced casual carpoolers.

Another advantage of the system is that while it could most immediately apply to the Bay Bridge Toll Plaza, it could be expanded to include tolls elsewhere, such as onramps, downtown cordons, express lanes, and so on. This could lead to increased occupancy not just on the Bay Bridge, but elsewhere in the Bay Area. While the Bay Bridge has an average occupancy rate of 1.54 persons per vehicle, the Bay Area as a whole has an occupancy rate of only 1.08 persons per vehicle (U.S. Census Bureau, 2014). As Table 4.5 demonstrates, while almost one out of six of commuters carpooled, most of those were marginally better than driving alone, at 2 persons per car. Only $2.7 \%$ of Bay Area commuters made better use of capacity at three or more persons per car, for a total occupancy rate of 1.08 persons per vehicle.

One major pitfall of the enhanced casual carpool idea is penetration. Forcing casual carpoolers to adopt this app might cause resentment, or even lower carpool rates as potential carpoolers become discouraged by the unfamiliar technology. FasTrak faces a similar problem, as evidenced by the $25 \%$ of Bay Bridge users that stick to paying by cash (Caltrans, 2015b). 
Table 4.5: Breakdown of Bay Area Commuters by Mode*

\begin{tabular}{|l|c|}
\hline \multicolumn{1}{|c|}{ Mode } & Percentage \\
\hline Car, truck, or van & $68.5 \%$ \\
\hline Drove alone & $59.0 \%$ \\
\hline Carpooled & $9.6 \%$ \\
\hline In 2-person carpool & $6.8 \%$ \\
\hline In 3-person carpool & $1.7 \%$ \\
\hline In 4-or-more person carpool & $1.0 \%$ \\
\hline Workers per car, truck, or van & 1.08 \\
\hline Public Transportation (excluding taxicab) & $17.2 \%$ \\
\hline Walked & $4.4 \%$ \\
\hline Bicycle & $2.0 \%$ \\
\hline Taxicab, motorcycle, or other means & $1.7 \%$ \\
\hline Worked at home & $6.1 \%$ \\
\hline
\end{tabular}

* (U.S. Census Bureau, 2014)

\subsubsection{Strategy 8: Shifting Attitudes on Carpooling}

Wang and Chen's study, outlined in the literature review, provides stark evidence that most carpoolers do so without need for incentive. In other words, high occupancy vehicles are so for factors other than HOV incentives. Providing HOV infrastructure or toll reductions in areas without either have been shown to only increase the rate of carpooling by less than $1 \%$ (Wang \& Chen, 2012). Instead, lone drivers in the study switched to carpooling due to attitudinal factors (e.g. being swayed by the environmental benefits of carpooling), whereas carpoolers switched to lone driving due to structural factors (e.g. increased availability of personal vehicles). Of additional note, carpoolers in the study who switched to driving alone perceived carpooling as being harder to achieve after switching than when they were actively carpooling, suggesting a cognitive dissonance for justifying the switch.

Pursuant to this research, perhaps a cultural shift would yield better results than additional HOV infrastructure. Many people nowadays seem concerned for the environment and the impact left on future generations, though perhaps the connection between vehicle occupancy rates and environmentalism is not as clear as it could be. An advertisement campaign similar to Flex Alert 
(power conservation) and Don't Trash California (litter prevention) could help shift attitudes and increase carpooling rates.

These public awareness programs have proven to be effective at getting the public-at-large to adopt more environmentally friendly habits. Flex Alert has been shown to decrease energy usage by $1000 \mathrm{MW}$ statewide, the equivalent to around two large power plants or a million households (Flex Alert, 2013). Don't Trash California has been declared a success as well based on trash reductions and public perception changes on what constitutes litter, the harm of litter, and the acceptableness of littering (County of Los Angeles, 2005). By promoting carpooling in a similar manner, a lone driver's sense of morality towards the environment and future generations can be invoked to increase the likelihood of that driver switching to carpooling.

The Flex Alert program cost $\$ 10$ million per year in 2013 and 2014, and \$11 million in 2016 (Edson, 2013, p. 5; California Independent System Operator Corporation, 2016). Comparatively, adding $1000 \mathrm{MW}$ of capacity is estimated to cost $\$ 965$ million for natural gas or $\$ 3,705$ million for solar photovoltaic (U.S. Energy Information Administration, 2016). And that is just to build the plants, never mind the operational costs for labor, maintenance, overhead, and fuel (for natural gas). Similarly, promoting carpooling through attitude changes rather than hardscape changes has the potential to aid traffic at a fraction of the cost.

\subsubsection{Strategy 9: Increased Enforcement}

Many of the other HOV facilities are under-enforced in the Bay Area. Even the Bay Bridge Toll Plaza, perhaps the most enforced facility in the region, reports a $13.5 \%$ HOV violation rate (Caltrans, 2012, p. 24). This disincentivizes carpooling, as users do not feel pressured into only using HOV facilities if they meet the requirements, as well as degrading HOV operations and thus reducing the attractiveness of qualifying to use the HOV facilities. This is especially the case in San Francisco, where drivers fill all onramp lanes during peak hours, regardless of HOV or general purpose designation. Seeing solo drivers using HOV infrastructure leads to resentment among lawabiding drivers, and it isn't hard to see how this would then increase the violation rate. After all, if 
everyone else is doing it, then what is the point of sticking to the slow lanes? Drivers who feel like they can cheat the system will no longer feel pressured to organize carpools or stop for casual carpoolers, reducing the efficiency of the system.

To fix this, increased enforcement will help ensure that violations are kept to a minimum. The Los Angeles Metro reports that the simple presence of California Highway Patrol (CHP) units reduces the HOV violation rate from $24 \%$ to $11 \%$ (Lazarus, 2014). Perhaps stationing CHP units near HOV facilities would help reduce violation rates in the Bay Area as well.

Another idea for reducing the violation rate comes from the Washington State Department of Transportation (WSDOT). They devised a program where drivers could call a hotline and report the license plates of HOV violators. However, instead of dealing with the questionable legality of tying enforcement into citizen reports, WSDOT simply sends educational materials to the address on file for the HOV violator's license plate. If the report was mistaken, then there is no harm and no foul to the falsely accused driver. However, if the driver was in fact cheating the system then this gives him or her a wake-up call that others are noticing. A psychologist could speculate if the materials actually guilt the offender into reforming or if it is simply shame from being caught, but WSDOT reports that most violators stop cheating the system after receiving the educational materials. The violation rate in the Puget Sound area of Washington averages less than five percent, compared to the national average of ten to fifteen percent (Washington State Department of Transportation, 2016).

Similar to appealing to psychology to increase the rate of carpooling mentioned before, perhaps this type of psychological strategy could help curtail the violation rate by altering mentalities rather than just behaviors. After all, for some commuters the risk of getting caught and fined is simply seen as an "opportunity cost." One driver in the DC metro area said that she would receive dirty looks from the other drivers, but she simply didn't care (Weiss, 2009). By getting these violators to care, the violation rate can be reduced and the HOV infrastructure allowed to operate as intended. 


\subsubsection{Strategy 10: Electronic Tolling at the Bay Bridge Toll Plaza}

As mentioned in the previous section, all electronic tolling has already been implemented on the Golden Gate Bridge to much success. The basic premise is to replace cash booths with cameras that snap a picture of passing license plates and sends the registered owner of the car a bill for the toll. FasTrak toll tags would work as they presently do. This would speed up the toll process and eliminate delays related to the toll collection process, since drivers would no longer need to make a cash transaction. With open road tolling, there would also be no need to slow down, further reducing delay.

\subsubsection{Golden Gate Bridge Toll Plaza Conversion Case Study}

For the Golden Gate Bridge, converting the existing toll booths to all electronic tolling cost $\$ 3,237,000$ (Dick, Wire, Witt, \& Mulligan, 2011, p. 1). This included strategic development, design, construction, software, testing, and project management. The estimated savings are $\$ 19.2$ million over the first ten years of service (Dick, Wire, Witt, \& Mulligan, 2011, p. 4). These savings come from a roughly three-quarters reduction in personnel costs, even against a doubling in transaction costs, as outlined in Appendix F.

Converting the toll booths to all electronic tolling is not the end of the story, however. This project still left the toll booths in place, which combined with the movable barrier on the Golden Gate Bridge has led to an uptick in crashes into the toll booth structure. Speeds on the bridge increased from an average of $35 \mathrm{MPH}$ to $50 \mathrm{MPH}$ upon installation of the barrier in January of 2015, resulting in an increase in the number of booth strikes from less than 10 in 2014, to 84 in 2015 (Rodriguez, 2016). Each strike costs from $\$ 7,000$ to $\$ 10,000$ to replace the one-time-use attenuators ("crash buffers"), meaning the increase in crashes is potentially draining $\$ 840,000$ annually from the estimated savings. Additionally, each crash takes out a lane or two and can cause traffic to back up for hours. Replacing the toll booths with an overhead gantry that would toll drivers while enabling them to maintain freeway speeds is estimated to cost between $\$ 4$ million and $\$ 5$ million. 
Another important facet from the Golden Gate Bridge conversion is how their board of directors handled the transition for toll-taking staff. The approach sought to soften the loss of these union jobs through a variety of incentive and retraining programs, including career counseling, internal hiring, tuition stipends, and extensive severance pay (The International Bridge, Tunnel and Turnpike Association, 2014). Perhaps most importantly, the transition was announced early and progressed over three years, ensuring toll collectors had plenty of time to plan for the conversion.

\subsubsection{Relevance to Bay Bridge Toll Plaza Conversion}

To be conservative, using the $\$ 5$ million cost figure for replacing four lanes of mainline capacity's worth of toll booths with overhead gantries comes out to $\$ 1.25$ million per lane of mainline capacity. At the Bay Bridge Toll Plaza there are five lanes of mainline capacity, which would cost $\$ 6.25$ million at the Golden Gate Bridge rates. In terms of savings, using the same analysis yields a savings of $\$ 4.8$ million per lane of mainline capacity. For the Bay Bridge, this translates to $\$ 24$ million of savings.

For additional operational advantages, this proposal should be combined with upcoming Section 4.2.2 to create a bidirectional all electronic toll facility. Even though there would not be a toll plaza to remove on the eastbound side, it would be conservative to maintain the $\$ 1.25$ million cost estimate per lane of mainline capacity. Since the eastbound direction is not tolled currently, there would be no additional savings realized. This creates a total estimated cost of $\$ 12.5$ million and a total estimated savings of $\$ 24$ million, for a net savings of $\$ 11.5$ million over ten years.

One concern with this measure is that increasing the capacity of the toll plaza will not increase capacity at the Bay Bridge. Without the plaza, there are still approximately eleven westbound lanes of incoming traffic that must merge into five lanes on the bridge. For instance, Figure 4.17 depicts the facility at peak congestion, where the toll plaza is operating more efficiently than the bridge, leading to queue spillback from the bridge downstream through the toll plaza. Eliminating the plaza would not improve flow during this time period. 


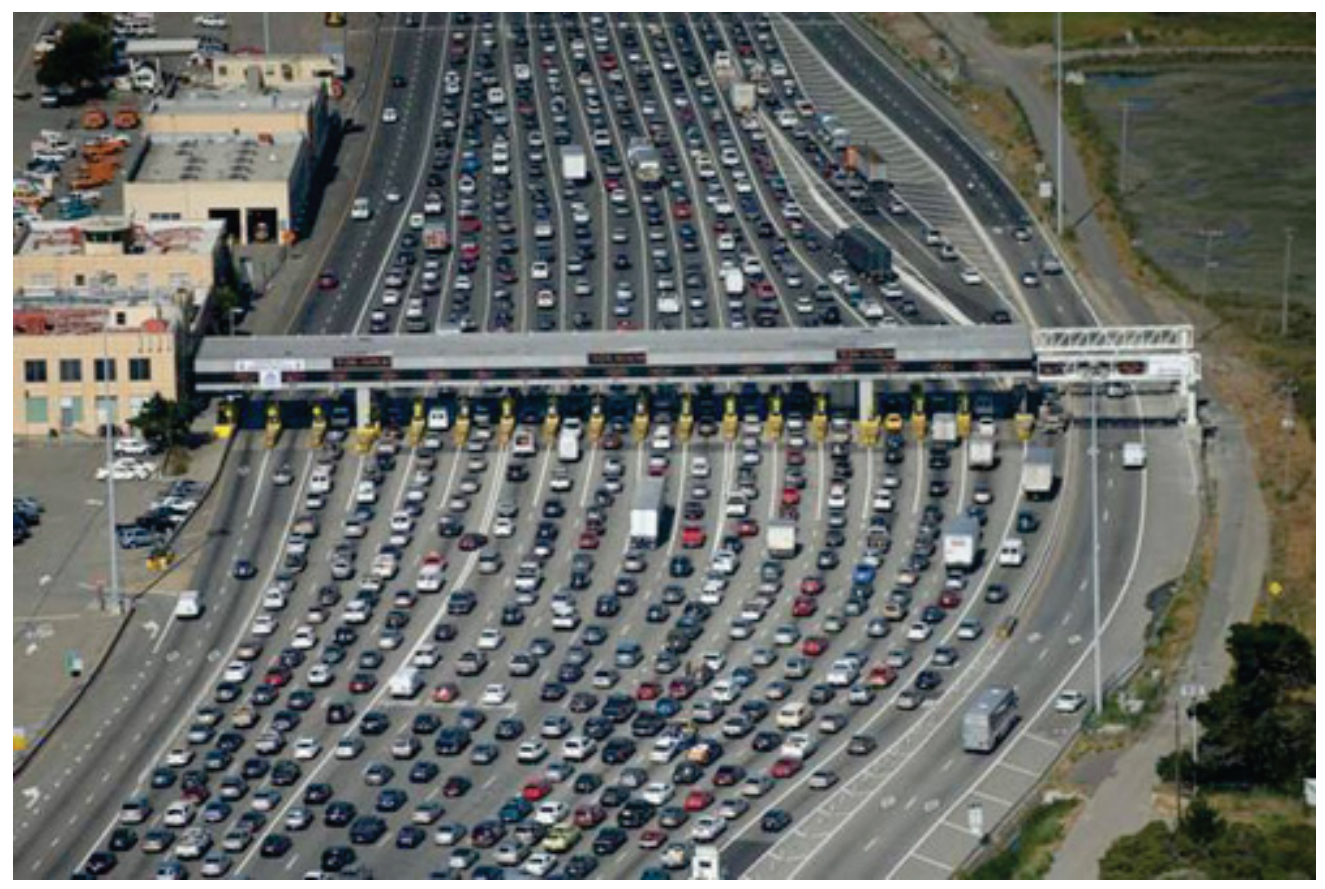

Figure 4.17: Bay Bridge Toll Plaza Congestion (Federal Highway Administration, 2011)

One other consideration is that the HOV lanes are free flowing even during the most congested hours, as seen in Figure 4.19 above on either side of the toll plaza. If the toll plaza was removed and the bottleneck shifted to the neck of the bridge where all incoming lanes merge down to the five that cross the bridge, then the design would need to ensure that the HOV lanes extend past this chokepoint. This will allow buses and HOVs to continue receiving queue-jump benefits post-conversion, although at the expense of non-HOV operations.

Lastly, any such transition to all-electronic tolling will need to keep in mind the human element - the toll collectors. Like with the Golden Gate Bridge, special care will need to be taken to ensure that employees are provided for to the best possible extent.

\subsubsection{Strategy 11: BART Capacity Increases}

As the most used mode during the peak hours, BART serves as an integral part of the Transbay corridor. By increasing capacity on BART, more users will elect to take the train over driving on the bridge. This can be done by either simply allowing more people on the train, or 
reducing overcrowding and raising comfort. Increasing capacity can be done in two primary ways: improving train capacity and improving station capacity.

\subsubsection{Improving Train Capacity}

BART can run a maximum train length of ten cars, but many trains run with less due to maintenance requirements, even during peak hours. During the 8:00-8:59am peak hour, 22 westbound trains arrived at the Embarcadero station. Of these, only eight had ten cars. Thirteen had only nine cars, and one had just eight cars. During the 5:15-6:14pm peak hour, 21 eastbound trains departed the Embarcadero station. Of these, only seven had ten cars. Again, thirteen had only nine cars, and one had just eight cars. By increasing all trains to ten cars, an additional fifteen cars in each direction can be serviced during their respective peak hour. This represents an increase in capacity of $7.3 \%$ for the westbound peak hour and $7.7 \%$ for the eastbound peak hour without needing to squeeze in any additional trains. This translates to an increase in seat capacity of 1050 persons, or crush capacity of 3000 persons for each direction. For comparison, the Bay Bridge carries around 3,270 westbound private vehicle users per lane during the 8:00-8:59am peak hour, and around 2,530 eastbound private vehicle users per lane during the 5:15-6:14pm peak hour. Therefore, simply maximizing the length of each existing train is roughly equivalent to adding an additional lane to the bridge in terms of capacity.

BART has ordered a new fleet of trains that will be added to the rolling stock to increase the length of all trains. Currently, BART operates 669 train cars, which will be increased to 905 train cars in 2018 as the new cars arrive and the old cars are slowly phased out. Eventually, the entire existing fleet will be replaced and BART will assume a total of 1,081 train cars (BART, 2016c). This will allow BART to run longer trains that can carry more riders, increasing the comfort and attraction of the service. 


\subsubsection{Improving Station Capacity}

However, train capacity is only part of the equation; perhaps equally important is station capacity. Many BART platforms are narrow with narrow stairs and escalators. If widened, not only could more people fit on the platform, but they could fit more comfortably too.

As outlined in Appendix G, BART is planning to add saddlebags to the Embarcadero and Montgomery Street stations, the two most crowded stations in the system. This will enable passengers to board on one side and exit on the other, creating a sense of flow and increasing capacity. As it stands, passengers must enter and exit trains on the same side, leading to directional conflict. Additionally, the queues for westbound and eastbound trains cross the platform during peak hours, leading to a maze of riders and uncomfortable conditions. Figure 4.18 shows the overcrowding at the Embarcadero station during peak commute hours.

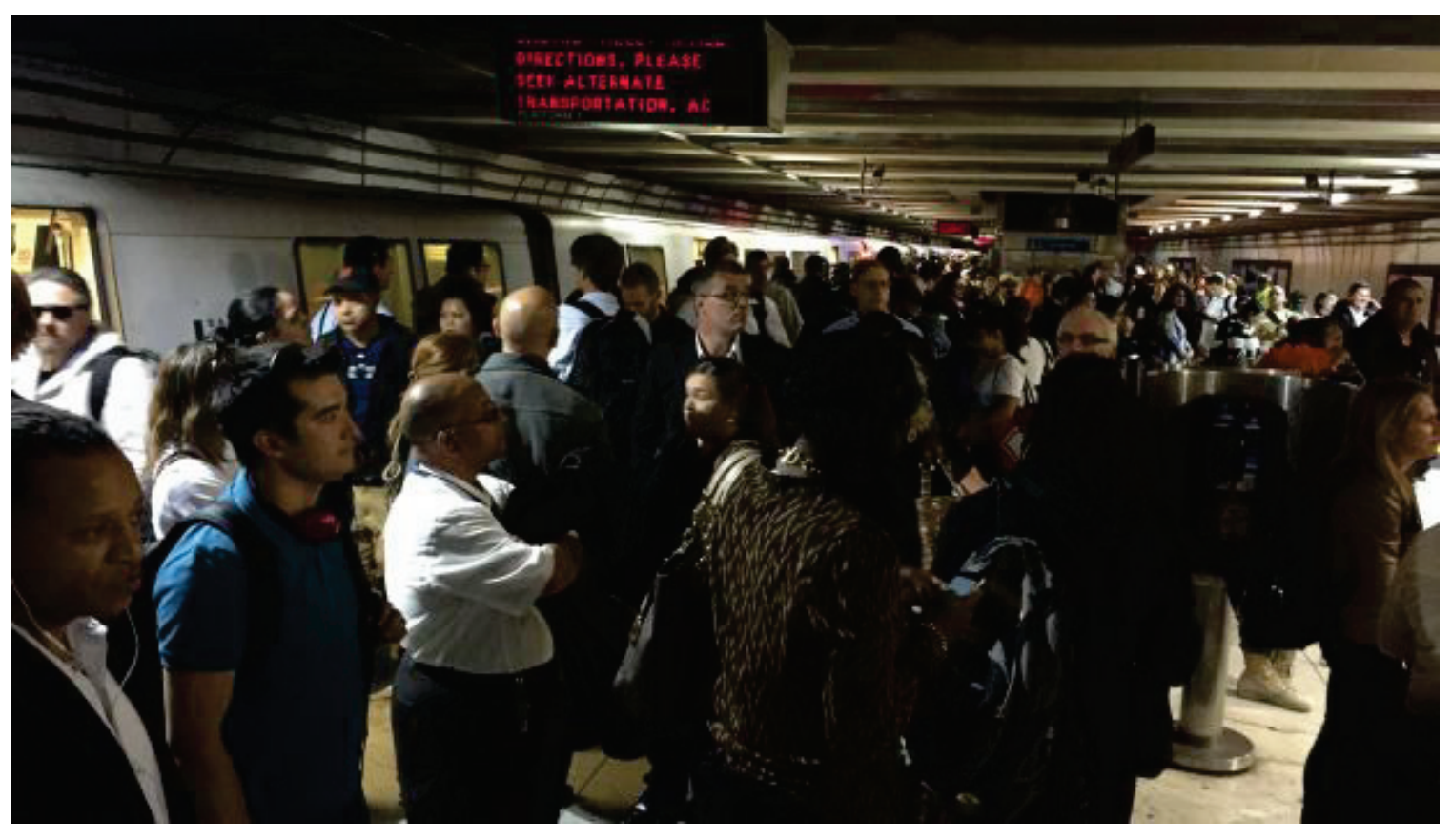

Figure 4.18: Platform Overcrowding Plagues BART During Peak Hours (Jones, 2016) 
Adding platform-side doors could further reduce discomfort from the wind and noise of passing trains. It will also improve safety by preventing riders from accessing the tracks, either for suicidal or accidental reasons. Since the mainline is only two tracks, one for each direction, a medical emergency such as a passenger on the tracks snarls BART service for hours on end and strands many riders. The main problem with this idea is that BART is acquiring new trains with three doors rather than two. The positioning of these doors do not exactly match the existing trains, presenting problems for platform-side doors. Once BART has fully transitioned to the new trains, however, platform-side doors should be implemented to increase comfort and safety, and ultimately ridership.

\subsubsection{Strategy 12: Altered BART Service}

Presently, BART trains stop at all stations along an entire route. This means that the busiest stations see as many trains as far-less busy stations. From one end of the line to the other, a train will stop at every station during every part of the day. This means that the North Concord station's 2,800 daily riders receives the same level of service as the Pleasant Hill station's 7,700 riders (BART, 2016d). On the mainline, West Oakland (7,400 daily riders) receives the same service as

the Embarcadero $(49,300)$ riders. This vast difference in use can be better catered by altering BART's current service patterns, through introduction of skip-stop "metro" service, and express trains.

$$
\text { 4.1.12.1 Skip-Stop "Metro" Service }
$$

By switching to a skip-stop schedule, trains schedules would be modified to promote more trains between busy stations, and faster trains from the suburbs to downtown cores. This service would improve BART service and increase ridership, potentially decreasing congestion on the Bay Bridge.

For example, Montgomery and Embarcadero in San Francisco both have over 46,800 entries per day, and $12^{\text {th }}$ St and $19^{\text {th }}$ St in Oakland both have over 13,800 entries per day, whereas West Oakland only serves 7,400 entries per day (BART, 2016d). Despite this, every train that stops 
in San Francisco also stops at West Oakland, as do two-thirds of trains coming from downtown Oakland (the other third heads south to Fremont rather than west to San Francisco). Allowing every other train (or more) to skip West Oakland will improve capacity by reducing the amount of time trains spend decelerating into the station, boarding, and accelerating again.

Expanding this idea to other stations, skip-stop service outside of the San FranciscoOakland urban core will allow passengers to access the downtown areas much more quickly, improving attraction and ridership. Skip-stop service within the urban core will improve capacity, as two adjacent trains can use two adjacent stations as one block. For example, a train at $12^{\text {th }}$ Street in Oakland and another at $19^{\text {th }}$ Street in Oakland can then pass West Oakland and simultaneously proceed into San Francisco to the Montgomery Street and Embarcadero stations, respectively. In other words, one train will proceed straight from $12^{\text {th }}$ Street to Montgomery Street, while the other proceeds straight from $19^{\text {th }}$ Street to the Embarcadero. Since these trains will operate concurrently, they will not fight each other for headway. As it stands with each train stopping at each station, the first one to arrive at the Embarcadero might encounter boarding delays, causing the second one to be stuck in the tube. Skip-stop service will reduce the compounding effect this has that leads to terrible systematic delays.

The main advantage of skip-stop service is splitting BART into two service groups (urban core and suburban express) that specifically caters to each market. The urban core gets more frequent service, and the suburbs get faster trains. However, the main disadvantage is the cost. In order to properly implement skip-stop service, new tracks will need to be constructed to allow express trains to bypass local trains. Appendix H features MTC's research into skip-stop service for BART.

\subsubsection{Express Service}

Less extreme than the skip-stop proposal, but still with great reductions in travel time, is implementing express service that takes advantage of existing headway patterns to squeeze in faster 
trains. This could be used either as a supplement to skip-stop "metro" service to better define the suburb express trains, or outright replace the program with a minimally expensive express pattern.

Research from Tang et al. points to the idea that the most economical way to decrease rail transit travel time is not increasing the maximum speed, but rather decrease the instances of reduced speeds (Tang, Dick, \& Caughron, 2016). As in, eliminating a speed-restricted section of track can be far more effective than increasing the maximum speed on the rest of the line. A visual demonstration of this concept is provided in Figure 4.19 below. The top chart shows in orange the time saved by eliminating a slow portion of track, versus the less time saved by increasing the top speed in the bottom chart.

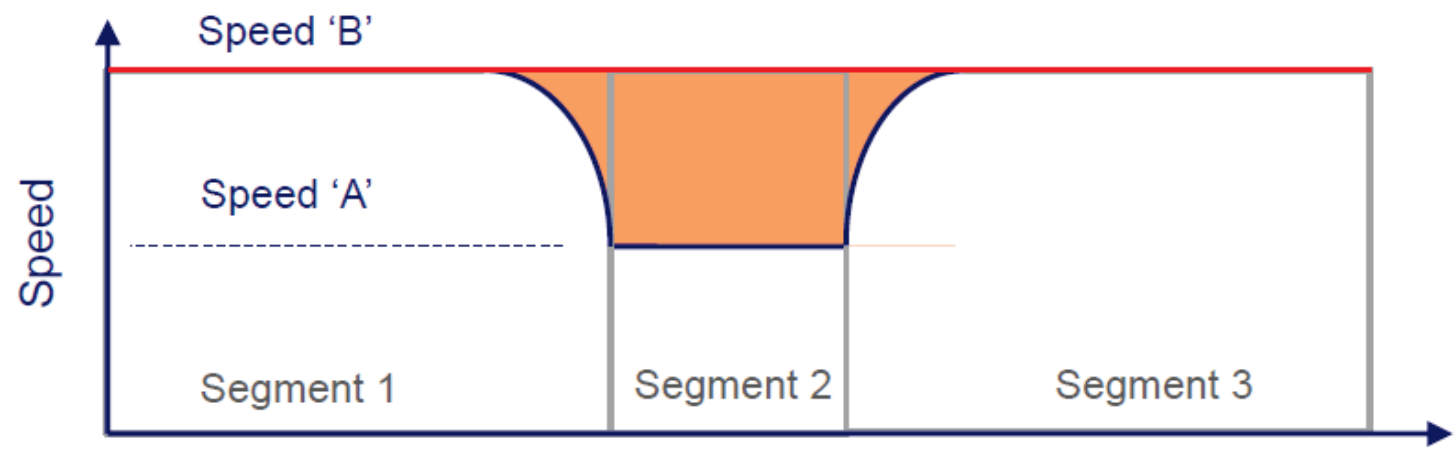

Distance

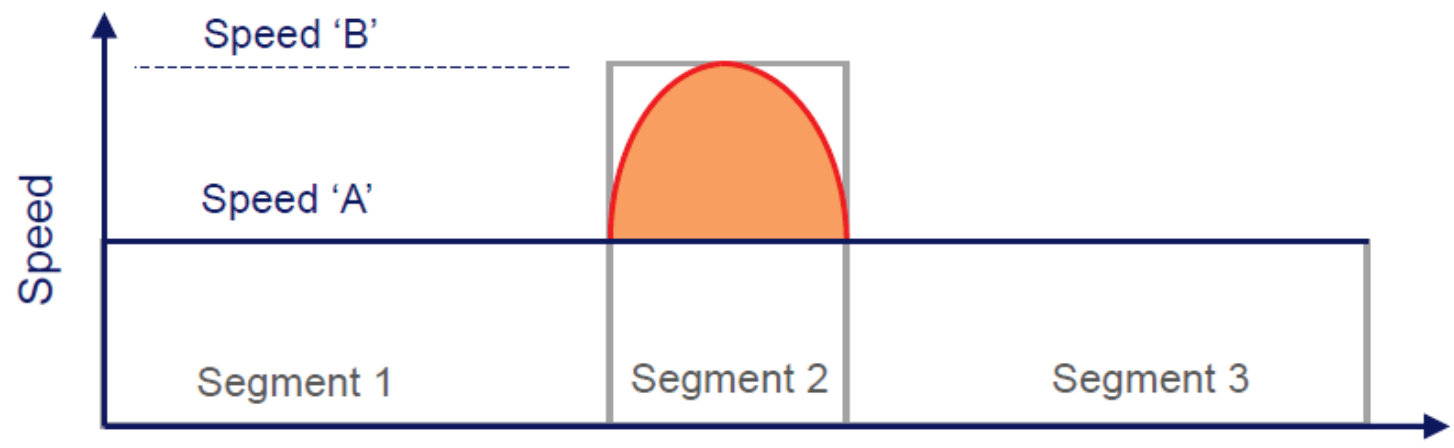

Distance

Figure 4.19: Time Savings from Eliminating Slow Segments (top) versus Increasing Top Speed (bottom) (Tang, Dick, \& Caughron, 2016) 
A surrogate for a slow area of track to improve is an underused station to skip. The Bay Area has its own perfect case study of this idea put to the test: Caltrain's Baby Bullet service. Rather than increase speeds through spending hundreds of millions of dollars on grade separation, straightened track, control systems, and rolling stock capable of faster speeds, Caltrain elected to simply eliminate stations with lower ridership. The Baby Bullet is able to travel between San Francisco and San Jose in an hour, versus the Local's travel time of an hour and a half (Caltrain, 2016). The Baby Bullet and Local services have the same top speed, but by skipping past most stations, the Baby Bullet achieves a one-third reduction in travel time.

BART could implement a similar system to reduce travel times by skipping less-used stations to bring trains in from the suburbs more quickly. By maintaining a top speed, precious minutes could be saved and comfort could even be argued to increase by the reduction in accelerations and decelerations. While the greatest time savings would require altering existing schedules, it would be possible to achieve some travel time reduction by squeezing express trains between the headways of existing trains. An express train leaving right before a local train would bypass less-used stations until it arrived at the end of the express section just after the prior local train. Essentially, the time savings would be equal to the headway between the two local trains minus the headway the express train must maintain with the local trains before and after it. Table 4.6 provides an example of this proposal in action, focusing on the Pittsburg/Bay Point line inbound to the Embarcadero in San Francisco. 
Table 4.6: Express BART Example Schedule

\begin{tabular}{|c|c|c|c|c|c|c|c|c|c|c|c|c|c|c|}
\hline 离 & 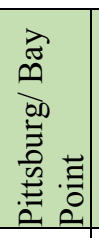 & $\begin{array}{l}\bar{D} \\
0 \\
0 \\
0 \\
0 \\
\tilde{0} \\
\tilde{0} \\
Z \\
Z\end{array}$ & $\begin{array}{l}\overline{0} \\
0 \\
0 \\
0 \\
\end{array}$ & 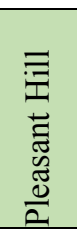 & 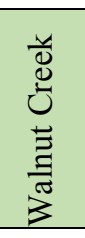 & 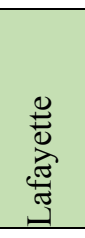 & 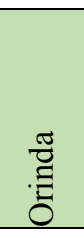 & 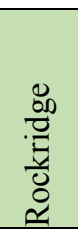 & 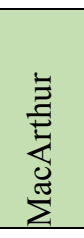 & $\begin{array}{l}\vec{\omega} \\
\vec{\Xi} \\
\stackrel{\vec{\sigma}}{=}\end{array}$ & $\begin{array}{l}\vec{n} \\
\stackrel{ \pm}{ \pm} \\
\text { I }\end{array}$ & 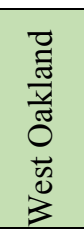 & 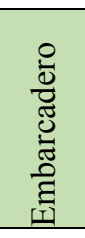 & 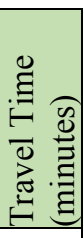 \\
\hline 373 & $8: 47$ & $8: 53$ & $8: 57$ & 9:02 & 9:05 & $9: 10$ & $9: 15$ & 9:20 & $9: 23$ & $9: 27$ & $9: 28$ & $9: 33$ & $9: 40$ & 53 \\
\hline Express & 9:00 & & & $9: 13$ & $9: 16$ & & & & $9: 28$ & & $9: 32$ & & $9: 42$ & 42 \\
\hline 375 & 9:02 & 9:08 & $9: 12$ & $9: 17$ & $9: 20$ & $9: 25$ & $9: 30$ & $9: 35$ & $9: 38$ & $9: 42$ & $9: 43$ & $9: 48$ & $9: 55$ & 53 \\
\hline
\end{tabular}

As can be seen, the express train would shave eleven minutes from the Pittsburg/Bay Point to Embarcadero travel time without affecting the local trains before or after it. However, this is just a demonstration as other lines join this one at the MacArthur and West Oakland stations. These other lines complicate the concept and would require further analysis to circumvent.

\subsection{DEMAND MANAGEMENT}

The second category of strategies for improving operations across the transbay corridor, demand management, contains four strategies that focus on shifting demand away from peak periods. These include tactics focusing on offsetting Bay Bridge vehicular demand to less impacted hours, reducing the need to bring a car to work, and changing the planning landscape of the Bay Area.

\subsubsection{Strategy 13: Congestion Pricing}

Presently, the Bay Bridge does charge more during peak hours and less for HOV. However, this could be taken further with dynamic pricing that reflects actual roadway conditions. As congestion increases, so do prices. This will have two main benefits: prices will better match actual congested conditions rather than a set schedule, and prices can more incrementally change, rather than having a binary congestion/no congestion price scheme. Additionally, the dynamic pricing 
would expand upon the existing carpool discount scheme, by offering further discounts to higher occupancy carpools rather than a flat discount for all vehicles that meet the minimum requirement.

\subsubsection{Congestion Pricing to Offset Demand}

Figure 4.20 features detector occupancy rate data for the months of August and September 2016. The detector occupancy rate measures how often a vehicle is on top of the detector. In freeflow conditions, the occupancy rate is less than 5\%. In standstill traffic, occupancy can reach 40$50 \%$. By measuring detector occupancy on either side of the bridge, the level of congestion can be determined across the day. The westbound loop detectors, located at postmile 7.7, are the last detectors before the toll plaza (Caltrans, 2016g). However, at 2000 feet upstream, they are still far back enough to detect congested conditions. The eastbound loop detectors, located at postmile 2.8, are less ideal as they are about 3000 feet onto the bridge from San Francisco, but there are no loop detectors further west on I-80 that might provide more prudent data (Caltrans, 2016h).

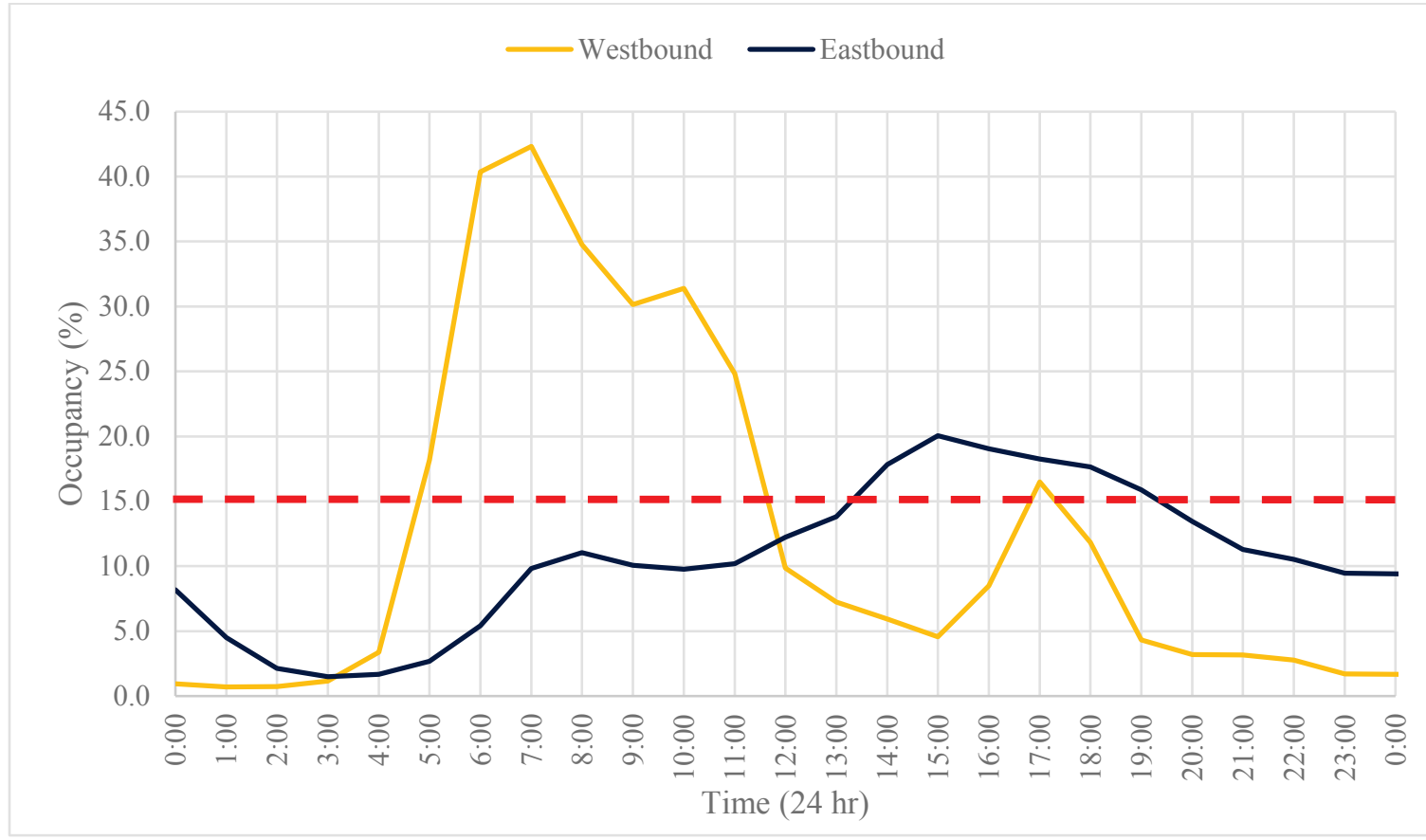

Figure 4.20: Detector Occupancy Rates at the Bay Bridge 
As can be seen, the westbound detector is heavily influenced by the toll plaza, jumping over $40 \%$ for the $6 \mathrm{am}$ and $7 \mathrm{am}$ hours when the plaza is at its peak congestion. On the other hand, the eastbound detector is downstream of the major chokepoint on the peninsula side, where all of the downtown San Francisco traffic crunches onto the bridge, and so reflects smoother conditions. However, eastbound congestion is severe enough that the eastbound detector picks it up, despite being past the downtown chokepoint.

At what point do conditions break down and traffic is officially congested? By inspection, it seems like the data alternates between around $10 \%$ and less during off-peak hours and over $15 \%$ during peak hours. Therefore, a congestion threshold of $15 \%$ was chosen and is represented by the dashed red line. This yields congested westbound hours of $5 \mathrm{am}$ to $11 \mathrm{am}$ and $5 \mathrm{pm}$, and eastbound hours of $2 \mathrm{pm}$ to $7 \mathrm{pm}$. During these hours, the bridge is at capacity not because of the physical constraints on the bridge, but rather because of the chokepoints at either end of the bridge. This would explain why the greatest number of vehicles cross the bridge right at the beginning of the peak periods before the congestion results in excessive queuing and delays, as discussed in Section

\subsection{1 and demonstrated by Figure 3.8.}

Congestion is not simply present or absent, however; some peak hours are worse than others. For example, Figure 4.20 shows that while the westbound direction is congested during the $5 \mathrm{am}$ to $11 \mathrm{am}$ hours, the absolute worst congestion is during the 6am and $7 \mathrm{am}$ hours. Implementing congestion pricing that spikes during these worst-of-the-worst hours could help offset demand to less impacted hours. Additionally, since the evening westbound peak only lasts one hour in terms of congestion (during the $5 \mathrm{pm}$ hour), it should not be too hard to implement congestion pricing to convince drivers to cross during the $4 \mathrm{pm}$ or $6 \mathrm{pm}$ hours instead.

\subsubsection{Congestion Pricing to Increase HOV Occupancy}

At present during carpool hours, HOVs are tolled $\$ 2.50$ versus $\$ 6$ for non-HOVs. HOVs at the toll plaza are defined as motorcycles, low emissions vehicles with appropriate tags, twoperson cars with two persons, and vehicles with at least three persons (FasTrak, 2015). Focusing 
on the last definition, there is no incentive to fill beyond the minimum three persons. As discussed in Section 4.1.7, this creates a counterintuitive etiquette where casual carpool drivers restrict themselves to two passengers in order to leave enough passengers for other drivers.

As discussed in Section 3.1.1, this leads to an occupancy rate of 3.5, barely higher than the minimum of three. Considering nearly 20,000 vehicles pass through the toll plaza daily, increasing the occupancy rate by one person per car would allow 20,000 more commuters through daily without any increases in vehicular demand or roadway capacity. Since on average 44,351 westbound commuters cross the bay during the 8am peak hour, including those in 2,903 HOVs, adding one person per HOV would add 2,903 commuters worth of capacity. This simple addition alone would increase the westbound transbay capacity by $6.5 \%$ during the $8 \mathrm{am}$ peak hour in terms of all mode capacity, and $17.8 \%$ for private vehicle capacity.

This extra person per HOV could be realized by incentivizing drivers to go beyond the minimum three. Rather than a simple $\$ 3.50$ discount on toll fare, a stepped discount could be implemented with greater discounts for higher occupancy. A capacity of five, the maximum for a typical sedan, could receive the ultimate fare discount: no toll whatsoever. This type of discount stepping could also apply to low emissions vehicles, giving more efficient vehicles (such as electric vehicles) greater discounts over less efficient, but still low emissive vehicles (such as hybrids). Two-seaters with two persons would pay the highest discounted fare. This might seem unfair as they are at capacity, but a two-seater takes up as much space and so contributes just as much to congestion as a sedan and so should be weighted accordingly. A motorcycle could pay the most discounted fare, as they consume minimal space and a properly behaved motorcyclist contributes minimally to congestion.

This stepped discount could be controlled either by Bluetooth or RFID technology as described in Section 4.1.7, or through an expansion of the FasTrak Flex program. Currently, FasTrak Flex allows riders to denote whether they have one, two, or three occupants in order to receive discount express lane fares on I-580. Expanding this to include four, five, or more occupants 
and tagging the device to a car size and capacity would allow this technology to be implemented on the Bay Bridge as prescribed in this section.

\subsubsection{Relation of Toll Effectiveness to Parking Fare Rates}

In 1995, 81\% of private vehicle commuters parked for free in San Francisco (Shoup, 2002, p. 3). While that number has certainly decreased since then due to programs such as the San Francisco Commuter Benefits Ordinance of 2009 that requires most employers to incentivize transit and vanpool usage for employees, there are still many places on the peninsula that offer free or very low cost parking to employees (SF Environment, 2009). When parking is free, many commuters consider toll fare to be trivial (A. Fremier, personal communication, September 20, 2016). This is probably a major factor as to why the 2010 Bay Bridge toll hike had no effect on demand (Matier \& Ross, 2014). If congestion pricing is to effect change, then it will need to be assisted by measures to raise the cost of parking.

\subsubsection{Strategy 14: Eastbound Tolling}

At present, there is only a toll to enter the San Francisco peninsula by bridge. Leaving the peninsula avoids all tolls, unless the trip involves another bridge such as the Carquinez Bridge to Solano County and beyond. This reduces the incentive to carpool out of the city or avoid the most congested hours, other than to make use of East Bay HOV lanes and avoid traffic, respectively. Adding on a toll fare element will further discourage people from driving alone and/or during the worst hours. Two methods for accomplishing this include creating a toll cordon around downtown San Francisco, and converting the Bay Bridge Toll Plaza into a bidirectional facility.

\subsubsection{Central Business District Congestion Tolling}

This concept would essentially cordon off downtown San Francisco, with a toll to pass the cordon. Similar to congestion pricing, the tax could be reduced or even lifted during non-peak hours. The San Francisco County Transportation Authority (SFCTA) has taken a look into this

concept (San Francisco County Transportation Authority [SFCTA], 2010a). As part of their research, SFCTA took a look at the systems in London, the United Kingdom, and Stockholm, 
Sweden. London charges a flat $\$ 13$ daily charge to cross the cordon any number of times, and they have seen a 30\% reduction in traffic, \$216 million in toll revenues, and a doubling of downtown speeds for remaining drivers. In Stockholm, drivers are charged $\$ 1.50$ to $\$ 3.00$ per crossing, and the city has seen traffic reduced by $22 \%$ and $\$ 100$ million collected in toll revenues. Both cities report increased commercial sales within the cordon due to increased transit funding as transit riders and pedestrians have been shown to spend more than private vehicle users (SFCTA, 2010b).

SFCTA proposes to implement a similar program in San Francisco, cordoning off the central business district by tolling traffic crossing Laguna Street, $18^{\text {th }}$ Street, and entering/existing US 101, I-80, or I-280 within the cordon. SFCTA has studied several proposals, one of which targets outflows from the cordon. Figure 4.21 maps this proposal. This proposal is most relevant to this thesis, as it would toll eastbound commuters leaving downtown San Francisco, providing a mirror to the toll plaza for westbound commuters. Combining the cordon with congestion pricing and HOV discounts would incentivize commuters to continue carpooling and driving off-peak throughout the day, rather than just for the morning rush.

Several key concerns with any cordon program are covered by SFCTA (SFCTA, n.d.). One such concern is for drivers who need to cross several times per day, such as parents dropping their children off at school or commercial delivery activities. This is allayed by a congestion cap that would limit tolls to a single daily fare for any number of crossings, similar to London's model. Another concern is splitting communities, but that could be rectified by "bubbling" the cordon at key neighborhoods, allowing residents and businesses right on the line to continue living as they are. The overall idea is to disincentivize commuting into downtown San Francisco alone during peak hours, not split the city in two. 


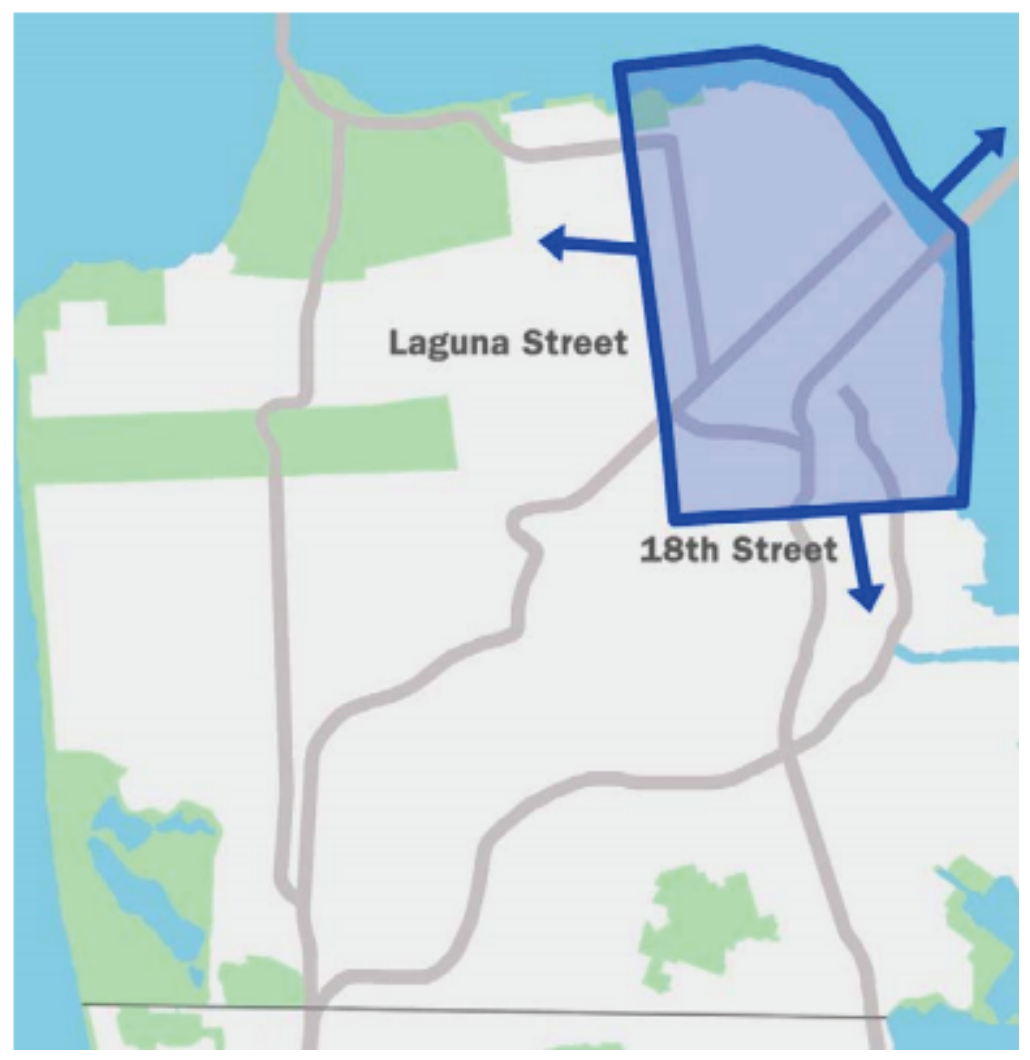

Figure 4.21: SFCTA Proposal for Downtown Outflow Cordon Tolling (SFCTA, 2010a)

\subsubsection{Convert the Bay Bridge Toll Plaza into a Bidirectional Facility}

When the Bay Bridge first opened in 1936, both levels were bidirectional with the upper deck carrying three lanes of cars each way, and the lower deck carrying a lane for buses/trucks each way with a third reversible lane, and two tracks for Key System and inter-urban trains. The toll plaza, too, was originally bidirectional. In 1963, the bridge was converted to drop all rail traffic, integrate buses and trucks with cars, and utilize each level of the bridge for one direction only, and the toll plaza switched to only tolling westbound traffic (Caltrans, 2002). The toll plaza conversion was done for operational purposes, as there was only real estate for enough lanes to toll in one direction with equal capacity to the new configuration on the bridge. Less lanes, and the bridge would be under capacity in the westbound direction as the toll plaza would create a bottleneck. 
In 1974, metering lights were added downstream of the toll plaza to better regulate the merging of traffic from 22 lanes to five (Richards, 2015). The arrival of FasTrak further necessitated these metering lights, as FasTrak-equipped vehicles can speed past the toll plaza without needing to stop, unlike drivers paying with cash. This increased the capacity of the toll plaza, while the bridge remained the same. The metering lights help even out the transition in capacity.

Technology has come even further since then, as the Golden Gate Bridge Highway and Transportation District has proven with their All Electronic Tolling project (Golden Gate Bridge Highway and Transportation District, 2016). While details about this program and its benefits will be covered in the next section, the relevant part to this section is that the toll plaza can handle up to four lanes of incoming traffic with eight lanes through the toll facility. This demonstrates a two-toone ratio for all electronic tolling to mainline capacity.

At the Bay Bridge Toll Plaza, there are 20 westbound and nine eastbound lanes, for 29 total lanes. On the bridge, this is reduced to ten total lanes. For bidirectional tolling at a capacity ratio similar to the Golden Gate Bridge Toll Plaza, the Bay Bridge Toll Plaza will need 20 lanes total, ten in each direction. Since there are currently 29 lanes of width available, this should not be a problem.

The advantage of bidirectional tolling is the same as outflow cordoning of downtown San Francisco, in that it applies the HOV and off-peak incentives of the westbound direction to the eastbound direction. One thing bidirectional tolling does better, though, is that it catches all traffic crossing the bridge, whereas the downtown cordon would not catch traffic originating from outside the cordon and crossing the bridge. While a big component of congestion on the Bay Bridge is from downtown San Francisco, many vehicles originate from elsewhere in the city or further down on the peninsula. 


\subsubsection{Strategy 15: Changing Corporate Cultures}

Office workers are a prime candidate for congestion reduction due to their flexible work conditions. While most white-collar workers are office-based, some are not including teachers, reporters, and members of the clergy. These workers usually have much stricter work environments that are not flexible. For instance, a reporter cannot do a field visit from home, nor can a teacher shift class hours to take advantage of shoulder commute periods. Likewise, blue-collar workers almost by definition must exert intense physical labor, so must stick to schedules outside their control (such as a factory itinerary or daylight hours). Lastly, the schedule of retail workers is essentially set by the shopping public, so altering their commute patterns is no trivial matter. All told, the most flexible employment group are office-based workers, and so they should be the target of efforts to change corporate cultures to reduce congestion.

San Francisco has a sizable office-based workforce due to the large number of financial and technological ("tech") companies present. Financial institutions include PricewaterhouseCoopers, Deloitte, Ernst \& Young, KPMG, Grant Thornton, Wells Fargo, and Charles Schwab. Tech companies include Zynga, Airbnb, Twitter, Uber, Lyft, Fitbit, Digg, Reddit, Chegg, Prezi, Square, and Salesforce. Other industries are present, such as Dolby and Lucasfilm representing the movie industry, Banana Republic, Gap Inc., and Levi Strauss representing the apparel industry, Kaiser Permanente and Dignity Health representing the healthcare industry, and PG\&E and Recology representing the utility industry. On the public side, large employers include the City and County of San Francisco, UC San Francisco, and the San Francisco Unified School District. Some of the largest office-based employers in San Francisco are listed in Table 4.7 below. 
Table 4.7: Large Office-Based Employers in San Francisco

\begin{tabular}{|c|c|}
\hline Company & San Francisco Employees \\
\hline Wells Fargo & 8,200 \\
\hline Gap Inc. & 6,000 \\
\hline Salesforce & 5,780 \\
\hline Twitter Inc. & 2,000 \\
\hline Uber Technologies Inc. & 1,980 \\
\hline Yelp Inc. & 1,717 \\
\hline Google Inc. & 1,500 \\
\hline Lending Club & 1,305 \\
\hline LinkedIn Corp. & 1,250 \\
\hline Lucasfilm Ltd. & 1,200 \\
\hline Autodesk Inc. & 1,200 \\
\hline Adobe Systems Inc. & 1,150 \\
\hline Cisco Systems Inc. & 1,050 \\
\hline Square Inc. & 1,000 \\
\hline
\end{tabular}

(Reyes, 2016; Cooper, 2014)

* Includes both retail and office employees

\subsubsection{Promote Telecommuting}

For many office workers in San Francisco, it is possible to get an entire day of productivity done from home. This is known colloquially as "telecommuting." If a business could be convinced to let their employees perform some work from home, then the number of commutes that business generates will be reduced.

Many businesses oppose work-from-home practices because it is harder to enforce productivity out of the office, and often in-person meetings are necessary to facilitate business operations. Likewise, many employees are not great candidates for conversion to fully telecommuting for these reasons. However, allowing or even encouraging employees to occasionally work from home will reduce commute loads. The companies listed in Table 4.9 above represent over 35,000 workers alone. If every employee was allowed to take one day every two weeks to telecommute, that would reduce the number of commuters from these offices by an average of 3,500 , or $10 \%$, daily (assuming a five day workweek). For comparison, recall from 
Section 4.4.1 that during the westbound all-commute peak hour of 8:00am-8:59am, the Bay Bridge carries 3,270 private vehicle users per lane.

Obviously the situation is more complex than this simple comparison. These newfound telecommuters would not all have commuted during one hour on one mode, but rather spread across the morning peak by a variety of modes. Additionally, many commuters come from the south up the peninsula, from the north across the Golden Gate, or from within San Francisco itself, rather than crossing the Transbay Corridor. Lastly, not all of these office employees would be able to work from home. While they are typically more flexible than other white-collar workers or bluecollar and retail workers as discussed above, there are still many office workers who have to be in the office, such as receptionists and high-level executives. On the other hand, the list covers only fourteen companies, when there are over 116,000 in San Francisco (U.S. Census Bureau, 2016). Additionally, while many public employees have inflexible work demands, there are certainly plenty who can occasionally telecommute among the 25,000 City and County of San Francisco employees, 20,000 UCSF employees, or employees of other public agencies (Cooper, 2014).

In order to increase the rate of telecommuting, the employers themselves will need to be convinced of its benefits other than simply reducing San Francisco's commute load. Simple savings appeals might help, such as emphasizing that work-from-home employees do not contribute to electricity, water, and food bills, nor do they need many IT functions (if the internet is down, that is the employee's problem). Also, two employees can work in the space of one if each works from home half of the time, reducing office real estate needs. However, codification might be necessary to effect real change. One possible avenue is an addendum to the 2009 San Francisco Commuter Benefits Ordinance. Currently, the ordinance prescribes that all businesses in San Francisco with more than 20 employees nationwide must offer direct subsidies or pre-tax deductions for transit or vanpools, or provide transit or vanpool service for employees themselves (SF Environment, 2009). Adding an alternative for telecommuting would bolster the rate of working from home, and thus outright reduce the overall number of commuters. 


\subsubsection{Changing Workplace Car Demands}

Another reason many office employees drive to work because they need to have their car accessible for work activities, such as meeting with clients. These commuters cannot plan to take transit in case they have an impromptu client meeting. Additionally, carpooling with others is avoided because the potential passenger has the same concern. This leads to many client-focused employees to drive themselves for structural reasons that are not affected by promoting transit or carpooling.

In order to reduce the congestion burden of these workers, appealing to the structural inflexibility of why they must drive alone will be necessary. Since the problem is that they must have a car at work, the solution is obviously to provide a car at work. Incentivizing or simply promoting car-sharing programs such as Zipcar or Carma City CarShare will allow these workers to keep their cars at home and either carpool or take transit to work. If they find that they need a car to drive out to a client, they can take a company-sponsored shared car.

Using car-sharing programs can even be competitive. Zipcar bills businesses starting at $\$ 10$ per hour, which includes insurance and gas (Zipcar, 2016). For comparison, the reimbursement rate for driving is $\$ 0.54$ per mile, which includes car depreciation, insurance, gas, and other maintenance expenses (Internal Revenue Service, 2015). At nineteen miles driven per hour, the two break even. Zipcar also offers direct billing service, which can reduce overhead from receipt accounting and paperwork.

Another way to reduce the need to bring personal cars to work is to promote ride-sharing programs (e.g. Uber, Lyft, etc.). These can be competitive if the client meeting is close to the office and potentially lengthy. This is because unlike a personal car or a Zipcar, rideshares do not need to factor in parking costs. Overall, promoting or going as far as incentivizing car-sharing and ridesharing can help office workers who need to drive to clients break free from having to drive to work. 


\subsubsection{Strategy 16: Land-Use Planning Changes}

For the sake of sustainability, before considering cars, transit, or anything else, one must consider land-use planning. Simply put, the best way to reduce commuter congestion is to bring the commuter residences closer to their workplaces. By promoting additional housing in San Francisco, and workplace relocation to the East Bay, entire swaths of Transbay commuters could be eliminated.

MTC realizes this, and includes "distributing total housing growth numbers to... job-rich cities" as a key component of the "Plan Bay Area" regional transportation plan for 2013-2040 (MTC, 2013). The process has already begun, with developments such as housing in the South of Market and Mission Bay districts of San Francisco and office space in the East Bay community of San Ramon (Li, 2016). An advertisement for an apartment community in downtown San Francisco promoting living near work and walking is presented in Figure 4.22.

Another important change in land-use planning is the densification of the neighborhoods near BART and other transit stations. BART has made great inroads with projects such as the MacArthur TOD, but even more will be required to stem the tide of increasing transbay commute demands (MacArthur Station, 2014). Locating offices as well near BART stations outside of San Francisco and downtown Oakland will help reduce peak transbay demands by enabling workers to "reverse commute" out of San Francisco and Oakland to the rest of the East Bay, or avoid the tube altogether by living in the East Bay. 


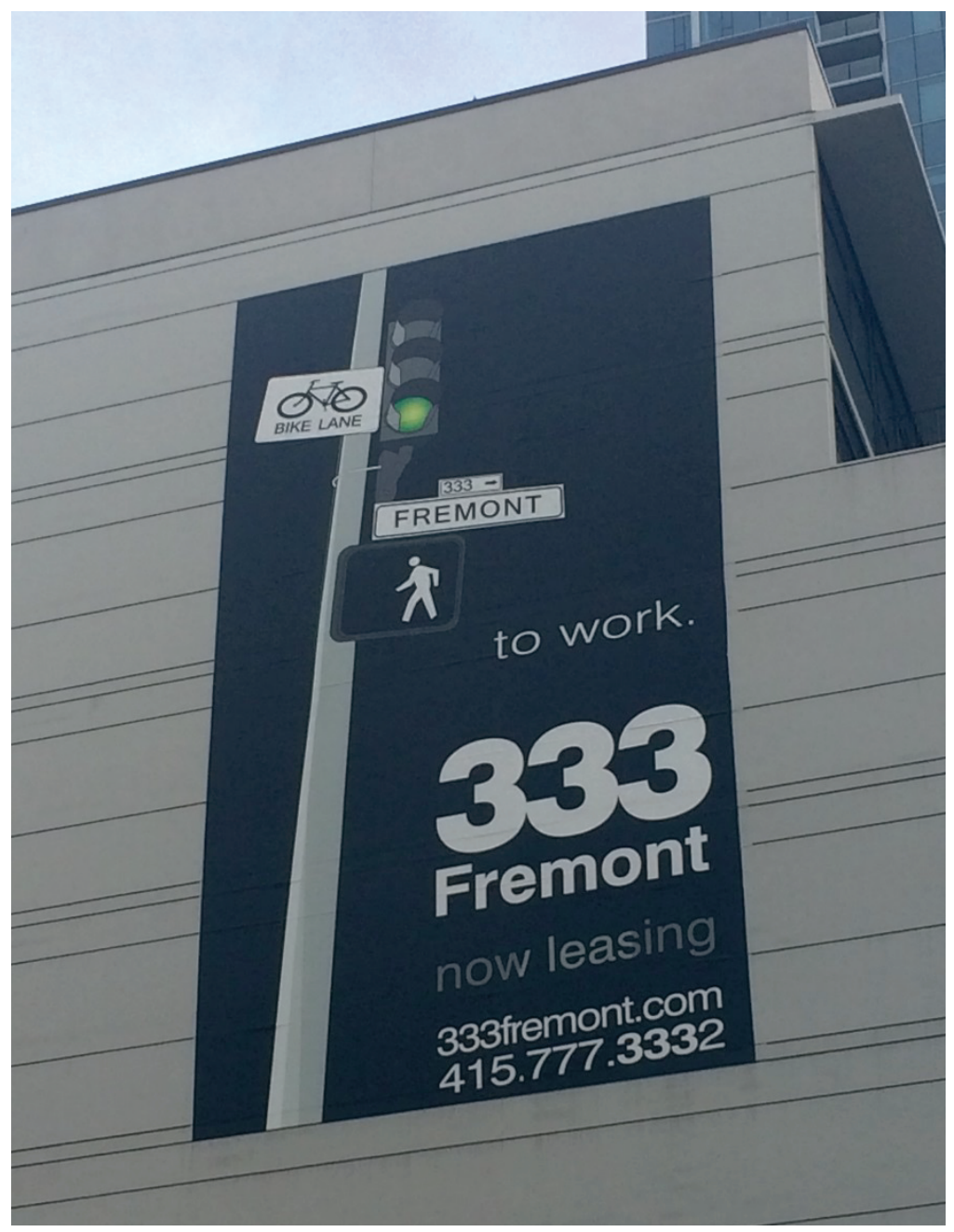

Figure 4.22: Advertisement for Walking to Work

An illustration of this concept is provided in Figure 4.23. The data consists of peak four hour counts for riders by mode in both directions, 6:00am to 10:00am and 3:30pm to 7:30pm. By comparing the peak counts (morning for westbound and evening for eastbound) and the off-peak counts (vice versa), the difference in ridership can be determined. In other words, comparing how many people cross the Bay into San Francisco in the morning versus the evening, and vice versa for those leaving San Francisco, can reveal how much capacity is unused by the directional imbalance. As it turns out, 87,193 more persons cross the Bay into San Francisco in the morning than the evening, and 86,018 more persons leave San Francisco across the Bay in the evening than 
the morning. Taking the lower number, this means that roughly 86,000 commuters could be accommodated with no changes to existing capacity by building their housing on the peninsula and work places in the East Bay.

As it stands, many BART stations are located in sprawling suburbs, and perhaps accordingly are the least-utilized. Excluding the Oakland International Airport station, the stations with the lowest ridership are: North Concord with 2,796 daily exits, Castro Valley with 3,017 daily exists, and South Hayward with 3,149 daily exits (BART, 2016d). The surrounding communities of these stations are all characterized by low density detached housing and businesses surrounded by ample surface parking. Adding both residential and commercial TOD will enable BART commuters to continue to BART from home to work without needing to use the Transbay Tube in the peak direction during peak hours, as well as attracting new riders and thus taking cars off the East Bay highways. 


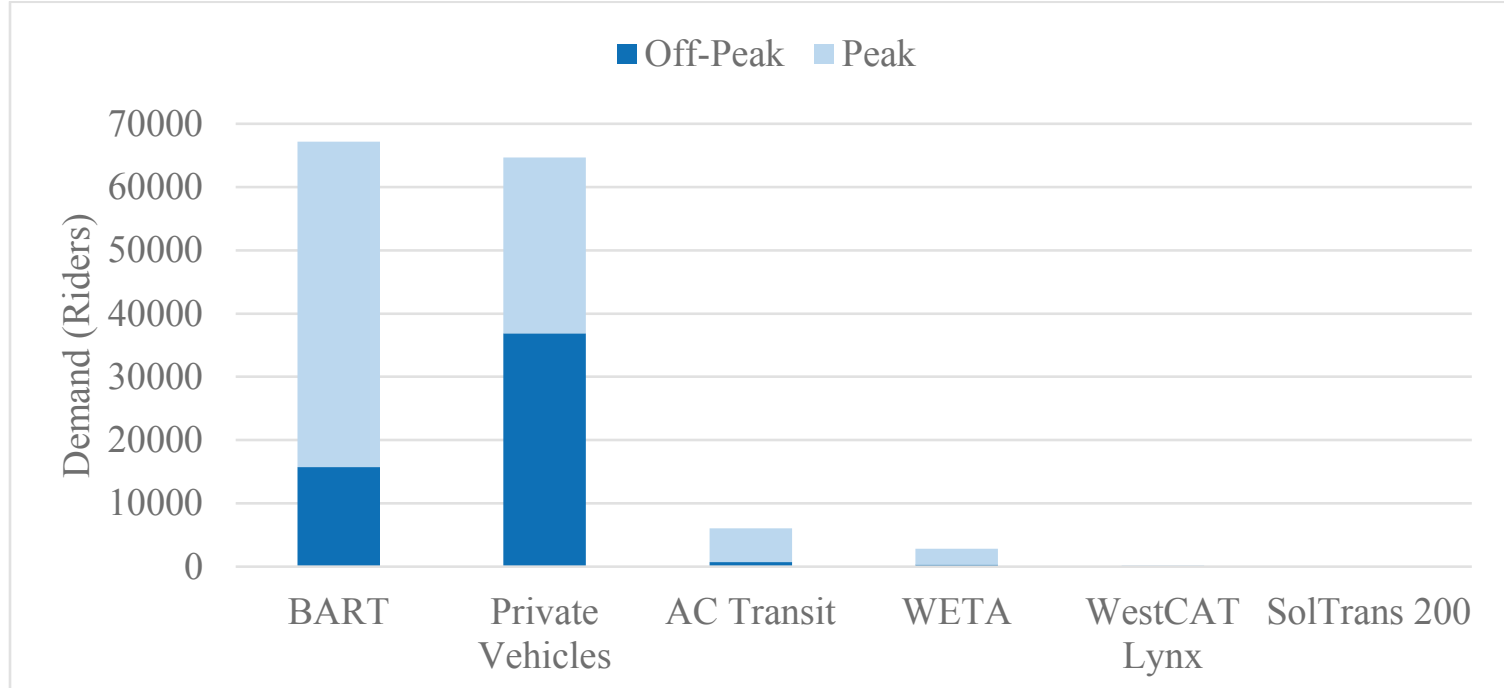

(a)

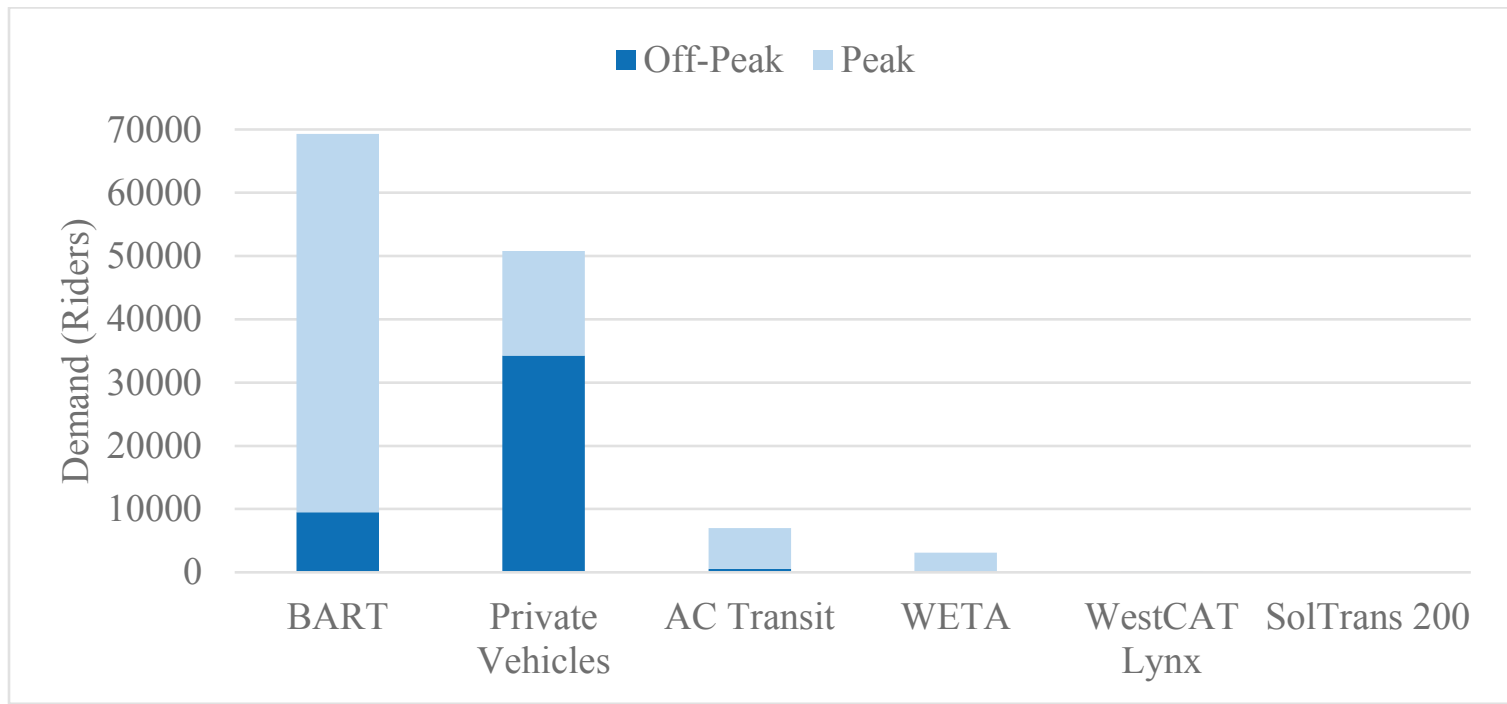

(b)

Figure 4.23: Peak vs. Off-Peak Demand by Mode in the Westbound (a) and Eastbound (b) Directions 


\section{RECOMMENDATIONS}

While it would be excellent to implement all sixteen proposed strategies for tackling congestion across the transbay corridor, limited funding and other constraints restrict what can be done. To that end, each strategy has been evaluated for merit in Section 5.1, plotted in terms of cost versus benefits in Section 5.2, and ranked in order of priority in Section 5.3.

\subsection{STRATEGY EVALUATION}

Each multi-part strategy has been split into its constituent parts. Each of these parts has been assessed for cost and effectiveness, either in terms of capacity increase or demand offset. Some elements are able to be directly quantified. However, most require some level of estimation. To this end, a series of bins has been devised to help sort the strategies while keeping estimates at an appropriately high level. For cost, this is binned as less than $\$ 500,000, \$ 500,000$ to $\$ 1,000,000$, $\$ 1,000,000$ to $\$ 5,000,000, \$ 5,000,000$ to $\$ 10,000,000, \$ 10,000,000$ to $\$ 50,000,000, \$ 50,000,000$ to $\$ 100,000,000$, and greater than $\$ 100,000,000$. There is also a "net gain" bin for the select few projects that will directly pay for themselves, either through increased revenues or decreased costs. Specific benefits are outlined in each subsection, but for comparison they are binned as no benefit, minimal benefit, some benefit, great benefit, and extensive benefit.

\subsubsection{Strategy 1: Upgrade West Grand Avenue Onramp to Bus Lane Standards}

Since this proposal only requires paint and inlet modifications, but offers important peak time savings for transit and HOVs, the value of this proposal is high and therefore should receive high priority. The base proposal (extending the existing HOV ramp to the I-580 eastbound onramp) offers the best time savings and is a prerequisite for the two extensions. These two extensions, from the I-580 eastbound onramp to the Maritime Street intersection and past the intersection, are not required for the base proposal to function, but queues from the plaza do spill back as far as the second extension during the worst commute hours, and so they should still be considered. 
The cost of this element is estimated to be $\$ 3,000,000$. This places the strategy in the $\$ 1,000,000$ to $\$ 5,000,000$ bin. In terms of benefit, MTC estimates 11 minutes of travel time savings for the nineteen existing and eight proposed buses that use this onramp during the morning peak hour (MTC, 2011, p. 8). The existing buses carry around 490 riders between Routes $\mathrm{O}, \mathrm{OX}, \mathrm{S}$, and W that all utilize the West Grand Avenue onramp. Eleven minutes saved for each of these riders translates to 90 person-hours saved every day. These routes have a capacity of around 1000 riders, meaning they are operating at $49 \%$ capacity. If saving eleven minutes incentivizes another $10 \%$ to ride, that would add 49 riders just during the one peak hour. Additionally, this is only considering transit ridership, but carpooling would see a boon here as well. Therefore, all three components of this strategy together are considered to have great benefit.

\subsubsection{Strategy 2: HOV Improvements at Powell Street and I-80 in Emeryville}

This proposal involves three key components: adding a right-side HOV lane to westbound I-80, converting the Powell Street to westbound I-80 ramp to HOV only and adding access from other directions, and adding a park-and-ride lot underneath I-80 at Powell Street. The first component is split into two alternatives: the cheaper but operationally worse component that converts the right-most existing lane to HOV only, and the more expensive but operationally better component that reroutes the new HOV lane onto the existing Powell Street onramp and builds a new lane on the outside of the existing junction, connecting back in before the toll plaza.

\subsubsection{Convert the Right Lane of I-80 to HOV}

For the first component, due to the expenses and operational headaches of implementing an HOV lane across the West Frontage Road onramp, it is recommended that the right-side HOV lane should only start with the converted Powell Street onramp, and not further upstream. Transit vehicles from further north than Powell Street should use the frontage road to access the HOV lane from the modified intersection at Powell Street and West Frontage Road. From there, simulation software and further analysis should be used to determine whether or not the mainline freeway can operationally handle being reduced from three general purpose lanes to two during HOV hours. If 
so, then the cheaper alternative of converting the right-most lane should be utilized. If not, then further study of constructing a new bypass lane on the outside of the interchange should be assessed. Either way, no HOV lane should be constructed before the Powell Street onramp.

The cost of the cheaper alternative to convert the rightmost lane to HOV is estimated to be $\$ 165,000$, which means it is binned as less than $\$ 500,000$. On the other hand, the more expensive new lane construction is more than five times greater, at $\$ 848,500$, or in the $\$ 500,000$ to $\$ 1,000,000$ bin. Either way, the queue to be jumped is roughly the same length as Strategy 1's West Grand Avenue queue jump and so could see a similar eleven minute savings. 1,126 morning peak hour riders would make use of this on AC Transit routes C, F, FS, G, H, J, L, LA, LC, and Z, WestCAT Lynx, for a time savings of 207 person-hours. Capacity on these routes during the peak hour is 2,107 riders, meaning the buses are currently at 53\%. A $10 \%$ boost in ridership from the time savings would yield an additional 113 riders. Countless additional HOVs and transit riders outside the peak hour would also make use of this improvement. Therefore, this element is considered to have great benefit for the cheaper alternative, while the more expensive alternative is to be sidelined due to expense and environmental concerns.

\subsubsection{Powell Street Onramp Conversion to HOV and Adding More Movements to Access the Onramp}

The second component, the Powell Street onramp conversion to HOV, should be pursued as a way to increase the use of this otherwise superfluous onramp and take advantage of the 0.8 mile queue jump it offers. According to past research, this conversion will cost $\$ 1,248,000$ and have a time-savings benefit of $\$ 6,468,000$, for a cost-benefit ratio of 5.18 (AECOM, 2012). This places the cost in the $\$ 1,000,000$ to $\$ 5,000,000$ bracket.

In terms of benefit, while a 5.18 ratio is great, further clarification can be useful. With rerouting to utilize the onramp, the 1,126 riders from the previous section would also make use of this queue jump. The length of queue skipped from this element is greater than either the previous element or the West Grand Avenue queue jump, but for the sake of being conservative 
the same eleven minute time savings value will be used. This yields an additional 207 person-hours during the morning peak hour alone for transit riders, as well as time savings benefits for HOV users and transit riders outside the peak hours. It is not likely that the ridership boost from this element would be independent of the previous element, as some overlap would occur, but an estimated additional 5\% ridership boost would yield 56 riders. All told, this element is estimated to have great benefit.

\subsubsection{Park-and-Ride Lot}

For the last component (the park-and-ride lot), the benefit is not particularly worth the expense. While this is a prime location in the greater regional analysis for a park-and-ride lot, 72 spots will not have a great impact on congestion. Operationally, the lot would be more worthwhile if it could be expanded across the street to add hundreds of more spaces, but this would require paving over the McLaughlin Eastshore State Park, a sensitive nature reserve.

In terms of cost, this lot is estimated to cost $\$ 494,000$, barely binning it as less than $\$ 500,000$. For benefit, 72 vehicles (most likely single-occupancy) could use the lot to group into carpools or board transit. While 72 users, or even 80 or 90 to account for two-person vehicles using the lot is not insignificant, it is also a daily value, so the peak hour would see even less. Most likely, the lot would fill up during the earliest commute hours (e.g. 5am), meaning the lot will have zero impact on peak congestion. Overall, this element is considered to have minimal benefit.

\subsubsection{Overall Recommendation}

All in all, the most recommended components of this strategy include converting the Powell Street onramp to HOV only, adding a left turn from Powell Street westbound onto the onramp, adding a through movement from West Frontage Road onto the onramp, and extending the now-HOV only lane from where the onramp merges onto westbound I-80 to the existing HOV lanes closer to the toll plaza. These components are all highly recommended due to the high costbenefit ratio they offer. 


\subsubsection{Strategy 3: MacArthur Onramp Bus Lane}

BATA's proposal to add an HOV onramp from MacArthur to I-580 west to the toll plaza is highly recommended as a way to promote carpooling and increase transit accessibility to the bridge. Building upon this proposal by extending the HOV lane to the existing toll plaza HOV lane will vastly improve this proposal by allowing buses and HOVs to jump the toll plaza queue on I580.

The cost is estimated to be around $\$ 11,117,500$, or on the low end of the $\$ 10,000,000$ to $\$ 50,000,000$ bin. The benefit is estimated around $\$ 13,340,000$ (AECOM, 2012). More specifically, a time-savings similar to the West Grand Avenue and Powell Street queue jumps can be expected. While no transit service use this path as a direct connection does not exist, future reroutes that use this queue jump could service the nearby neighborhoods, attracting new riders. Therefore this strategy is considered to have some benefit.

\subsubsection{Strategy 4: Expand Bus Service}

This recommendation includes expanding bus service for three East Bay agencies: AC Transit, WestCAT, and SolTrans.

\subsubsection{AC Transit}

For AC Transit, the $\$ 27.8$ million $(\$ 10-\$ 50$ million bin) bus replacement and pilot programs will help increase ridership. Exactly how much is to be determined, but MTC's study purports that it is worthwhile, and so pursuing this program is recommended (MTC, 2011). This element is estimated to have some benefit, as eight new peak hour buses could service around 460 new riders. At the current $49 \%$ occupancy for the routes through the pilot program study area, this translates to 223 new riders during the morning peak hour. Additionally, the new buses will inspire additional ridership. Therefore, this element is considered to have great benefit.

\subsubsection{WestCAT}

For WestCAT, it is highly recommended to alter the Lynx and 30Z routes to create one route that connects Hercules and Martinez to San Francisco with express freeway-based service, 
and a local route that circulates around Hercules. Combined with a frequency increase for the express service, this should see increased ridership thanks to faster and more reliable service that makes more connections to existing lines.

Since the only changes are reroutes, the only costs will be changing signage, training drivers, and advertising the changes to riders. This all should cost less than $\$ 500,000$, the smallest cost bin. For benefit, if this streamlining sees an additional 20\% ridership, that would mean 117 more riders across the day. This will help increase the daily occupancy rate from $15.7 \%$ to $18.9 \%$. Not the greatest, but would help improve the Lynx's farebox recovery ratio in addition to taking plenty of cars off the road. Therefore, this element is considered to have some benefit.

\subsubsection{SolTrans}

Regarding SolTrans, expansion of Route 200 is not recommended due to its nature of providing WETA capacity relief, as well as the old age of the buses. Instead, WETA should focus on acquiring additional ferries and improving its water-based service. As well, SolTrans should focus as planned on increasing the efficiency and frequency of existing services to the El Cerrito Del Norte and Walnut Creek BART stations.

Since there is no detailed expansion of Route 200 and all signs point to scrapping the route anyhow, this automatically places this element in the lowest priority category without needing to be charted on a cost-benefit matrix.

\subsubsection{Strategy 5: Commuter Parking}

This strategy proposes seven new park-and-ride lots, three by MTC and four by this thesis.

\subsubsection{I-80 and Buchanan Street}

This lot, proposed by MTC, is estimated to cost $\$ 1,838,000$ ( $\$ 1-\$ 5$ million bin) and provide 268 stalls. Due to its central location to I-80 with plenty of transit access, it is anticipated to see high use and thus garners some benefit. 


\subsubsection{I-880 and Fruitvale Avenue}

This lot, proposed by MTC, is estimated to cost $\$ 1,865,500$ ( $\$ 1-\$ 5$ million bin) and provide 272 stalls. Due to its central location to I- 880 with plenty of transit access, including the two proposed AC Transit pilot projects, it is anticipated to see high use and thus garners some benefit.

\subsubsection{I-880 and High Street}

This lot, proposed by MTC, is estimated to cost $\$ 1,097,500$ ( $\$ 1-\$ 5$ million bin) and provide 160 stalls. Due to its central location to I-880 with plenty of transit access, including the two proposed AC Transit pilot projects, it is anticipated to see high use and thus garners some benefit.

\subsubsection{I-580 and Fairmont Drive/Foothill Boulevard}

This proposed lot, original to this thesis, is estimated to cost $\$ 754,500$ ( $\$ 500,000$ $\$ 1,000,000$ bin) and provide 110 stalls. Due to its central location to I-580 with plenty of existing transit access, it is anticipated to see high use and thus garners some benefit.

\subsubsection{I-580 and Golf Links Road/98 ${ }^{\text {th }}$}

This proposed lot, original to this thesis, is estimated to cost $\$ 1,193,500$ ( $\$ 1-\$ 5$ million bin) and provide 174 stalls. Due to its central location to I-580 with minimal need for transit rerouting, it is anticipated to see high use and thus garners some benefit.

\subsubsection{SR-24 and Telegraph Avenue/56 $6^{\text {th }}$ Street}

This proposed lot, original to this thesis, is estimated to cost $\$ 583,000$ ( $\$ 500,000$ $\$ 1,000,000$ bin) and provide 85 stalls. It is centrally located to the SR-24 freeway, but lacks transit access and so it is anticipated to see little use and thus garners minimal benefit.

\subsubsection{I-580 and Broadway/Piedmont Avenue}

This proposed lot, original to this thesis, is estimated to cost $\$ 1,371,500$ ( $\$ 1-\$ 5$ million bin) and provide 200 stalls. Due to its poor access to the freeway and lack of San Francisco-bound transit services, it is anticipated to see low use and thus garners no benefit. 


\subsubsection{BART Parking Capacity Increases}

BART parking is very scalable. It could be adding in a small surface lot near a far-flung station, or adding hundreds of spots in a garage near the urban core. A prudent estimate would be $\$ 50$ million to $\$ 100$ million, which would pay for a few garages in key locations. At $\$ 18,599$ per stalls for a new parking garage, this would translate to 2,688 to 5,376 stalls (Cudney, 2015). While not all of the occupants of these new spots would head to San Francisco, nonetheless adding BART parking capacity can be assumed to have some benefit for the transbay commute.

\subsubsection{Partner with Ridesharing Apps for Station Access}

As shown in the Summit, New Jersey case study, the city opted to forgo building a new parking garage and instead subsidize Uber rideshare fares to the station for $\$ 167,000$ per annum (Hawkins, 2016). This was a wise move, as a new parking garage can cost upwards of $\$ 12$ million (Gordian, 2013). The Summit station has a daily ridership of 3,638, comparable to many BART stations in the outer suburbs (NJ Transit, 2012, p. 28). If BART was to implement a similar program at several stations with similar ridership, it would cost somewhere between $\$ 500,000$ and $\$ 1,000,000$. By enabling additional riders to access the stations without needing to add parking capacity, this element can have great benefit.

\subsubsection{Overall Recommendation}

All three MTC lots are recommended, as they add 700 stalls of capacity in three key locations. Of the proposed lots in this thesis, three are recommended. In order of decreasing importance, these are: I-580 and Fairmont Drive/Foothill Boulevard, I-580 and Golf Links Road $/ 98^{\text {th }}$, and SR-24 and Telegraph Avenue $/ 56^{\text {th }}$ Street. These are ordered as such due to decreasing access to existing transit and ease of implementation. The one lot not recommended is at I-580 and Broadway/Piedmont Avenue. Despite being the largest and in a key location, poor freeway connections diminish the effectiveness of this lot. Additionally, the land has existing use, versus the other sites that are currently empty, undeveloped lots. 
Outside of the above lots, it is also recommended that BART increase parking capacity in order to better serve existing riders who often have to drive to multiple stations to find a spot, hurting the greenhouse gas reduction mission of the service.

Lastly, this strategy closes out with a recommendation to partner with mobile ridesharing applications to assist getting riders to the stations. The case study provided exemplifies how such a system can greatly improve transit accessibility without having to spend millions on expensive parking garages.

\subsubsection{Strategy 6: Partner with Developers of Ridesharing Mobile Applications}

Through partnering with vanpool/minibus apps and casual carpool apps, public agencies can help supplement their bus service with flexible transit options. Each of these elements most likely costs around $\$ 500,000$ to $\$ 1,000,000$ to implement and maintain, based on similar experiences elsewhere (Victoria Transport Policy Institute, 2015). Partnering with vanpool/minibus apps offer great benefit, as it can drastically increase occupancy rates by providing direct vanpool and minibus service between a specific workplace and the homes of its employees. Partnering with casual carpool apps would have minimal benefit, however, due to the lower capacities of casual carpools versus vanpools and minibuses. Additionally, partnerships casual carpool apps could lead to increased VMT, as drivers are encouraged to circle back and pick up more riders, incurring a deadhead trip.

\subsubsection{Strategy 7: Enhanced Casual Carpooling}

In Kelley's original research, it is determined that an enhanced casual carpooling program would theoretically cost $\$ 2.7$ million per year to operate, placing this strategy in the $\$ 1$ million to $\$ 5$ million bin (Kelley, 2007). The program would likely see some benefit, as carpoolers seek to increase their occupancy and thus lower tolls. However, as much as this strategy would help increase carpool occupancy rates, it would be difficult to implement as it would require all users to adopt the program in order to function. Therefore, it is recommended to pursue this strategy, but not at the expense of other easier-to-implement strategies. 


\subsubsection{Strategy 8: Shifting Attitudes on Carpooling}

Promoting carpooling as the environmentally and socially conscious choice has been proven to be far more effective than physical HOV improvements or other incentives (Wang \& Chen, 2012). Such a campaign would be much cheaper as well. As discussed in Section 4.1.8, Flex Alert, a similar government outreach program, costs around $\$ 10$ to $\$ 11$ million annually. Assuming a similar cost for a promotional ad campaign, this strategy is binned in the $\$ 10$ to $\$ 50$ million bracket, albeit at the lower end of the estimate. However, for this value extensive benefit can be drawn for a fraction of the cost of other HOV improvements that are less effective. Due to the low cost and high value, this strategy is highly recommended.

\subsubsection{Strategy 9: Increased Enforcement}

Adding patrols to HOV facilities will reduce the rate of violation (Lazarus, 2014). However, this can be costly, detract officers from more pressing matters, and create a culture of "us-verse-them" that causes violators to resent officers rather than reconsider their actions. A far more effective strategy would be to implement a program like WSDOT's citizen reporting system that lets violators know they are being noticed, and gain compliance through shaming rather than punishment.

\subsubsection{Adding HOV Facility Patrols}

As this tactic would mostly be diverting existing officers, the cost is estimated to be minimal. Some cost could be occurred though if adding officers to the service is deemed necessary. This element is expected to cost less than $\$ 500,000$ either way. However, it is estimated to have minimal benefit, as it would only work when officers are around and create resentment as discussed above.

\subsubsection{Citizen Reporting System}

This tactic would require signage, advertising, and overhead for a small taskforce to implement. These together could cost around $\$ 500,000$ to $\$ 1,000,000$, and offer extensive benefit 
similar to the experience of WSDOT, whose system reports half the violation rate of the national average (Washington State Department of Transportation, 2016).

\subsubsection{Strategy 10: Electronic Tolling at the Bay Bridge Toll Plaza}

The Golden Gate Bridge Toll Plaza has shown that converting their toll booths to all electronic tolling can pay huge dividends. Further, removing the now-empty toll booths in favor of a non-obstructive toll gantry will further save the toll plaza money. The Bay Bridge Toll Plaza would do well to follow suit.

In terms of dollars, the conversion is expected to cost $\$ 6,250,000$ to implement, but will save $\$ 24,000,000$ for a net gain of $\$ 17,750,000$ using methodology from Section $4 \cdot 1 \cdot 10.2$. This means this project will yield a net gain upon implementation. It will have some benefit, by decreasing toll delays during most hours. However, it will have minimal effect during the worst peak times, as traffic is congested through the toll plaza, not just at it. As well, any design removing the toll plaza will need to maintain the effectiveness of the HOV lanes by extending them past the chokepoint, lest buses and HOVs lose their queue-jump incentive.

\subsubsection{Strategy 11: BART Capacity Increases}

To increase the overall capacity of BART, both train and station capacity will need to be increased.

\subsubsection{Improve Train Capacity}

Maximizing the train capacity across the peak hour will require 15 additional train cars. While adding an extra car or two per train has minimal operational costs, additional maintenance costs will be incurred from keeping the extra fifteen cars online, rather than retiring them once BART's new cars enter service. BART's operational expenses related to maintenance and electricity for train propulsion amount to around $\$ 605.3$ million annually (BART, 2014b, pp. 411). Across 669 revenue cars, this yields $\$ 904,783$ spend per car annually. For fifteen cars kept in service at this expense, a net cost of around $\$ 13,800,000$ is obtained, placing this element in the $\$ 10$ million to $\$ 40$ million bin. For this cost, an additional seat capacity of 1,050 riders and crush 
capacity of 3,000 riders is added just during the peak hour. Since for the price, these cars would be operational as often as any other car, not just during the peak hour, they could be used other times as well, further increasing capacity and comfort. Therefore, this tactic will have extensive benefit upon implementation.

\subsubsection{Improve Station Capacity}

This element is expected to cost $\$ 449,300,000$ (AECOM, 2012, p. 31) to improve the Montgomery and Embarcadero Stations, which places it well into the greater than $\$ 100$ million bin. Adding station capacity will have extensive benefit by greatly reducing platform crowding during peak periods and increasing pedestrian flow within the station. However, this approach is more long-term, as it will take years to be designed and implemented.

\subsubsection{Strategy 12: Altered BART Service}

This strategy features two methods that could work in tandem to improve travel times on BART: skip-stop "metro" service and express service. Both should be actively pursued, but the express service can be implemented today while the skip-stop service is evaluated, designed, constructed, and implemented. Once the necessary infrastructure has been built to accommodate skip-stop service, then it could either replace or enhance the express service.

\subsubsection{Skip-Stop "Metro" Service}

An exact cost estimate would require analysis of need for and cost of station bypasses. These bypasses are needed to allow trains to skip past others. However, it can be said that the cost will be in the largest bin, over $\$ 100$ million, as it will require a large capital expense for new bridges or tunnels for the bypass tracks in several locations. The benefit will be extensive, though, as this proposal drastically decreases trip times, which improve appeal and thus ridership. Additionally, it is expected that this service will be mandatory to keep up with demand once it surpasses 500,000 daily riders (AECOM, 2012, p. 33). 


\subsubsection{Express Service}

Implementing the express service proposal is anticipated to cost $\$ 5$ million to $\$ 10$ million for signage, outreach, overhead, and design. Since Caltrain implemented the Baby Bullet, daily ridership has increased $143 \%$ (Caltrain, 2015, p. 3). This service is obviously not comparable to what BART would be able to implement, due to the contrasting nature of the Caltrain and BART services. However, even a 5\% increase in ridership for BART would mean 11,700 additional transbay riders, yielding great benefit for the system as drivers are taken off the road.

\subsubsection{Strategy 13: Congestion Pricing}

Implementing congestion pricing is anticipated to cost $\$ 5$ million to $\$ 10$ million for signage, outreach, overhead, and design. However, while congestion pricing is a great idea, its effectiveness is questionable. The current system has been shown to make a negligible difference in commute patterns, quite possibly due to the abundance of free or low cost parking available to commuters (A. Fremier, personal communication, September 20, 2016). Therefore the strategy should be pursued, but not at the expense of other strategies with proven effectiveness as it only offers minimal benefit.

\subsubsection{Strategy 14: Eastbound Tolling}

This strategy could be accomplished by one of two methods: cordon tolling in downtown San Francisco, and bidirectional tolling at the Bay Bridge Toll Plaza.

\subsubsection{Downtown San Francisco Cordon}

A similar cordon program in London, United Kingdom, cost $\$ 124$ million per annum to implement, with revenues of $\$ 223$ million per annum for a net gain of $\$ 99$ million per annum (Litman, 2011, p. 11). Implementation in San Francisco would probably be similar, resulting in a net gain. However, while cordon tolling may help with congestion in and around San Francisco, it causes far too many headaches for consideration as a transbay congestion reduction strategy. In other words, it is a worthwhile idea that should be implemented, but not in the scope of reducing congestion on the bridge alone. As well, many transbay trips do not end up in downtown San 
Francisco, but rather elsewhere in San Francisco or in San Mateo County. Cordon tolling would have no impact on these trips and so offers minimal benefit.

\subsubsection{Convert the Bay Bridge Toll Plaza into a Bidirectional Facility}

A method far more directly relevant to reducing transbay congestion is to convert the Bay Bridge Toll Plaza into a bidirectional facility. This could be combined with Strategy 10 (Electronic Tolling) for minimal impact to traffic, and Strategy 13 (Congestion Pricing) to promote carpooling and dissuade peak hour travel. On its own, this project would probably cost around $\$ 6,250,000$ for the same reasons as the westbound direction outlined in Section 5.1.10. No additional revenue is anticipated though, as public goodwill concerns would most likely requisite splitting the westbound toll with the eastbound toll, so that the new eastbound toll does not unfairly tax commuters. Benefits could be considered split with the westbound direction, though, yielding $\$ 12$ million for both rather than \$24 million for the westbound direction, as outlined in Section 5.1.10. This would still categorize both strategies as a net gain no matter how it is split. On its own, bidirectional tolling would have some benefit, as it would incentivize eastbound carpooling and demand management, but it would not drastically alter the commute landscape.

\subsubsection{Strategy 15: Changing Corporate Cultures}

Outreach to San Francisco's numerous offices promoting telecommuting, carpooling, and changing workplace vehicle demands can help reduce congestion by taking single occupancy vehicles off of the road. Programs and outreach for these tactics can be done immediately and at a low cost, so are highly recommended. Quantifying the cost and effect is difficult, as it could easily scale from a small taskforce operation to an all-out citywide mobilization. $\$ 1$ million to $\$ 5$ million for outreach and carshare subsidies, along with legislative changes detailed in Section 4.2.3.1, could net some benefit as drivers either stay home or are allowed to keep their cars at home. As estimated in Section 4.2.3.1, potentially 3,500 or more drivers could be taken off of the road daily by allowing them to telecommute, carpool, or take transit. Doubled for round trips (one eastbound and one 
westbound), this would reduce daily demand by 7,000 vehicles or more on the Bay Bridge, and so garner extensive benefit upon implementation.

\subsubsection{Strategy 16: Land-Use Planning Changes}

While the purpose of this thesis is to explore short-term solutions to transbay congestion and changing land-use planning is a long-term strategy, it is nonetheless important to begin now to effectively plan for the future. Unlike a second bridge or tube that will not begin planning for many more years to come (if ever), land-use planning changes can and needs to begin now. The cost is low, less than $\$ 500,000$, as most of the work would be done within government agencies through advising land-use changes that enable people to live closer to work and transit nodes. Some outreach costs would be incurred though, as the public-at-large might need convincing of this strategy's necessity. Changing land-uses has the potential to create extensive benefit, as the most direct way to reduce demand on the bridge is to reduce the need to cross the bay in the first place, which can be achieved by bringing homes closer to workplaces and vice versa.

\subsection{STRATEGY COST VERSUS BENEFITS}

Each strategy has now been assessed for cost and benefit using broad bins to assist with fiscal uncertainties. Table 5.1 lists the strategies and their cost and benefit categories. For strategies with multiple components, the components have been denoted alphabetically under the number of its parent strategy. Of note, Strategy 4c (expanding SolTrans Route 200 bus service), has been dropped from the analysis due to its planned abandonment.

Figure 5.1 maps these strategies visually, using smaller circles with more defined borders to denote more exact cost estimates. Of note, while left-to-right positioning within each column roughly approximates cost, top-to-bottom positioning within each row is simply numerical rank. E.g. all of the strategies listed in the "Some Benefit" row have approximately the same benefit no matter their vertical positioning, but strategies on the right of the $\$ 1 \mathrm{~m}-\$ 5 \mathrm{~m}$ cost column are anticipated to be more expensive than those on the left. Lastly, the graph has a background shading 
from green to yellow to orange to red, to denote decreasing priority optimization. This is discussed further in the next section.

Table 5.1: Roster of Strategies with Cost and Benefit Bins

\begin{tabular}{|c|c|c|c|}
\hline \multicolumn{2}{|r|}{ Name } & Cost Bin & $\begin{array}{l}\text { Benefit } \\
\text { Bin }\end{array}$ \\
\hline $1 \mathrm{a}$ & $\begin{array}{l}\text { Upgrade West Grand Avenue Onramp to Bus Lane } \\
\text { Standards - Base Proposal }\end{array}$ & \multirow{3}{*}{$\$ 1 m-\$ 5 m$} & \multirow{3}{*}{ Great } \\
\hline $1 b$ & $\begin{array}{l}\text { Upgrade West Grand Avenue Onramp to Bus Lane } \\
\text { Standards - I-580 Eastbound Onramp to Maritime Avenue } \\
\text { Intersection Extension }\end{array}$ & & \\
\hline $1 \mathrm{c}$ & $\begin{array}{l}\text { Upgrade West Grand Avenue Onramp to Bus Lane } \\
\text { Standards - Extension Past Maritime Avenue Intersection }\end{array}$ & & \\
\hline $2 \mathrm{a}$ & $\begin{array}{l}\text { HOV Improvements at Powell Street and I- } 80 \text { in Emeryville } \\
\text { - Convert Right Lane of I- } 80 \text { to HOV from Before West } \\
\text { Frontage Road Onramp to Powell Street Onramp }\end{array}$ & $\$ 500 k-\$ 1 m$ & None \\
\hline $2 \mathrm{~b}$ & $\begin{array}{l}\text { HOV Improvements at Powell Street and I- } 80 \text { in Emeryville } \\
\text { - Convert Right Lane of I- } 80 \text { to HOV from Powell Street } \\
\text { Onramp to Existing HOV }\end{array}$ & $<\$ 500 k$ & Great \\
\hline $2 \mathrm{c}$ & $\begin{array}{l}\text { HOV Improvements at Powell Street and I- } 80 \text { in Emeryville } \\
\text { - Powell Street Onramp Conversion to HOV and Adding } \\
\text { More Movements to Access the Onramp }\end{array}$ & $\$ 1 m-\$ 5 m$ & Great \\
\hline $2 \mathrm{~d}$ & $\begin{array}{l}\text { HOV Improvements at Powell Street and I- } 80 \text { in Emeryville } \\
\text { - Park-and-Ride Lot }\end{array}$ & $<\$ 500 k$ & Minimal \\
\hline 3 & MacArthur Onramp Bus Lane & $\$ 10 m-\$ 50 m$ & Some \\
\hline $4 \mathrm{a}$ & Expand Bus Service - AC Transit & $\$ 10 m-\$ 50 m$ & Great \\
\hline $4 \mathrm{~b}$ & Expand Bus Service - WestCAT & $<\$ 500 k$ & Some \\
\hline $4 \mathrm{c}$ & Expand Bus Service - SolTrans & - & - \\
\hline $5 \mathrm{a}$ & Commuter Parking - I-80 and Buchanan Street & $\$ 1 m-\$ 5 m$ & Some \\
\hline $5 b$ & Commuter Parking - I- 880 and Fruitvale Avenue & $\$ 1 m-\$ 5 m$ & Some \\
\hline $5 \mathrm{c}$ & Commuter Parking - I-880 and High Street & $\$ 1 m-\$ 5 m$ & Some \\
\hline $5 \mathrm{~d}$ & $\begin{array}{l}\text { Commuter Parking - I-580 and Fairmont Drive/Foothill } \\
\text { Boulevard }\end{array}$ & $\$ 500 k-\$ 1 m$ & Some \\
\hline $5 \mathrm{e}$ & Commuter Parking - I-580 and Golf Links Road/98 & $\$ 1 m-\$ 5 m$ & Some \\
\hline $5 f$ & $\begin{array}{l}\text { Commuter Parking }- \text { SR-24 and Telegraph Avenue } / 56^{\text {th }} \\
\text { Street }\end{array}$ & $\$ 500 k-\$ 1 m$ & Minimal \\
\hline $5 \mathrm{~g}$ & Commuter Parking - I-580 and Broadway/Piedmont Avenue & $\$ 1 m-\$ 5 m$ & None \\
\hline $5 \mathrm{~h}$ & Commuter Parking - BART Parking Capacity Increases & $\$ 50 m-\$ 100 m$ & Some \\
\hline $5 \mathrm{i}$ & $\begin{array}{l}\text { Commuter Parking - Partner with Ridesharing Apps for } \\
\text { Station Access }\end{array}$ & $\$ 500 k-\$ 1 m$ & Great \\
\hline $6 \mathrm{a}$ & $\begin{array}{l}\text { Partner with Developers of Ridesharing Mobile } \\
\text { Applications - Vanpools/Minibuses }\end{array}$ & $\$ 500 k-\$ 1 m$ & Great \\
\hline $6 b$ & $\begin{array}{l}\text { Partner with Developers of Ridesharing Mobile } \\
\text { Applications - Casual Carpools }\end{array}$ & $\$ 500 k-\$ 1 m$ & Minimal \\
\hline 7 & Enhanced Casual Carpooling & $\$ 1 m-\$ 5 m$ & Some \\
\hline
\end{tabular}




\begin{tabular}{|c|l|c|c|}
\hline \multicolumn{2}{|c|}{ Name } & Cost Bin & $\begin{array}{c}\text { Benefit } \\
\text { Bin }\end{array}$ \\
\hline 8 & Shifting Attitudes on Carpooling & $\$ 10 \mathrm{~m}-\$ 50 \mathrm{~m}$ & Extensive \\
\hline $9 \mathrm{a}$ & Increased Enforcement - Adding HOV Facility Patrols & $<\$ 500 \mathrm{k}$ & Minimal \\
\hline $9 \mathrm{~b}$ & Increased Enforcement - Citizen Reporting System & $\$ 500 \mathrm{k}-\$ 1 \mathrm{~m}$ & Extensive \\
\hline 10 & Electronic Tolling at the Bay Bridge Toll Plaza & Net Gain & Some \\
\hline $11 \mathrm{a}$ & BART Capacity Increases - Improving Train Capacity & $\$ 10 \mathrm{~m}-\$ 50 \mathrm{~m}$ & Extensive \\
\hline $11 \mathrm{~b}$ & BART Capacity Increases - Improving Station Capacity & $>\$ 100 \mathrm{~m}$ & Extensive \\
\hline $12 \mathrm{a}$ & Altered BART Service - Skip-Stop “Metro" Service & $>\$ 100 \mathrm{~m}$ & Extensive \\
\hline $12 \mathrm{~b}$ & Altered BART Service - Express Service & $\$ 5 \mathrm{~m}-\$ 10 \mathrm{~m}$ & Great \\
\hline 13 & Congestion Pricing & $\$ 5 \mathrm{~m}-\$ 10 \mathrm{~m}$ & Minimal \\
\hline $14 \mathrm{a}$ & Eastbound Tolling - Downtown San Francisco Cordon & Net Gain & Minimal \\
\hline $14 \mathrm{~b}$ & $\begin{array}{l}\text { Eastbound Tolling - Convert the Bay Bridge Toll Plaza into } \\
\text { a Bidirectional Facility }\end{array}$ & $\mathrm{Net}$ Gain & Some \\
\hline 15 & Changing Corporate Cultures & $\$ 1 \mathrm{~m}-\$ 5 \mathrm{~m}$ & Extensive \\
\hline 16 & Land-Use Planning Changes & $<\$ 500 \mathrm{k}$ & Extensive \\
\hline
\end{tabular}




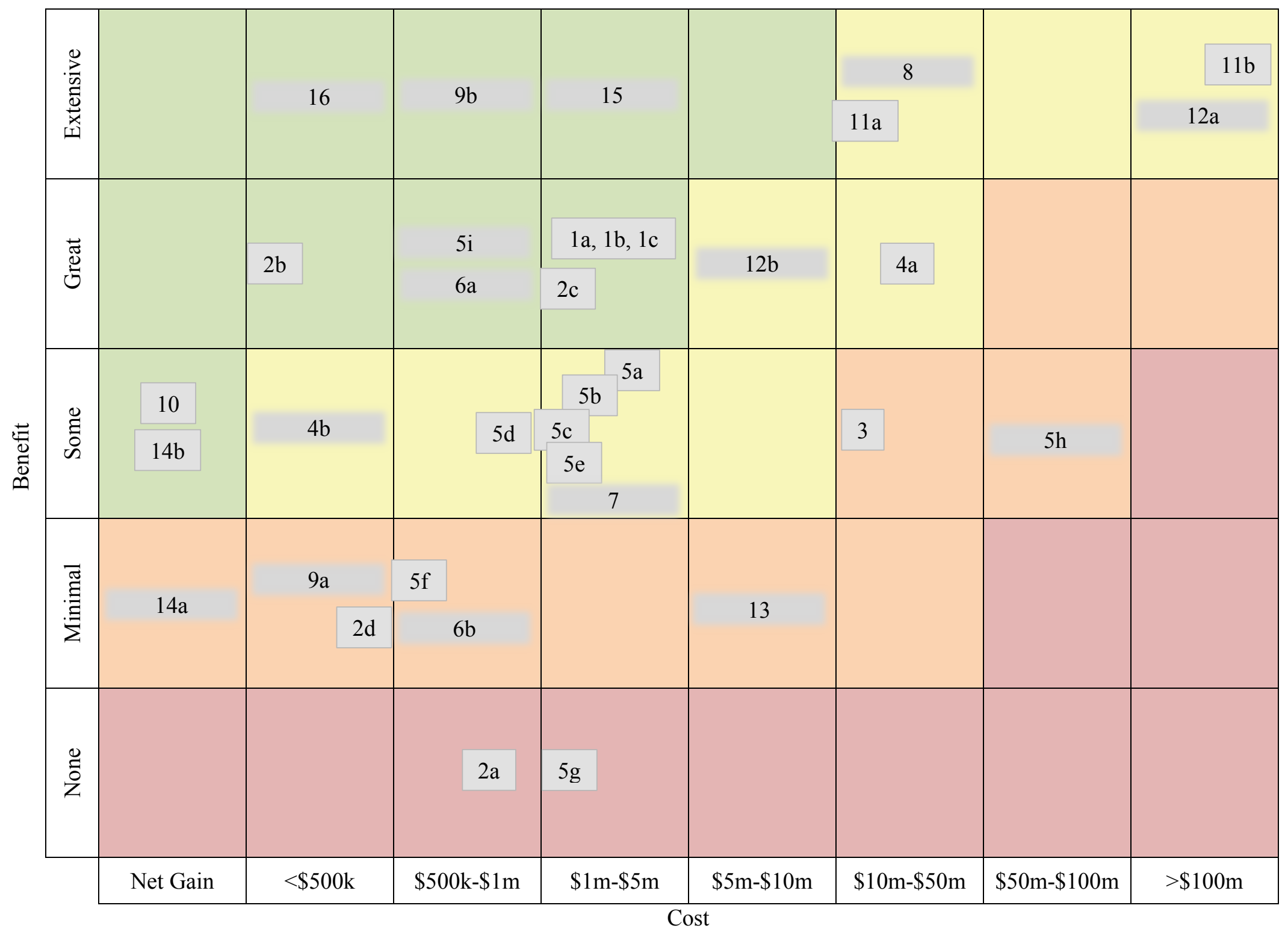

Figure 5.1: Strategy Cost versus Benefit Map 


\subsection{STRATEGY PRIORITIZATION}

Now that these strategies have been outlined, detailed, estimated for cost and benefit, tabulated, and graphed, they can be grouped by priority for implementation. Table 5.2 lists these strategies by priority group. The first group consists of strategies that should be vigorously pursued as soon as possible. The second group consists of strategies that should be implemented, but are not as essential as the first group. The third group consists of strategies that would help congestion if implemented, but are less economical and thus less important to pursue in the near-term. The fourth and last group consists of the select few strategies that have been recommended against and should not be implemented as currently designed. It is important to note that the contents of each group are not ranked by priority, but rather the arbitrary order in which they are listed throughout the thesis. 
Table 5.2: Roster of Strategies by Priority

\begin{tabular}{|c|c|}
\hline \multicolumn{2}{|c|}{ Priority 1: Implement Now } \\
\hline $1 \mathrm{a}$ & Upgrade West Grand Avenue Onramp to Bus Lane Standards - Base Proposal \\
\hline $1 \mathrm{~b}$ & $\begin{array}{l}\text { Upgrade West Grand Avenue Onramp to Bus Lane Standards - I-580 Eastbound Onramp } \\
\text { to Maritime Avenue Intersection Extension }\end{array}$ \\
\hline $1 \mathrm{c}$ & $\begin{array}{l}\text { Upgrade West Grand Avenue Onramp to Bus Lane Standards - Extension Past Maritime } \\
\text { Avenue Intersection }\end{array}$ \\
\hline $2 \mathrm{~b}$ & $\begin{array}{l}\text { HOV Improvements at Powell Street and I- } 80 \text { in Emeryville - Powell Street Onramp } \\
\text { Conversion to HOV and Adding More Movements to Access the Onramp }\end{array}$ \\
\hline $2 \mathrm{c}$ & $\begin{array}{l}\text { HOV Improvements at Powell Street and I- } 80 \text { in Emeryville - Convert Right Lane of I- } 80 \\
\text { to HOV from Powell Street Onramp to Existing HOV }\end{array}$ \\
\hline $5 \mathrm{i}$ & Commuter Parking - Partner with Ridesharing Apps for Station Access \\
\hline $6 \mathrm{a}$ & Partner with Developers of Ridesharing Mobile Applications - Vanpools/Minibuses \\
\hline $9 \mathrm{~b}$ & Increased Enforcement - Citizen Reporting System \\
\hline 10 & Electronic Tolling at the Bay Bridge Toll Plaza \\
\hline $14 \mathrm{~b}$ & Eastbound Tolling - Convert the Bay Bridge Toll Plaza into a Bidirectional Facility \\
\hline 15 & Changing Corporate Cultures \\
\hline 16 & Land-Use Planning Changes \\
\hline \multicolumn{2}{|c|}{ Priority 2: Implement Soon } \\
\hline $4 \mathrm{a}$ & Expand Bus Service - AC Transit \\
\hline $4 \mathrm{~b}$ & Expand Bus Service - WestCAT \\
\hline $5 \mathrm{a}$ & Commuter Parking - I-80 and Buchanan Street \\
\hline $5 \mathrm{~b}$ & Commuter Parking - I-880 and Fruitvale Avenue \\
\hline $5 \mathrm{c}$ & Commuter Parking - I-880 and High Street \\
\hline $5 \mathrm{~d}$ & Commuter Parking - I-580 and Fairmont Drive/Foothill Boulevard \\
\hline $5 \mathrm{e}$ & Commuter Parking - I-580 and Golf Links Road/98 ${ }^{\text {th }}$ \\
\hline 7 & Enhanced Casual Carpooling \\
\hline 8 & Shifting Attitudes on Carpooling \\
\hline $11 \mathrm{a}$ & BART Capacity Increases - Improving Train Capacity \\
\hline $11 \mathrm{~b}$ & BART Capacity Increases - Improving Station Capacity \\
\hline $12 \mathrm{a}$ & Altered BART Service - Skip-Stop "Metro" Service \\
\hline $12 \mathrm{~b}$ & Altered BART Service - Express Service \\
\hline \multicolumn{2}{|c|}{ Priority 3: Implement When Feasible } \\
\hline $2 \mathrm{~d}$ & HOV Improvements at Powell Street and I-80 in Emeryville - Park-and-Ride Lot \\
\hline 3 & MacArthur Onramp Bus Lane \\
\hline $5 \mathrm{f}$ & Commuter Parking - SR-24 and Telegraph Avenue $/ 56^{\text {th }}$ Street \\
\hline $5 \mathrm{~h}$ & Commuter Parking - BART Parking Capacity Increases \\
\hline $6 \mathrm{~b}$ & Partner with Developers of Ridesharing Mobile Applications - Casual Carpools \\
\hline $9 \mathrm{a}$ & Increased Enforcement - Adding HOV Facility Patrols \\
\hline 13 & Congestion Pricing \\
\hline $14 \mathrm{a}$ & Eastbound Tolling - Downtown San Francisco Cordon \\
\hline \multicolumn{2}{|c|}{ Priority 4: Recommend Against Implementation } \\
\hline $2 \mathrm{a}$ & $\begin{array}{l}\text { HOV Improvements at Powell Street and I- } 80 \text { in Emeryville - Convert Right Lane of I- } 80 \\
\text { to HOV from Before West Frontage Road Onramp to Powell Street Onramp }\end{array}$ \\
\hline $4 \mathrm{c}$ & Expand Bus Service - SolTrans \\
\hline $5 \mathrm{~g}$ & Commuter Parking - I-580 and Broadway/Piedmont Avenue \\
\hline
\end{tabular}


At the top of the list (in no particular order) are onramp improvements, such as restriping and upgrading the inlets on West Grand Avenue to support an HOV queue jump from before the Maritime Avenue intersection to the existing HOV onramp, converting the Powell Street onramp into HOV only, adding access from more directions, and connecting the top of the ramp directly to the existing HOV lanes right before the toll plaza. Partnering with developers of ridesharing apps also received highest priority, to help commuters access transit stations and to provide vanpool/minibus service. One carpool strategy is highly recommended - implementing a citizen report system for carpool violators. Two tolling strategies that work have highest priority as well, that is implementing electronic tolling at the Bay Bridge Toll Plaza and converting the toll plaza into a bidirectional facility. Lastly, two "bigger picture" items are included: shifting corporate cultures away from requiring single-occupancy vehicle use and shifting land-use planning to make use of TODs and reverse commutes.

Once these strategies have been implemented or at least secured financially and politically, priority should be given to the second tier of strategies. These include expanding or altering AC Transit and WestCAT transbay bus service, adding five park-and-ride lots, implementing an enhanced casual carpool system, shifting attitudes on carpooling, increasing BART train and station capacity, and implementing express and/or skip-stop "metro" service on BART.

After all of the above strategies have been exhausted, the lowest level of recommended strategies should be tackled. These include the MacArthur onramp and queue jump, additional parkand-ride capacity, partnering with rideshare apps to promote causal carpooling, partnering with casual carpool app developers to increase carpool rates, increasing HOV enforcement, and applying congestion pricing and/or a downtown San Francisco toll cordon.

Three strategies were explored, but should not be implemented. The HOV lane on I- 80 from before the West Frontage Road onramp to the Powell Street onramp should not be implemented as it offers little benefit for huge expense. Expanded bus service for SolTrans is not recommended due to fleet age and superfluous nature of the service. Lastly, the park-and-ride lot 
at I-580 and Broadway/Piedmont Avenue is isolated from the freeway and would replace an existing land use.

With these strategies prioritized, they can be tackled and implemented as soon as feasible in order to improve the notoriously horrendous transbay commute. This will allow commuters to get where they are going faster, reducing time wasted in traffic or cramped in trains, buses or ferries, all the while improving overall health and the economy. 


\section{CONCLUSIONS}

As shown throughout this thesis, congestion is a major issue on the transbay corridor across all modes of transportation, including private vehicles and buses on the Bay Bridge, BART in the Transbay Tube, and ferry services across the Bay. This severe congestion was quantitatively assessed for demand, capacity, and occupancy, in order to glean potential opportunities for improvement. Sixteen strategies were compiled, combining existing proposals and plans relevant to the transbay corridor with several new proposals, both original to this thesis and building upon past experiences and suggestions of others. These strategies were detailed and evaluated in terms of costs and benefits, ultimately being ranked in priority order. While it would be fantastic to implement every component of all sixteen strategies here and now, budget shortfalls, political will, bureaucratic inertia, and other constraints prevent this idealism.

\subsection{RESEARCH LIMITATIONS}

There are several limitations to this research. Perhaps most notably is that while the data provided is mostly complete, there are some assumptions that had to be made. One such assumption is the eastbound private vehicle occupancy of 1.54 persons per vehicle, based on a weighted average of westbound HOV and non-HOV occupancies. Another assumption is that the average private vehicle has a capacity of five persons, which was based on the median value for fleet sales data rather than an average of operational fleet data or even better, exact counts by vehicle type on the bridge. One other assumption is that BART users immediately exit the system upon arrival. While generally this is true, aberrations in exit times could affect the binning of the data, producing slightly different results. Speaking of transit, another assumption was capacity for AC Transit, which was based on load factors rather than direct capacity numbers. Lastly, WestCAT Lynx data required some guesswork in order to bin fare counts to different buses, as not all fares were logged in the exact time and place that the rider got on the bus. For instance, some fares were logged with

coordinates over the Bay or a timestamp that surpasses the last arrival time of the day. While none 
of these assumptions are significant enough to entirely sideline this thesis, replacing them with direct and empirical values would help to further refine the analysis.

Another limitation of this research is the wide range of data. Ridership and vehicle counts spanned September to October in 2015 and June to October in 2016, as well as pockets of data pulled from other time periods, such as vehicle occupancy rates from 2012. This could lead to aberrations in analysis as more recent numbers are more likely to show higher demand.

One other limitation is the upcoming Transbay Terminal. Presently, East Bay buses wade through traffic in downtown San Francisco to access the Temporary Transbay Terminal. However, once the new Transbay Terminal and its direct bus-only connection to the Bay Bridge opens, buses will be able to more quickly access the Transbay Terminal, improving reliability, reducing travel times, and increasing ridership. Ridership data tends to fluctuate year-by-year with a generally upward trend, but the opening of the Transbay Terminal will likely have a significant impact on ridership growth.

One major limitation of this research is that while some costs and benefits were quantified, many were estimated. This is due to limitations of the nature of a thesis, in that a full complement of technical experts is not available to accurately assess the time savings, ridership growth, or other metrics of success and their costs for each of the strategies. For the purviews of this research, estimates based on similar examples will have to do.

One limitation that is not rectifiable with any budget or staff size is that the situation is constantly evolving over time. Many of the news articles used in this research were published less than a month before being integrated into the thesis. As mentioned before, ridership data is constantly fluctuating and generally increasing. Therefore, if this thesis was to be done a year earlier or a year later, differences in both data procured and recommendations developed could occur.

One last limitation is that congestion on the Bay Bridge corridor is overall a unique case. There is plenty of literature on improving individual components, such as the various congestion cordon case studies, or effects of improving transit on ridership, but the situation as a whole is 
rather peerless. The San Francisco Bay presents a unique geographical barrier that is just wide enough to prevent a multitude of crossings (unlike e.g. a river), but just narrow enough to promote the notion that crossing is not a huge endeavor (unlike e.g. the English Channel). This lends the Bay Area to have heavy transbay travel demands, as Chapter 3 thoroughly demonstrated, but few routes on which to cross. The limitation here is that solutions that work in other places with more conventional constraints might run into operational issues in the Bay. One example from the literature review is Jochum et al.'s suggestion for Columbus to implement a light rail system. This proposal would not work on the transbay corridor because it would require either taking away from auto capacity at great operational and fiscal expense, or building a second tube or bridge to accommodate the tracks. At that point, the light rail right-of-way would be better utilized as a second BART crossing rather than its own entity.

\subsection{FUTURE RESEARCH GOALS}

This research takes an inventory of existing research and greatly expands upon it. Future research would be wise to take into account the shortcomings of this research, as well as continuing to expand the toolkit of potential solutions. One future goal should be to replace the assumptions listed above with exact values where possible. For instance, seat count data for private vehicles was assumed using the median seats per car sold, whereas exact counts would be more preferable. Additionally, research on the rate of casual carpooling, as well as origin-destination demand counts, could help further shed light on how this tactic operates and areas for improvement. Relatedly, costs and benefits should be estimated using empirical and established practices.

An overarching goal of future research should be to continue to brainstorm new ideas as well as adopt the best practices from elsewhere. This will ensure that no fresh opportunities are missed because the researchers are set in old ways. Some opportunities include improved methods of implementing dynamic tolling and even seemingly unlikely ideas such as reversible lanes or HOV lanes on the bridge itself. After all, the Bay Bridge itself was once deemed impossible. 
One last goal is to continue to monitor the evolving transbay commute conditions. With each transbay mode at capacity during peak hours, the projected $30 \%$ growth in Bay Area population will have a difficult time traveling between Oakland and San Francisco without capacity enhancements or demand management. A keen eye will be needed to adapt to shifting demographics and emerging technologies. This will become especially important once connected and autonomous vehicles start to enter the mainstream. 


\section{REFERENCES}

AECOM. (2012). San Francisco Bay Crossings Study Update. Oakland, CA: Bay Area Toll Authority.

Alameda County Transit. (2015). Staff Report (AC Transit Report No. 15-191). Oakland, CA: Alameda County Transit. Retrieved from http://www.actransit.org/wpcontent/uploads/board_memos/15-191\%20Transbay\%20Ridership.pdf

Alameda County Transit. (2015). Transbay Service. Retrieved February 29, 2016, from http://www.actransit.org/rider-info/transbay-service/

Alameda County Transportation Commission. (2011). Project 22780. Oakland, CA: Alameda County Transportation Comission.

American Highway Users Alliance. (2015). Unclogging America's Arteries 2015: Prescriptions for Healthier Highways. Washington, DC: American Highway Users Alliance.

Arup. (2014). I-80 / I-680 / I-780 / State Route 12 Transit Corridor. Solano Transportation Authority.

BART. (2014a). Building a Better BART. Oakland, CA: Bay Area Rapid Transit. Retrieved from https://www.bart.gov/

sites/default/files/docs/BART\%20Building\%20a\%20Better\%20BART\%20Executive\%20 Summary_0.pdf

BART. (2014b). Short Range Transit Plan and Capital Improvement Program. Oakland, CA: BART. Retrieved November 23, 2016, from https://www.bart.gov/sites/default/files/docs/FY15FY24\%20BART\%20SRTP\%20CIP\%208.28.14.pdf

BART. (2016a, September 22). Bay Area Rapid Transit. Retrieved September 22, 2016, from System Facts: http://www.bart.gov/about/history/facts

BART. (2016b). 2016 Monthly Ridership Reports. Retrieved October 18, 2016, from http://www.bart.gov/about/reports/ridership

BART. (2016c, November 2). Why New Cars. Retrieved November 2, 2016, from Bay Area Rapid Transit: http://www.bart.gov/about/projects/cars/why-new-cars

BART. (2016d). Index of /ridership. Oakland: BART. Retrieved November 2, 2016, from http://64.111.127.166/ridership/

Bay Area Rapid Transit [BART]. (2015). BART_Ridership_FY73_FY15. Retrieved February 29, 2016, from http://www.bart.gov/sites/default/files/docs/BART_Ridership_FY73_FY15.xls

Bay Area Toll Authority. (2016). San Francisco-Oakland Bay Bridge. (Bay Area Toll Authority) Retrieved February 29, 2016, from http://bata.mtc.ca.gov/bridges/sf-oak-bay.htm 
Belmonte, P. (2014). All Aboard: Investigating Public Transit Use across Income Levels and Implications for Transportation Policy in the United States. Master of Public Policy Thesis, Georgetown University, Washington, DC. Retrieved from https://repository.library.georgetown.edu/handle/10822/709891

Cabanatuan, M. (2015, January 31). Prospects for 2nd BART tube gain momentum, but wait could be long. San Francisco, CA: SFGATE. Retrieved from http://www.sfgate.com/bayarea/article/Prospectsfor2ndBARTtubegainmomentumbut605 4215.

California Independent System Operator Corporation. (2016). Comments of the California Independent System Operator Corporation. California Independent System Operator Corporation. Retrieved October 26, 2016, from http://www.caiso.com/Documents/20164-15_A1208007_FlexAlert_PD_Comments_Final.pdf

Caltrain. (2015). Caltrain 2015 Annual Passenger Count. Retrieved November 23, 2016, from http://www.caltrain.com/Assets/_Marketing/pdf/2015+Annual+Passenger+Counts.pdf

Caltrain. (2016, April 4). Weekday Timetable. Retrieved November 2, 2016, from Caltrain.com: http://www.caltrain.com/schedules/weekdaytimetable.html

Caltrans. (2002, Spring). East Span News Spring 2002. Retrieved November 1, 2016, from San Francisco-Oakland Bay Bridge East Span Seismic Safety Project: http://www.dot.ca.gov/dist4/eastspans/spring02.html

Caltrans. (2012). 2012 Bay Area Managed Lanes. Office of Highway Operations. Oakland: Caltrans.

Caltrans. (2014). 2014 Annual Average Daily Truck Traffic on the California State Highway System. Division of Traffic Operations, Office of Performance. Sacramento, CA: Caltrans. Retrieved from http://www.dot.ca.gov/trafficops/census/docs/2014_aadt_truck.pdf

Caltrans. (2015a). 2014 Traffic Volumes on the California State Highway System. Sacramento, CA: Caltrans.

Caltrans. (2015b). SFOBB_TollPlaza Counts_2015Fall.

Caltrans. (2015c). Ramp Volumes on the California State Freeway System District 4. Sacramento: Caltrans. Retrieved from http://www.dot.ca.gov/trafficops/census/docs/2014-ramp-voldistrict04.pdf

Caltrans. (2015d). FY 2007-2015 Park Ride Lot Usage. Sacramento: Caltrans.

Caltrans. (2016a).PeMS_SFOBB_Eastbound_EastSpan.

Caltrans. (2016b).PeMS_SFOBB_Westbound_EastSpan. 
Caltrans. (2016c, October 3). Modify Inlet. Retrieved October 3, 2016, from California Department of Transprotation:

http://sv08data.dot.ca.gov/contractcost/graph.php?code=152604\&unit=EA\&startPage=re sults.php $\% 3$ Fitem $\% 253$ Dinlet $\% 2526 \mathrm{~min} \% 253 \mathrm{D} \% 2526 \mathrm{max} \% 253 \mathrm{D} \% 2526 \mathrm{minU} \% 253 \mathrm{D}$ \%2526maxU\%253D\%2526unit\%253DEA\%2526Year\%253Dy2016\%2526sortby\%253D item $\% 2526$ desc $\% 253 \mathrm{D} \% 2526$ convert $\% 253 \mathrm{D} 1 \% 2526$ o

Caltrans. (2016d, October 3). Remove Painted Traffic Stripe. Retrieved October 3, 2016, from California Department of Transportation:

$\mathrm{http} / /$ sv08data.dot.ca.gov/contractcost/results.php?item=remove+paint\&ob=0\&DISTRIC $\mathrm{T} \% 5 \mathrm{~B} \% 5 \mathrm{D}=04 \& Y$ ear $\% 5 \mathrm{~B} \% 5 \mathrm{D}=\mathrm{y} 2016 \& \mathrm{~min}=\& \max =\& \operatorname{minU}=\& \max \mathrm{U}=\&$ unit $=\mathrm{LF} \& \mathrm{con}$ vert $=1 \&$ start $=$ Search

Caltrans. (2016e, October 3). Traffic Stripe. Retrieved October 3, 2016, from California Department of Transportation:

http://sv08data.dot.ca.gov/contractcost/results.php?item=paint\&min=\&max $=\& \min U=\&$ $\max U=\&$ unit $=$ LF $\& D I S T R I C T=04 \& Y$ ear $=y 2016 \&$ sortby $=i$ tem $\& d e s c=\&$ convert $=1 \& o b=$ 0

Caltrans. (2016f, October 3). Remove Concrete Barrier. Retrieved October 3, 2016, from California Department of Transportation:

http://sv08data.dot.ca.gov/contractcost/graph.php?code=153221\&unit=LF\&startPage=res ults.php $\% 3$ Fitem $\% 253$ Dremove $\% 252$ Bconcrete $\% 252$ Bbarrier $\% 25260 b \% 253 \mathrm{D} 0 \% 2526 \mathrm{Y}$ ear $\% 25255 \mathrm{~B} \% 25255 \mathrm{D} \% 253 \mathrm{Dy} 2016 \% 2526 \mathrm{Year} \% 25255 \mathrm{~B} \% 25255 \mathrm{D} \% 253 \mathrm{Dy} 2015 \% 252$ 6 Year $\% 25255 \mathrm{~B} \% 25255 \mathrm{D} \% 253 \mathrm{Dy} 2014 \% 2526$ Year

Caltrans. (2016g, November 1). Performance > Aggregates $>$ Time Series. Retrieved November 1, 2016, from PeMS:

http://pems.dot.ca.gov/?report_form=1\&dnode=VDS\&content $=1$ loops\&tab $=$ det_timeserie s\&station_id $=401503 \&$ s_time_id $=1470009600 \&$ s_time_id_f $=08 \% 2 \mathrm{~F} 01 \% 2 \mathrm{~F} 2016+00 \% 3$ 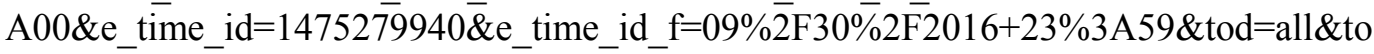 d_from $=0 \&$ tod_to $=0 \&$ dow_ $1=0$ on $\&$ dow $2=0$

Caltrans. (2016g, October 3). Remove Asphalt Concrete Surfacing. Retrieved Octboer 2016, 2016, from California Department of Transportation:

http://sv08data.dot.ca.gov/contractcost/graph.php?code=150857\&unit=SQYD\&startPage $=$ results.php $\% 3$ Fitem $\% 253$ Dremove $\% 2526$ ob $\% 253 \mathrm{D} 0 \% 2526$ DISTRICT $\% 25255 \mathrm{~B} \% 252$ 55D\%253D04\%2526Year\%25255B\%25255D\%253Dy2016\%2526min\%253D\%2526ma $\mathrm{x} \% 253 \mathrm{D} \% 2526 \mathrm{minU} \% 253 \mathrm{D} \% 2526 \mathrm{maxU} \% 253 \mathrm{D} \% 2526$ unit $\%$

Caltrans. (2016h, November 1). Performance > Aggregates $>$ Time Series. Retrieved November 1, 2016, from PeMS:

http://pems.dot.ca.gov/?report_form $=1 \&$ dnode $=$ VDS\&content $=1$ loops\&tab $=$ det_timeserie s\&station_id $=402814 \&$ s_time_id $=1470009600 \&$ s_time_id_f $=08 \% 2 \mathrm{~F} 01 \% 2 \mathrm{~F} 2016+00 \% 3$ 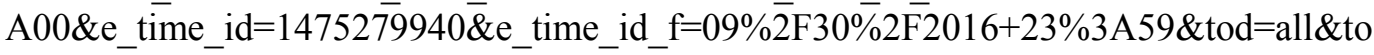 d_from $=0 \&$ tod_to $=0 \&$ dow_ $1=0$ on\&dow $2=0$

Caltrans. (n.d.). Life-Cycle Cost Analysis Procedures Manual. Sacramento: Caltrans. Retrieved from http://www.dot.ca.gov/hq/maint/Pavement/Offices/Pavement_Engineering/LCCA_Docs/ Appendix5_Aug_1_2013.pdf 
Capital Corridor Joint Powers Authority. (2015, October 26). Capitol Corridor Schedule. Retrieved February 29, 2016, from http://www.amtrak.com/ccurl/785/584/CapitolCorridor-Schedule-102615.pdf

Chariot. (2016a, October 25). Richmond Racer. Retrieved October 25, 2016, from Chariot: https://www.chariot.com/routes/richmond-racer

Chariot. (2016b, October 25). Chariot for Work. Retrieved October 25, 2016, from Chariot: https://www.chariot.com/enterprise

Cooper, J. (2014, January 3). Top 5 Largest San Francisco Employers. Retrieved November 5, 2016, from San Francisco Business Times:

http://www.bizjournals.com/sanfrancisco/blog/2014/01/top-5-largest-san-franciscoemployers.html

County of Los Angeles. (2005). County of Los Angeles Department of Public Works Joins Forces with Caltrans to Eliminate Storm Water Pollution. Department of Public Works. Los Angeles: County of Los Angeles. Retrieved from http://dpw.lacounty.gov/PRG/StormWater/Partnership_NR_FINAL.pdf

Cudney, G. (2015, March). Parking Structure Cost Outlook for 2015. Retrieved November 23, 2016, from Carl Walker: http://www.carlwalker.com/wp-content/uploads/2015/07/CarlWalker-2015-Cost-Article.pdf

Dick, D., Wire, J., Witt, K., \& Mulligan, D. (2011). Discussion and Possible Action Relative to the Strategic Development Plan for All Electronic Toll Collection on the Golden Gate Bridge. San Francisco: Golden Gate Bridge Highway and Transportation District. Retrieved November 2, 2016, from http://goldengate.org/board/2011/agendas/documents/FA01.27.11s4AETstaff_rpt.pdf

Edson, K. (2013). Legislative and State Regulatory Update. California Independent System Operator Corporation. Retrieved October 26, 2016, from http://www.caiso.com/Documents/LegislativeStateRegulatoryUpdate-May2013.pdf

Employment Devlopment Department. (2013). Special Report of 2006 to 2010 County-to-County Commuting Flows. U.S. Census Bureau.

FasTrak. (2015). Where to Use. Retrieved November 1, 2016, from FasTrak: https://www.bayareafastrak.org/en/howitworks/whereToUse.shtml\#bay

Federal Highway Administration. (2011, March 30). Retrieved November 2, 2016, from http://www.fhwa.dot.gov/ipd/images/revenue/webinar_033011/033011_image001.jpg

Federal Transit Administration. (2016, March 2016). How FTA Develops Regulations and Circulars. Retrieved October 25, 2016, from United States Department of Transportation: https://www.transit.dot.gov/regulations-and-guidance/fta-circulars/how-fta-developsregulations-and-circulars

Flex Alert. (2013). Conservation in Action. Retrieved October 26, 2016, from Flexalert.org: http://flexalert.org/component/content/category/8-learn 
Goh, M. (2002, March). Congestion Management and Electronic Road Pricing in Singapore. Journal of Transport Geography, 10(1), 29-38. Retrieved from http://www.sciencedirect.com/science/article/pii/S0966692301000369

Golden Gate Bridge Highway and Transportation District. (2016). Toll Payment Choices. Retrieved November 1, 2016, from All Electronic Tolling on the Golden Gate Bridge: http://www.goldengate.org/tolls/tollpaymentchoices.php

Gordian. (2013). Parkign Garage Information. Retrieved November 23, 2016, from RSMeans Data: https://www.rsmeans.com/models/garage.aspx

Hawkins, A. (2016, October 3). New Jersey Town Decides to Pay Uber Instead of Building a Parking Lot. Retrieved October 15, 2016, from The Verge:

http://www.theverge.com/2016/10/3/13147680/uber-new-jersey-free-ride-parking-lottrain-commute

Hursh, M. (2015). Staff Report. Oakland, CA: Alameda-Contra Costa Transit District.

IHS Markit. (2014, Wednesday 16). SUVS and Crossovers Overtake Sedans to Become Most Popular Vehicle Body Style in the U.S., IHS Automotive Finds. Retrieved November 22, 2016, from News Releases: http://news.ihsmarkit.com/press-release/automotive/suvsand-crossovers-overtake-sedans-become-most-popular-vehicle-body-style-

Internal Revenue Service. (2015, December 17). 2016 Standard Milage Rates for Business, Medical and Moving Announced. Retrieved November 5, 2016, from IRS.gov: https://www.irs.gov/uac/newsroom/2016-standard-mileage-rates-for-business-medicaland-moving-announced

Jochum, C., Clendenin, T., Good, C., Mescher, J., \& Blevins, N. (2015). Comprehensive Public Transportation. Columbus: Ohio State University. Retrieved from https://kb.osu.edu/dspace/handle/1811/68900

Jones, N. (2016, January 15). BART Offers San Francisco Super Bowl City Commuting Tips. Retrieved November 2, 2016, from CBS SF Bay Area: http://sanfrancisco.cbslocal.com/2016/01/15/bart-offers-san-francisco-super-bowl-citycommuting-tips/

Kelley, K. (2007). Casual Carpooling - Enhanced. Journal of Public Transportation, 10(4), 119130. Retrieved from http://scholarcommons.usf.edu/cgi/viewcontent.cgi?article=1262\&context=jpt

Lazarus, D. (2014, November 19). Does Anyone Get Ticketed for Cheating on Freeway Toll Lanes? Retrieved October 26, 2016, from Los Angeles Times: http://www.latimes.com/business/la-fi-laz-express-toll-lane-tickets-20141119-story.html

Li, R. (2016, September 1). Exclusive: Skin Care Company Signs Lease for Huge East Bay Expansion. Retrieved November 5, 2016, from San Francisco Business Times: http://www.bizjournals.com/sanfrancisco/blog/real-estate/2016/09/east-bay-office-sunsetbishop-ranch-rodan-fields.html

Litman, T. (2011). London Congestion Pricing - Implications for Other Cities. Victoria Transport Policy Institute. Retrieved November 23, 2016, from http://www.vtpi.org/london.pdf 
MacArthur Station. (2014). Home. Retrieved November 5, 2016, from MacArthur Station: http://macarthurstation.com/

Matier, P., \& Ross, A. (2014, May 19). Peak-Hour Tolls Have Little Effect on Bay Bridge Congestion. Retrieved November 1, 2016, from SF Gate:

http://www.sfgate.com/bayarea/matier-ross/article/Peak-hour-tolls-have-little-effect-onBay-Bridge-5487995.php

Metropolitan Transportation Commission [MTC]. (2009, April). Transportation 2035 Plan for the San Francisco Bay Area FINAL. Oakland, CA: Metropolitan Transportation Commission. Retrieved from http://www.mtc.ca.gov/planning/2035_plan/FINAL/T2035_Plan-Final.pdf

Middlebrook, R., \& Mladjov, R. (2014, February). San Francisco - Oakland Bay Bridge Second Crossing. San Francisco, CA: STRUCTURE Magazine.

MTC. (2011). West Grand Avenue On-Ramp and Immediate Transbay Mobility Improvement Projects. Oakland, CA: Metropolitan Transportation Commission.

MTC. (2013). Plan Bay Area. Oakland: Metropolitan Transportation Commission. Retrieved November 5, 2016, from http://mtc.ca.gov/sites/default/files/0-Introduction.pdf

NJ Transit. (2012). Quarterly Ridership Trends Analysis. NJ Transit Market Analysis \& Pricing. NJ Transit. Retrieved November 23, 2016, from http://media.nj.com/bergen_impact/other/1Q2013.pdf

Phillips, K. (2016, August 17). BART Parking Spaces Filling Up Quickly. Retrieved October 15, 2016, from East Bay Times: http://www.eastbaytimes.com/2008/03/25/bart-parkingspaces-filling-up-quickly/

Plotner, S. (2015). RSMeans Building Construction Cost Data (73 ed.). Rockland, Maryland: Gordian.

Reyes, L. (2016, March 4). San Francisco's 25 Largest Tech Employers. Retrieved November 5, 2016, from San Francisco Business Times:

http://www.bizjournals.com/sanfrancisco/blog/techflash/2016/03/san-franciscos-25largest-tech-employers.html

Richards, G. (2015, August 20). Bay Bridge Metering Lights Will Be Upgraded (First Time Since 1974). Retrieved November 2016, 2016, from The Mercury News:

http://www.mercurynews.com/2015/08/20/bay-bridge-metering-lights-will-be-upgradedfirst-time-since-1974/

Richards, G. (2016, October 14). Roadshow: BART Trying to Squeeze in More Parking Spaces. Retrieved October 15, 2016, from The Mercury News: http://www.mercurynews.com/2016/10/14/roadshow-more-parking-at-new-bart-stations/

Rodriguez, J. F. (2016, August 29). Golden Gate Bridge may Remove Toll Plaza After 84 Drivers Crash Into It. Retrieved November 2, 2016, from SF Examiner: http://www.sfexaminer.com/golden-gate-bridge-may-remove-toll-plaza-84-drivers-crash/ 
San Francisco Bay Ferry. (2016). San Francisco Bay Ferry. (San Francisco Bay Ferry) Retrieved February 29, 2016, from http://sanfranciscobayferry.com/

San Francisco County Transportation Authority [SFCTA]. (2010a). Mobility, Access and Pricing Study | Home. Retrieved November 1, 2016, from sfcta.org: http://www.sfcta.org/transportation-planning-and-studies/congestionmanagement/mobility-access-and-pricing-study-home

SF Casual Carpool. (2015). Etiquette. Retrieved October 25, 2016, from SF Casual Carpool: http://sfcasualcarpool.com/etiquette

SF Environment. (2009). Requirements of San Francisco's Commuter Benefits Ordinance. SF Environment. San Francisco: City and County of San Francisco. Retrieved November 1, 2016, from http://www.commuteconnection.com/assets/pdf/SF\%20Commuter\%20Benefits\%20Ordin ance.pdf

SFCTA. (2010b). Case Studies: Stockholm and London. San Francisco: SFCTA. Retrieved November 1, 2016, from http://www.sfcta.org/sites/default/files/content/Planning/CongestionPricingFeasibilityStu dy/PDFs/MAPS_case_studies_111310.pdf

SFCTA. (n.d.). Mobility, Access and Pricing Study | Myth vs. Fact. Retrieved November 1, 2016, from sfcta.org: http://www.sfcta.org/mobility-access-and-pricing-study-myth-vs-fact

Shoup, D. (2002). Parking Cash Out. Los Angeles: University of California, Los Angeles. Retrieved November 1, 2016, from http://shoup.bol.ucla.edu/Parking\%20Cash\%20Out\%20Report.pdf

Smith, Y. (2016, November 30). Can Uber Ever Deliver? Part One - Understanding Uber's Bleak Operating Economics. Retrieved December 8, 2016, from Naked Capitalism: http://www.nakedcapitalism.com/2016/11/can-uber-ever-deliver-part-one-understandingubers-bleak-operating-economics.html

Solano Transportation Authority. (2014). Results of Solano Transportation Authority Intercity Routes Ridership Study. Suisun City.

Tang, H., Dick, T., \& Caughron, B. (2016). A Model for Optimal Selection of Projects to Improve Running Time and Operating Cost Efficiency on Passenger Rail Corridors. Washington, DC: Transportation Research Board.

The International Bridge, Tunnel and Turnpike Association. (2014, March). Success Stories from the Tolling Industry. Retrieved December 8, 2016, from SmartMove: http://ibtta.org/sites/default/files/documents/MAF/SmartMove_Golden\%20Gate\%20Brid ge.pdf

Transbay Service. (2016). (Alameda County Transit) Retrieved February 29, 2016, from http://www.actransit.org/rider-info/transbay-service/

Transportation Analytics. (2016). Short Range Transit Plan. Water Emergency Transportation Authority. 
U.S. Census Bureau. (2014). Means of Transportation to Work. Retrieved October 25, 2016, from American Fact Finder:

http://factfinder.census.gov/faces/tableservices/jsf/pages/productview.xhtml?src=bkmk

U.S. Census Bureau. (2016, November 5). QuickFacts San Francisco City, California. Retrieved November 5, 2016, from United States Census Bureau:

http:/www.census.gov/quickfacts/table/BZA010214/0667000,00

U.S. Energy Information Administration. (2016, June 3). Costruction Cost Data for Electric Generators Installed in 2013. Retrieved October 26, 2016, from Independent Statistics \& Analysis: http://www.eia.gov/electricity/generatorcosts/

Victoria Transport Policy Institute. (2015, December 21). Ridesharing - Carpooling and Vanpooling. Retrieved November 23, 2016, from TDM Encyclopedia:

http://www.vtpi.org/tdm/tdm34.htm

Wang, T., \& Chen, C. (2012, December). Attitudes, Mode Switching Behavior, and the Built Environment: A Longitudinal Study in the Puget Sound Region. Transportation Research Part A: Policy and Practice, 46(10), 1594-1607. Retrieved from http://www.sciencedirect.com/science/article/pii/S0965856412001310

Washington State Department of Transportation. (2016, March). HERO Program Common Questions. Retrieved from Washington State Department of Transportation: https://www.wsdot.wa.gov/HOV/HeroFAQ.htm

Water Emergency Transportation Authority. (2013, January). Short Range Transit Plan Final FY2012-FY2021. San Francisco, CA: Water Emergency Transportation Authority. Retrieved February 29, 2016, from http://sanfranciscobayferry.com/sites/default/ files/weta/publications/WETASRTPFINAL0113.pdf

Water Emergency Transportation Authority. (2014). Downtown San Francisco Ferry Terminal Expansion Project EIS/EIR. San Francisco, CA: Water Emergency Transportation Authority. Retrieved from http://sanfranciscobayferry.com/sites/default/files/weta/publications/WETASRTPFINAL 0113.pdf

Weiss, E. (2009, February 15). HOV Cheaters Run the Numbers: 65 MPH vs. $\$ 1,000$. Retrieved October 26, 2016, from Washington Post: http://www.washingtonpost.com/wpdyn/content/article/2009/02/14/AR2009021401833.html?sid=ST2009021401992

WestCAT Lynx. (2015, August 31). Express Bus Service between Hercules and San Francisco's Temporary Transbay Terminal. Retrieved February 29, 2016, from http://www.westcat.org/lynx/assets/Lynx_Brochure_31August2015.pdf

What Are Casual Carpools? (2016, October 25). Retrieved October 25, 2016, from Ridenow.org: http://www.ridenow.org/carpool/what.htm

Zipcar. (2016, November 5). Rates \& Plans. Retrieved November 5, 2016, from Zipcar.com: http://www.zipcar.com/business/check-rates/sf 


\section{APPENDICES}

\section{Appendix A: MTC Element 1}




\section{Element 1}

West Grand Avenue On-Ramp Shoulder Running Lane with Transit Signal Priority Along West Grand
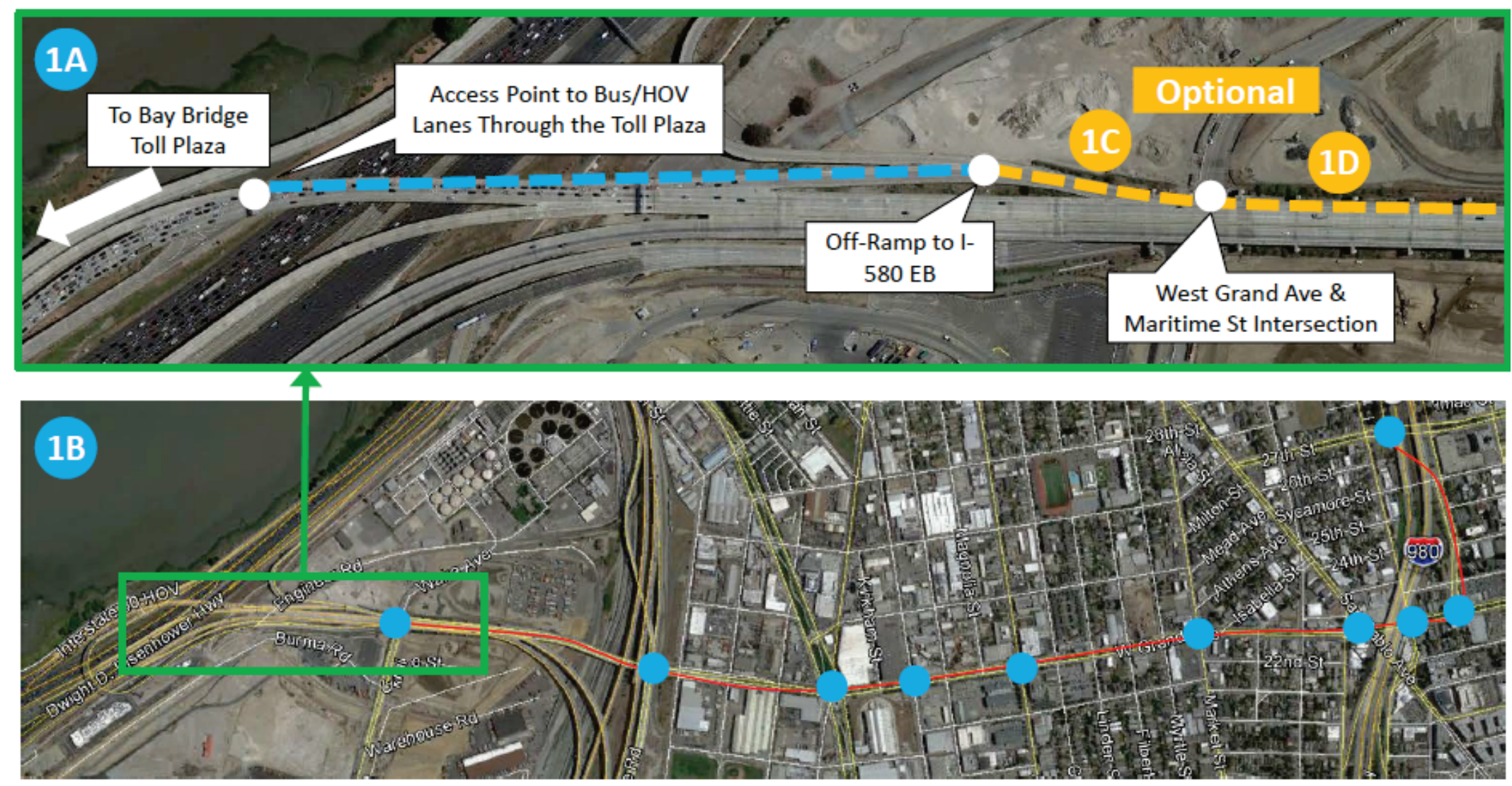

Shoulder Running Lane for Buses and HOVs

- (Optional) Extend Shoulder Running Lane

- Transit Signal Priority Corridor 


\section{Element $1 \mathrm{~A}$}

Provide a shoulder running lane for buses and HOVs on the right hand side, between I-580 off-ramp to Bus/HOV direct access
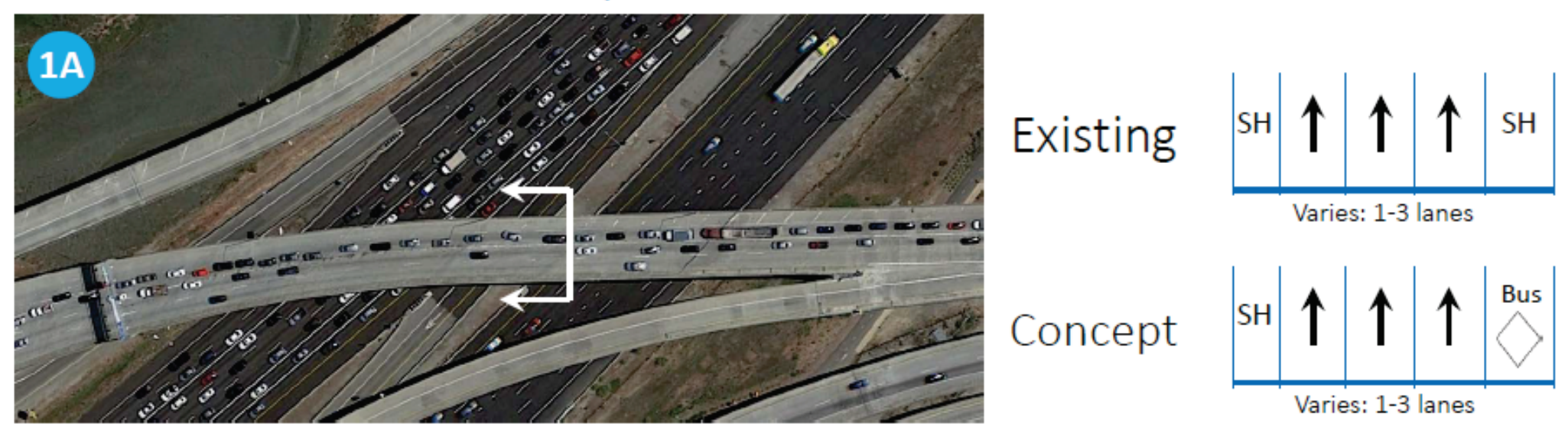

Some Buses Already Use Existing Shoulder to Get Direct Access to the Toll Plaza

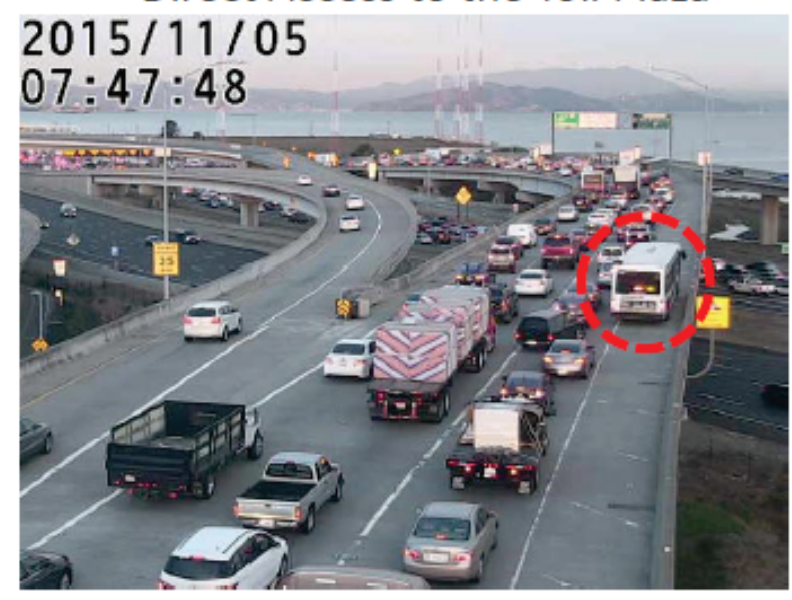

Labor Day Weekend (BART Closure): West Grand Operated as a Bus-Only On-ramp

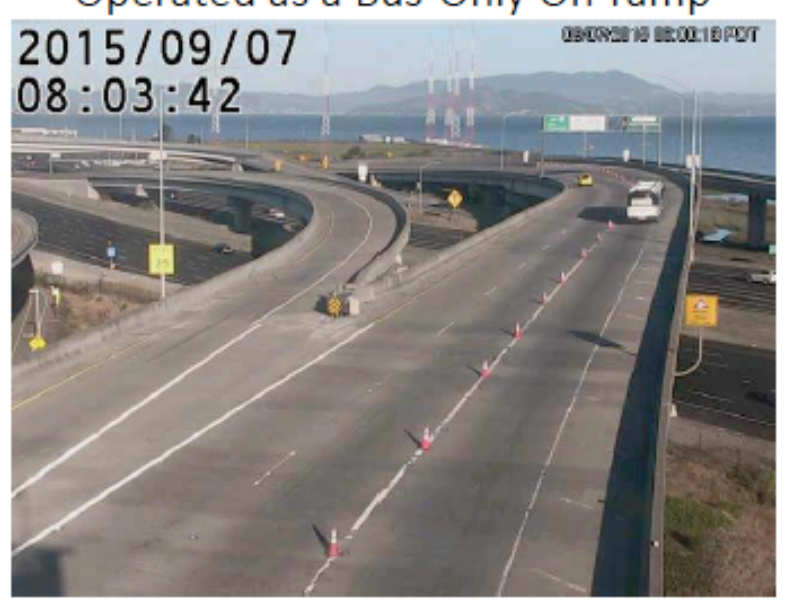




\section{Element $1 A$ - Drainage Grates}

- Existing Drainage Grates Should Be Travel Load Rated Based on Standard Plans

- Routine Maintenance is Required to Keep Inlets Free of Debris
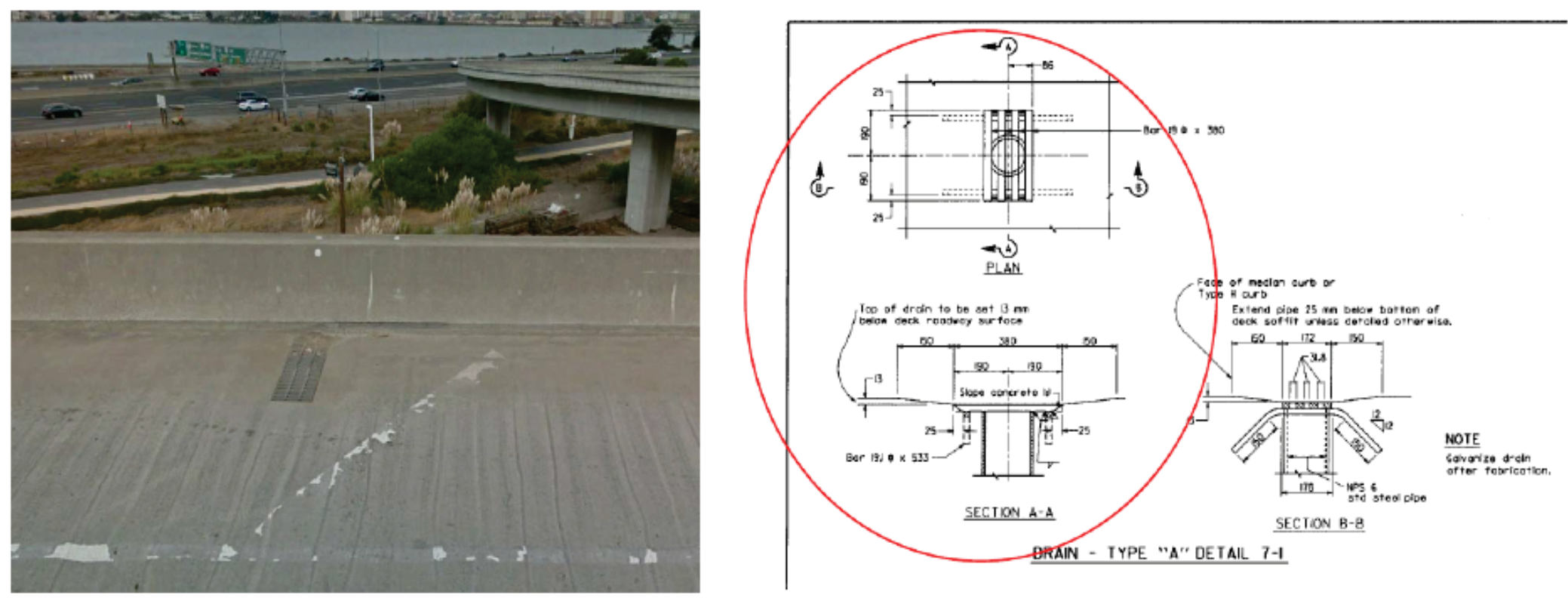


\section{Element 1C (Optional)}

Provide a shoulder running lane for buses and HOVs on the right hand side, between Maritime St. and I-580 EB off-ramp
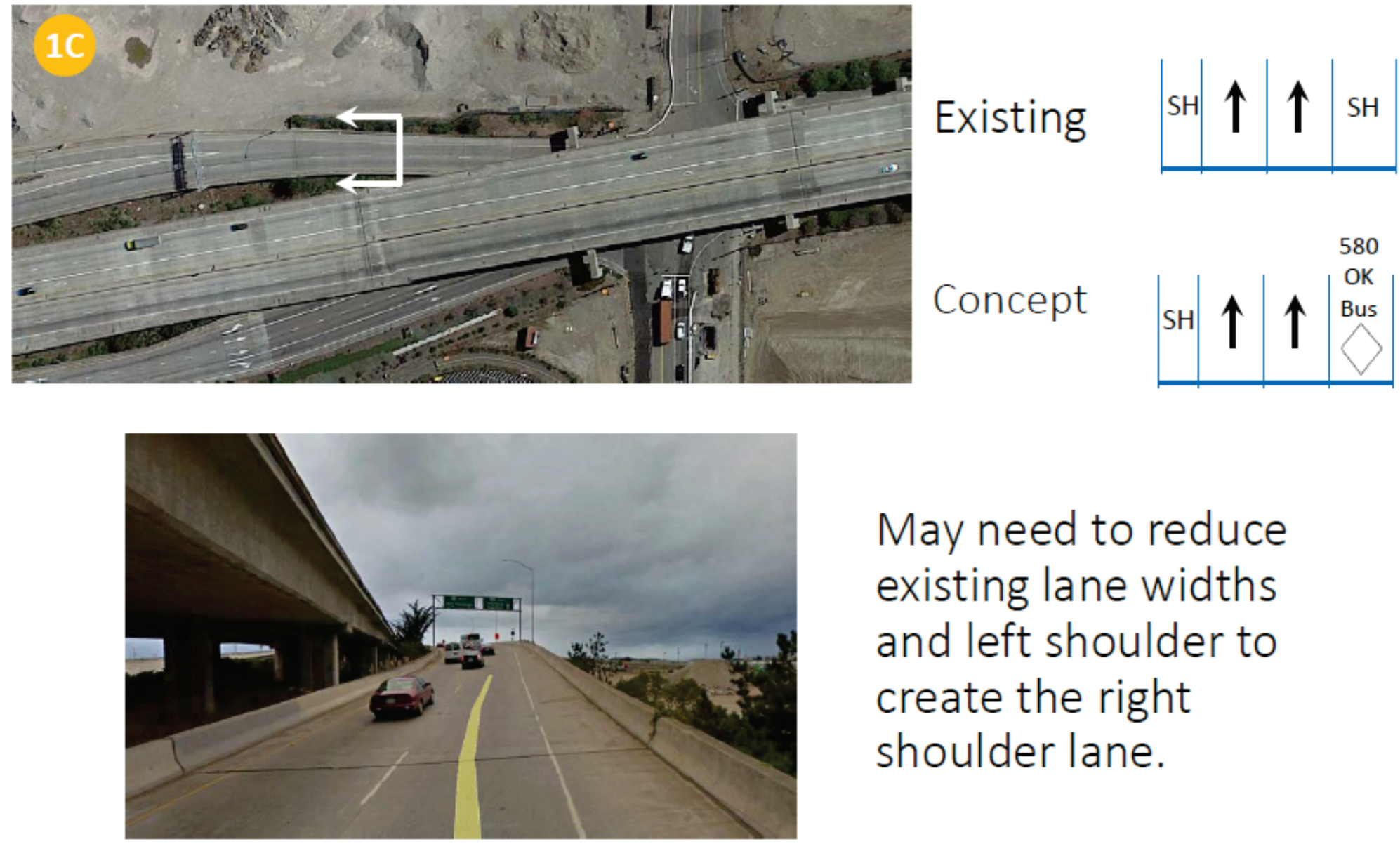

May need to reduce existing lane widths and left shoulder to create the right shoulder lane. 


\section{Element 1D (Optional)}

Provide a shoulder running lane for buses on the right hand side on West Grand Avenue westbound approach to Maritime St. intersection
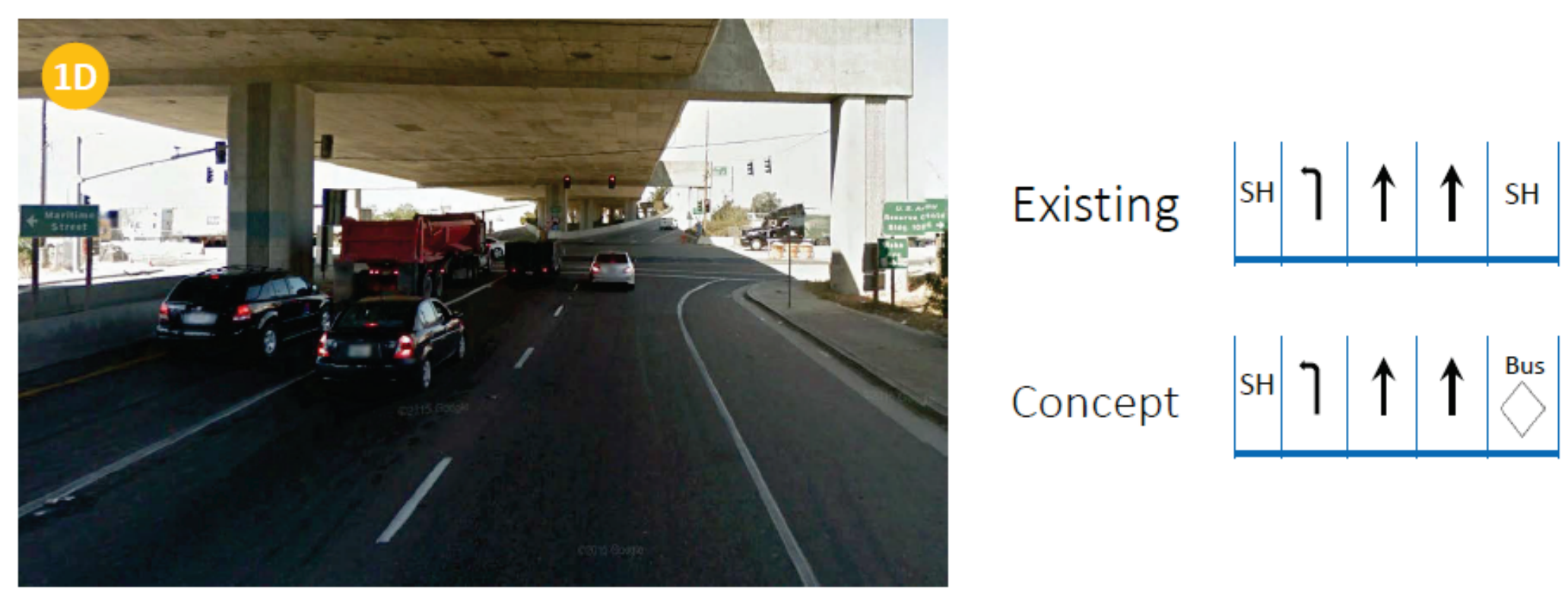

Provide Transit Signal Priority (TSP) for buses for the westbound approach to advance buses from the shoulder running lane. 


\section{Potential Design Exceptions for Project Element 1}

\section{West Grand Avenue On-Ramp Shoulder Running Lane}

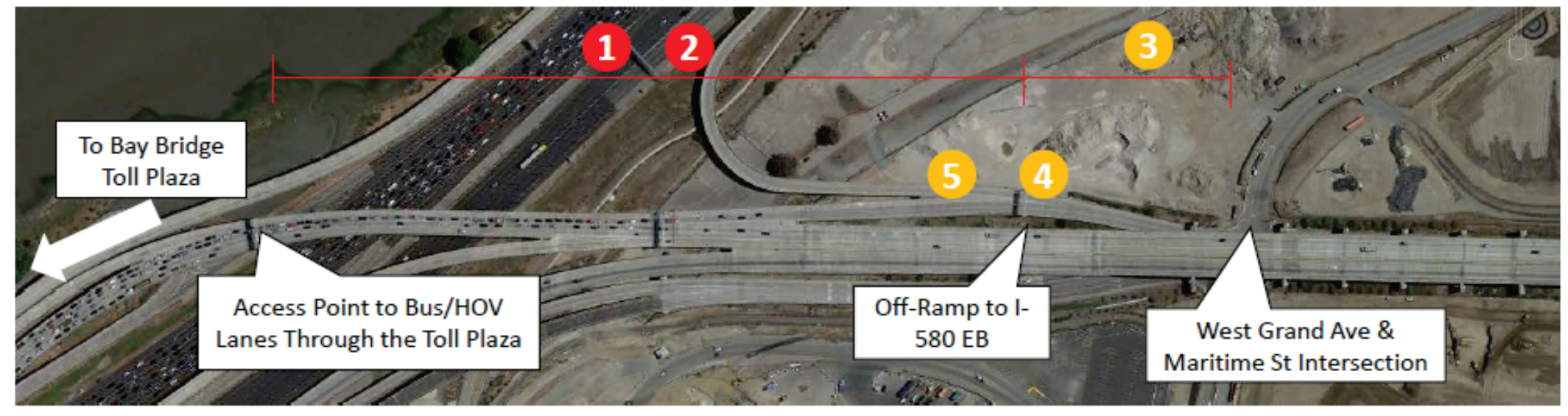

For Element $1 \mathrm{~A}$

1. Nonstandard lane widths along West Grand Avenue on-ramp: from I-580 offramp to HOV/Bus direct access: 11-foot lanes for about 1,300 feet.

2. Nonstandard right shoulder along West Grand Avenue on-ramp: from I-580 off-ramp to Bus/HOV access: about 1,300 feet.

Additional Design Exceptions for Optional Elements 1C and 1D:

3. Nonstandard shoulder and lane widths between the Maritime Street intersection to I-580 off-ramp

4. Nonstandard off-ramp gore to I-580 eastbound.

5. Nonstandard lane merge west of I-580 eastbound off-ramp. 
Appendix B: BATA Alternative 5: Powell St. / I-80 Ramp HOV Improvement 


\section{Highway Approach Improvement Alternatives}

Alternative 5: Powell Street / I-80 Ramps Intersection - HOV Improvement (Recommended)

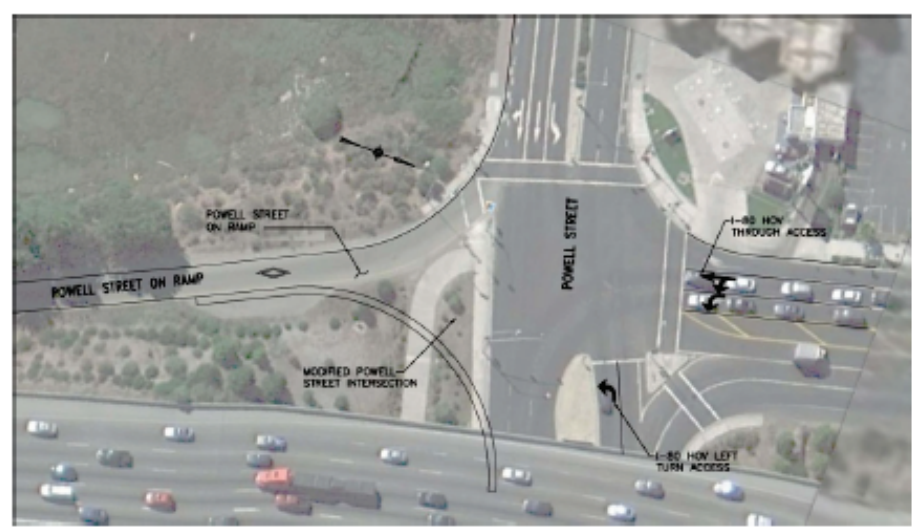

- Cost (FY2011\$): $\$ 1,248,000$

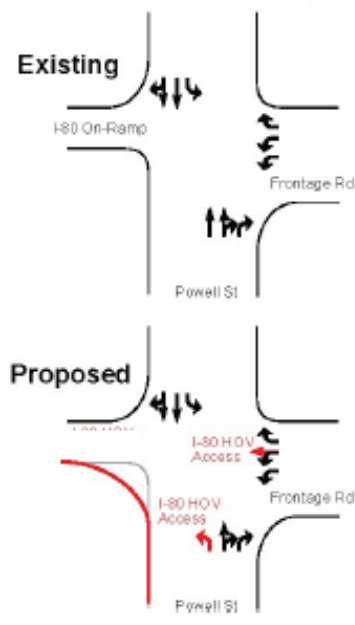

- Time Savings Benefit: $\$ 6,468,000$

- Benefit / Cost Ratio: 5.18, Rank \#1 
Appendix C: BATA Alternative 2: MacArthur Boulevard Bus Ramp 
Highway Approach Improvement Alternatives

Alternative 2: MacArthur Boulevard Bus Ramp (Recommended)

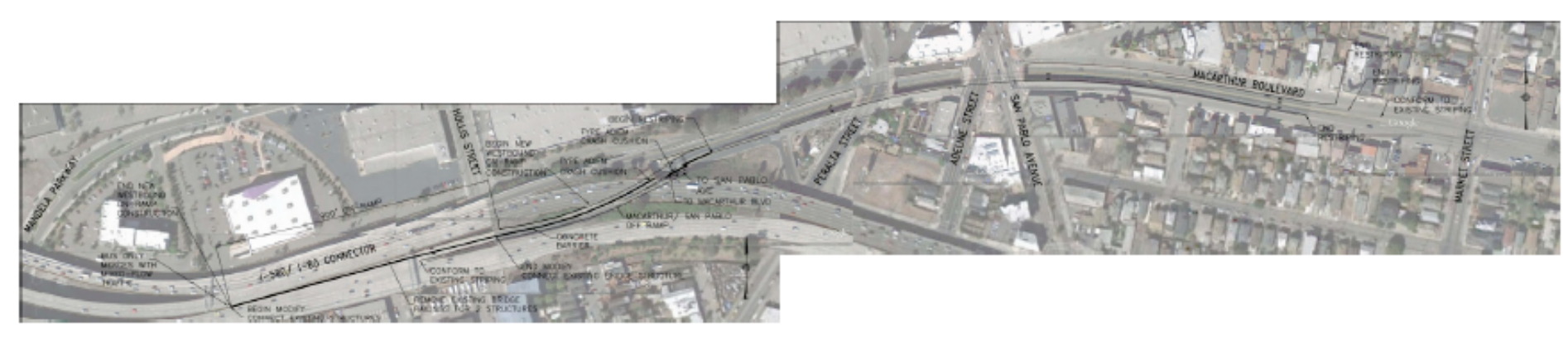

- Cost (FY2011\$): \$11,100,000

- Time Savings Benefit: \$13,340,000

- Benefit / Cost Ratio: 1.20, Rank \#4 
Appendix D: MTC Element 2 


\section{Element 2}

Add New Transbay Pilot Services and Reroute Existing AC Transbay Routes

New Transbay Pilot Services

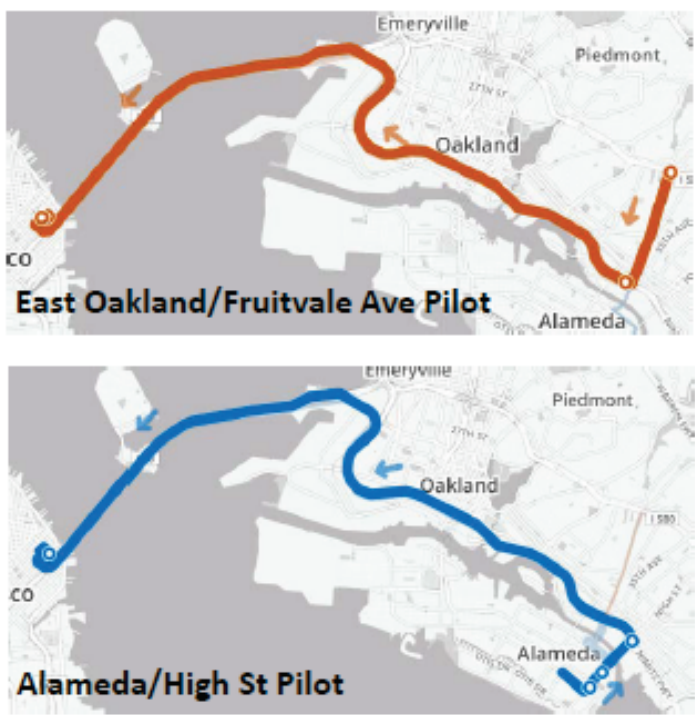

AC Transit estimates West Grand improvements could save 11 minutes per trip

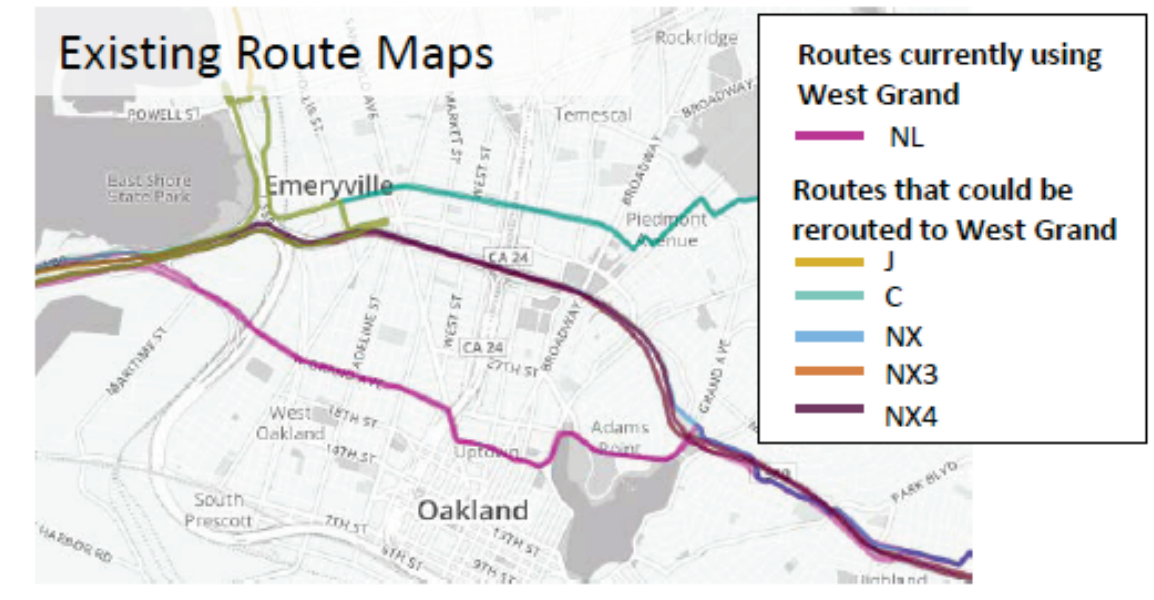

Existing+Future Routes Using West Grand

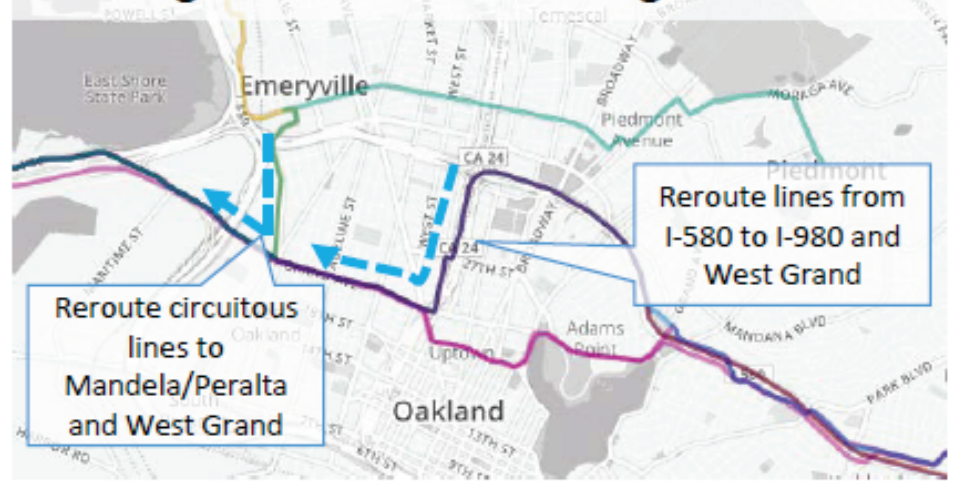




\section{Project Estimated Cost and Schedule}

\begin{tabular}{|c|c|c|}
\hline Project Component & Cost & Schedule (months) * \\
\hline $\begin{array}{l}\text { 1. W Grand On-Ramp Shoulder Running Lane** } \\
\text { 1A - SRL: West of 580 off-ramp } \\
\text { 1B - Transit Signal Priority along W Grand } \\
\text { 1C - SRL: Intersection to 580 off-ramp (Optional) } \\
\text { 1D - SRL: East of Maritime (Optional) }\end{array}$ & $\$ 3,000,000$ & $12+$ \\
\hline $\begin{array}{l}\text { 2. AC Transit - Express Buses *** } \\
\text { 20 Replacement Buses (Grand Ave and Buchanan) } \\
\text { 8 New Buses for Pilot Services (Fruitvale Ave and High St) } \\
\text { 3-Year O\&M Cost for Pilot Services }\end{array}$ & $\$ 27,800,000$ & $\begin{array}{c}\text { Immediate rerouting \& } \\
\text { bus procurement }\end{array}$ \\
\hline $\begin{array}{l}\text { 3. Commuter Parking Lots } \\
\text { 3A - Buchanan } \\
\text { 3B - Fruitvale } \\
\text { 3C - High Street }\end{array}$ & $\$ 4,800,000$ & \\
\hline \begin{tabular}{l} 
Total \\
\hline
\end{tabular} & & \\
\hline
\end{tabular}

Notes:

* Schedule: number of months estimated from notice to proceed, and includes Caltrans PID process, design and construction.

** New and replacement buses will be either double-deckers or articulated buses to be procured over $18-24$ months. 
Appendix E: MTC Element 3: Commuter Parking Lots 


\section{Element 3}

Provide Additional Commuter Parking Lots

- Implement commuter parking to facilitate carpooling and transit ridership

- Tie to new and augmented Transbay service to alleviate Transbay congestion and BART crowding in core area

3A

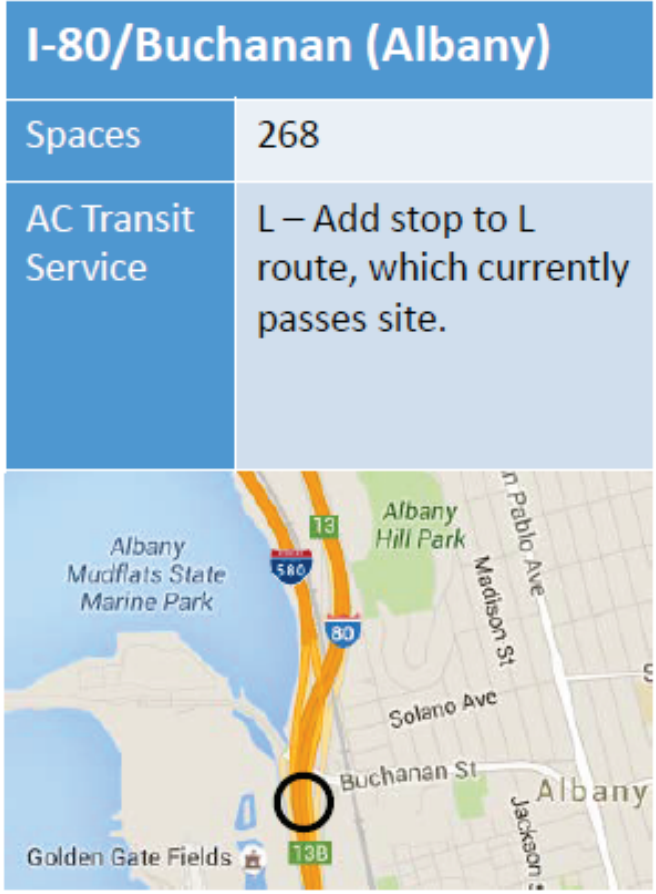

3B

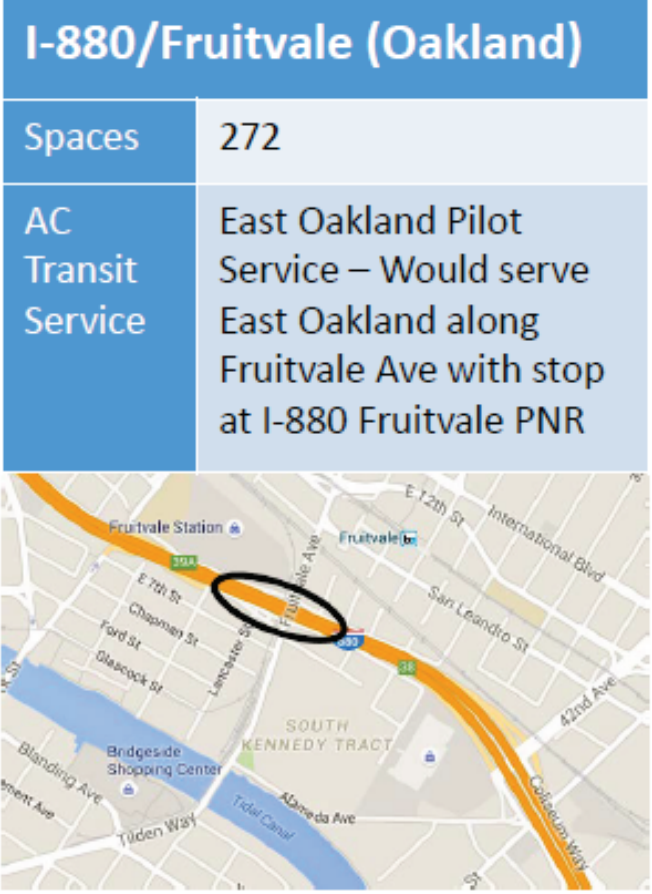

3C

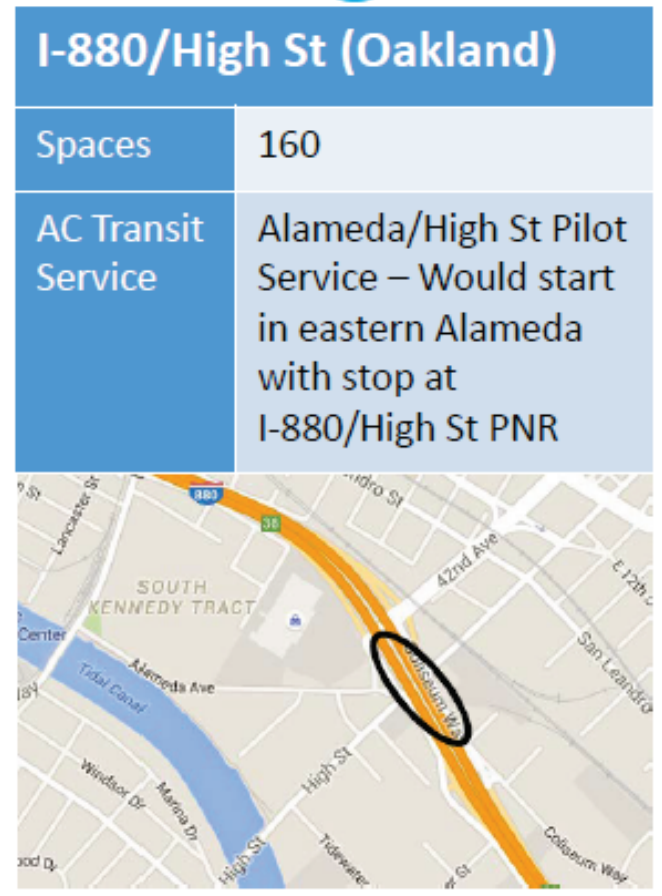


Appendix F: All Electronic Toll Collection Strategic Development Plan Financial Breakdown 
DRAFT

\section{APPENDIX A: Detailed Financial Information}

\section{All Electronic Tolling Strategic Development Plan}

10-Year Cost Projection (data are for fiscal years)

Numbers are in thousands

\begin{tabular}{|c|c|c|c|c|c|c|c|c|c|c|}
\hline SUMMARY & 2011 & 2012 & 2013 & 2014 & 2015 & 2016 & 2017 & 2018 & 2019 & 2020 \\
\hline Current System & $\$ 9,156$ & $\$ 9,334$ & $\$ 9,520$ & $\$ 9,714$ & $\$ 9,914$ & $\$ 10,117$ & $\$ 10,326$ & $\$ 10,537$ & $\$ 10,754$ & $\$ 10,975$ \\
\hline AET & & & $\$ 8,255$ & $\$ 7,914$ & $\$ 7,889$ & $\$ 7,860$ & $\$ 7,832$ & $\$ 7,804$ & $\$ 7,857$ & $\$ 7,918$ \\
\hline AET Cost Differential & & & $\$(1,265)$ & $\$(1,800)$ & $\$(2,025)$ & $\$(2,257)$ & $\$(2,494)$ & $\$(2,733)$ & $\$(2,897)$ & $\$(3,057)$ \\
\hline \multicolumn{11}{|l|}{ Total Costs } \\
\hline \multicolumn{11}{|l|}{ Current System } \\
\hline Personnel Costs & $\$ 5,567$ & $\$ 5,702$ & $\$ 5,846$ & $\$ 5,998$ & $\$ 6,155$ & $\$ 6,316$ & $\$ 6,481$ & $\$ 6,649$ & $\$ 6,823$ & $\$ 7,000$ \\
\hline Cash Collection Personnel & $\$ 4,780$ & $\$ 4,895$ & $\$ 5,017$ & $\$ 5,146$ & $\$ 5,279$ & $\$ 5,415$ & $\$ 5,555$ & $\$ 5,697$ & $\$ 5,844$ & $\$ 5,994$ \\
\hline ETC Personnel & $\$ 787$ & $\$ 807$ & $\$ 829$ & $\$ 852$ & $\$ 876$ & $\$ 901$ & $\$ 926$ & $\$ 952$ & $\$ 979$ & $\$ 1,006$ \\
\hline Transaction Costs & $\$ 3,589$ & $\$ 3,632$ & $\$ 3,674$ & $\$ 3,716$ & $\$ 3,759$ & $\$ 3,801$ & $\$ 3,845$ & $\$ 3,888$ & $\$ 3,931$ & $\$ 3,975$ \\
\hline $\csc$ Costs & $\$ 2,447$ & $\$ 2,476$ & $\$ 2,505$ & $\$ 2,534$ & $\$ 2,563$ & $\$ 2,592$ & $\$ 2,622$ & $\$ 2,651$ & $\$ 2,681$ & $\$ 2,711$ \\
\hline Bank and Credit Card Fees & $\$ 1,061$ & $\$ 1,075$ & $\$ 1,088$ & $\$ 1,101$ & $\$ 1,115$ & $\$ 1,128$ & $\$ 1,142$ & $\$ 1,156$ & $\$ 1,169$ & $\$ 1,183$ \\
\hline Other Costs & $\$ 81$ & $\$ 81$ & $\$ 81$ & $\$ 81$ & $\$ 81$ & $\$ \quad 81$ & $\$ \quad 81$ & $\$ \quad 81$ & $\$ \quad 81$ & $\$ \quad 81$ \\
\hline CURRENT SYSTEM TOTAL & $\$ 9,156$ & $\$ 9,334$ & $\$ 9,520$ & $\$ 9,714$ & $\$ 9,914$ & $\$ 10,117$ & $\$ 10,326$ & $\$ 10,537$ & $\$ 10,754$ & $\$ 10,975$ \\
\hline \multicolumn{11}{|l|}{ AET } \\
\hline Personnel Costs & & & $\$ 1,536$ & $\$ 1,580$ & $\$ 1,624$ & $\$ 1,670$ & $\$ 1,716$ & $\$ 1,764$ & $\$ 1,813$ & $\$ 1,864$ \\
\hline ETC Personnel & & & $\$ 749$ & $\$ 770$ & $\$ 792$ & $\$ 814$ & $\$ 837$ & $\$ 860$ & $\$ 884$ & $\$ 909$ \\
\hline AET Personnel & & & $\$ 787$ & $\$ 810$ & $\$ 832$ & $\$ 856$ & $\$ 879$ & $\$ 904$ & $\$ 929$ & $\$ 955$ \\
\hline Transaction Costs & & & $\$ 6,719$ & $\$ 6,334$ & $\$ 6,265$ & $\$ 6,190$ & $\$ 6,116$ & $\$ 6,040$ & $\$ 6,044$ & $\$ 6,054$ \\
\hline CSC Costs & & & $\$ 4,961$ & $\$ 4,616$ & $\$ 4,542$ & $\$ 4,462$ & $\$ 4,382$ & $\$ 4,301$ & $\$ 4,301$ & $\$ 4,307$ \\
\hline Bank and Credit Card Fees & & & $\$ 1,522$ & $\$ 1,482$ & $\$ 1,487$ & $\$ 1,492$ & $\$ 1,498$ & $\$ 1,503$ & $\$ 1,507$ & $\$ 1,511$ \\
\hline Other Costs & & & $\$ 236$ & $\$ 236$ & $\$ 236$ & $\$ 236$ & $\$ 236$ & $\$ 236$ & $\$ 236$ & $\$ 236$ \\
\hline AET TOTAL & & & $\$ 8,255$ & $\$ 7,914$ & $\$ 7,889$ & $\$ 7,860$ & $\$ 7,832$ & $\$ 7,804$ & $\$ 7,857$ & $\$ 7,918$ \\
\hline
\end{tabular}


DRAFT

\section{All Electronic Tolling Strategic Development Plan}

10-Year Revenue Projection (data are for fiscal years; numbers are in thousands)

\begin{tabular}{|c|c|c|c|c|c|c|c|c|c|c|}
\hline SUMMARY & 2011 & 2012 & 2013 & 2014 & 2015 & 2016 & 2017 & 2018 & 2019 & 2020 \\
\hline Current System & $\$ 102,304$ & $\$ 102,449$ & $\$ 102,595$ & $\$ 102,740$ & $\$ 102,887$ & $\$ 103,031$ & $\$ 103,177$ & $\$ 103,322$ & $\$ 103,469$ & $\$ 103,613$ \\
\hline AET & & & $\$ 102,825$ & $\$ 102,766$ & $\$ 102,909$ & $\$ 103,047$ & $\$ 103,177$ & $\$ 103,303$ & $\$ 103,642$ & $\$ 103,984$ \\
\hline AET Revenue Differential & & & 230 & 26 & 22 & 16 & - & (19) & 173 & 371 \\
\hline \multicolumn{11}{|l|}{ Revenue Breakdown } \\
\hline \multicolumn{11}{|l|}{ Current System } \\
\hline FasTrak & $\$ 62,388$ & $\$ 63,238$ & $\$ 64,093$ & $\$ 64,952$ & $\$ 65,816$ & $\$ 66,683$ & $\$ 67,555$ & $\$ 68,431$ & $\$ 69,312$ & $\$ 70,196$ \\
\hline Cash & $\$ 37,941$ & $\$ 37,231$ & $\$ 36,516$ & $\$ 35,797$ & $\$ 35,074$ & $\$ 34,346$ & $\$ 33,614$ & $\$ 32,878$ & $\$ 32,138$ & $\$ 31,393$ \\
\hline Violation & $\$ \quad 1,975$ & $\$ \quad 1,980$ & $\$ 1,986$ & $\$ \quad 1,991$ & $\$ 1,997$ & $\$ \quad 2,002$ & $\$ \quad 2,008$ & $\$ \quad 2,013$ & $\$ \quad 2,019$ & $\$ \quad 2,024$ \\
\hline CURRENT SYSTEM TOTAL & $\$ 102,304$ & $\$ 102,449$ & $\$ 102,595$ & $\$ 102,740$ & $\$ 102,887$ & $\$ 103,031$ & $\$ 103,177$ & $\$ 103,322$ & $\$ 103,469$ & $\$ 103,613$ \\
\hline \multicolumn{11}{|l|}{ AET } \\
\hline FasTrak & & & $\$ 71,290$ & $\$ 72,169$ & $\$ 73,052$ & $\$ 73,940$ & $\$ 74,831$ & $\$ 75,728$ & $\$ 75,936$ & $\$ 76,145$ \\
\hline License Plate & & & $\$ 21,992$ & $\$ 22,396$ & $\$ 21,940$ & $\$ 21,481$ & $\$ 21,020$ & $\$ 20,556$ & $\$ 20,612$ & $\$ 20,669$ \\
\hline Violation & & & $\$ 9,543$ & $\$ 8,201$ & $\$ 7,917$ & $\$ 7,626$ & $\$ 7,326$ & $\$ 7,019$ & $\$ 7,094$ & $\$ \quad 7,170$ \\
\hline AET TOTAL & & & $\$ 102,825$ & $\$ 102,766$ & $\$ 102,909$ & $\$ 103,047$ & $\$ 103,177$ & $\$ 103,303$ & $\$ 103,642$ & $\$ 103,984$ \\
\hline
\end{tabular}


Appendix G: BATA BART Alternative: Capacity Expansion Description 
Transit Improvement Alternatives

\section{BART: Capacity Expansion}

- "Saddlebags" at Embarcadero and Montgomery Stations will be necessary once daily systemwide ridership reaches 500,000 passengers (expected by 2025 )

- "Saddlebags" will improve the capacity within the Transbay Tube

- Side platforms will improve: - Side passenger boarding

- Vertical circulation

-Platform density

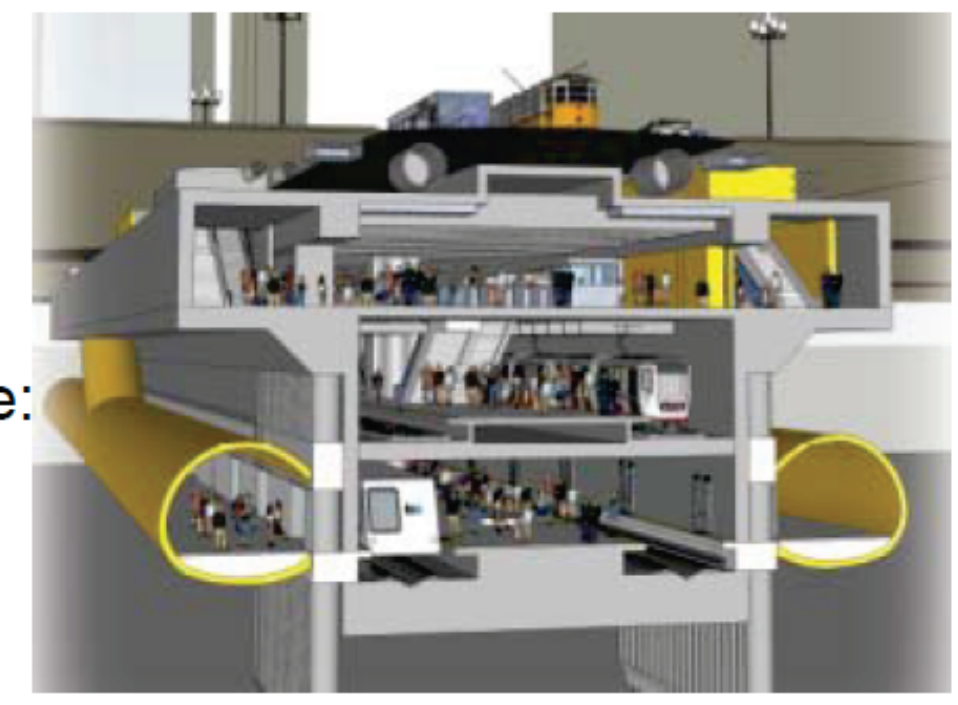




\section{Transit Improvement Alternatives}

\section{BART: Capacity Expansion}

- The estimated cost (FY2011\$) of the BART capacity improvements including side platform tunnel and vertical circulation shafts is:

- Embarcadero Station: $\$ 277,500,000$

- Montgomery Station: $\$ 171,800,000$

- The total estimated cost (FY2011\$) of the BART capacity improvements is approximately $\$ 449,300,000$ 
Appendix H: BATA BART Alternative: Skip-Stop Description 


\section{Transit Improvement Alternatives}

BART: East Bay and West Bay Skip-Stops w/ new San Francisco Alignment

- Currently, the stations at both ends of the Tube constrain transbay BART operations

- Introducing a skip-stop configuration would significantly increase the capacity of the Transbay Tube

- Implementation would be necessary once daily systemwide ridership reaches 500,000 passengers (expected by 2025)

- Improvements would be necessary on both sides of the bay in order to sufficiently increase transbay capacity

- Cost: N/A 


\section{Transit Improvement Alternatives}

\section{BART: East Bay and West Bay Skip-Stops with San Francisco Improvements}

-West Bay Skip-Stop with San Francisco Improvements

- Skip-stop would allow trains to bypass the existing platform

- New alignment could serve Embarcadero and Montgomery Stations
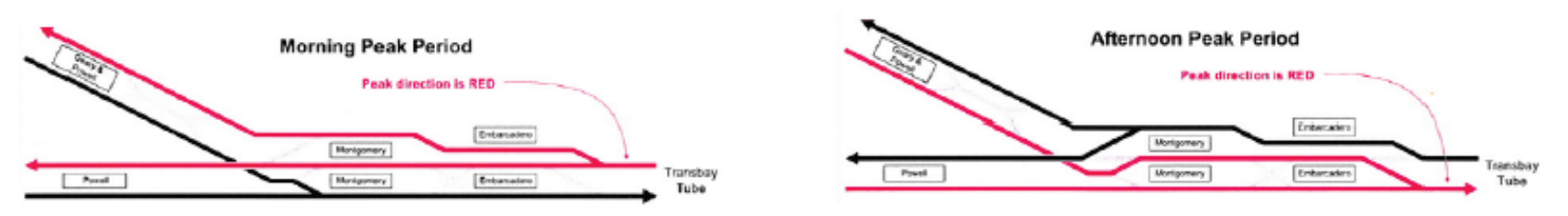

- East Bay Skip-Stop

- Skip-stop configuration would increase Transbay Tube capacity

- There are several proposed skip-stop configurations
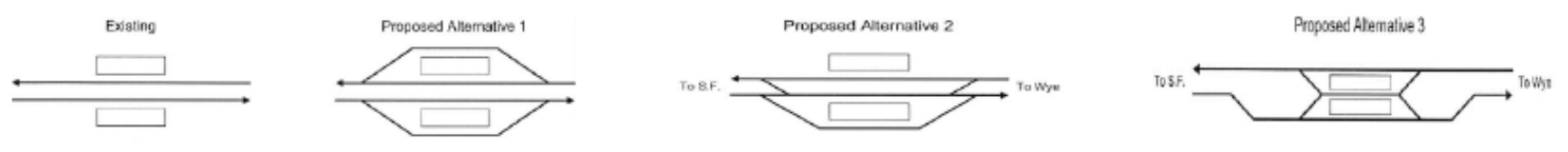